\title{
Otimização de Projeto Orientado ao Desempenho em Arquitetura
}

Dissertação de Mestrado I 2019 Instituto de Arquitetura e Urbanismo Universidade de São Paulo
Dyego da Silva Digiandomenico

Orientador Prof. Dr. David Moreno Sperling Coorientador Prof. Dr. Cláudio Motta Toledo 


\section{UNIVERSIDADE DE SÃO PAULO}

CURSO DE PÓS-GRADUAÇÃO - INSTITUTO DE ARQUITETURA E URBANISMO

DYEGO DA SILVA DIGIANDOMENICO

OTIMIZAÇÃO DE PROJETO ORIENTADO

AO DESEMPENHO EM ARQUITETURA

Versão Corrigida

Dissertação apresentada ao Instituo de Arquitetura e Urbanismo da Universidade de São Paulo para obtenção do título de Mestre em Arquitetura e Urbanismo.

Programa de Pós-Graduação em Arquitetura e Urbanismo.

Linha de Pesquisa: Projeto, Inovação e Sustentabilidade

Área de Concentração: Arquitetura, Urbanismo e Tecnologia.

Orientador:

Prof. Dr. David Moreno Sperling

Coorientador:

Prof. Dr. Cláudio Fabiano Motta Toledo

São Carlos, 2019 


\section{AUTORIZO A REPRODUCAO TOTAL OU PARCIAL DESTE TRABALHO, POR QUALQUER MEIO CONVENCIONAL OU ELETRONICO, PARA FINS DE ESTUDO E PESQUISA, DESDE QUE CITADA A FONTE}

Ficha catalográfica elaborada pela Biblioteca do Instituto de Arquitetura e Urbanismo com os dados fornecidos pelo(a) autor(a)

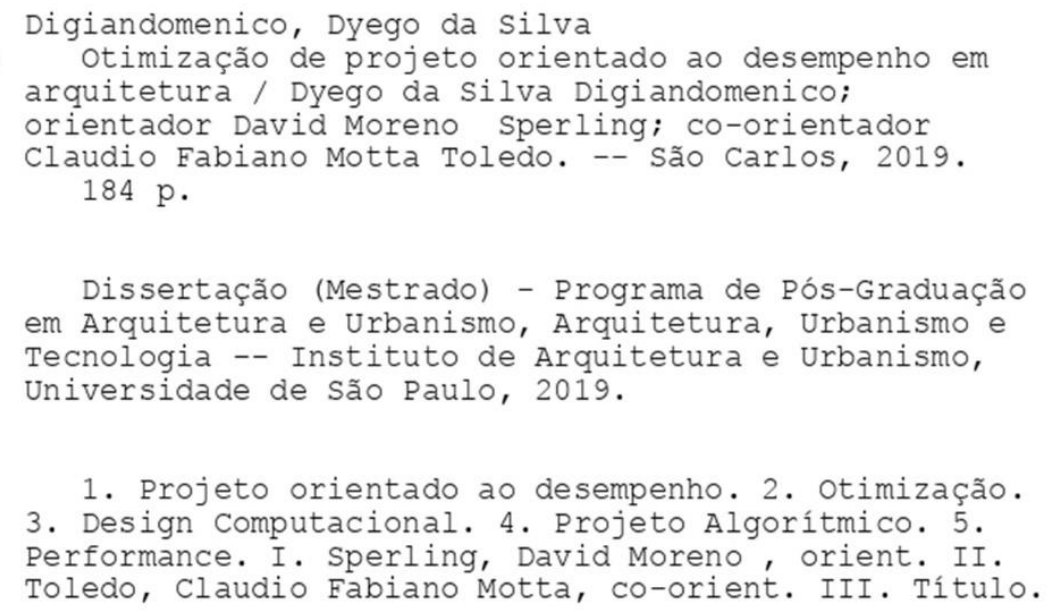

Bibliotecária responsável pela estrutura de catalogação da publicação de acordo com a AACR2:

Brianda de Oliveira Ordonho Sígolo - CRB - 8/8229 


\section{FOLHA DE JULGAMENTO}

Candidato(a): Dyego da Silva Digiandomenico

Título da dissertação: “Otimização de projeto orientado ao desempenho em arquitetura".

Data da defesa: 20/05/2019

Orientador: Prof. Dr. David Moreno Sperling

\section{Comissão Julgadora:}

Resultado:

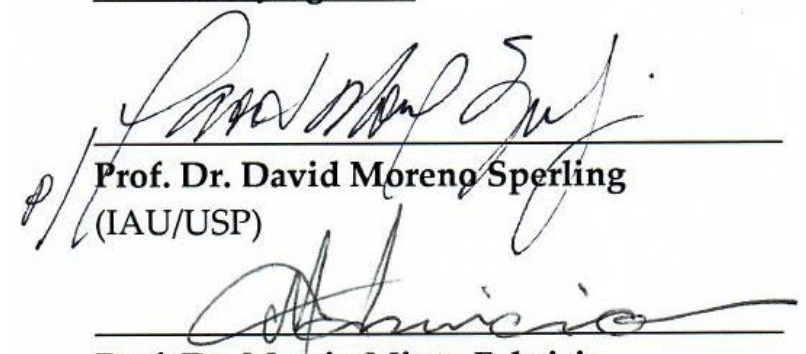

Não votante

Prof. Dr. Marcio Minto Fabricio

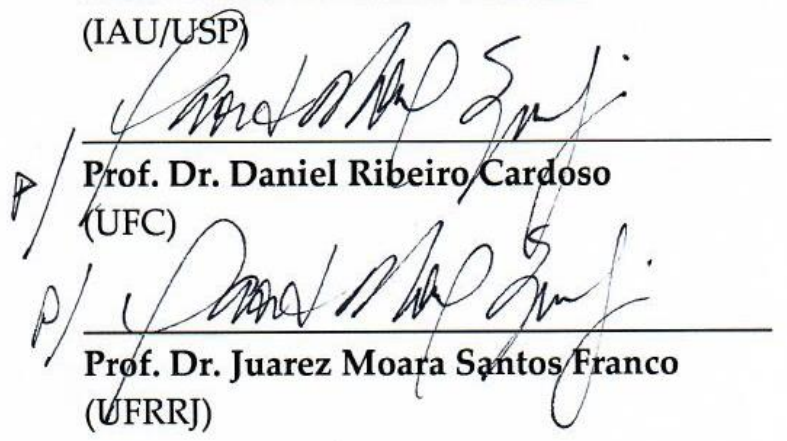

APROVADO

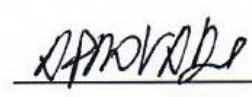

DPROVARD

Coordenador e Presidente da Comissão de Pós-Graduação do Programa de PósGraduação em Arquitetura e Urbanismo: Prof. Dr. Tomás Antonio Moreira. 

Ao povo brasileiro. 



\section{AGRADECIMENTOS}

Agradeço ao David Sperling, Cláudio Toledo, Jean Amaro e Humberto Chagas, pessoas fundamentais na realização da presente pesquisa.

À Gabriele Landim, por quem me faltam palavras para agradecer e expressar seu significado na minha vida.

Aos fundadores e colaboradores da Wikipédia e Sci-Hub, em especial à Alexandra Elbakyan, pelos esforços promovidos ao livre acesso do conhecimento e ao rearranjo da difusão cientifica.

A todas pessoas amigas que de alguma maneira apoiaram o presente trabalho e minha formação acadêmica.

À FAPESP e CAPES pelo financiamento, referente aos processos $n^{\circ}$ 2016/05720-0 e 2018/01376-8, Fundação de Amparo à Pesquisa do Estado de São Paulo, que destinou parte dos recursos produzidos pela força de trabalho dos brasileiros para apoiar a realização desta pesquisa.

Aos trabalhadores da Universidade de São Paulo por promoverem as condições necessárias para o desenvolvimento da presente pesquisa, e por colaborarem com o ensino público e gratuito de qualidade no país. 



\section{RESUMO}

O processo de projeto de arquitetura, engenharia e construção (AEC) tem evoluído consideravelmente com a finalidade de responder à complexidade dos sistemas interconectados de um edifício (TOULOUPAKI e THEODOSIOU, 2017). Vêm sendo solicitados à arquitetura contemporânea, processos de projeto capazes de quantificar e qualificar o maior número de variáveis presentes nos sistemas de um edifício, com a intenção de balancear suas dinâmicas e inter-relações (SHI e YANG 2013). A presente pesquisa utiliza o processo de projeto orientado ao desempenho como condutor de sua investigação. Os projetos e pesquisas que exploram o desempenho através da otimização de projetos em AEC são predominantemente internacionais. Além desse aspecto, grande parte dos processos e seus conjuntos de procedimentos não são publicados, especialmente os métodos para gerar os algoritmos utilizados. Muitas destas não detalham, tampouco disponibilizam suas implementações. Tal condição impossibilita conclusões seguras sobre as características das otimizações produzidas, dificulta a reprodução dos métodos e desampara discussões sobre soluções alternativas. Desta maneira, torna-se reduzida a reflexão na arquitetura sobre quais métodos são mais apropriados para a otimização de determinados problemas do projeto arquitetônico (WORTMANN et al., 2015). Neste contexto, a presente pesquisa estrutura-se na metodologia Design Science (SIMON, 1996), dada sua natureza de produção de conhecimento através da abordagem pragmática e interdisciplinar, envolvendo conteúdo da arquitetura e da ciência da computação. Pode-se por fim afirmar que com o apoio da metodologia empregada na presente pesquisa, desde a revisão bibliográfica ao plug-in ArchOptimum desenvolvido nos experimentos realizados, obteve-se resultados que colaboram com a compreensão e abertura dos potenciais da associação entre a arquitetura e a ciência da computação através do design computacional.

Palavras-chave: Projeto orientado ao desempenho. Otimização. Design Computacional. Projeto Algorítmico. Performance. 



\section{ABSTRACT}

The architecture, engineering, and construction (AEC) design process has evolved considerably in order to respond to the complexity of the interconnected building systems (TOULOUPAKI and THEODOSIOU, 2017). In contemporary architecture, computational design processes are capable of quantifying and qualifying better variables present in the building, balancing their dynamics and interrelationships (SHI and YANG 2013). This research uses the process of Performance-oriented Architectural Design as the driver of its investigation. Research and projects in AEC that explore performance through optimization are predominantly international. In addition, most of the processes and their sets of procedures are not published, especially the methods to generate the algorithms used. Many of these do not detail and make their implementations available. This makes it impossible to secure conclusions about the characteristics of the optimizations produced, makes it difficult to reproduce the methods, and disregards discussions about alternative solutions. These facts reduce the reflection on which methods are more appropriate for the optimization of specific problems of the architectural design (WORTMANN et al., 2015). In this context, the present research is structured in the Design Science methodology (SIMON, 1996), given its nature of knowledge production through the pragmatic and interdisciplinary approach, involving the content of architecture and computer science. Finally, it is possible to state that with the support of the methodology used in the present research, from the bibliographic review to the ArchOptimum plug-in developed in the experiments, we obtained results that collaborate with the understanding and opening the potencies of the association between architecture and computer science through Computational Design.

Keywords: Performance-driven Design; Optimization; Computational Design; Algorithmic Design; Performance. 



\section{SUMÁRIO}

1. INTRODUÇÃO 25

1.1. PROBLEMA DE PESQUISA 30

1.2. QUESTÕES 32

1.3. OBJETIVOS 33

1.4. METODOLOGIA 33

1.5. ESTRUTURA DA DISSERTAÇÃO 39

CAPÍTULO 1

2. ARQUITETURA E O PROCESSO DE PROJETO ORIENTADO AO DESEMPENHO 41

2.1. PROCESSO DE PROJETO E A COMPUTAÇÃO 41

2.2. A MÁQUINA DE ARQUITETURA E A ABORDAGEM EVOLUTIVA 43

2.3. OTIMIZAÇÃO EM ARQUITETURA 47

2.4. DESEMPENHO 48

2.5. OTIMIZAÇÃO DE PROJETO ORIENTADO AO DESEMPENHO 51

2.6. DESIGN COMPUTACIONAL 53

2.7. SIMULAÇÃO DE DESEMPENHO 57

2.8. ESPAÇO DE DESIGN 60

2.9. TIPOS DE EXPLORAÇÃO DO ESPAÇO DE DESIGN 65

2.10. OTIMIZAÇÃO COMPUTACIONAL EM ARQUITETURA 73

2.11. CLAREZA SOBRE O MÉTODO DE OTIMIZAÇÃO 84

CAPÍTULO 2

3. MÉTOdOS DE OTIMIZAÇÃO 87

3.1. ALGORITMOS DETERMINÍSTICOS 88

3.2. ALGORITMOS NÃO DETERMÍSTICOS 89 
3.3. COMPUTAÇÃO EVOLUTIVA 90

3.4. ALGORITMOS EVOLUTIVOS 91

3.5. SISTEMAS EVOLUTIVOS 93

3.6. FATORES EVOLUTIVOS 94

3.7. TERMINOLOGIA FUNDAMENTAL EM AE 95

3.8. ALGORITMOS CANÔNICOS 98

3.8.1. PROGRAMAÇÃO EVOLUTIVA 98

3.8.2. ESTRATÉGIA EVOLUTIVA 99

3.8.3. ALGORITMO GENÉTICO 101

3.8.4. CRITÉRIOS DE SELEÇÃO PARA AES 102

$\begin{array}{lll}\text { 3.8.5. ROLETA } & 102\end{array}$

$\begin{array}{ll}\text { 3.8.6. TORNEIO } & 104\end{array}$

$\begin{array}{ll}\text { 3.8.7. ELITISMO } & 104\end{array}$

$\begin{array}{ll}\text { 3.8.8. RANQUE } & 105\end{array}$

3.8.9. OPERADORES GENÉTICOS 105

3.8.10. MUTAÇÃO 106

3.8.11. RECOMBINAÇÃO 106

3.8.12. RECOMBINAÇÃO DE UM PONTO 107

3.8.13. RECOMBINAÇÃO DE N-PONTOS 107

3.8.14. RECOMBINAÇÃO UNIFORME 108

3.8.15. RECOMBINAÇÃO BLEND CROSSOVER 109

3.8.16. CONSIDERAÇÕES SOBRE O AG 109

CAPÍTULO 3

4. EXPERIMENTOS 111

4.1. CONTEXTO DO EXPERIMENTO A 111 
4.2. METODOLOGIA

4.3. PROBLEMA ARQUITETÔNICO 114

4.4. PROJETO DE PLATAFORMA E FERRAMENTAS 117

4.5. ALGORITMO GENÉTICO PROPOSTO 120

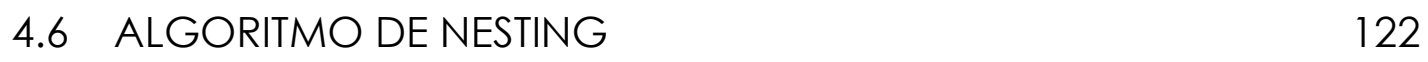

4.7. DISCUSSÃO E CONCLUSÕES DO EXPERIMENTO 125

$\begin{array}{ll}\text { 4.8. CONTEXTO DO EXPERIMENTO B } & 127\end{array}$

4.9. METODOLOGIA 129

4.10. PROBLEMA ARQUITETÔNICO 129

4.11. PROJETO DE PLATAFORMA E FERRAMENTAS 147

4.12. ALGORITMO GENÉTICO PROPOSTO 148

4.13. COMPARAÇÃO ENTRE OS MÉTODOS 151

4.14. DISCUSSÃO E CONCLUSÕES DO EXPERIMENTO 164

$\begin{array}{ll}\text { CONSIDERAÇÕES FINAIS } & 167\end{array}$

5. CONCLUSÃO 167

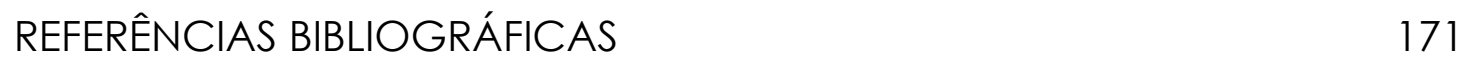





\section{LISTA DE FIGURAS}

Figura 1: Ivan Sutherland demonstrando Sketchpad. Fonte: UVC via IA https://archive.org/movies/thumbnails.php?identifier=AlanKeyD1987 (2018).26

Figura 2: Museu Marítimo Nacional da China, uso de métodos de otimização na fachada e estrutura do projeto. Fonte: Alfredo Andia e Thomas Spiegelhalter (2014)

Figura 3: Otimização da fachada e estrutura removendo o material ineficiente e subutilizado. Fonte: Alfredo Andia e Thomas Spiegelhalter (2014).

Figura 4: Diagrama de implementação da metodologia Design Science. Fonte: Adaptado de Takeda, et al. (1990).

Figura 5: Design de estrutura de ginásio gerado por processo semiautomático a partir de uma única peça. Fonte: John Frazer (1966).

Figura 6: Habitação estudantil Simmons Hall, no MIT. Fonte: Kolarevic e Malkawi (2005). Foto: Andy Ryan

Figura 7: Simulação CFD (Computational Fluid Dynamics) aplicada na integração do desempenho da arquitetura, estrutura e sistemas prediais do projeto Simmons Hall. Fonte: Kolarevic e Malkawi (2005).

Figura 8: A otimização de projeto orientado ao desempenho é combinação entre design computacional, simulação de desempenho e a otimização computacional. Fonte: Adaptado de Touloupaki; Theodosiou (2017).

Figura 9: A esquerda janela do Rhinoceros a direta janela do plug-in Grasshopper. 1. indica a pré-visualização da geometria gerada no Grasshopper, 2. indica as viewports do Rhinoceros, 3. Indica a tela de aplicação do Grasshopper. Fonte: Mode Lab (2017).

Figura 10: Representação do Espaço de Design. Fonte: Adaptado de Keeling (2015). 
Figura 11: Conhecimento sobre o projeto ao longo do tempo. Fonte: Adaptado de Keeling (2015).

Figura 12: Tendência de conhecimentos especializados mais em domínio ou solução. Fonte: Adaptado de Keeling (2015).

Figura 13: Representação do espaço de design. Fonte: Adaptado de Nagy (2016)

Figura 14: Espaços de design e suas relações com os tipos de exploração e ênfase na Exploitation. Fonte: Adaptado de Benjamin (2012). 69

Figura 15: Permutações geométricas devido a otimização do trem Zefiro, da Bombardier Transportation. Fonte: adaptado de Benjamin (2012). 70

Figura 16: Espaços de design e suas relações com os tipos de exploração com ênfase na Exploration. Fonte: adaptado de Benjamin (2012).

Figura 17: Hyundai Motorstudio Goyang. Fonte: Katsuhisa Kida (2018). 75

Figura 18: Representações dos esforços e do sistema estrutural otimizado pelo Octopus. Fonte: Bollinger+Grohmann (2018). 76

Figura 19: Representações dos esforços e do sistema estrutural otimizado pelo Octopus. Fonte: Bollinger+Grohmann (2018). . .76

Figura 20: 1 viewport do Rhinoceros com a geometria sendo otimizada, 2 parâmetros do projeto em slide numbers sendo controlados pela Galapagos. 3 Tela de Interface do Galapagos operando a otimização da geometria. Fonte: Andrea Mercurio (2016) 78

Figura 21:A esquerda modelo elementar inicial, a direita modelo otimizada perante as variáveis e restrições do projeto. Fonte: Vannini; Bueno; Turkienicz (2012).

Figura 22: Interior do pavilhão que teve sua acústica otimizada. Fonte: Foged; Pasold; Jensen (2014). 
Figura 23: Comparação entre os melhores indivíduos a cada dez gerações de alternativas de projeto obtidas a partir da otimização da distribuição da insolação de forma homogênea sobre a volumetria do edifício. Fonte: Martino (2015).

Figura 24: Subdivisões descendentes da Inteligência Artificial. Adaptado de OLIVIERI (2004).

Figura 25: Fluxograma de Algoritmo Evolutivo Clássico. Adaptado de Gabriel (2010). .93

Figura 26: Exemplo do processo de codificação e decodificação. Fonte: Autor.

Figura 27: Exemplo das partes do Algoritmo Evolutivo com suas terminologias. Fonte: Gabriel e Delbem (2010).

Figura 28: Fluxograma do algoritmo genético. Fonte: Tamakoshi (2016). 102

Figura 29: Sistema de seleção por roleta. Fonte: Autor. 103

Figura 30: Representação do operador de mutação. Fonte: Tamakoshi (2016). 106

Figura 31: Recombinação de um ponto. Fonte: Tamakoshi (2016)..... 107

Figura 32: Recombinação de n-ponto. Fonte: Tamakoshi (2016). ....... 108

Figura 33: Recombinação uniforme. Fonte: Tamakoshi (2016)............. 108

Figura 34: Construção de casa sistema Wikihouse. Fonte: Urbannext (2017).

Figura 35: llustração de sistema construtivo Wikihouse. Fonte: Autores.

Figura 36: Peças do modelo Wikihouse dispostas na chapa e cortas por fresadora CNC. Fonte: Urbannext (2017).

Figura 37: Exemplo de peças a serem distribuídas em chapa para corte. Fonte: Urbannext (2017). 
Figura 38: Estrutura da ferramenta computacional proposta. Fonte: Autores.

Figura 39: Fluxograma do funcionamento do AG proposto. Fonte: Autores.

Figura 40: Média e desvio dos valores das melhores soluções ao longo do tempo. Fonte: Autores.

Figura 41: Melhores resultados obtidos em cada execução. Fonte: Autores.

Figura 42:Resultado das peças planificadas como nesting. Fonte: Autores.

Figura 43: Vancouver Academic Building. Fonte: Perkins+Will (2017) .. 130

Figura 44: Modelo base no Rhinoceros para a criação do modelo paramétrico no Grasshopper. Fonte: Autores.

Figura 45: Diagrama de interação e potências do Ladybug. Fonte: Ladybug Tools (2018). 133

Figura 46: Diagrama de interação e potências do Honeybee. Fonte: Ladybug Tools (2018).

Figura 47. Interface do Design Explorer na plotagem dos resultados. Fonte: Design Explore (2018). 136

Figura 48: Processo DSC na avaliação de uma parte de um pavimento do edifício. Fonte: (HAYMAKER et al. 2018).

Figura 49: Processo DSC adaptado para realizar a avaliação de todos os pavimentos do edifício. Fonte: Autores.

Figura 50: Tipos de painéis disponíveis a serem alocados nos grupos da fachada. Fonte: Perkins+Will. 140

Figura 51: Melhor indivíduo obtido através do ArchOptimum. Fachada Sul. Fonte: Autores 
Figura 52: Melhor indivíduo obtida através do método do escritório Perkins+Will. Fachada Sul. Fonte: Autores.

Figura 53: Melhor indivíduo obtido através do ArchOptimum. Fachada Norte. Fonte: Autores.

Figura 54: Melhor indivíduo obtida através do método do escritório Perkins+Will. Fachada Norte. Fonte: Autores. 159

Figura 55: Gráfico de Coordenadas Paralelas de todos os parâmetros de todos indivíduos. A cor azul representa os melhores resultados, a vermelha os piores resultados. Fonte: Autores. 160

Figura 56: Gráfico de Coordenadas Paralelas dos parâmetros utilizados no cálculo do fitness e o respectivo resultado de todos indivíduos. A cor azul representa os melhores resultados, a vermelha os piores resultados. Fonte: Autores.

Figura 57: Gráfico de Coordenadas Paralelas dos parâmetros utilizados no cálculo do fitness e o respectivo resultado dos indivíduos gerados através do ArchOptimum. A cor azul representa os melhores resultados, a vermelha os piores resultados. Fonte: Autores.

Figura 58: Gráfico de Coordenadas Paralelas dos parâmetros utilizados no cálculo do fitness e o respectivo resultado dos indivíduos gerados através do método do escritório Perkins+Will. A cor azul representa os melhores resultados, a vermelha os piores resultados. Fonte: Autores. 163 



\section{LISTA DE ABREVIATURAS E SIGLAS}

AEC

AEs

$A G$

BSP

BTO

DOE

DSC

EE

ISE

MIT

NRC

OPOD

PE
Arquitetura, Engenharia e Construção.

Algoritmos Evolutivos

Algoritmo Genético.

Building Performance Simulation.

Building Technologies Office.

Department of Energy.

Design Space Construction.

Estratégia Evolutiva.

Fraunhofer Institute for Solar Energy Systems.

Massachusetts Institute of Technology.

National Research Council.

Otimização de Projeto Orientado ao Desempenho.

Programação Evolutiva. 



\section{INTRODUÇÃO}

As tecnologias computacionais estão promovendo transformações significativas no processo de projeto em arquitetura, resultado de inúmeras e importantes pesquisas desenvolvidas em mais de meio século. Durante a década de 1960 foram realizados avanços tecnológicos consideráveis no desenvolvimento de interfaces gráficas que interferiram consideravelmente no processo de projeto em arquitetura (MITCHELL, 1977).

Os pesquisadores Steve Coons e Larry Roberts foram pioneiros na área da computação gráfica, e nos primeiros anos da década de 1960 desenvolveram um algoritmo computacional que construía perspectivas através de operações aritméticas repetitivas. Assim, as coordenadas assinalavam os pontos finais ao longo das linhas pares $x e y$, representandoos no plano da imagem. O resultado do procedimento eram imagens brutas em wire-frame (armação) de objetos tridimensionais (MITCHELL, 1994).

Pouco tempo depois, no ano de 1963, ocorre outra importante contribuição: o matemático Ivan Sutherland desenvolveu o Sketchpad para sua tese de doutorado no Massachusetts Institute of Technology. O Sketchpad, é considerado o primeiro programa CAD (Computer Aided Design), cuja tradução literal é desenho assistido por computador.

Assim, o Sketchpad é reconhecido como elemento fundamental para as primeiras pesquisas sobre a interação humano-computador, das quais surge o conceito de interface gráfica para o usuário (GUI - graphical user interface), possibilitando a interação com o computador sem a necessidade de longos códigos digitados nos terminais de comando, permitindo ao usuário utilizar cliques para desenhar (MITCHELL, 1994).

Para construir uma linha reta, por exemplo, Sutherland (1964) explicou na introdução de sua tese que ao direcionar a caneta luminosa para a tela e pressionar o botão "draw", o computador cria uma linha reta que estica como uma tira elástica da posição inicial para a posição corrente da caneta. 

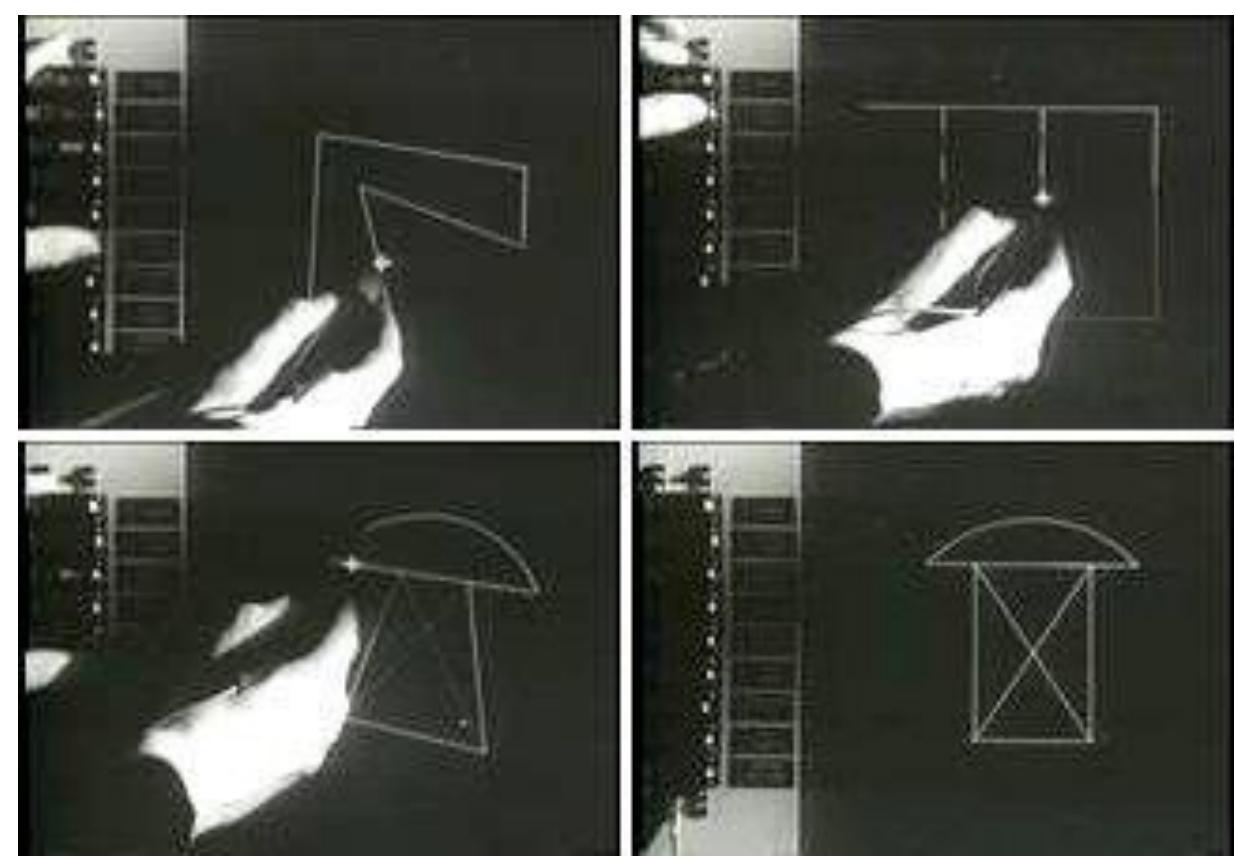

Figura 1: Ivan Sutherland demonstrando Sketchpad. Fonte: UVC via IA https://archive.org/movies/thumbnails.php?identifier=AlanKeyD1987 (2018)

Contudo, a principal habilidade distinta do Sketchpad foi a capacidade de mover partes do desenho sem o apagar, tornando o desenho digital um modelo de processo de concepção (SUTHERLAND, 1964). O sistema do Sketchpad também possibilitava a realização de modelos tridimensionais no estudo das formas. Através de rotações e o ocultamento das arestas posteriores pelas faces anteriores, demonstrando a capacidade de simular aspectos físicos do modelo construído digitalmente.

Mitchell (1977), afirma que os potenciais do CAD demonstrados por Sutherland chamaram a atenção, especialmente dos engenheiros, mas também dos arquitetos. Deste experimento derivaram pesquisas significativas, especialmente as produzidas no Departamento de Engenharia Civil do Massachusetts Institute of Technology (MIT) e no Departamento de Engenharia Civil da Pennsylvania State University.

Segundo Menges (2011), parte dessas pesquisas desenvolvidas na década de 1960 já reproduziam geometrias computacionais com instâncias paramétricas, funcionando através de método associativo e sistemas baseados em regras. Assim, espaço, estrutura e geometria se inter- 
relacionavam continuamente no modelo, gerando resultados variados, através da manipulação dos parâmetros.

Com a evolução exponencial da capacidade de processamento dos computadores e o barateamento e popularização dessas máquinas ao longo das décadas, nos encontramos hoje diante de acessíveis e potentes recursos tecnológicos a serem explorados no processo de projeto em arquitetura.

No entanto, de acordo com a literatura científica contemporânea, desenvolver o processo de projeto arquitetônico mediado por tecnologias computacionais requer o domínio de métodos próprios (OXMAN, 2007; WOODBURY, 2010), dada a complexidade e dinâmica envolvendo as informações que podem ser gerenciadas através desses recursos.

A exploração de métodos computacionais no processo de projeto é conhecida por design generativo ou design computacional. Jabi (2014), definiu o design computacional como o processo baseado no pensamento algorítmico, que expressa as regras e parâmetros que compõem, codificam e declaram a relação entre a intenção do projeto e a resposta obtida. Portanto, o design computacional está relacionado ao desenvolvimento de projetos criados pela descrição de códigos, que relacionam as variáveis e restrições declaradas no projeto, geralmente atreladas à criação e transformação de geometrias. Esta metodologia é conhecida por projeto paramétrico ou projeto computacional.

O projeto paramétrico atrela valiosos recursos da computação à criação e mediação das relações de elementos operados no processo de projeto em arquitetura. Assim, os recursos computacionais, associados a avanços na fabricação digital, amplamente explorados nas indústrias aeroespacial, automobilística e naval, entre outras, atribuem novas dimensões às possibilidades em arquitetura (KOLAREVIC, 2009).

Desta maneira, é possivel entender que as estruturas dinâmicas presentes nas relações entre os componentes de materiais e matérias vivas, 
entre meio artificial e natural, as quais respondem a condições variadas de seu comportamento e ciclo de vida, possam ser simuladas e validadas através de algoritmos inter-relacionados e aplicados ao processo de projeto paramétrico e fabricação digital em arquitetura (WEINSTOCK, 2010).

Nesse panorama, na arquitetura contemporânea, os processos de projeto caminham para o emprego de métodos computacionais capazes de viabilizar que quantidades cada vez maiores de variáveis e restrições sejam incorporadas à concepção do projeto, desde o seu início. Assim, os processos de projeto em arquitetura, engenharia e construção (AEC) têm se sofisticado consideravelmente com a intenção de responder a demandas mais complexas (TOULOUPAKI; THEODOSIOU, 2017).

Um exemplo da força dessas demandas são as exigências dos sistemas de classificação de sustentabilidade que aumentaram muito desde a crise do petróleo dos anos de 1970, com posições científicas concretas sobre a influência da ação humana nas mudanças climáticas (SHI et al. 2016). O aumento dessa demanda na construção é ilustrado pelo grande número de esquemas e normas de avaliação de padrões de sustentabilidade desenvolvidos em todo o mundo nas últimas décadas (SHI et al., 2016; TOULOUPAKI; THEODOSIOU, 2017).

Dessa maneira, a AEC vem empregando métodos e recursos computacionais sofisticados nos seus processos para que os projetos sejam eficientes em atender os objetivos propostos. Isso significa, verificar os resultados do processo de projeto e otimizá-los. Essa abordagem é conhecida como otimização de projeto orientado ao desempenho' e é definida como a determinação em estabelecer requisitos de desempenho que possam ser quantificáveis. Assim, percebe-se que a otimização integrada de múltiplas variáveis pode guiar e aperfeiçoar o projeto (SH); YANG 2013).

1 Do original em inglês "Performance-driven architectural design". 
Ademais, a literatura aponta que a otimização de projeto orientado ao desempenho tem grande relevância na AEC. Isso porque a otimização aumenta consideravelmente os padrões de eficiência dos resultados nas respostas às demandas diversas de projeto. Entre elas, é possível elencar: estudos de massa, orientação e implantação de edifícios, projeto de fachadas, sistemas estruturais, qualidade do ar, energia, sistemas de aquecimento, ventilação e ar-condicionado, iluminação natural e artificial, logística, acústica, ciclo de vida, custos, entre outros (SHI, 2010; MACHAIRAS et al., 2013; TOULOUPAKI; THEODOSIOU, 2017).

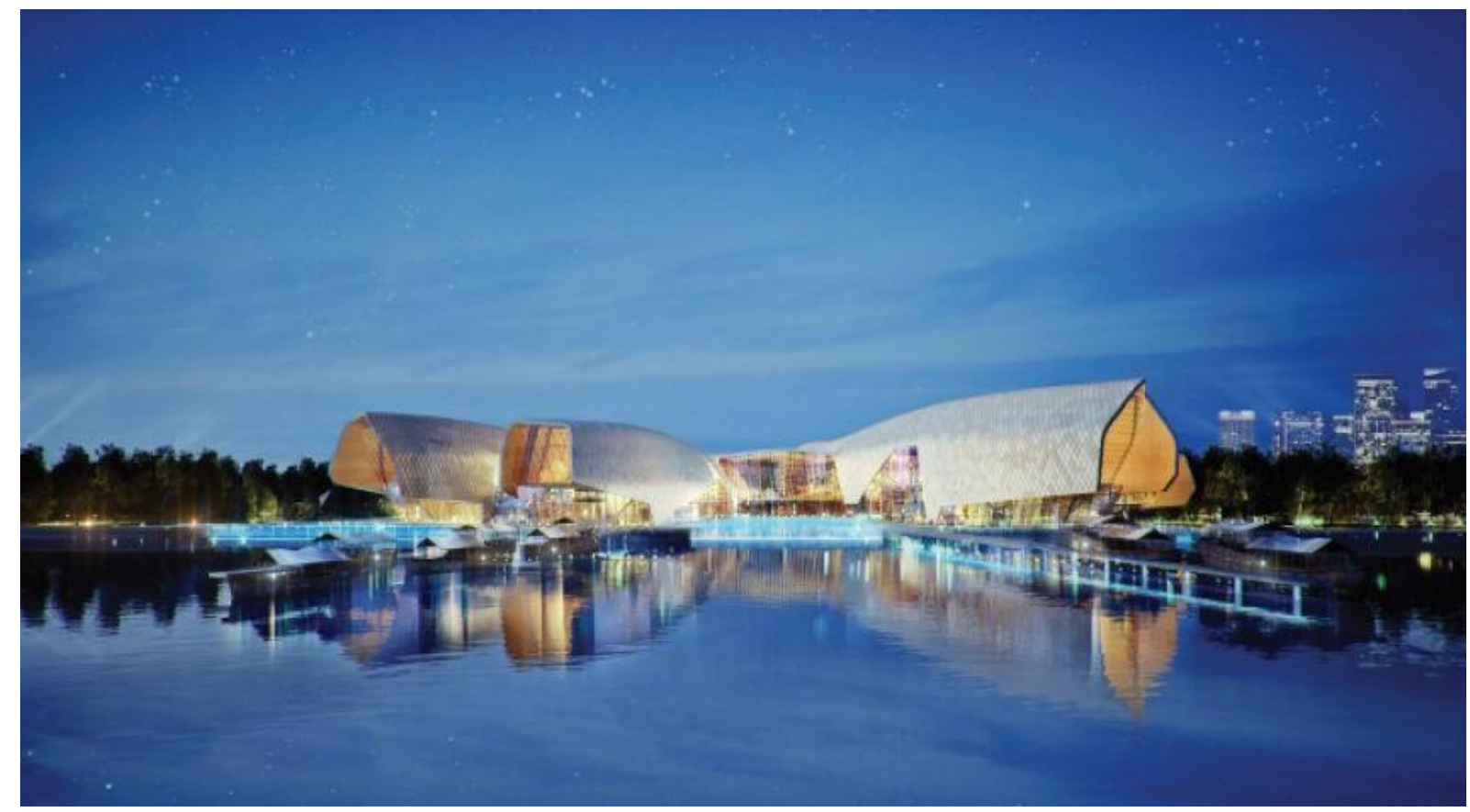

Figura 2: Museu Marítimo Nacional da China, uso de métodos de otimização na fachada e estrutura do projeto. Fonte: Alfredo Andia e Thomas Spiegelhalter (2014). 

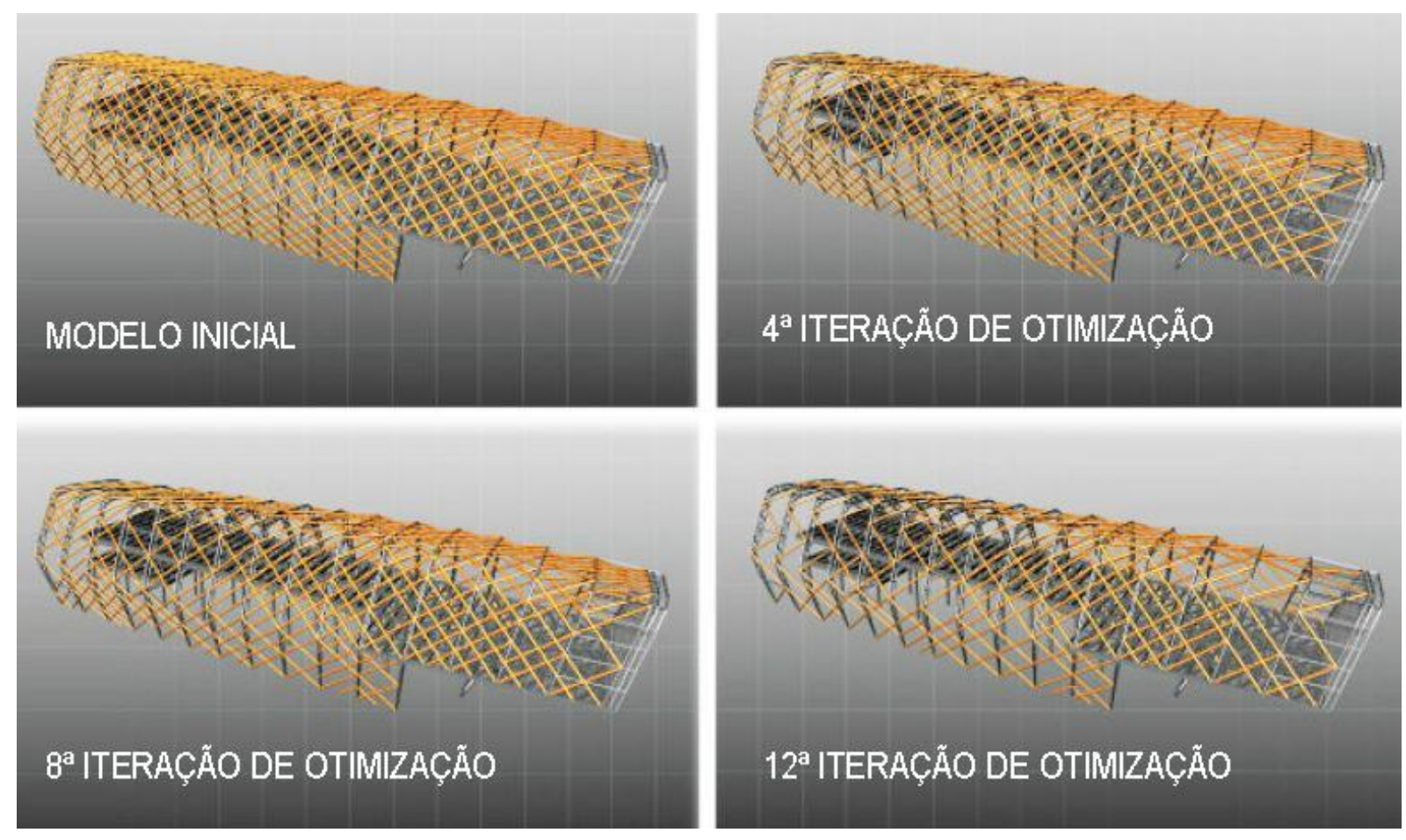

Figura 3: Otimização da fachada e estrutura removendo o material ineficiente e subutilizado. Fonte: Alfredo Andia e Thomas Spiegelhalter (2014).

Portanto, os recursos computacionais aplicados à otimização de projeto orientado ao desempenho estão permitindo que os projetistas e pesquisadores respondam à complexidade dos sistemas interconectados do edifício, o que representa uma abordagem mais holística sobre o projeto (BESSERUD, 2014).

Dentro desse contexto a presente pesquisa investiga o problema apresentado a seguir.

\subsection{PROBLEMA DE PESQUISA}

As pesquisas e projetos que exploram profundamente 0 design computacional na otimização de projetos em AEC são predominantemente internacionais. Além desse aspecto, grande parte dos processos e seus conjuntos de procedimentos não são publicados, especialmente os métodos para gerar os algoritmos utilizados. Machairas, Tsangrassoulis e Axarli (2013) ao analisarem pesquisas que implementam algoritmos de otimização em 
arquitetura, afirmam que muitas dessas não detalham ou não disponibilizam as implementações.

Tal condição impossibilita conclusões seguras sobre as características das otimizações produzidas, dificulta sua reprodução e desampara discussões sobre soluções alternativas. Assim, torna-se reduzida a reflexão na arquitetura sobre quais métodos são mais apropriados para a otimização de determinados problemas do projeto arquitetônico (WORTMANN et al., 2015).

Após observações de cunho histórico sobre a inserção de métodos da computação no processo de projeto de arquitetura, Kotnik (2010) afirma que tais inserções têm gerado um conjunto de competências. Assim, estão surgindo conhecimentos, procedimentos e técnicas arquitetônicas. Os profissionais da AEC precisam compreender estas habilidades para realizar revisões eficientes nos processos de projeto computacional.

Contudo, para explorar tais competências é preciso que compreendamos a relevância da revisão de metodologias em arquitetura. Nesse sentido, é necessário questionar os métodos tradicionais de processo de projeto, nos quais o objeto arquitetônico se manifesta através da representação pelo desenho, baseado em conhecimentos implícitos que podem não contemplar de maneira suficiente a produção de soluções eficientes.

Em contrapartida, apesar da baixa publicização dos métodos como descrito, no processo computacional de projeto em arquitetura, existe a explicitação dos processos cognitivos, que estão baseados na capacidade de configurar o processo, de programar, de implementar e interagir com representações declaradas através de algoritmos.

Portanto, através do processo computacional, o arquiteto, enquanto projeta, pode se concentrar na formulação e modelagem do seu processo como um todo, não apenas no desenho do objeto arquitetônico. Essas atualizações nos processos de projeto de arquitetura a partir de métodos e procedimentos advindos da computação também são apontadas por 
Oxman (2006). Para ela, os processos computacionais de projeto apresentam impacto crescente de transformação sobre a produção de arquitetura. Também, essa transformação sugere a necessidade de um reexame das teorias e metodologias, no sentido de explicar e orientar futuras pesquisas e desenvolvimentos (OXMAN, 2006).

A afirmação de Oxman, em trabalho datado de 2006, continua relevante e seu teor ainda é encontrado em trabalhos mais recentes de outros pesquisadores. Esses afirmam que o design computacional pede 0 reexame das teorias que apoiam a área da arquitetura a fim de torná-la permeável a fronteiras de diferentes campos do conhecimento. Essa ação possibilita, inclusive, a alimentação e o esclarecimento acerca dos métodos fundamentais no processo de projeto (HENSEL 2010; MENGES 2013).

Portanto, minimizar a fronteira entre as áreas do conhecimento que compõem o design computacional e a arquitetura pode contribuir com a citada revisão de processos, atribuindo eficiência ao projeto. Dessa maneira, a compreensão dos métodos de otimização advindos da computação, abordados na presente pesquisa, pode amparar e estimular a aplicação desses métodos na área da arquitetura.

Assim, a partir das observações apresentadas até aqui, foram formuladas as seguintes questões, a hipótese e o objetivo da pesquisa, descritos a seguir.

\subsection{QUESTÕES}

1. Quais são os principais métodos de otimização aplicados no design computacional e de que maneira atuam no projeto orientado ao desempenho em AEC?

2. Quais revisões no processo de projeto de arquitetura podem ser amparadas por teorias relacionadas à otimização no design computacional? 
3. Como a compreensão dos métodos de otimização no design computacional aplicado a AEC torna a otimização mais eficiente, verificável e reproduzível para arquitetos?

\subsection{OBJETIVOS}

\section{Geral}

Compreender como e em que medida a associação entre a arquitetura e a ciência da computação, através do design computacional, possibilita resoluções eficientes dentro da otimização do projeto orientado ao desempenho.

\section{Específicos}

1. Desenvolver conteúdo teórico sobre otimização no design computacional em AEC.

2. Compreender como a otimização aplicada no design computacional atua no projeto orientado ao desempenho em AEC.

3. Desenvolver material que explicite as características dos métodos de otimização em projetos orientados ao desempenho.

\subsection{METODOLOGIA}

A presente pesquisa estrutura-se na metodologia Design Science (SIMON, 1996), dada sua natureza pragmática e interdisciplinar, envolvendo conhecimentos da arquitetura e da ciência da computação. Simon (1996) argumenta que a Design Science tem o enfoque na produção de um corpo do saber com rigor e validação científica, que se dedica a produzir conteúdo para a concepção e desenvolvimento de artefatos. Os artefatos comumente desenvolvidos através da Design Science são algoritmos, interfaces humano-computador e modelos de processos de projeto, incluindo os da arquitetura. 
Assim, para demonstrar detalhadamente a aplicação metodológica adotada, a presente pesquisa baseia-se na adaptação do modelo de implementação da Design Science desenvolvido por Takeda, et al. (1990). A estrutura organizada em conhecimentos, fases e produtos, é representada no diagrama a seguir:

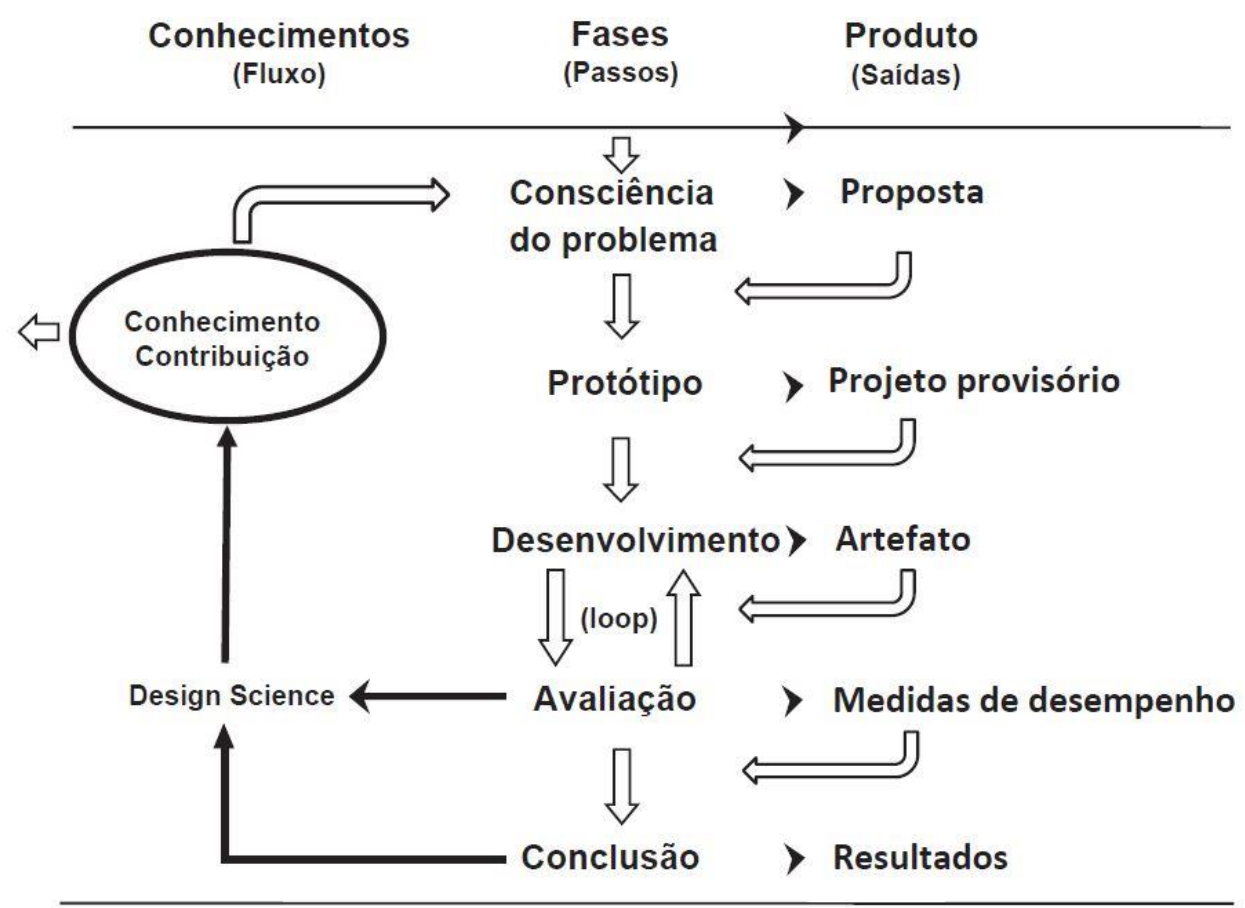

Figura 4: Diagrama de implementação da metodologia Design Science. Fonte: Adaptado de Takeda, et al. (1990).

O modelo de implementação proposto funciona através do fluxo recursivo de conhecimentos, reunidos no encadeamento das fases que determinam cada passo da pesquisa e seus respectivos produtos esperados. Dessa maneira, a aplicação do modelo e a descrição das etapas desta metodologia seguem detalhadas a seguir.

Consciência do problema (Fase): A "Consciência do problema" da presente pesquisa aponta que a clareza sobre o método de otimização empregado no processo de projeto em arquitetura contribui com a melhora dos resultados. A falta de clareza sobre o método de otimização aplicado pode ser problemática ao resultado do projeto, pois as especificidades de um método de otimização deveriam ser baseadas nas necessidades e na natureza de um problema específico (COENDERS; WAGEMANS 2005; KOZIEL; 
YANG 2011; MACHAIRAS et al., 2013; WORTMANN et al. 2015; WORTMANN; NANCINNI 2016).

Além disso, o uso de plug-ins closed sources², que são caixas-pretas ${ }^{3}$ no processo de projeto de arquitetura, não contribui com a clareza dos métodos aplicados.

Dessa maneira, a compreensão dos métodos de otimização advindos da computação pode estimular o seu entendimento e aplicações na área da arquitetura.

Proposta (Produto): A partir da questão levantada na "Consciência do problema", desenvolveu-se uma proposta formal de pesquisa. Essa "Proposta" procurou atingir os objetivos específicos da pesquisa através dos seguintes procedimentos metodológicos:

\section{Consulta a fontes secundárias}

A revisão bibliográfica ocorreu ao longo de todas as fases da pesquisa, e se concentrou nas seguintes temáticas: design computacional em AEC; otimização de projeto orientado ao desempenho em AEC; métodos de otimização computacional; métodos de otimização computacionais em arquitetura. Dentro da metodologia adotada a revisão bibliográfica é uma fonte do fluxo de conhecimento, alimentando todas as fases da metodologia, especialmente a "Consciência do problema", "Desenvolvimento" e "Avaliação".

\section{Estágio de pesquisa no Exterior}

2 "Closed Source" em português é entendido por "fonte fechada", ou "programa proprietário". Significa que o programa de computador tem o código-fonte não publicado para consulta ou alteração.

3 Nas ciências e estudos de sistemas, "caixa-preta" é um sistema fechado de complexidade potencial. Os dados são inseridos através de entradas na "caixa-preta", onde ocorrem processamentos cujas estruturas de seu funcionamento permanecem ocultas, e os resultados são oferecidos nas saídas. Amplamente conhecido pelo termo em inglês "BlackBox" 
O estágio no Exterior também contribuiu com o desenvolvimento de conhecimento que alimentam as fases da metodologia, especialmente a "Protótipo", "Desenvolvimento" e "Avaliação". O estágio se concentrou em conhecimentos práticos desenvolvidos ao longo de implementações, testes e avaliações de algoritmos de otimização. Parte dos conhecimentos práticos foram verificados junto ao grupo ADA (Algorithmic Design for Architecture) do IST-ULISBOA, sob supervisão do Prof. Dr. António Leitão. O estágio de pesquisa no Exterior se constitui por várias sub-etapas, que serão detalhadas no Capítulo 3 da presente pesquisa.

\section{Estudo de caso}

A presente pesquisa adota como estudo de caso o processo do projeto do Vancouver Academic Building, do escritório de arquitetura Perkins+Will. Através de métodos do Design Computacional, o projeto de arquitetura é otimizado para balancear objetivos conflitantes e atender prérequisitos de certificações internacionais de qualidade, como por exemplo, o International Passive House Association (IPHA).

O estudo de caso alimenta o fluxo de conhecimento da pesquisa, especialmente as fases "Desenvolvimento" e "Avaliação" e está diretamente relacionado com o "Experimento". O estudo de caso será descrito no Capítulo 3 da presente pesquisa.

\section{Experimentos}

Passou-se à etapa de realização de dois experimentos. O primeiro experimento desenvolvido trata da otimização da forma e material utilizado no sistema construtivo Wikihouse. Foi implementado e realizado testes de métodos de otimização em um objeto arquitetônico de escala menor e representa a realização da primeira fase dos experimentos.

O segundo experimento desenvolvido está diretamente relacionado com o estudo de caso realizado. Assim, comparou-se a otimização implementada pelo escritório de arquitetura Perkins+Will e o método proposto e implementado nesta pesquisa. Ambos foram aplicados no 
mesmo projeto, com a finalidade de identificar quais as potencialidades e limites dos métodos e qual deles é mais eficiente na otimização do projeto de arquitetura estudado. Ambos os experimentos são apresentados detalhadamente no Capítulo 3.

No contexto experimental, para verificações práticas, foi desenvolvido um plug-in de otimização, que é o "Artefato" da presente pesquisa. Assim, foi também investigada a viabilidade do desenvolvimento de um plug-in de código aberto, cujos métodos foram testados para verificação da eficiência na resolução dos problemas arquitetônicos estudados.

Os experimentos alimentaram o fluxo de conhecimento da pesquisa, especialmente as fases "Protótipo", "Desenvolvimento", "Avaliação" e "Conclusão", descritas a seguir.

Protótipo (Fase): Na metodologia Design Science a fase "Protótipo" está diretamente conectada com a fase "Proposta", elaborada com base na fase "Consciência do problema". Assim, partindo da "Consciência do problema", a fase "Protótipo" equivale ao momento de testes e explorações que alimentarão recursivamente a atualização do protótipo do artefato da pesquisa (VAISHNAVI, 2015).

Nessa fase foi realizada a implementação do estudo de caso do projeto Vancouver Academic Building por meio da recriação do processo computacional de otimização que gerou o projeto originalmente. Ainda nessa fase também foram desenvolvidos os protótipos do "Artefato e 0 modelo computacional do projeto Wikihouse.

Durante a implementação dos protótipos, foram testados algoritmos de otimização distintos, nos quais cada uma de suas partes passaram por ajustes baseados nos conhecimentos práticos e teóricos que foram reunidos nos procedimentos metodológicos.

Projeto provisório (Produto): Nesse momento, foram sistematizados e documentados os testes e explorações realizados na fase anterior. Deste 
modo, os protótipos que apresentaram o melhor desempenho foram selecionados para avançar à fase seguinte e, então, foram aperfeiçoados.

Desenvolvimento (Fase): Nessa fase, segundo a Design Science (VAISHNAVI, 2015), o projeto provisório é aprimorado e implementado. Com isso, por se tratar de algoritmos, prevê-se a construção formal de provas de testes. Os testes servirão para verificar sua execução passo a passo observando as variáveis, a entrada de dados e saída de resultados.

Após os testes e melhorias necessários, finalizaram-se as primeiras versões do conjunto de algoritmos dos métodos de otimização implementados pela presente pesquisa. O produto dessa fase é o "Artefato", descrito a seguir.

Artefato (Produto): O "Artefato" é um plug-in de otimização para arquitetura, que aplica um conjunto de algoritmos verificados pela presente pesquisa. O plug-in foi desenvolvido de maneira open source, assim poderá ter seu desempenho verificado facilmente e ser adaptado a outros problemas de arquitetura.

A realização do "Artefato", baseado na Design Science (VAISHNAVI, 2015), é fruto e fonte do fluxo de conhecimento da pesquisa. Além disso, a reflexão, análise e avalição do desempenho do "Artefato" colabora com os conhecimentos abordados na pesquisa.

Avaliação (Fase): Nessa fase o artefato é avaliado de acordo com critérios implícitos e explícitos relativos a hipóteses que serão feitas sobre o comportamento esperado do artefato. Dessa maneira, na fase de "Avaliação" há a subfase de reunião dos critérios de análise de desempenho do "Artefato", com a finalidade de identificar seus potenciais e limites (VAISHNAVI, 2015).

Assim, na avaliação foi realizado o experimento comparativo entre o método de otimização implementado pelo escritório de arquitetura Perkins+Will e o "Artefato" desenvolvido pela presente pesquisa. O "Artefato" também foi avaliado no experimento que otimiza o material utilizado no 
sistema construtivo do projeto Wikihouse. Os critérios de avaliação estão descritos no Capítulo 3.

Medidas de desempenho (Produto): As "Medidas de desempenho" obtidas através do experimento comparativo dos métodos de otimização avaliados foram reunidas e sistematizadas com a finalidade de alimentar a fase "Conclusão".

Conclusão (Fase): A "Conclusão" representa a fase final do ciclo da pesquisa. Reúne os principais achados identificados através do fluxo de conhecimento, alimentado pelos procedimentos metodológicos descritos anteriormente. Os produtos da fase "Conclusão" estão reunidos em "Resultados".

Resultados (Produto): Os "Resultados" obtidos pela presente pesquisa foram organizados e sistematizados no formato adequado para serem publicados em congressos e periódicos.

\subsection{ESTRUTURA DA DISSERTAÇÃO}

A presente dissertação está dividida em 3 capítulos. A dissertação apresenta a introdução, em que demonstra o contexto, problema, objetivos e metodologia da pesquisa. O Capítulo 1 apresenta o contexto da otimização de projeto orientado ao desempenho e alguns dos principais potenciais e limites dessa abordagem em arquitetura. O Capítulo 2 apresenta métodos de otimização com ênfase em sistemas evolutivos, demonstrando seus conceitos fundamentais e principais conjuntos de procedimentos envolvidos em suas implementações. O Capítulo 3 apresenta os experimentos realizados na pesquisa, demonstrando o desenvolvimento de implementações de otimizações aplicadas em processos de projeto de arquitetura orientado ao desempenho. Por fim, a última parte apresenta considerações finais da pesquisa. 


\section{CAPÍTULO 1}

\section{ARQUITETURA E O PROCESSO DE PROJETO ORIENTADO AO DESEMPENHO}

Será apresentado a seguir o processo de projeto orientado ao desempenho, processo considerado como condutor do interesse desta pesquisa. Também apresentaremos sua relação com a exploração do espaço de design ${ }^{4}$ e como os diferentes tipos de busca por soluções neste espaço influenciam a eficiência do desenvolvimento de projeto.

\subsection{PROCESSO DE PROJETO E A COMPUTAÇÃO}

O processo de projeto de arquitetura, engenharia e construção (AEC) tem evoluído consideravelmente com a finalidade de responder à complexidade dos sistemas interconectados de um edifício (TOULOUPAKI e THEODOSIOU, 2017). Vêm sendo solicitados à arquitetura contemporânea, processos de projeto capazes de quantificar e qualificar o maior número de variáveis presentes nos sistemas de um edifício, com a intenção de balancear suas dinâmicas e inter-relações (SHI e YANG 2013). Contudo, tais solicitações não são algo emergente, mas sim o produto decorrente de décadas do amadurecimento das teorias e práticas.

Nesse contexto, dentre outros eventos, o lançamento do primeiro satélite artificial na órbita do planeta Terra, Sputnik, em 1957, gerou uma grande mudança nas pesquisas científicas. Bayazit (2004) afirma que o

${ }^{4}$ Nos referiremos ao termo "espaço de design" como tradução de "design space", ao invés de "espaço de projeto" para mantermos mais aproximação com o termo no inglês. 
lançamento do satélite pelos soviéticos não só aqueceu a Guerra Fria, mas significou a transição do rumo das pesquisas por parte das agências governamentais americanas. Assim, deslocaram-se as pesquisas com foco em objetos e parques militares para pesquisas em criatividade e $\mathrm{O}$ financiamento de investigações de processos de projeto de bens manufaturados ganhou força (BAYAZIT, 2004).

Oliveira e Pinto (2009) apontam que nesse período é formada uma consciência generalizada sobre a necessidade de melhor compreender os processos de projeto, através da análise e avaliação de seus métodos.

Um dos principais desdobramentos dessa consciência resultou na Conferência em Métodos Sistemáticos e Intuitivos na Engenharia, Desenho Industrial, Arquitetura e Comunicações (The Conference on Systematic and Intuitive Methods in Engineering, Industrial Design, Architecture and Communications), realizada em 1962 em Londres. Trabalhos como o de Bayazit (2004) e Jones (1976) demonstram a importância dessa conferência na história da pesquisa de métodos de projeto, reunindo pessoas que tiveram grande relevância para o desenvolvimento dessa área. Um fator importante dentro do desenvolvimento de tais pesquisas orientadas a métodos sistemáticos foi a introdução do computador em seus processos.

O engenheiro Joseph Christopher Jones (1963), um dos líderes e organizador da conferência em Londres, teve notabilidade por diversas contribuições, entre elas, por propor a divisão do processo de projeto em três etapas: (1) análise, que se refere ao levantamento de dados para o programa do projeto; (2) síntese, que se refere à geração de soluções de projeto; e (3) avaliação, que se refere à escolha entre as avaliações desejadas.

A teoria de Jones (1963) foi apropriada rapidamente por pesquisadores do campo da computação, por qualificar que computadores desempenhem um papel importante no processo de projeto:

De fato, se o projeto podia ser pensado em três etapas separadas, então o computador seria uma ferramenta ideal: 
os dados levantados na etapa de análise alimentariam o computador, que os processaria, gerando soluções alternativas (síntese); o computador poderia, inclusive, prover informações sobre a eficiência do projeto face ao programa de necessidades (avaliação) (MALARD, 1997).

No entanto, no início dos anos 70 houve um esvaziamento no entusiasmo com a pesquisa em métodos nos processos de projeto, fato que levou Jones a renunciar ao meio, declarando sua insatisfação com os rumos que vinham sendo tomados. A rigidez dos processos propostos e discussões metodológicas com fim em si mesmas provocaram o que o autor classificou como o "processo no lugar do progresso" (JONES, 1980).

Contudo, as teorias elaboradas com as pesquisas em processo de projeto ao longo dos anos 1960, como a teoria da divisão em três etapas (JONES, 1963), colaboraram com diversas produções a partir dos anos 1970. Entre as quais, somadas a pesquisas práticas na computação, pesquisas sobre o uso de abordagens evolutivas em projetos de arquitetura, qual comparecem a seguir.

\subsection{A MÁQUINA DE ARQUITETURA E A ABORDAGEM EVOLUTIVA}

Shi (2010) indica que o trabalho "The Architecture Machine" do arquiteto e cientista da computação Nicholas Negroponte (1970), como o primeiro exemplo de reflexão sobre a ideia da produção de arquitetura através de métodos de otimização assistida por computador. Por essa via, o desempenho do projeto passaria a ser usado como o critério para dirigir o processo de projeto.

A máquina de arquitetura ${ }^{5}$ de Negroponte (1970) propunha transformar este processo em um diálogo entre humano-computador, dividindo as principais capacidades da máquina em três eixos: (1) Geração, ambiente para configuração rápida de projeto; (2) Avaliação, verificação

\footnotetext{
5 Do original em inglês "The Architecture Machine", tradução nossa
} 
com os aspectos desejados do projeto arquitetônico; e (3) Adaptação, aprendizagem da máquina para responder com alternativas de projeto.

É possível estabelecer relações entre tais capacidades da máquina de Negroponte (1970) com a teoria da divisão do processo de projeto em três etapas apresentada por Jones (1963). Contudo, a principal contribuição na proposta de Negroponte (1970) é o eixo adaptação. Isto significa que após a avaliação, a máquina de arquitetura provoca a adaptação da proposta de projeto, ou seja, a otimização do projeto. A adaptação representa os avanços da época nas recentes discussões nos campos da inteligência artificial, cibernética, teoria da conversação e aprendizagem de máquina.

Apesar de ser uma proposta conceitual, dada a limitação técnica da computação na época, a máquina de arquitetura inspirou diversos trabalhos posteriores. Como descrito pelo autor: "A maioria das máquinas que discutirei não existe no momento. Os capítulos são basicamente extrapolações para o futuro, derivadas de experiências com vários sistemas de design auxiliados por computador..." (NEGROPONTE, 1970, p. 4, tradução nossa6).

Shi (2010) apresenta o sistema SSHA desenvolvido por Bijl e Shawcross (1974) como exemplo de trabalho derivado da máquina de arquitetura de Negroponte (1970). O sistema SSHA se concentra no processo de projeto computacional de sistemas aplicados ao layout de implantação de habitações, apresentando variações de propostas e geração de informações tridimensionais. Entre outros trabalhos derivados, llal (2007) cita os sistemas OXSYS de Hoskins (1973) e o sistema Harness de Meager (1973), ambos aplicados ao processo de projetos hospitalares e relacionados à máquina de arquitetura de Negroponte (1970).

As propostas de Negroponte (1970) contribuíram com trabalhos posteriores de muitas maneiras. Podemos destacar seu direcionamento para o emprego da futura capacidade computacional no processo de projeto:

6 Do inglês: "Most of the machines that I will be discussing do not exist at this time. The chapters are primarily extrapolations into the future derived from experiences with various computer-aided design systems..." 
Existem três maneiras possíveis pelas quais as máquinas podem auxiliar o processo de projeto: (1) os procedimentos atuais podem ser automatizados, acelerando e reduzindo o custo das práticas existentes; (2) os métodos existentes podem ser alterados para se adequarem às especificações e constituição de uma máquina, sendo que apenas as questões supostamente compatíveis com a máquina são consideradas; (3) o processo de design, considerado como evolutivo pode ser apresentado a uma máquina também considerada evolutiva, e um treinamento de resiliência e crescimento mútuos pode ser desenvolvido (NEGROPONTE, 1970, p. 6, tradução nossa ${ }^{7}$ ).

A terceira maneira possível pela qual as máquinas podem auxiliar o processo de projeto, trata da abordagem evolutiva (NEGROPONTE, 1970) e possui relações diretas com a aplicação de métodos de otimização.

Calixto (2016) afirma que o projeto de arquitetura desenvolvido a partir de princípios da computação evolutiva teve início na década de 1960 a partir das investigações desenvolvidas por John Frazer e seus alunos. Como derivação de tais investigações, Frazer (1975) publicou o livro "An Evolutionary Architecture", que relata investigações da correlação presente nos processos de criação de formas na arquitetura e teorias de morfogênese das ciências da natureza. Frazer (1975) demonstra através da emulação da evolução natural a criação de modelos arquitetônicos virtuais capazes de responder a mudanças ambientais (PASK, 1975).

7 Do original em inglês: "There are three possible ways in which machines can assist the design process: (1) current procedures can be automated, thus speeding up and reducing the cost of existing practices; (2) existing methods can be altered to fit within the specifications and constitution of a machine, where only those issues are considered that are supposedly machine-compatible; (3) the design process, considered as evolutionary, can be presented to a machine, also considered as evolutionary, and a mutal training, resilience, and growth can be developed." 


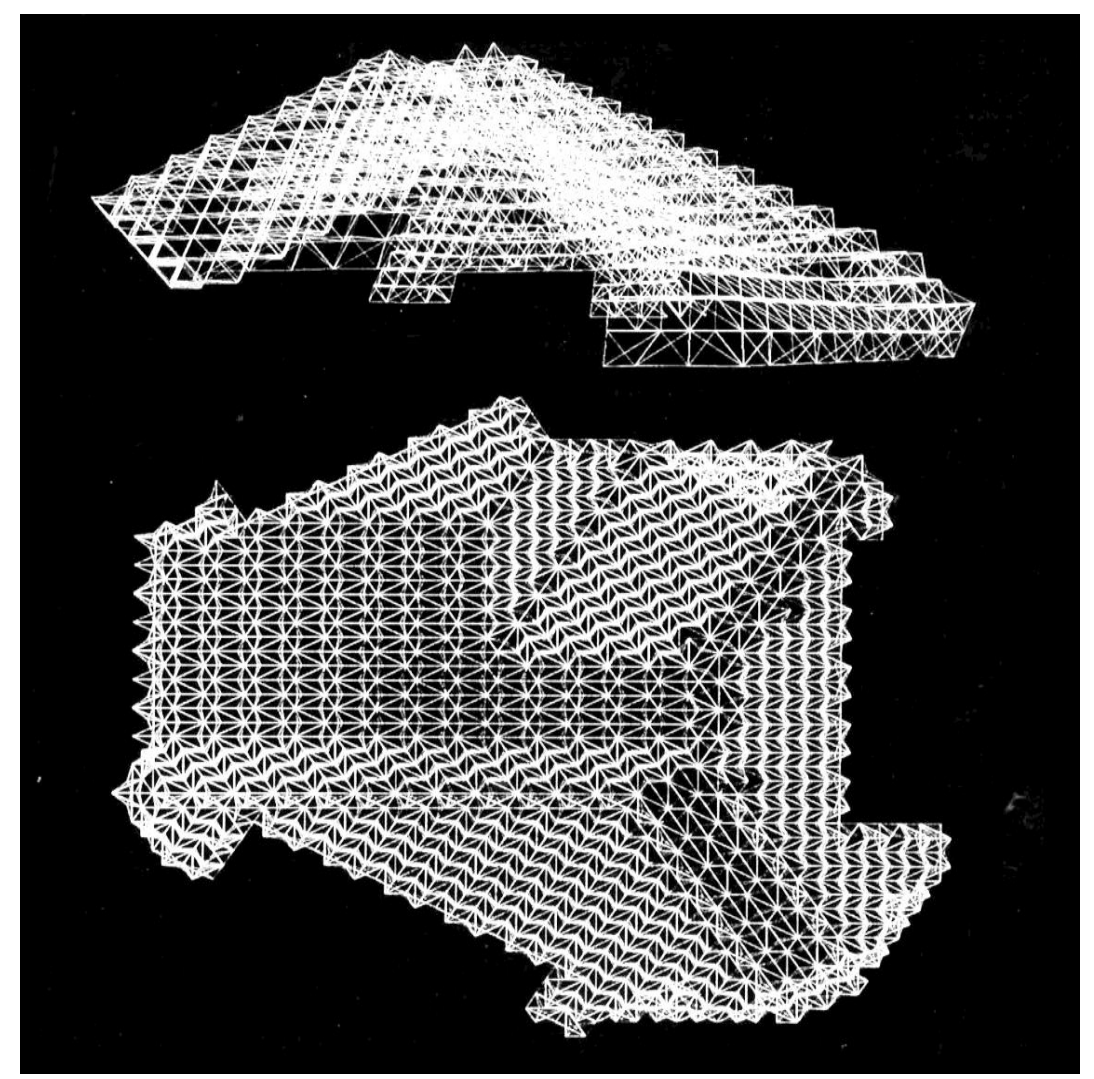

Figura 5: Design de estrutura de ginásio gerado por processo semiautomático a partir de uma única peça. Fonte: John Frazer (1966).

Outro trabalho importante na exploração da computação no processo de projeto de arquitetura, especialmente na área da computação evolutiva, é "Evolutionary design by computers" de Peter J. Bentley (1999). Ao longo do livro, Bentley (1999) sustenta a possibilidade de atribuir qualidades de autonomia, inovação e até criatividade ao computador, conferindo novas maneiras em seu uso no processo de projeto.

O autor defende a possibilidade de utilização de algoritmos evolutivos (Capítulo 2) em todas as etapas do projeto, e se refere a esta abordagem como "design by computers". Ao longo do livro são apresentados projetos de diversos tipos, desde a estrutura de satélites, imagens artísticas, esculturas, mobiliários, arquitetura de casas, hospitais, pontes e guindastes.

O trabalho reúne dezoito projetos originais de trinta e três autores, todos demonstrando aspectos da aplicação de algoritmos evolutivos (BENTLEY, 1999). Os trabalhos são apresentados em seções que dividem o 
entendimento e aplicações dos algoritmos evolutivos em quatro categorias: otimização de projeto evolutivo (evolutionary design optimization), projeto evolutivo criativo (creative evolutionary design) arte evolucionária (evolutionary art) e formas evolucionárias de vida artificial (evolutionary artificial life forms).

A categoria "otimização de projeto evolutivo" (evolutionary design optimization) tem relações diretas com a presente pesquisa por demonstrar o emprego de métodos da computação evolutiva na otimização de projetos. Investigaremos o assunto na seção seguinte, a fim de aprofundar a compreensão sobre o emprego da otimização em projetos de arquitetura

\subsection{OTIMIZAÇÃO EM ARQUITETURA}

O termo "otimizar" se refere a encontrar a melhor solução possível para um problema maximizando os efeitos desejados e minimizando os efeitos indesejados (SCHEURER, 2014). Na mesma linha, o termo "otimização de construção" se refere à aplicação de métodos que utilizam algoritmos na busca do balanceamento ideal de parâmetros presentes desde a concepção até a fabricação do projeto de AEC (LARS JUNGHANS, 2014).

Ao longo das últimas décadas, os métodos de otimização de desempenho apareceram em diversas aplicações e pesquisa na AEC, tais abordagens foram nomeadas de formas distintas. Touloupaki e Theodosiou (2017) apresentam algumas em sua revisão sistemática sobre o assunto, também complementamos com outras nomenclaturas: otimização de projeto computacional (computational design optimization) (LUEBKEMAN; SHEA, 2005); projeto baseado em desempenho (performance-based design) (OXMAN; HAMMER, 2007; HEMSATH 2013); projeto por simulação (design by simulation) (XIA et al., 2008); otimização de projeto multidisciplinar (multidisciplinary design optimization) (CALDAS; 2008, WELLE et al., 2010; LIN; GERBER, 2014; DIAZ et al., 2017); otimização de projeto arquitetônico (architectural design optimization) (CICHOCKA, MUSIKHINA, 2014; 
WORTMANN; NANCINNI 2016) e otimização de projeto orientado ao desempenho (performance-driven design optimization, ou apenas performance-driven design) (SHI, 2010).

Adotaremos o termo otimização de projeto orientado por desempenho (OPOD), ou apenas projeto orientado ao desempenho, para nos referirmos à abordagem que aplica ferramentas de simulação, análise de desempenho e métodos de otimização em modelos paramétricos de arquitetura.

Adotamos a abordagem de otimização de projeto orientado ao desempenho (OPOD), pois o próprio nome exprime seu conceito, definido por estabelecer requisitos de desempenho que possam ser quantificáveis, para que a otimização integrada de múltiplas variáveis possa guiar e aperfeiçoar o desempenho do projeto de arquitetura (SHI e YANG, 2013). Utilizamos o termo "abordagem" (SIMON, 1996) e não "metodologia" pela confusão lexicográfica das referências bibliográficas que exprimem significados diferentes para os termos "método", "metodologia" e "abordagem". Aparentemente existe a preocupação em arquitetura de criar nomenclaturas para fundar metodologias e consequentemente autorias. Contudo, a presente pesquisa não se concentra na reflexão de tal escopo e discussão.

\subsection{DESEMPENHO}

O termo desempenho possui diversos significados. Pode significar, por exemplo, um modo de executar determinada tarefa que terá, posteriormente, seu grau de eficiência submetido a uma análise e apreciação. Em arquitetura, o termo é frequentemente usado para elucidar um método genérico que descreve diversas considerações de projeto, como descrito por Shi (2010):

Diversos termos podem ser colocados com desempenho à frente e formar um termo que faz sentido para os arquitetos, por exemplo, desempenho térmico, desempenho estrutural, 
desempenho antichamas, etc. Uma maneira mais eficaz de entender o que desempenho realmente significa para 0 projeto arquitetônico é estudar quais os problemas de desempenho precisamos considerar ao projetar um edifício que seja seguro. (SHI, 2010, p. 2, tradução nossa ${ }^{8}$ ).

Considerando que desempenho está ligado a segurança e ao conforto dos ocupantes do edifício (SHI, 2010), é muito comum em diversos países que exista uma legislação ou sistema envolvendo normas de qualidade ligadas ao desempenho dos edifícios. A sustentabilidade é outro eixo de avaliação de projeto, que cresce consideravelmente desde a crise do petróleo dos anos de 1970 (SHI et al. 2016). O número de sistemas de classificação de sustentabilidade desenvolvidos em todo o mundo nas últimas décadas ilustra a força dessa demanda em AEC (SHI et al., 2016; TOULOUPAKI; THEODOSIOU, 2017).

Os sistemas Building Research Establishment (BRE) da Grã-Bretanha, Leadership in Energy and Environment Design (LEED) do Estados Unidos, Green Building Tool (GB Tool) do Canadá e Comprehensive Assessment System for Built Environment Efficiency (CASBEE) do Japão são exemplos de sistemas de classificação sustentável conhecidos e aplicados em edifícios no mundo todo. Candance e Wood (2008) demonstram como tais sistemas, apesar de singulares, apresentam diversas similaridades, entre as quais destaca-se a ampla integração de critérios socioeconômicos a critérios de desempenho ambiental que devem ser atendidos pelo projeto dos edifícios, além de critérios fundamentais de segurança e conforto.

Assim, a aplicação de processos de projeto orientados ao desempenho apresenta contribuições significativas à AEC, por aumentar consideravelmente os padrões do projeto, respondendo às diversas

8 Do original em inglês: "Almost any term can be put in front of performance and form a phrase that makes sense to architects, e.g., thermal performance, structural performance, fire-resistant performance, etc. A more effective way to understand what performance really means to architectural design is to study what performance issues we need to consider in designing a building." 
solicitações presentes no seu escopo. A otimização, pode ser aplicada em questões como: estudos de massa, projeto de fachadas, orientação e implantação de edifícios, sistemas estruturais, sistemas de aquecimento, ventilação e ar-condicionado, qualidade do ar, energia, iluminação natural e artificial, acústica; logística, ciclo de vida, custos, e etc. (SHI, 2010; MACHAIRAS et al., 2013; TOULOUPAKI; THEODOSIOU, 2017).

Um exemplo de edifício que incorporou a otimização integrando o desempenho da arquitetura, estrutura e sistemas prediais é a habitação estudantil Simmons Hall, no MIT, projetada pelo arquiteto Steven Holl. O edifício não possui ar-condicionado tradicional e todos seus elementos foram projetados para minimizar a carga de resfriamento.

Todas as três mil janelas foram dimensionadas e posicionadas de acordo com a quantidade de luz solar que deveria adentrar os dormitórios durante todo o ano. Além disso, a massa térmica da fachada absorve o calor solar e uma quantidade muito pequena de ar resfriado e desumidificado ajuda no controle térmico sempre que a temperatura externa à edificação ultrapassa $26,66^{\circ} \mathrm{C}$.

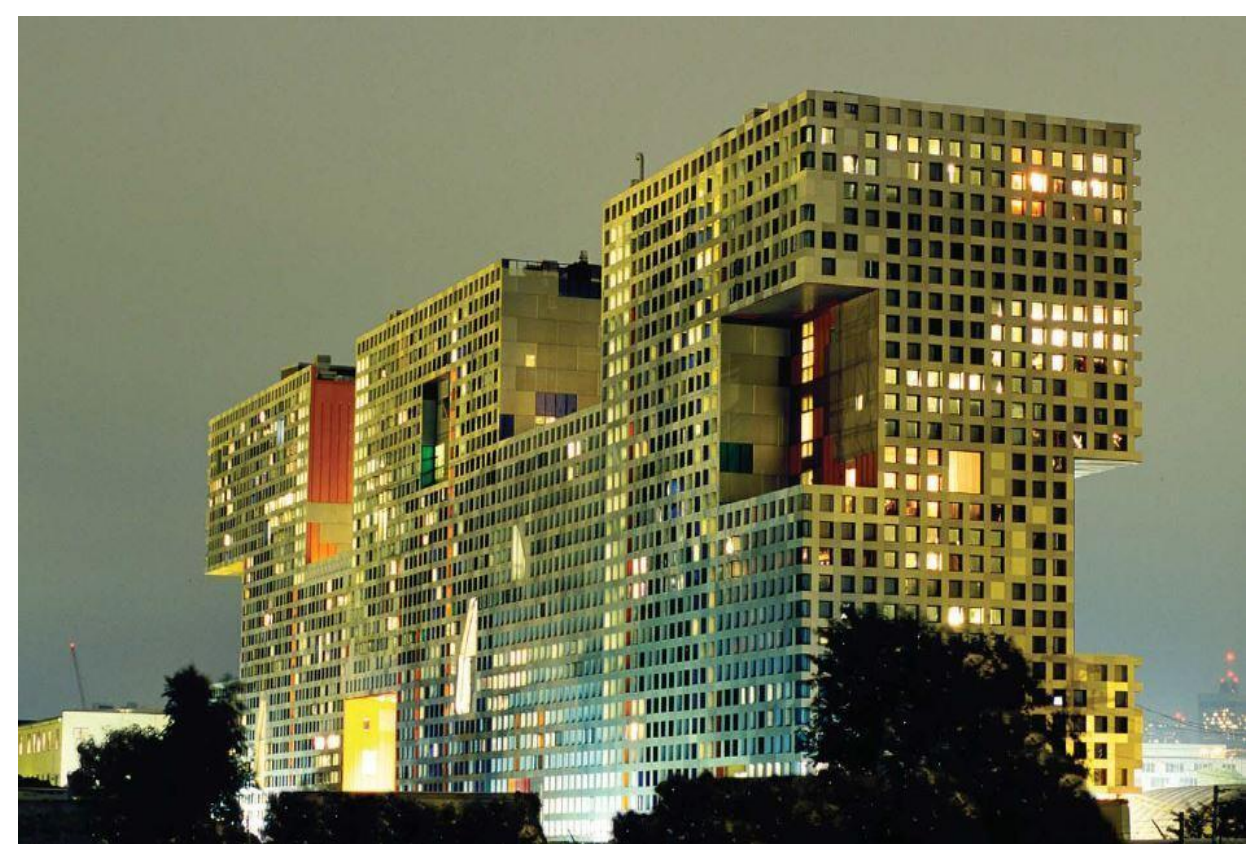

Figura 6: Habitação estudantil Simmons Hall, no MIT. Fonte: Kolarevic e Malkawi (2005). Foto: Andy Ryan. 


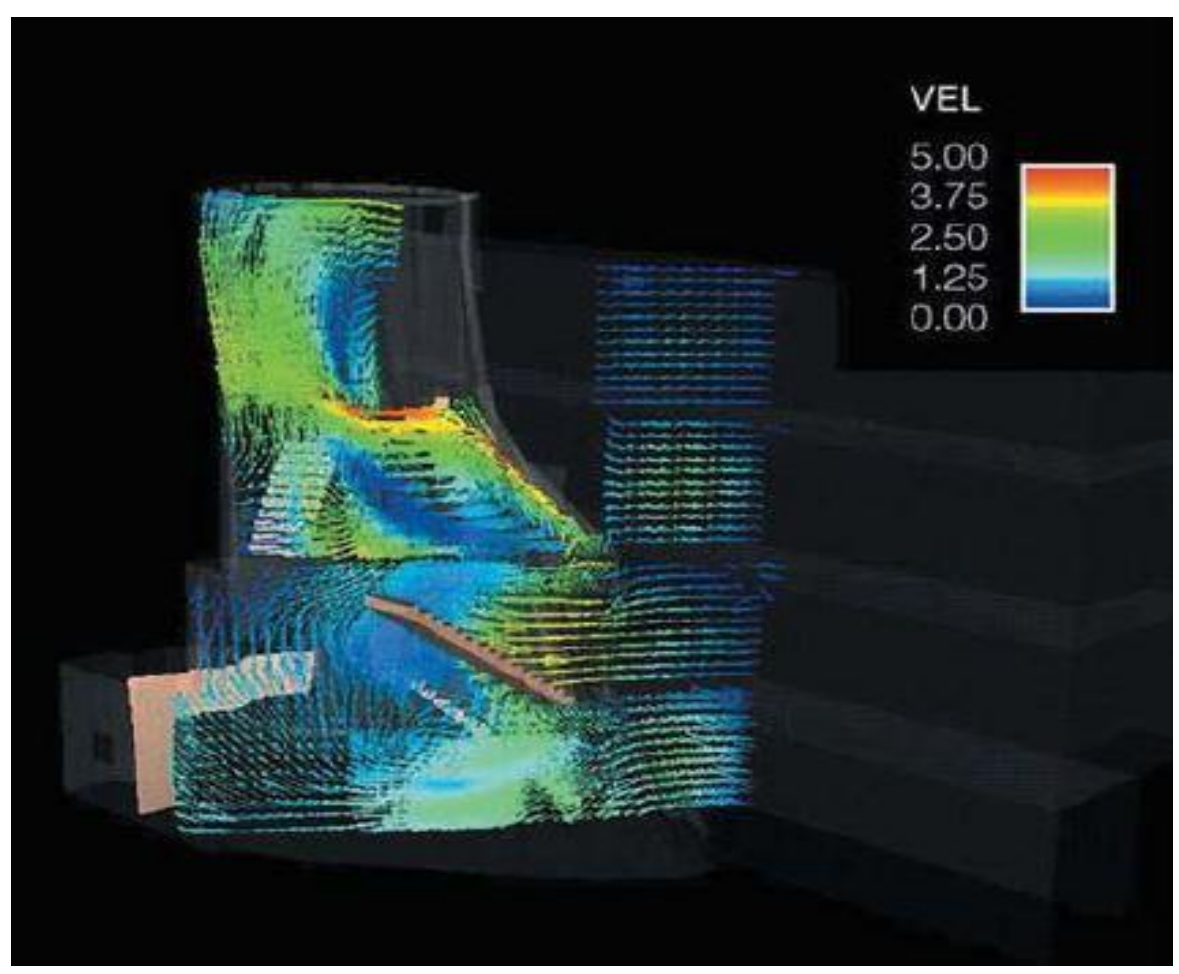

Figura 7: Simulação CFD (Computational Fluid Dynamics) aplicada na integração do desempenho da arquitetura, estrutura e sistemas prediais do projeto Simmons Hall. Fonte: Kolarevic e Malkawi (2005).

Dessa maneira, os fundamentos e aplicações relacionadas a otimização e desempenho em arquitetura serão apresentados a seguir.

\subsection{OTIMIZAÇÃO DE PROJETO ORIENTADO AO DESEMPENHO}

A otimização de projeto orientado ao desempenho envolve design computacional, simulação de desempenho e otimização computacional, que são conhecimentos desenvolvidos e aplicados em áreas distintas.

Embora predominem em pesquisas e projetos nas engenharias, computação e indústria, o emprego de otimização tem aumentado na arquitetura por atribuírem maior controle, variedade de soluções e desempenho do projeto (MACHAIRAS et al., 2013).

Esta abordagem é possivel devido a intersecção de três esferas: o Design Computacional, que permite conceber e descrever modelos de projeto paramétricos e generativos; Simulações de Desempenho, que permitem simular a performance de alternativas de projeto e Otimização 
Computacional, que permite empregar técnicas e algoritmos de otimização nestes projetos.

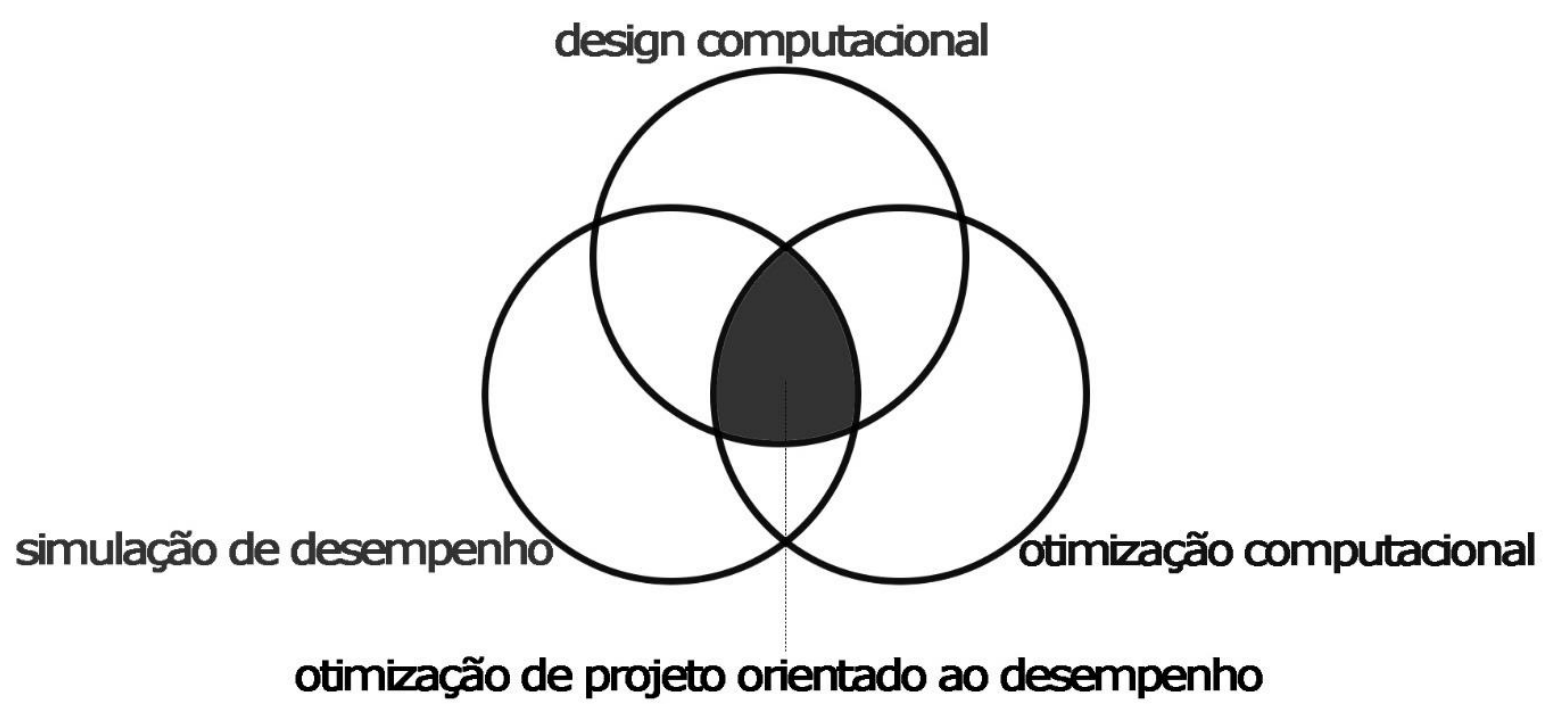

Figura 8: A otimização de projeto orientado ao desempenho é combinação entre design computacional, simulação de desempenho e a otimização computacional. Fonte: Adaptado de Touloupaki; Theodosiou (2017).

A interdisciplinaridade envolvida promove 0 fluxo de trabalho computacional, que pode envolver, por exemplo, as seguintes etapas:

1. Um modelo é definido por meio dos parâmetros do projeto.

2. O modelo é analisado através de simuladores que geram seus dados de desempenho.

3. A partir dos resultados obtidos na simulação, o modelo passa por métodos de otimização que buscam alternativas de projeto com desempenho superior.

4. As alternativas de projeto encontradas com a otimização são analisadas com a simulação e se não atenderem o objetivo de desempenho desejado são repetidos os passos 3. e 4., caso contrário o processo é finalizado.

Esta recursividade entre a simulação e otimização das alternativas de projeto é, responsável pelo aperfeiçoamento do desempenho do projeto. A 
otimização é guiada pelo método aplicado na investigação de alternativas dentro do campo dos parâmetros estabelecidos para o projeto.

Ao longo da última década, a associação entre programas de modelagem paramétrica e simuladores em um ambiente computacional integrado está facilitando a implementação desta abordagem em arquitetura. Isso acontece principalmente pela popularização do uso de linguagens de programação visual, como GenerativeComponents, Grasshopper e Dynamo.

Os termos "Projeto de Arquitetura Assistido por Computador (CAAD)", "Design Digital" e "Design Computacional" são sinônimos e todos se referem, de maneira geral, a métodos de projeto que utilizam poder computacional em projetos de arquitetura (HARDING, 2014). Desdobramos a seguir seu contexto.

\subsection{DESIGN COMPUTACIONAL}

As capacidades de otimização do projeto se fundiram com a facilidade de automatização dos processos. Desta maneira, os requisitos, restrições e intenções de um problema de arquitetura não são mais tratados como entidades isoladas. Desta maneira, o Design Computacional, pode resolver problemas de maneira holística pela capacidade de programar a interação entre estas entidades, uma vez que programas de computador podem processar desenhos complexos em soluções arquitetônicas cada vez mais específicas (MENGES; AHLQUIST, 2011).

O Design Computacional também está baseado no pensamento algorítmico, que expressa as regras e parâmetros que compõem, codificam e declaram a relação entre a intenção do projeto e a resposta obtida no projeto (JABI, 2014).

Nesta área, existem duas abordagens amplamente conhecidas. A primeira é o design generativo, onde o projetista tipicamente utiliza um sistema baseado em parâmetros de modelagem, como um programa de 
computador, para explorar alternativas de projeto através de algoritmos iterativos (GARBER, 2014). A segunda abordagem é o design paramétrico, que não necessariamente utiliza programas de computador, mas está relacionado a expressão do conjunto de parâmetros e regras de relações que definem e formalizam a interação entre a intenção do projeto e o resultado obtido.

Usaremos a definição mais próxima à compreensão matemática de Design Computacional, o desenvolvimento de processos de projetos que geram modelos através da descrição de constantes e variáveis por meio de algoritmos. Portanto, seguindo a definição matemática, existem dois tipos de quantidades nesta definição, as constantes e as variáveis (WEBER, 1976):

Variável é uma quantidade que assume todos os valores significativos de um problema. Pode ser discreta, quando é finita ou numerável, como o número de janelas em um edifício. Pode ser uma variável contínua, ou seja, uma quantidade que forma um intervalo ou união de números reais, como o peso de uma laje em um edifício.

Constante ou constante absoluta é uma quantidade cujo valor não muda em um problema particular, como por exemplo a proporção numérica de Pi.

Parâmetro ou constante paramétrica, é um valor que possui a mesma quantidade em cada problema, mas pode assumir valores diferentes em problemas distintos, como a proporção numérica do volume de uma sala, por exemplo.

Ao realizamos a modelagem paramétrica de um projeto, utilizamos parâmetros para controlar a geometria do modelo tridimensional. A maneira mais usual para descrever um modelo é através da programação visual, uma linguagem de programação declarativa (DAVIS, 2013). Os programas que oferecem esse tipo de linguagem são uma alternativa para os usuários que não programam textualmente, e tornam a programação mais acessível 
a um público mais vasto de arquitetos sem educação formal em computação. (AISH, 2013; REAS el al., 2010)

A programação visual permite explicitar graficamente uma coleção de operações através de nós com funções pré-programadas, conectadas através de fios (arestas) que representam a direção do fluxo de dados e tipos de iteração, por exemplo a iteração simples ou recursão (JANSSEN; STOUFFS, 2015).

Os programas de modelagem paramétrica mais utilizados em arquitetura são:

Grasshopper: uma linguagem e ambiente de programação visual desenvolvido por David Rutten. É disponibilizado como um plug-in para a aplicação CAD` Rhinoceros 3D (Robert McNeel \& Associates).

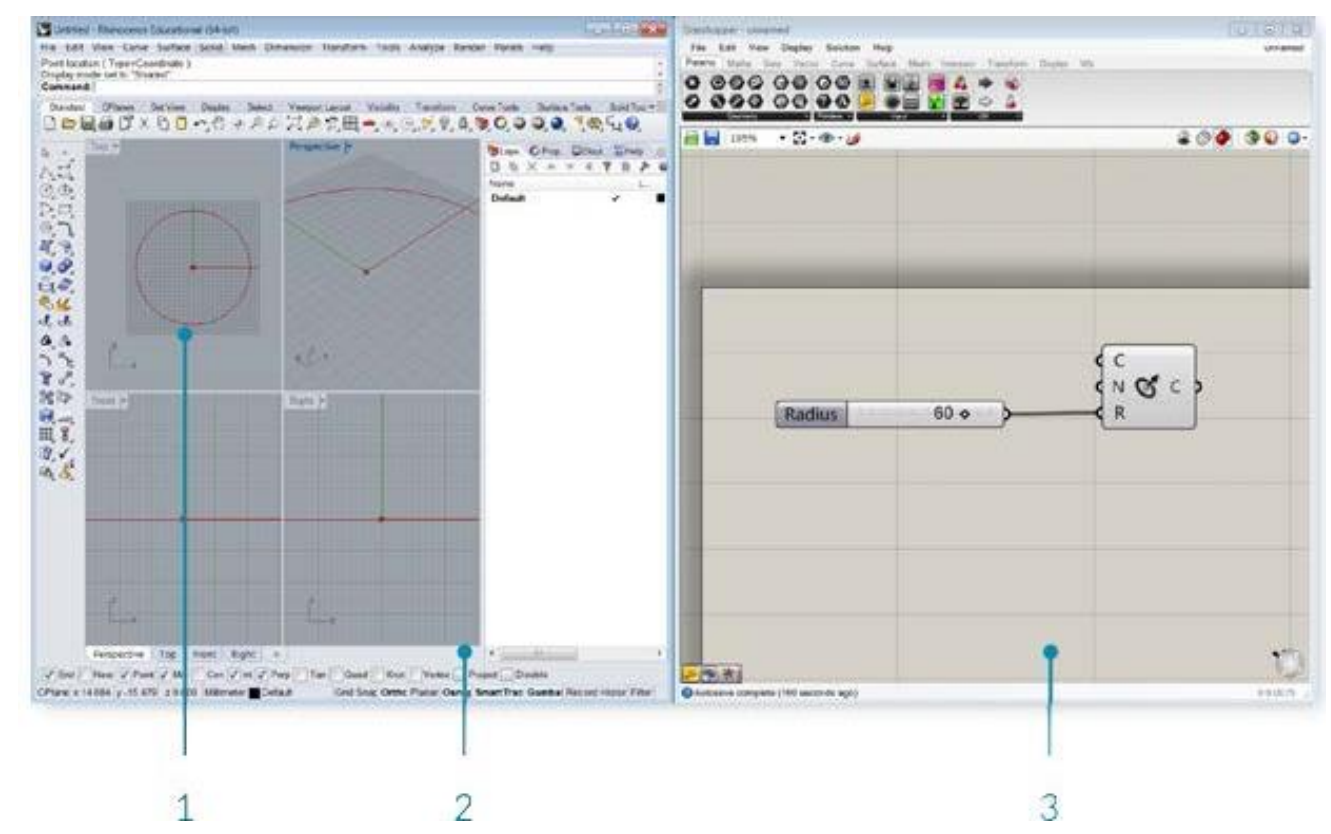

Figura 9: A esquerda janela do Rhinoceros a direta janela do plug-in Grasshopper. 1. indica a pré-visualização da geometria gerada no Grasshopper, 2. indica as viewports do Rhinoceros, 3. Indica a tela de aplicação do Grasshopper. Fonte: Mode Lab (2017).

9 Computer-aided design (CAD) ou desenho auxiliado por computador é o nome genérico do sistema computacional (software) utilizados por diversas áreas, entre elas, a engenharia, geologia, geografia, arquitetura e design na realização de desenhos e modelos. 
No Grasshopper os programas são criados através da modelagem de fluxo de dados (JANSSEN; STOUFFS, 2015), onde componentes inseridos na tela representam funções, parâmetros e elementos geométricos. As ligações entre os componentes estabelecem as relações entre eles e ordenam as operações encadeadas. Dessa maneira, é possível desenvolver algoritmos aplicados aos mais diversos problemas, seja para a criação, análise ou otimização de modelos paramétricos sem o conhecimento prévio de programação textual. No entanto, também é possível estender as funcionalidades do Grasshopper através de scripts textuais nas linguagens VB.NET, C\# e Python. A interface também permite a instalação de plug-ins adicionais desenvolvido por terceiros. Além disso, apesar de ser uma linguagem de programação visual que funciona exclusivamente no programa CAD no Rhinoceros, é possível exportar o modelo para programas BIM $^{10}$ (FERREIRA; LEITÃO, 2016).

Dynamo: uma linguagem e ambiente de programação visual disponibilizado para o programa BIM Revit (Autodesk). Assim como no Grasshopper, Dynamo permite declarar o código através da conexão de nós e fios, e é classificado como uma linguagem que suporta modelagem processual (JANSSEN; STOUFFS, 2015), um tipo de modelagem mais avançada por suportar iterações e recursividade em loops. Dynamo também suporta a criação e edição de programas através da programação textual em Python (FERREIRA; LEITÃO 2016).

GenerativeComponents: um sistema computacional paramétrico desenvolvido por Bentley Systems. É disponibilizado na aplicação BIM Microstation (Bentley). O usuário pode modelar e manipular a geometria diretamente, além de aplicar regras que expressam o relacionamento entre os elementos do modelo. Assim como Grasshopper,

10 Building Information Modeling (BIM), ou modelagem da informação da construção é uma representação digital de informações compartilhadas das características físicas e funcionais de uma instalação. 
GenerativeComponentes também é suporta modelagem de fluxo de dados (JANSSEN; STOUFFS, 2015). A interface suporta o uso de programação textual através do GCScript e de C\# (FERREIRA; LEITÃO 2016).

No processo de projeto orientado ao desempenho tais programas são aplicados na produção dos modelos do projeto. A partir dos modelos paramétricos é possivel realizar simulações que geram as análises de desempenho. As propriedades da simulação serão descritas a seguir.

\subsection{SIMULAÇÃO DE DESEMPENHO}

A simulação é responsável por produzir fenômenos artificiais, cujos resultados balizam as análises do modelo avaliado, portanto, é essencial no processo de projeto orientado ao desempenho. Os empregos de simulações em projetos de AEC são explorados pela disciplina nomeada por Building Performance Simulation (BPS). A combinação entre modelagem paramétrica e simulação de desempenho pode ser aplicada em diversas demandas do projeto: eficiência energética, ventilação, acústica, aquecimento, resfriamento, iluminação artificial e natural, entre outros.

O uso de sistemas BPS é essencial no processo de projeto de edifícios sustentáveis, que buscam reduzir os impactos no meio ambiente e nos ocupantes por meio de estratégias que conservam os recursos disponíveis e reduzem o desperdício (TOULOUPAKI; THEODOSIOU, 2017). Contudo, para atender às metas de sustentabilidade estabelecidas é necessário que haja o desenvolvimento contínuo de novos conceitos, tecnologias e materiais capazes de melhorar o desempenho dos edifícios.

A simulação de desempenho do edifício tem o potencial de fornecer informações relacionadas às partes interessadas, incluindo arquitetos, construtores, cientistas de materiais, consultores de construção sustentável, engenheiros e profissionais de serviços da construção (CLARKE; HENSEN, 2015). 
No entanto, apesar de amplamente disponíveis, os sistemas computacionais BSP ainda apresentam limitações em sua implementação no processo de projeto. Ainda que os programas possuam comunidades de desenvolvedores ativos e recebam atualizações com regularidade, estendendo sua capacidade de modelagem, seus conceitos subjacentes e arquitetura de software básica não têm mudado. Dessa maneira, as propriedades do edifício simulado, seja forma ou matéria, não são diversificáveis durante a execução da simulação, inviabilizando a avaliação de sistemas do edifício que são adaptáveis (ROEL, et al., 2018).

Existem também limitações de interoperabilidade entre os simuladores e os softwares CAD e BIM. Além disso, há a necessidade de treinamento das equipes de projeto para operar os sistemas BPS. Estes aspectos podem aumentar o tempo e esforço de preparação para aplicar simulações de performance em um projeto, uma vez que esses programas possuem uma curva de aprendizado acentuada para serem devidamente utilizados (HIEN et al. 2000).

Contudo, modelagem e simulação podem trazer respostas valiosas sobre a relação entre os aspectos do projeto e seu desempenho. Sua aplicação vem se tornando cada vez mais comum no processo de projeto de arquitetura, pois podem contribuir com 0 desenvolvimento de tecnologias inovadoras (ROEL, et al., 2018).

Para a aplicação confiável da simulação no processo de projeto é necessário a compreensão de alguns aspectos. As simulações realizam operações próprias através de métodos de cálculos específicos dos problemas do projeto que se pretende analisar. Segundo Junghans (2014) os simuladores, atualmente utilizam os seguintes métodos de cálculo:

Cálculo estático: Baseados em equações simples com número limitado de valores que representam um fenômeno específico, por exemplo o clima. Apresentam a vantagem de um custo computacional reduzido, ou seja, um tempo de cálculo pequeno. Porém, esses cálculos não são capazes de 
correlacionar variações, como variações de temperatura, radiação solar ou ganhos internos de calor. Desse modo, os métodos estáticos podem apresentar cálculos imprecisos se aplicados a medidas variáveis.

Cálculo dinâmico: Diferente do cálculo estático, é capaz de correlacionar variações. Os programas baseados no método de cálculo dinâmico são capazes de quantificar valores respectivos a um intervalo de tempo através de dados (meteorológicos, por exemplo), correspondentes a uma região em determinado período. Por isso é o método mais utilizado em programas de simulação dinâmica. Contudo, as simulações são computacionalmente custosas, ou seja, exigem mais tempo para serem executadas.

Cálculo de superfície climática: O método gera uma matriz de dados para o tipo de superfície analisada a partir de pré-simulações dinâmicas. Esse método pode superar a eficiência do custo computacional dos programas baseados em métodos de simulação dinâmica. Porém, a matriz deve ser descrita com os fatores que se pretende avaliar, como por exemplo, ventilação natural, luz do dia, sombreamento e psicometria.

Tais métodos são aplicados em diversos programas de sistemas BPS que surgiram nas últimas décadas, sendo que os programas mais utilizados são: EnergyPlus (U.S. Department of Energy's), usado para modelar o consumo de energia (como aquecimento, resfriamento, ventilação, iluminação, entre outros) e uso de água em edifícios; Radiance (Radiance.org), usado para análise e visualização de iluminação; TRNSYS (Trnsys), um programa para avaliação do desempenho de sistemas de energia térmica, elétrica e sistemas dinâmicos como o fluxo de tráfego; IDAICE (EQUA) e DOE-2 (Hirsch \& Associates) que ajuda a prever o uso e custo de energia para edifícios.

Em BPS, muitas vezes mais de um critério é avaliado na mesma execução. Para isso, pesquisadores e desenvolvedores modelaram a estratégia de cossimulação, na qual dois os mais simuladores resolvem 
equações trocando dados durante o tempo da execução (TRCKA et al. 2009). A cossimulação pode se tornar particularmente importante para $\circ$ projeto orientado ao desempenho por integrar simulações de diferentes domínios físicos inter-relacionados usando ferramentas distintas. Além disso, facilita o acoplamento de novas tecnologias que apresentam recursos que podem não estar previamente disponíveis nos programas consolidados, apoiando a otimização de projetos com maior complexidade.

Assim, o emprego dos programas BPS e de algoritmos de otimização no processo de projeto orientado ao desempenho, permite explorações estruturadas no espaço de design. Portanto podem ajudar os profissionais da AEC a encontrar as soluções de projeto mais promissoras entre as diversas alternativas possíveis (EVINS 2013; ATTIA et al. 2013).

A estreita relação entre simulação e otimização na exploração de alternativas de projeto requer uma compreensão sobre o próprio espaço de design, portanto seus principais conceitos serão descritos a seguir.

\subsection{ESPAÇO DE DESIGN}

Para ampliar a compreensão do uso do design computacional, simulação e otimização no processo de projeto em arquitetura, é interessante haver entendimento sobre o conceito de espaço de design ou espaço de projeto, termo largamente utilizado por arquitetos ao descreverem o processo de projeto e a resolução de problemas (KEOUGH, BENJAMIN，2010; BENJAMIN，2012; SCHEURER， 2013; RUTTEN， 2010; WORTMANN, et al., 2015; NAGY, 2017).

Chaszar e Joyce (2016) argumentam que o espaço de design fornece um modelo conceitual atraente, se não definitivo, para descrever e analisar a atividade de projeto. Para Westerlund (2005), espaço de design pode ser aplicado como um modelo conceitual para entender o processo de projeto e é definido como o espaço que contém todas as soluções possíveis para o projeto (BENJAMIN, 2012). 
O espaço de design pode ser conceitualmente representado por pontos dentro de um espaço, sendo os pontos a representação dos projetos (CHASZAR; JOYCE, 2016). Assim, o espaço de design serve para apontar intenções de projeto durante todo o processo.

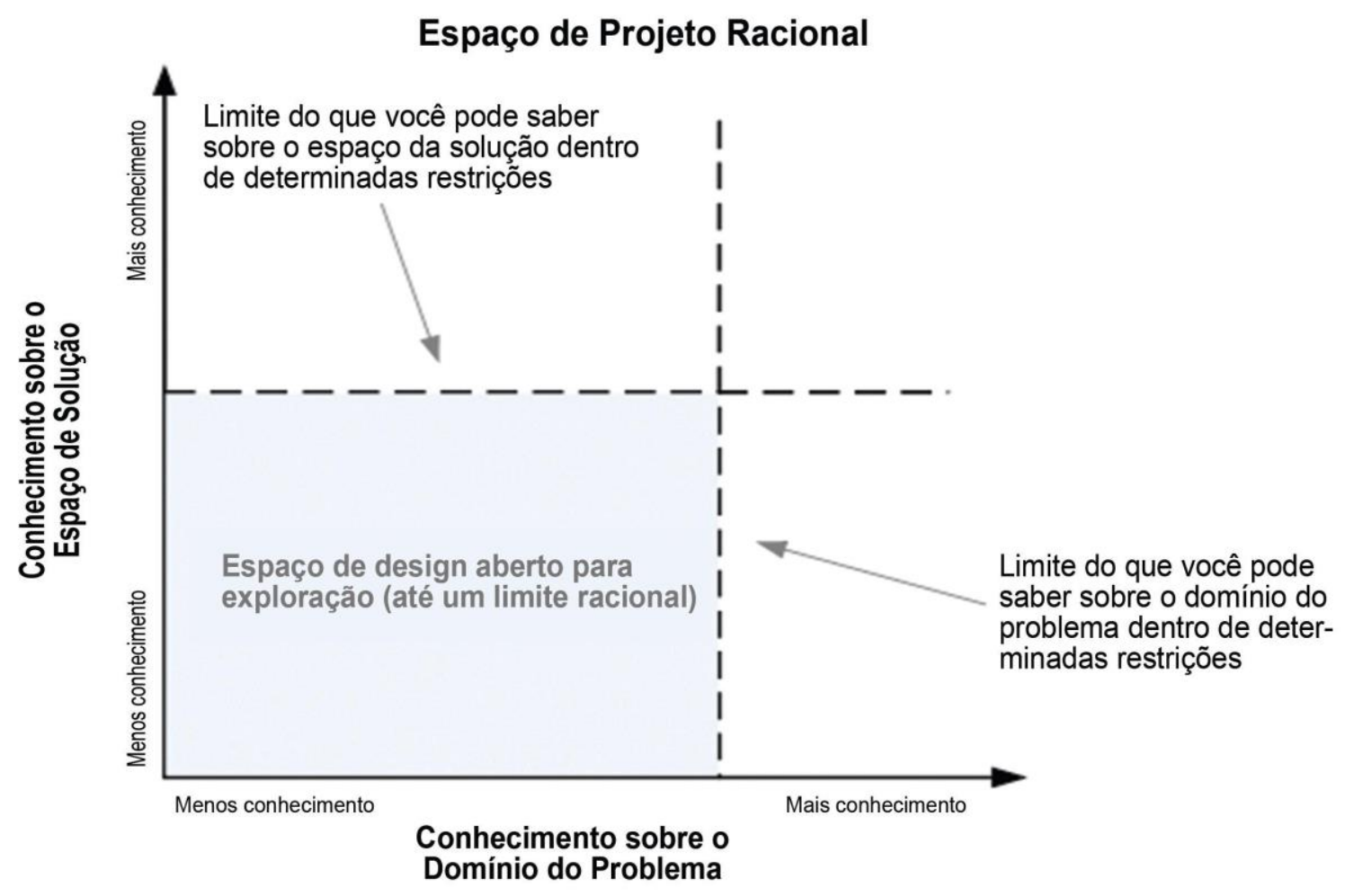

Figura 10: Representação do Espaço de Design. Fonte: Adaptado de Keeling (2015).

Todo espaço de design está dentro de um espaço n-dimensional, onde $n$ representa o número de parâmetros que dirigem o projeto (NAGY, 2016). Neste cenário, de maneira geral o processo de projeto consiste de em se mover entre os pontos dentro do espaço de possibilidades (CHASZAR; JOYCE, 2016). Isso significa que todo o conhecimento adquirido durante $O$ processo resulta em mais compreensão sobre o próprio espaço de design, que por sua vez representa todas as $n$ soluções possíveis para o projeto.

Westerlund (2005) e Nagy (2016) afirmam que espaços de design não podem ser completamente descritos por causa de sua complexidade e tamanho. É possível exemplificar a ideia geral deste conceito com uma representação gráfica adaptada de Keeling (2015), a qual mostra que qualquer sistema projetado estará dentro da compreensão que o projetista 
tem sobre o espaço de design. Portanto, o quanto o projetista sabe sobre o domínio do problema e o espaço de solução, determina o quanto o processo de projeto está apropriado ao desenvolvimento do projeto ideal (KEELING, 2015).

Conhecimento de Projeto através do Tempo

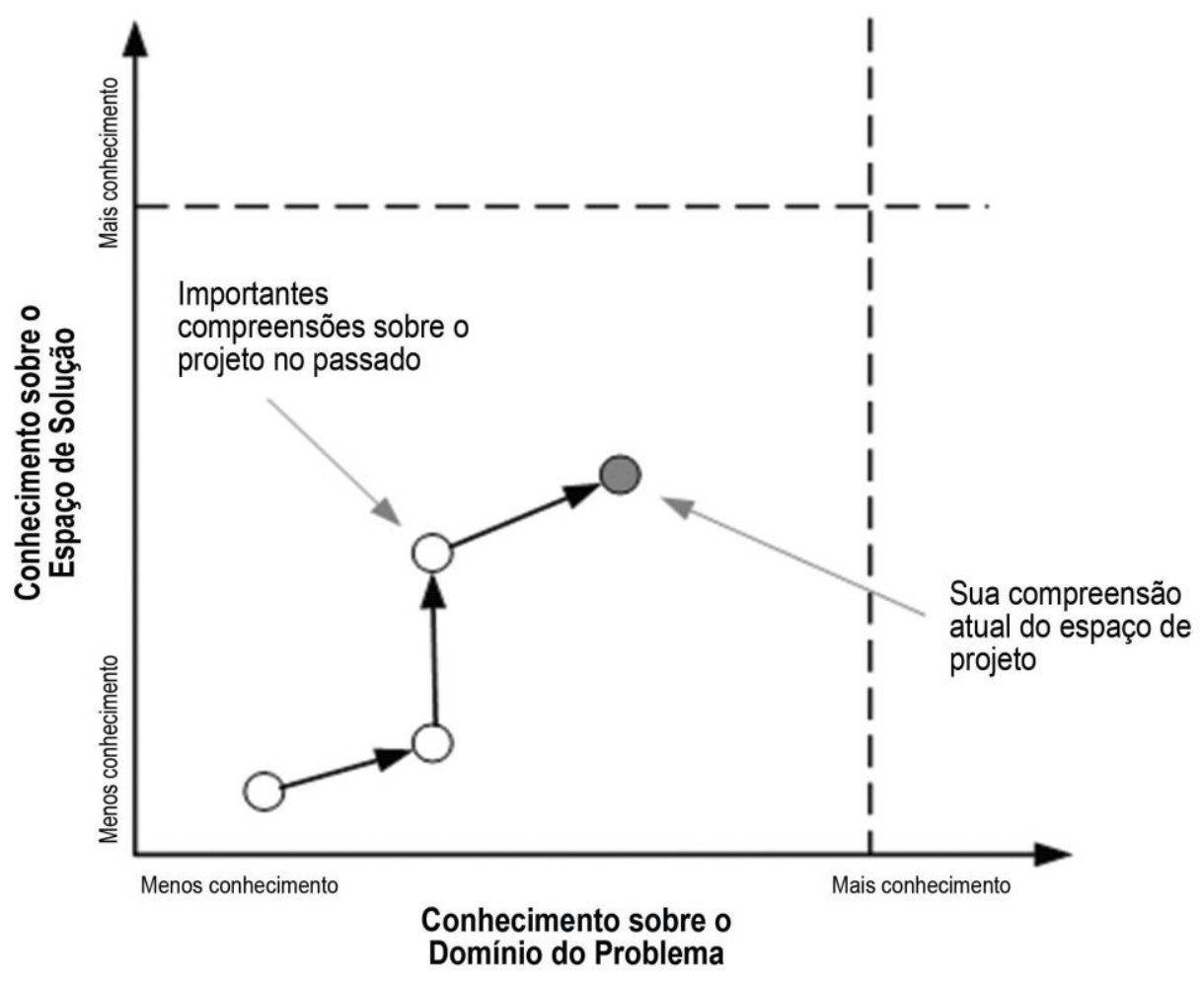

Figura 11: Conhecimento sobre o projeto ao longo do tempo. Fonte: Adaptado de Keeling (2015).

Sendo assim, é possível criar uma curva (figura acima) sobre o conhecimento em torno do espaço de design que pode indicar algumas diretrizes. Keeling (2015) argumenta que se a curva permanecer horizontal, pode significar que se sabe muito sobre o problema e pouco sobre soluções, isso indica que a equipe possui muito conhecimento de domínio específico. Já a curva predominantemente vertical, indica uma equipe provavelmente especialista na resolução de um problema padrão, porém sem muito conhecimento sobre o problema geral (figura abaixo). 
Especialistas em Domínio

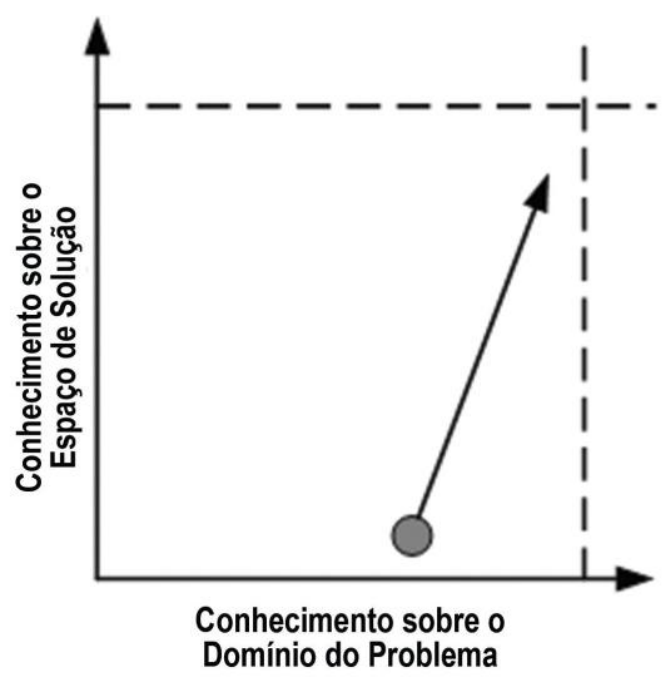

Especialistas em Solução

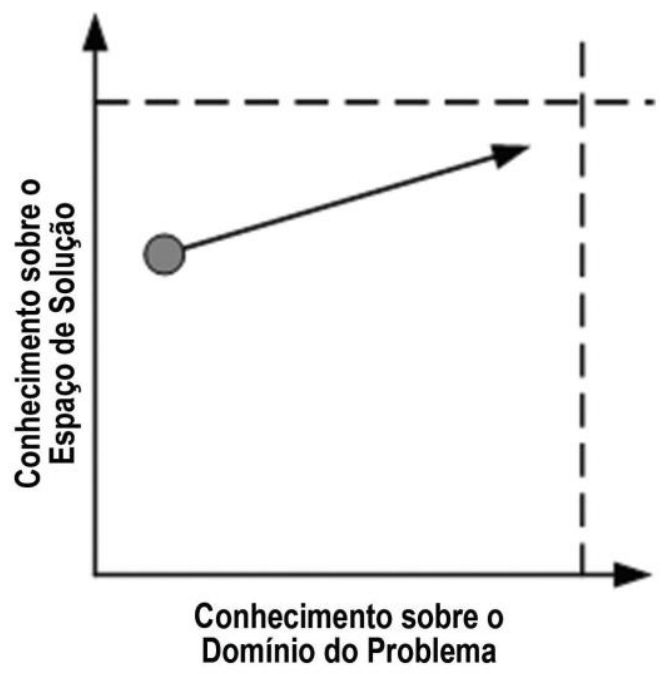

Figura 12: Tendência de conhecimentos especializados mais em domínio ou solução. Fonte: Adaptado de Keeling (2015).

Um exemplo para o caso "especialistas em domínio" é de uma equipe de projetistas concentrada em um programa de requisitos de um concurso de arquitetura. Nesse caso a equipe ainda não desenvolveu um padrão de solução, porém conhece as especificidades do problema arquitetônico. $O$ caso "especialistas em solução" pode ser exemplificado como uma equipe de especialista em fachadas "pele de vidro" em edifícios. Nesse caso a equipe já desenvolveu um padrão de solução de sucesso, porém ainda não conhece as especificidades do problema geral do programa arquitetônico que envolve outros fatores. O conhecimento da curva de design ajuda a observar se o processo se dedica a detalhes do projeto ou se a resolução do problema salta diretamente para uma implementação de solução genérica, deixando boa parte do espaço de soluções inexplorado.

Nagy (2016) identifica dois aspectos primários na formulação do espaço de design: viés e variância (bias and variance). Viés se caracteriza por uma condição de design muito simples, por exemplo, um modelo de uma cadeira, onde a posição de cada perna é um parâmetro. Neste caso, o modelo se torna tendencioso a gerar soluções de cadeiras com quatro pernas, não importando quanto os parâmetros variem. Isso leva à limitação 
da exploração, podendo deixar o resultado da busca com resultado subótimo (NAGY, 2016.

Já variância se refere a uma condição em que o espaço de design é muito flexível e muito maior do que o necessário para resolver o problema dado. Isso reflete em um modelo em que a solução é difícil de pesquisar, com explorações muitas vezes improdutivas e sem novas descobertas (NAGY, 2016). Como exemplo, um modelo de cadeira no qual a dimensão do encosto é um parâmetro, contudo sem limites de variação em suas dimensões. Observar estes pontos ajuda o projetista a manter um equilíbrio entre viés e variância na construção do espaço de design.

Assim, se uma solução parece funcionar ela permanece dentro do espaço de design, e se algum método mostra que certos aspectos não serão adequados, as soluções com tais aspectos serão colocadas fora do espaço de design (WESTERLUND, 2005). Esses aspectos são usados para orientar a liberdade de explorar alternativas diferentes e escolher o resultado de projeto mais apropriado:

De todo o trabalho realizado durante o processo de projeto, construímos conhecimento e experiência no espaço de design, ou seja, as possiviveis soluções. Aprendemos e obtemos a experiência do espaço de design ao encontrar 'coisas' que funcionam, ou seja, se encaixam no espaço de design, bem como ao encontrar 'coisas' que não funcionam. A restrição é um aspecto importante do trabalho de projeto"' (WESTERLUND, 2005, p. 24, tradução nossa).

São essas características que tornam o termo "espaço de design" frequentemente usado para descrever soluções de processos de otimização. Gero (1985) caracteriza a otimização como a busca por cumprir metas, e afirmava: "é a existência de metas que torna o design proposital e necessita

11 Do original em inglês: "From all work done during the design process we construct knowledge and experience of the design space, i.e. the possible solutions. We learn and get experience of the design space both when finding 'stuff' that works, i.e. fit into the design space, as well as when finding 'stuff' that does not work. Constraints are an important aspect of design work". 
de decisões sobre as melhores maneiras de atingir esses objetivos" (GERO, 1985, p. 42, tradução nossa ${ }^{12}$ ).

As metas de design em arquitetura fazem parte do conhecimento fundamental sobre o programa arquitetônico. Por exemplo, a determinação das alturas máximas e mínimas da altura do pé direito de uma sala, ou área máxima e mínima de um ambiente representam um limite nas metas do espaço n-dimensional na busca por soluções de projeto.

É justamente na escolha das "melhores maneiras" para atingir os objetivos de projeto que se debruçam os esforços de pesquisas da área de processo de projeto orientado ao desempenho. Uma vez que o espaço de design é dinâmico, pois sofre reajustes conforme os requisitos e as metas mudam, é necessário que os esforços entre homem e computadores sejam combinados de maneira eficiente.

Segundo Chaszar e Joyce (2016), humanos possuem maior capacidade para transformar espaços de design do que procedimentos computacionais, porém, possuem muito menos capacidade de explorar possibilidades de projeto dentro desses espaços. Isso justifica a crescente demanda por pesquisas em otimização de projetos de arquitetura usando poder computacional. Os autores argumentam que a combinação de modelagem paramétrica associada a métodos de otimização pode contribuir significativamente em expandir os limites da área, uma vez que ferramentas de simulação podem fornecer feedback sobre cada modelo avaliado e ajudar o projetista a avaliar um espaço muito grande de opções (CHASZAR; JOYCE, 2016).

\subsection{TIPOS DE EXPLORAÇÃO DO ESPAÇO DE DESIGN}

Durante $O$ desenvolvimento desta pesquisa, foram encontradas abordagens distintas em artigos e pesquisas sobre a busca pela solução

12 Do original em inglês: "It is the existence of goals which makes design purposeful and necessitates decisions about the best ways to achieve those goals." 
dentro do espaço de design em projetos orientados ao desempenho. Embora todos utilizassem algoritmos de otimização e fossem de objetivo único ou múltiplo, observou-se que as justificativas de otimização se agrupam, de maneira geral, em dois grupos:

Otimização como exploração de projeto sem objetivos bem definidos.

A maioria das pesquisas deste grupo justifica o uso do método de otimização escolhido para explorar o processo criativo de geração de ideias, além de usar resultados preliminares para reajustar 0 problema ou função objetivo. Por exemplo, Janssen (2015) afirmou: "O objetivo de tais métodos não é otimização, mas sim a descoberta de configurações de projeto originais e inesperadas, que são de alto desempenho em relação aos critérios que estão sendo avaliados" (JANSSEN, 2015, p.443, tradução nossa $\left.{ }^{13}\right)$.

Implementações de otimização em projetos de arquitetura com justificativa semelhante podem ser encontradas em Besserud e Cotton (2008), Keough e Benjamin (2010), Shi e Yang (2013) Bradner, lorio e Davis (2014), Claussnitzer et al. (2014), Costa et al. (2014) e Su e Yan (2015).

\section{Otimização para a resolução de problemas bem definidos}

Algumas pesquisas usam métodos de otimização para explorar um espaço de design contínuo, ou seja, estão interessadas no melhor resultado de desempenho possível na busca dirigida. Assim, o interesse geral da otimização é selecionar a solução vencedora entre um conjunto de alternativas plausíveis ou a opção que obteve melhor desempenho na função objetivo. Por exemplo, Coender e Wagemans (2006) descrevem, em sua pesquisa sobre otimização estrutural usando programas paramétricos, que a tendência para o maior uso de geometrias complexas na arquitetura levou os engenheiros estruturais a acompanhar a mudança de paradigma na construção civil.

13 Do original em inglês: "In this research, the goal of such methods is not optimization but rather the discovery of original and unexpected design configurations, which are high performing with respect to the criteria being evaluated." 
Essa mudança de paradigma a que se referem evidência que a engenharia deixou de somente utilizar análise de desempenho e otimização para obter o melhor indivíduo. Passou, então, a integrar desempenho estrutural em processos de "descoberta da forma" (form-finding), referindo-se ao processo de modelar geometrias não-padrão em projetos de construção. Implementações de otimização em projetos de arquitetura com justificativa semelhante podem ser encontradas em Petersen e Svendsen (2012), Coender e Wagemans (2006) e Wortmann et al. (2016).

Por este motivo, a partir das informações sobre a construção do espaço de design, esta pesquisa buscou investigar os tipos de busca por soluções neste espaço, e como as duas abordagens acima se relacionam com os métodos de otimização.

Existem abordagens diferentes para pesquisar uma solução dentro do espaço de design. O arquiteto David Benjamin (2012) define duas delas, exploitation e exploration ${ }^{14}$, que representam como a busca por soluções se relacionam com as restrições de projeto. Westerlund (2005) apresenta duas abordagens semelhantes, "experimental" e "exploratória", sendo que a primeira determina se a solução é adequada ou não à proposta de projeto e a segunda busca alternativas de soluções.

O entendimento destas duas abordagens auxilia o projetista a compreender se a busca está mais aproximada da eficiência ou da criatividade, ou ainda se está em um equilíbrio entre ambos os lados (BENJAMIN, 2012). Discutiremos a abordagem de Benjamin pela relação direta que possui com área de arquitetura, por sua relevância na literatura e por ser referência a outros autores da área de design computacional.

14 Optamos por utilizar os termos em inglês por considerar que não existe uma palavra adequada em português que as diferencie sem alterar seu significado. 

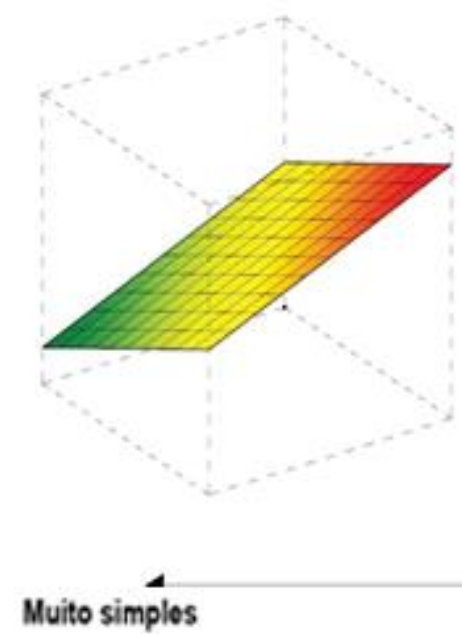
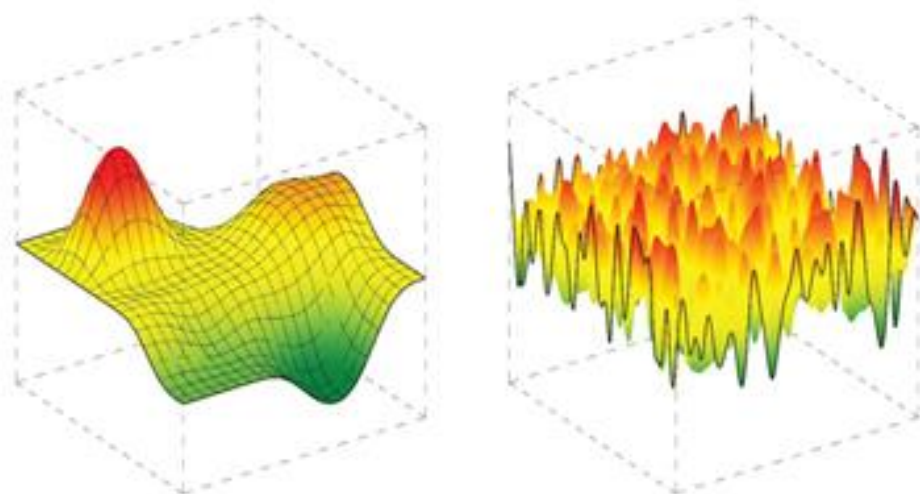

Equilibrado

comploxo mas ainda continuo
Muito discontinuo

(random)

Figura 13: Representação do espaço de design. Fonte: Adaptado de Nagy (2016).

As abordagens exploitation e exploration descritas por Benjamin (2012) foram baseadas inicialmente na eficiência de Pareto e no problema do campo da estatística, chamado problema com várias probabilidades (multiarmed bandit). Ambos os conceitos tratam de trocas (trade-offs) e a busca por equilíbrio entre demandas concorrentes.

Eficiência de Pareto ou otimização de Pareto é um conceito da Economia Política descrito em 1906 pelo engenheiro e economista italiano Vilfredo Pareto. É um conceito que se refere à alocação de recursos em uma sociedade em estado de equilíbrio, pois considera-se que na sociedade, ninguém pode ser melhorado sem que alguém se torne pior (BENJAMIN, 2012). Numa estrutura ou modelo (seja ele econômico ou de qualquer sistema em que possa ser aplicada a Eficiência de Pareto) uma alocação de recursos pode ser considerada "melhoria de Pareto" quando as melhorias podem ser feitas em pelo menos um aspecto sem reduzir o bem-estar de quaisquer outros aspectos. Se houver uma alocação de recursos que satisfaça essa condição, a alocação encontra um "ótimo de Pareto".

O processo de projeto alinhado com os objetivos de exploitation busca se aproximar rapidamente do melhor desempenho, ou seja, explora um espaço de soluções mais estreito a fim de alcançar o resultado mais eficiente possível. 


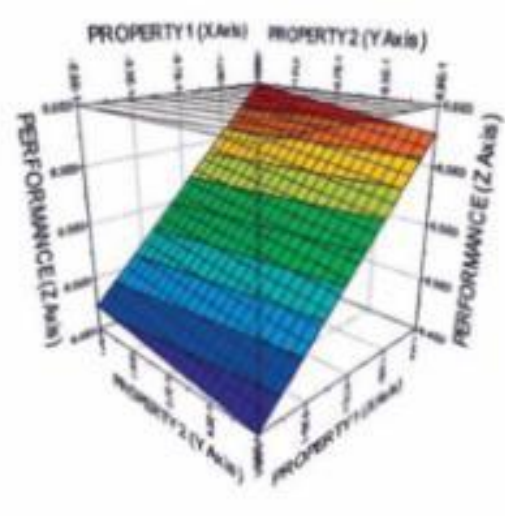

EXPLOITATION

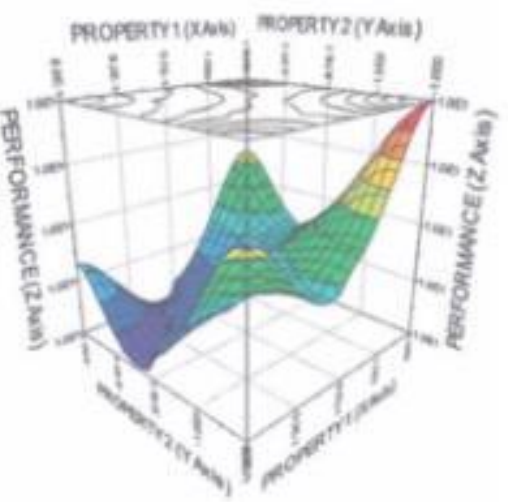

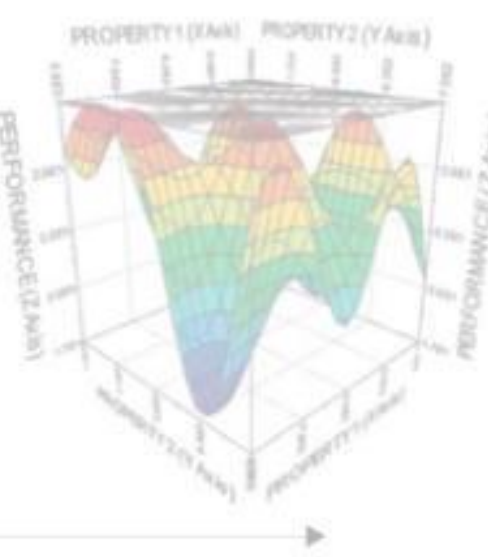

EXPLORATIOS

Figura 14: Espaços de design e suas relações com os tipos de exploração e ênfase na Exploitation. Fonte: Adaptado de Benjamin (2012).

Ademais, em matemática, o máximo (ou mínimo) global são os pontos máximo e mínimo de uma função, onde a função atinge seus valores extremos. Um exemplo da literatura que pode ilustrar essa busca é o trabalho de Petersen e Svendsen (2012), que aplicaram um método de otimização para encontrar uma proposta de projeto de edifícios próxima do ótimo econômico ao utilizar o desempenho para minimizar os custos de conservação de energia no projeto do edifício.

Nesse sentido, "ótimo" é a resposta para o problema de otimização. Ou seja, o ótimo global, que corresponde ao menor (ou maior) valor possível para a função objetivo definida.

Outro exemplo, agora dentro da área de design ou geração de forma, é o desempenho aerodinâmico a partir da otimização do cone frontal de um trem de alta velocidade. Descrito por Benjamin (2012), esse trabalho tem como objetivo a busca da forma de melhor desempenho, possuindo a menor força de arrasto e a maior estabilidade contra o vento. 


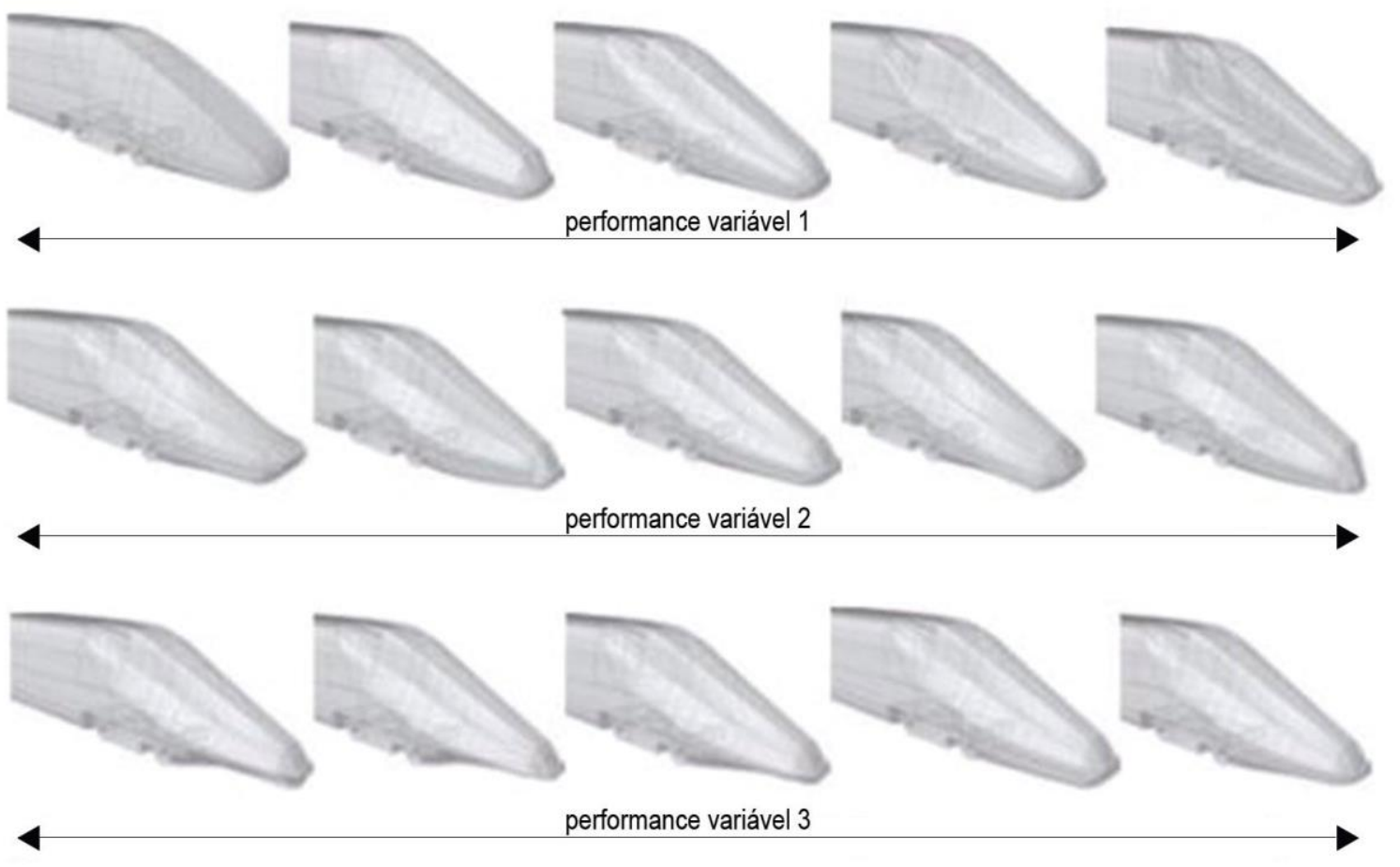

Figura 15: Permutações geométricas devido a otimização do trem Zefiro, da Bombardier Transportation. Fonte: adaptado de Benjamin (2012).

De outro lado, o desenvolvimento de projetos alinhados à exploration partem de um espaço de design mais amplo e descontínuo, onde pode haver muitas regiões com bons desempenhos e que não são necessariamente o máximo global. Permite-se assim a possibilidade de resultados variados, desde que estejam acima de um limiar mínimo de desempenho.

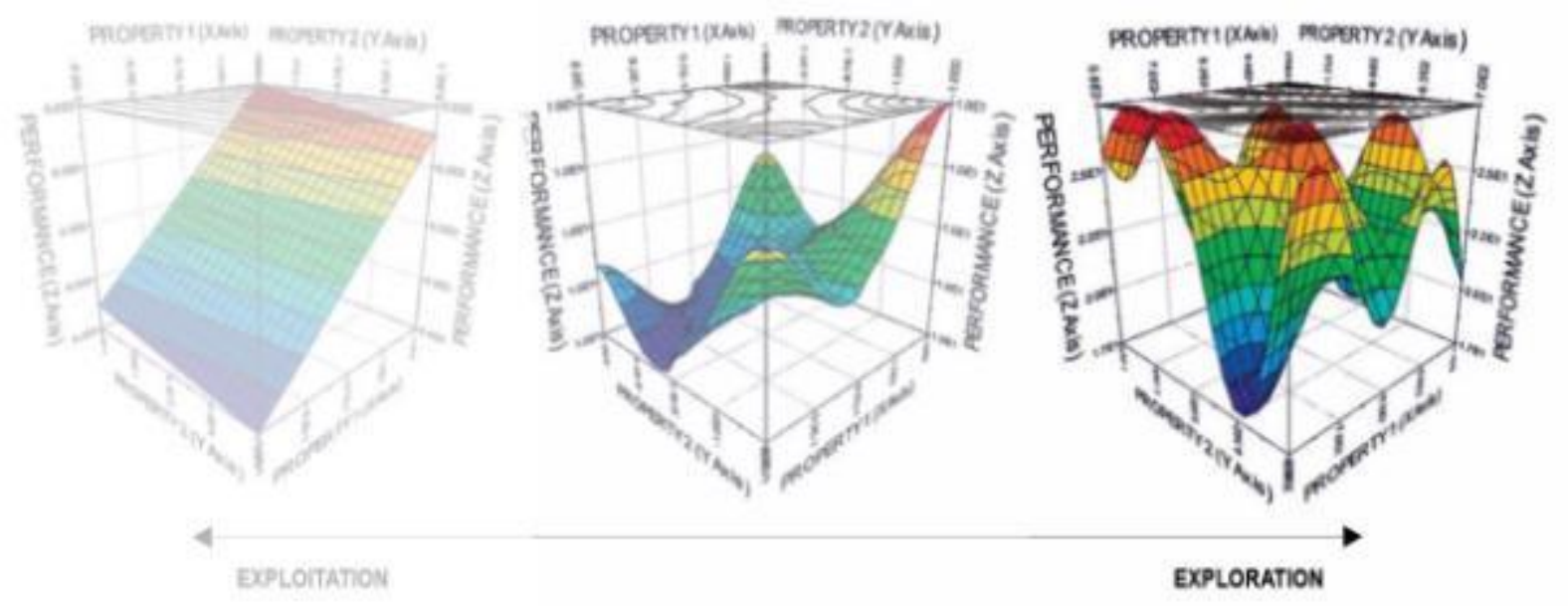

Figura 16: Espaços de design e suas relações com os tipos de exploração com ênfase na Exploration. Fonte: adaptado de Benjamin (2012). 
Essas duas abordagens podem ser visualizadas na estrutura interna do espaço de design a fim de melhorar o entendimento de como os projetos (representados pelos vértices das malhas na figura acima) estão relacionados entre si. Nagy (2016) analisa que não há regras concretas para o espaço de design, exceto pelo fato de que o caos, configurado por um espaço altamente descontínuo, deve ser evitado.

Isso porque o processo de pesquisa pode passar por uma amostragem aleatória, onde não se aprende sobre o espaço de design ou não se encontram melhores soluções ao longo do tempo. Também fica evidente, que um espaço com baixa complexidade não vale o desenvolvimento da otimização computacional, já que se pode intuir a melhor solução sem o uso de processos computacionais (NAGY, 2016).

Tanto Nagy (2016) quanto Benjamin (2012) argumentam que a melhor abordagem é a procura por variedade de modelos, assim, as decisões menos quantificáveis e mais subjetivas podem ser componentes importantes no projeto arquitetônico, pois alimentam a diversidade de soluções (BENJAMIN, 2012; NAGY, 2016).

Benjamin ressalta que 0 processo de projeto em arquitetura pode variar entre o mito da eficiência e o mito da criatividade, sendo que a exclusividade do primeiro pode ignorar decisões de projetos que não são quantificáveis, assim como a exclusividade do segundo pode ignorar dados mais precisos ou métricas de desempenho. Estes estão presentes em quase todas as atividades diárias condicionadas por lógicas numéricas, devido ao nosso contexto tecnológico (Benjamim, 2012).

Também é possivel encontrar na engenharia relatos de que muitos dos casos de otimização de projeto de estruturas estão posicionados em um balanceamento de exploitation e exploration. Isso acontece pelo fato de que a maioria dos problemas pode ser não-linear, apresentando múltiplos caminhos ou sentidos (KOZIEL, YANG, 2011; MACHAIRAS et al., 2013; WORTMANN; WORTMANN, et al., 2015). 
Segundo a Teoria Geral dos Sistemas de Bertalanffy (1975), a nãolinearidade é um pressuposto dos Sistemas Complexos, que possuem redes com caminhos distintos que podem ser inimagináveis ao projetista do sistema.

[...] configurar e restringir o espaço da solução e construir a medida do desempenho é a parte cruel do problema. Muito provavelmente é mais essencial do que as etapas restantes de procurar uma solução que seja ótima em relação à medida de desempenho e ao sistema de restrição. Em outras palavras, para tornar a otimização possível, o projetista tem de transformar um problema de projeto complexo em um bem definido, formulando um modelo paramétrico e critérios quantitativos para avaliar variantes de projeto. Da mesma forma, na caracterização de Lawson (Lawson, 2006, pp. 121122), os problemas de projeto são inerentemente complexos e, portanto, necessariamente requerem o julgamento subjetivo do projetista: raramente o projetista pode simplesmente otimizar um requisito sem sofrer algumas perdas em outro lugar (WORTMANN; et al., 2015, p.473, tradução nossa ${ }^{15}$ )

Koziel e Yang (2011) relatam que a busca por uma solução ótima é complicada devido à incerteza de sistemas do mundo real. Por exemplo, as propriedades dos materiais, que embora possam ser descritas computacionalmente possuem sempre um certo grau de variação nãohomogênea. Assim, a escolha de materiais que não estão de acordo com os padrões do projeto pode afetar significativamente o design escolhido. Por esse motivo, soluções sub-ótimas ou robustas são muitas vezes a melhor escolha nesses casos (KOZIEL, YANG, 2011). É nesse sentido que Gero (1985) afirmava que:

[...] a visão intelectual moderna sustenta que a perfeição é um conceito ilusório (exceto na arte) e que só podemos alcançar o 'melhor' em contextos definidos e que a melhoria ao longo do tempo e do espaço é desejável e possível (e talvez até

15 Do original em inglês: "But setting up and constraining the solution space and constructing the measure of performance is the wicked part of the problem. Very likely it is more essential than the remaining steps of searching for a solution which is optimal relative to the measure of performance and the constraint system. In other words, to make optimization possible, the designer has to turn a complex design problem into a well-defined one by formulating a parametric model and quantitative criteria for evaluating design variants. Similarly, in Lawson's characterization (Lawson, 2006, pp. 121-122), design problems are inherently complex, and therefore necessarily require the designer's subjective judgment: Rarely can the designer simply optimize one requirement without suffering some losses elsewhere." 
necessária) [...] A noção de um único projeto globalmente ótimo, que é o objetivo da otimização de projeto de critério único, precisa ser abandonada na otimização do projeto multicritério [...] (GERO, 1985, p. xiii, tradução nossa $\left.{ }^{16}\right)$.

Assim, afirma-se que o uso e desenvolvimento do design computacional, simulação de desempenho e otimização em arquitetura são estratégias intrínsecas à construção e às buscas no espaço de design. Isso significa que, em processo de projeto, a construção do espaço de design também compreende as relações entre métodos, ferramentas e soluções de projeto.

Outrossim, esta pesquisa argumenta que não apenas as características da modelagem paramétrica e as especificidades de cada tipo de plataforma para a escrita de algoritmos em arquitetura influenciam na busca no espaço de soluções, mas também o fazem os métodos de otimização aplicados no processo de projeto. Uma vez que tais conhecimentos envolvidos no processo de projeto orientado ao desempenho são aprofundados, podem dar suporte à criação de espaços de design mais adaptados ao problema que se deseja solucionar. Portanto, descrevem-se algumas das características da otimização em arquitetura a seguir.

\subsection{OTIMIZAÇÃO COMPUTACIONAL EM ARQUITETURA}

Após a ascensão do desenvolvimento de modelos paramétricos por meio do uso da programação visual em AEC, houve um aumento no número de trabalhos aplicando otimização computacional no processo de projeto explorando o espaço de design. O processo mais comum adotado na aplicação da otimização é o conhecido por "caixa-preta", sobre o qual o profissional da AEC não possui necessariamente conhecimentos sobre o

16 Do original em inglês: "The modern intellectual view maintains that perfection is an illusory concept (except in art) and that we can only achieve the 'best' in defined contexts and that improvement over time and space is both desirable and possible (and perhaps even necessary)." / "The notion of a single unique globally optimum design which is the aim of single criterion design optimization needs to be abandoned in multicriteria design optimization." 
funcionamento dos métodos de otimização aplicados. Para isso, são utilizados plug-ins de otimização com pacotes de Interface Gráfica com o Usuário (GUI17), que tornam o processo de otimização mais acessível.

O Grasshopper é o programa que mais possui plug-ins de otimização disponíveis (TOULOUPAKI; THEODOSIOU, 2017). Isso se dá pela comunidade ativa do programa que colabora com a popularização do programa através de fóruns. Além disso, o Kit de Desenvolvimento de Software (SDK ${ }^{18}$ ) do Grasshopper é aberto, isso significa que há disponível um conjunto de ferramentas de desenvolvimento que permitem a criação de plug-ins para o programa.

Segundo Wortmann (2018), entre os plug-ins de otimização utilizados no Grasshopper podemos citar:

Goat, desenvolvido por Flöry et. al (2012), possui uma biblioteca gratuita que contém alguns métodos de otimização de busca direta baseadas em gradiente. O plug-in possui em seu pacote de otimização os métodos de região de confiança quadrática BOBYAQA (Bound Optimization BY Quadratic Approximation), otimização numérica desenvolvida por Michael JD Powell, aplicado a resolução de otimização restrita, ou seja, cuja função objetivo tem restrições em algumas variáveis. O plug-in também possui os métodos COYBLA (Constrained optimization by linear approximation) aplicado a problemas restritos onde a derivada da função objetivo não é conhecida, também desenvolvido por Michael JD Powell. Nelder-Mead method, um método numérico tipicamente aplicado na busca de mínimo e máximo de uma função objetiva de otimização não linear em um espaço de design multidimensional. Além do método por amostragem DIRECT, a pesquisa estocástica e o CRS2 (Controlled Random Search).

Octopus, desenvolvido por Vierlinger (2012), possui métodos de otimização SPEA-2, uma variação do The Strength Pareto Evolutionary 
Algorithm, aplicado para encontrar ou aproximar conjunto de ótimo de Pareto para problemas de otimização multiobjetivo, e HypE método de otimização para problemas de multiobjetivo. O plug-in ganhou visibilidade por ser utilizado pelo Bollinger+Grohmann Ingenieure no projeto Hyundai Motorstudio Goyang em Seul, Coreia do Sul.

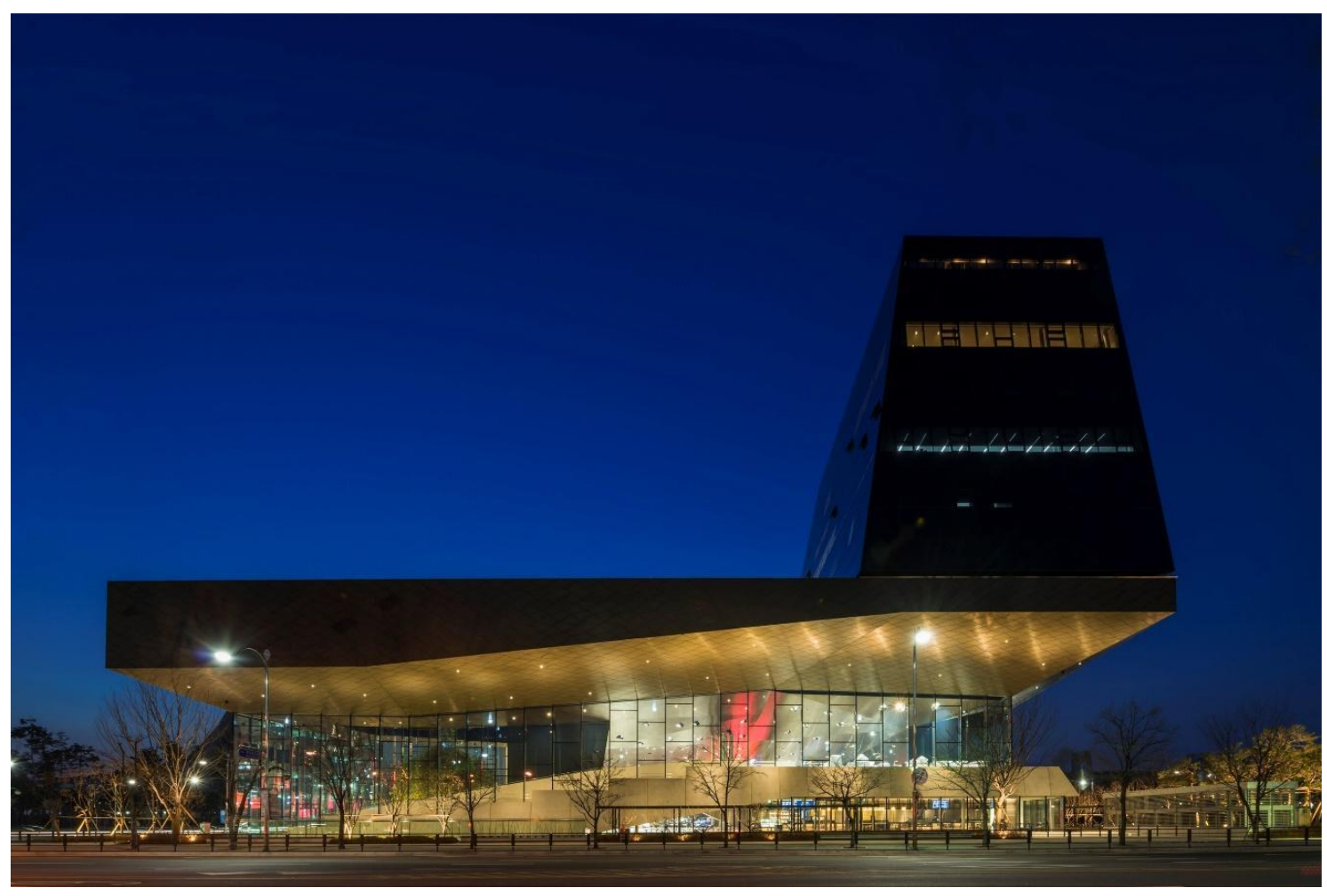

Figura 17: Hyundai Motorstudio Goyang. Fonte: Katsuhisa Kida (2018).

O plug-in favoreceu a otimização do sistema estrutural do edifício, composto de quatro núcleos de concreto e aglomerados de colunas de aço. O objetivo da otimização foi minimizar o deslocamento da estrutura, sua massa e o número de aglomerados das colunas de aço (CICHOCKA, 2018). 


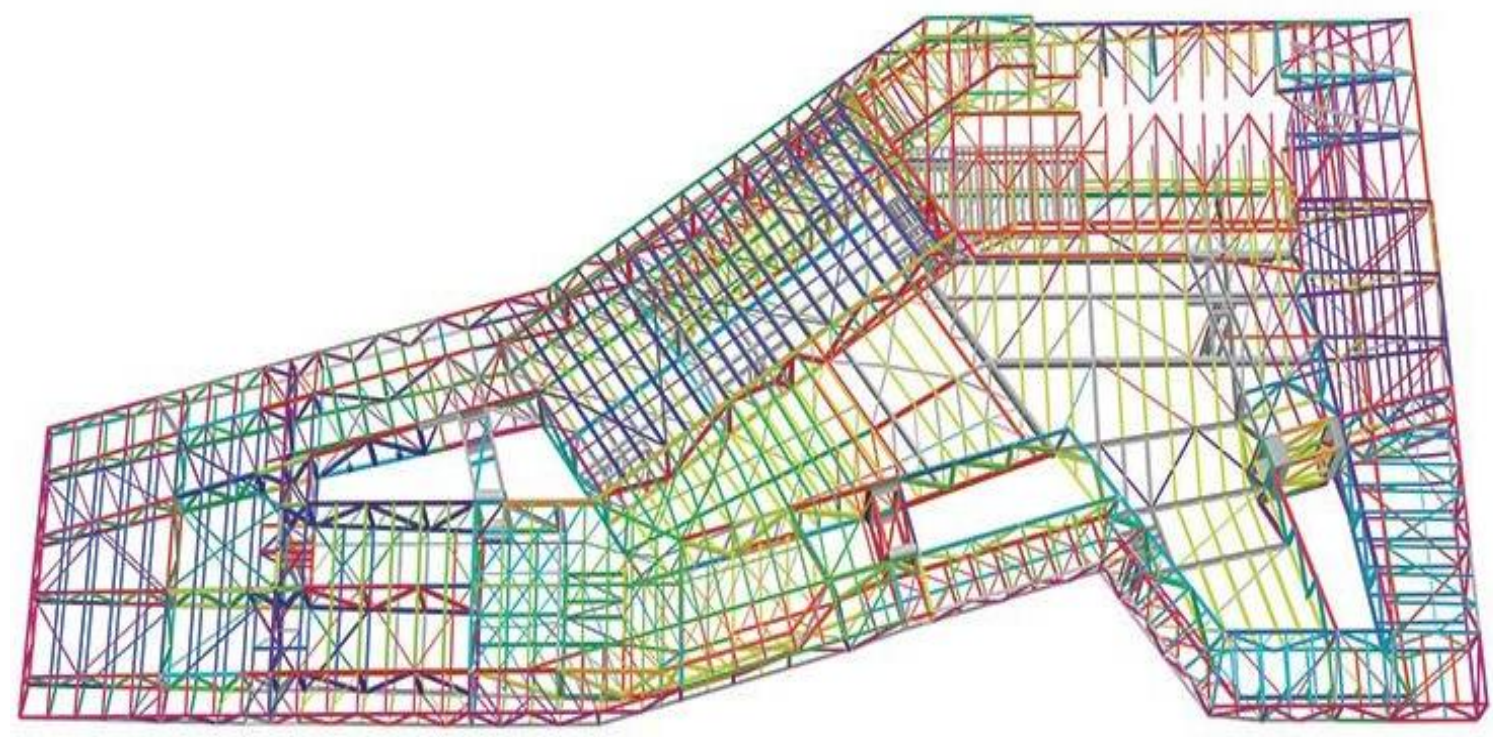

Figura 18: Representações dos esforços e do sistema estrutural otimizado pelo Octopus. Fonte: Bollinger+Grohmann (2018).

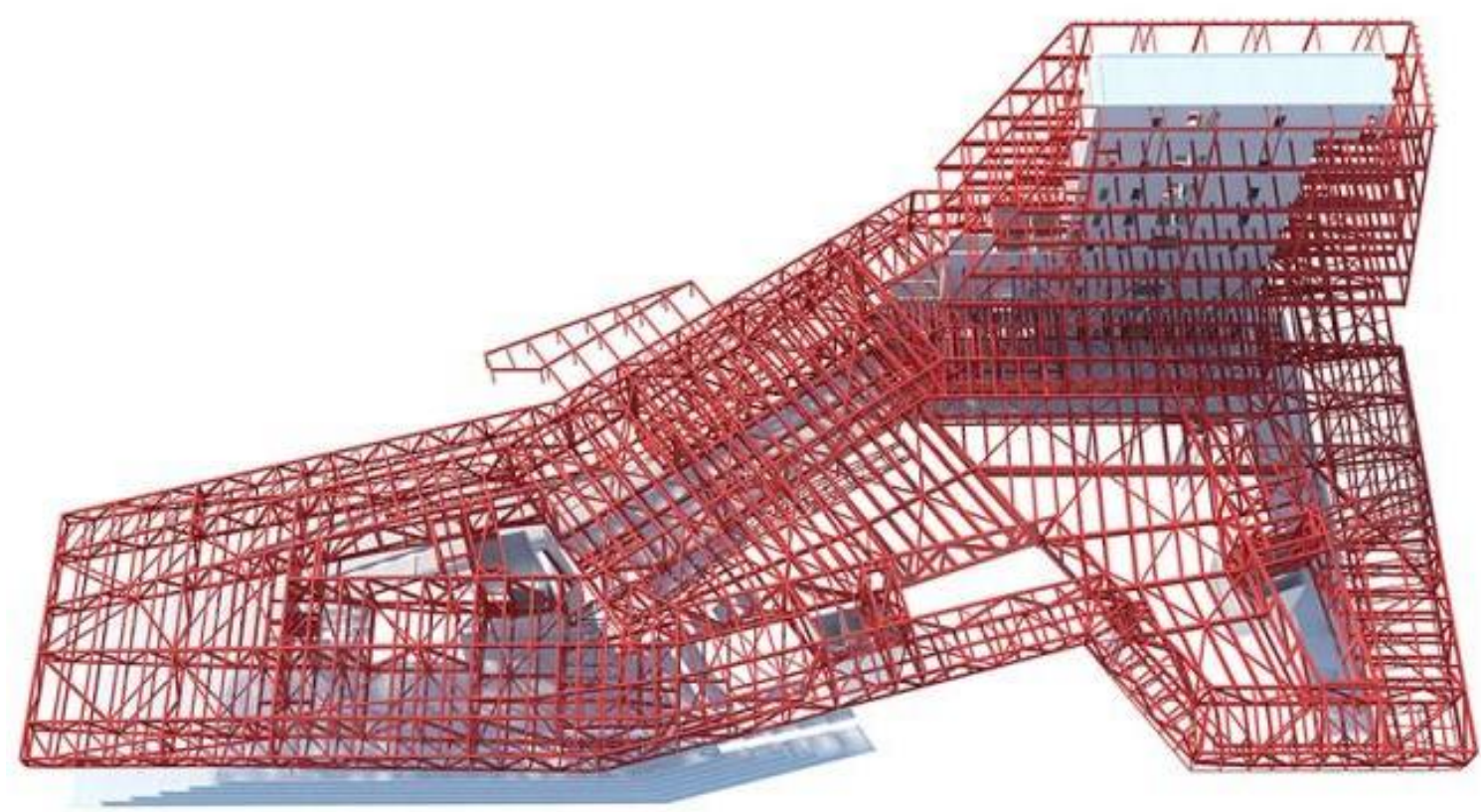

Figura 19: Representações dos esforços e do sistema estrutural otimizado pelo Octopus. Fonte: Bollinger+Grohmann (2018).

Opossum, desenvolvido por Wortmann (2016), é um plug-in de otimização baseado em modelos. Funciona como interface para a biblioteca RBFOpt de código aberto, que oferece diversos modelos RBF (Radial Basis Function) de otimização e algoritmos baseados em modelos (COSTA et al., 2014, WORTMANN, 2018). 
FRoG, desenvolvido por Wortmann et al. (2017). O plug-in é uma variante open-source do Opossum que não possui um algoritmo de otimização próprio, mas facilita a conexão de outros algoritmos existentes com o Grasshopper (WORTMANN, 2018).

Nelder-Mead Optimization, desenvolvido por Gregson (2017), o plug-in possui uma variação do algoritmo Nelder-Mead method. A variação permite que restrições sejam adicionadas e o algoritmo lide automaticamente com elas durante a otimização.

Design Space Exploration, desenvolvido por Mueller et al. (2017), o plug-in oferece otimização e análise. Possui os métodos NSGA-II (Nondominated Sorting Genetic Algorithm II), uma extensão de algoritmo genético para otimização de função multiobjetivo. K-means um método clustering que objetiva particionar $n$ observações dentre $k$ grupos, onde cada observação pertence ao grupo mais próximo da média. Modelagem com os modelos Ensemble Neural Network, conjunto de redes de aprendizado, onde redes neurais são usadas em conjunto para resolver um problema, e Random Forest, um método de aprendizado para classificação, regressão e outras operações de conjuntos de dados (TSERANIDIS et al., 2016).

Silvereye, desenvolvido por Cichocka et. al (2016) possui o método PSO (particle swarm optimization), que cria uma população de soluções candidatas, também chamadas de partículas, que se movem em torno do espaço design.

Galapagos, desenvolvido por Rutten (2010), mesmo desenvolvedor do Grasshopper, onde o plug-in está incluso de maneira nativa. O Galapagos possui dois métodos, o Algoritmo Genético (GA ${ }^{19}$ ) (descrito no capítulo 2) e o Recozimento Simulado $\left(\mathrm{AS}^{20}\right)$, uma metaheurística de otimização para a

\footnotetext{
19 Do inglês "Genetic Algorithm"

20 Do inglês "Simulated annealing"
} 
busca do ótimo global de determinada função objetivo em um grande espaço de design.

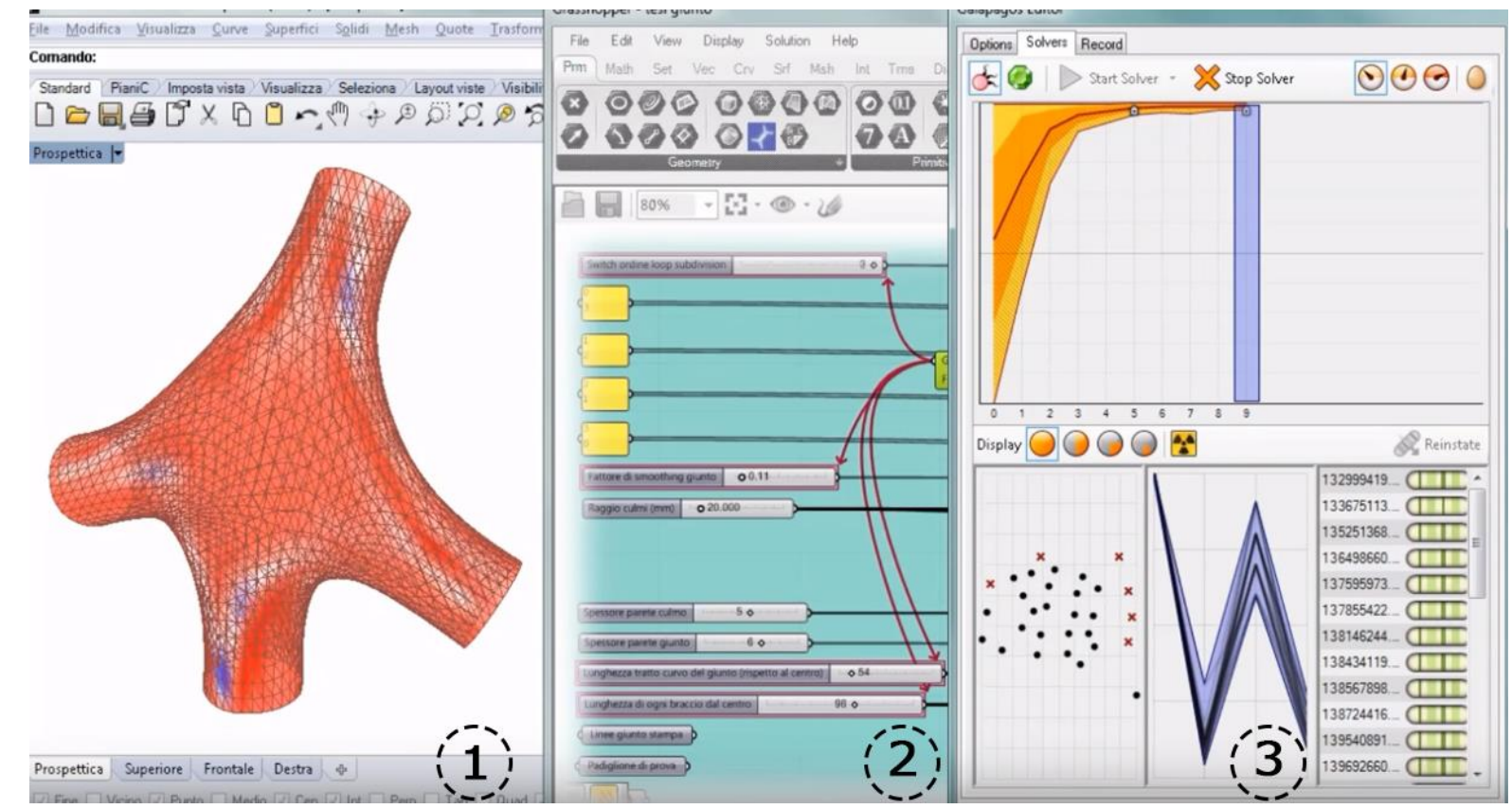

Figura 20: 1 viewport do Rhinoceros com a geometria sendo otimizada, 2 parâmetros do projeto em slide numbers sendo controlados pela Galapagos. 3 Tela de Interface do Galapagos operando a otimização da geometria. Fonte: Andrea Mercurio (2016).

Como alternativa aos plug-ins disponíveis no Grasshopper existe o otimizador caixa-preta Optimo nativo do programa Dynamo Studio, que integra ferramentas de BSP do Revit à otimização. Optimo foi desenvolvido por Asl et al. (2014), tem código fonte aberto e implementa o algoritmo NGSA-II.

Existem ainda outros otimizadores, contudo, a diferença de popularidade entre eles é notável, sendo os plug-ins disponíveis para o Grasshopper os mais populares. Isso especialmente no que se refere ao uso do Galapagos, destaque nas pesquisas publicadas em arquitetura por seu uso recorrente (SHI e YANG, 2013).

Detectamos a seguir alguns projetos que exploram o processo de projeto orientado ao desempenho. Como critério de seleção foram escolhidos projetos que aplicaram design computacional com modelagem 
paramétrica, algum nível de simulação de desempenho e a otimização através do Galapagos.

Spaeth e Menges (2011) usam o desenvolvimento de projeto orientado a desempenho através do Galapagos para avaliar critérios acústicos e morfológicos de um ambiente. Os autores concluíram a pesquisa afirmando que a integração dos critérios do projeto, simulação acústica e algoritmo de otimização é pretendida e tem o potencial de melhorar significativamente o sistema de projeto.

Vannini, Bueno e Turkienicz (2012) desenvolveram um processo que utilizou o Galapagos na otimização do projeto através da translação dos vértices e a rotação da forma, transformando a geometria elementar do projeto. Assim, investigaram a orientação de fachadas de acordo com o potencial de incidência solar para a instalação de painéis fotovoltaicos utilizando Galapagos na otimização. Os autores concluíram que a utilização da metodologia promoveu variabilidade geométrica e eficiência energética.

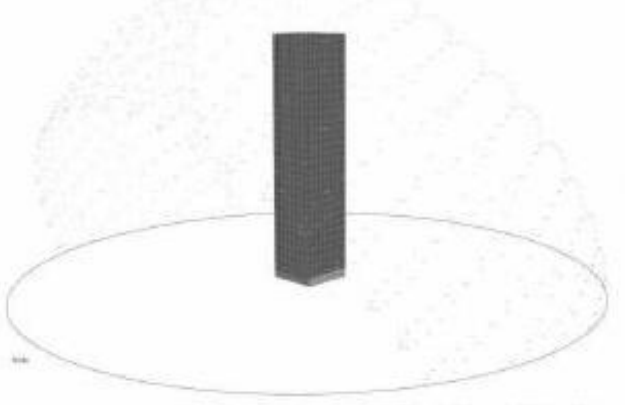

(a) $588 \mathrm{KWh} / \mathrm{m}^{2}$

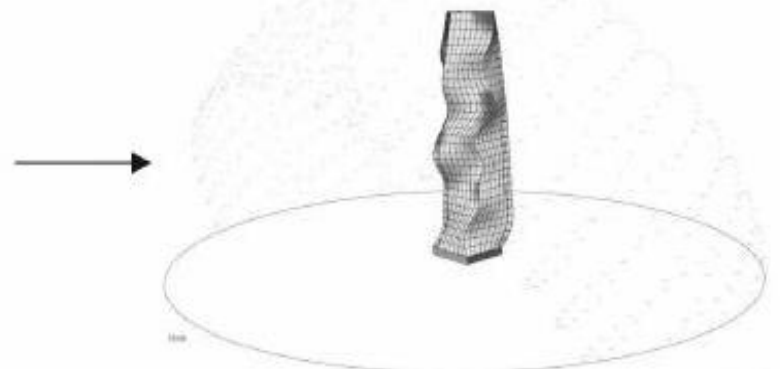

(b) $675 \mathrm{KWh} / \mathrm{m}^{2}$

Figura 21:A esquerda modelo elementar inicial, a direita modelo otimizada perante as variáveis e restrições do projeto. Fonte: Vannini; Bueno; Turkienicz (2012).

Camporeale (2013), aplicou algoritmos genéticos do plug-in na otimização de crescimento urbano a partir da análise de iluminação solar em espaços abertos. A autora conclui que ferramentas de modelagem paramétrica, simulação e otimização, podem melhorar as condições de conforto, economizando energia para alcançar um ambiente melhor. 
Jin e Jeong (2014) aplicaram otimização com algoritmos genéticos através do uso do Galapagos no processo de projeto de uma construção de forma livre. A finalidade era medir e otimizar as trocas de calor na fachada proposta. Os autores concluíram que foi possível otimizar o desempenho térmico da fachada de edifícios de forma livre, em correspondência com o clima e as características de cada cidade.

Foged, Pasold e Jensen (2014) combinaram com a otimização a simulação acústica e propriedades de materiais no desenvolvimento de uma arquitetura sonora, performativa e estética de um pavilhão. Os autores demonstraram nos resultados que o Galapagos foi eficiente no processo de exploração do espaço de design.

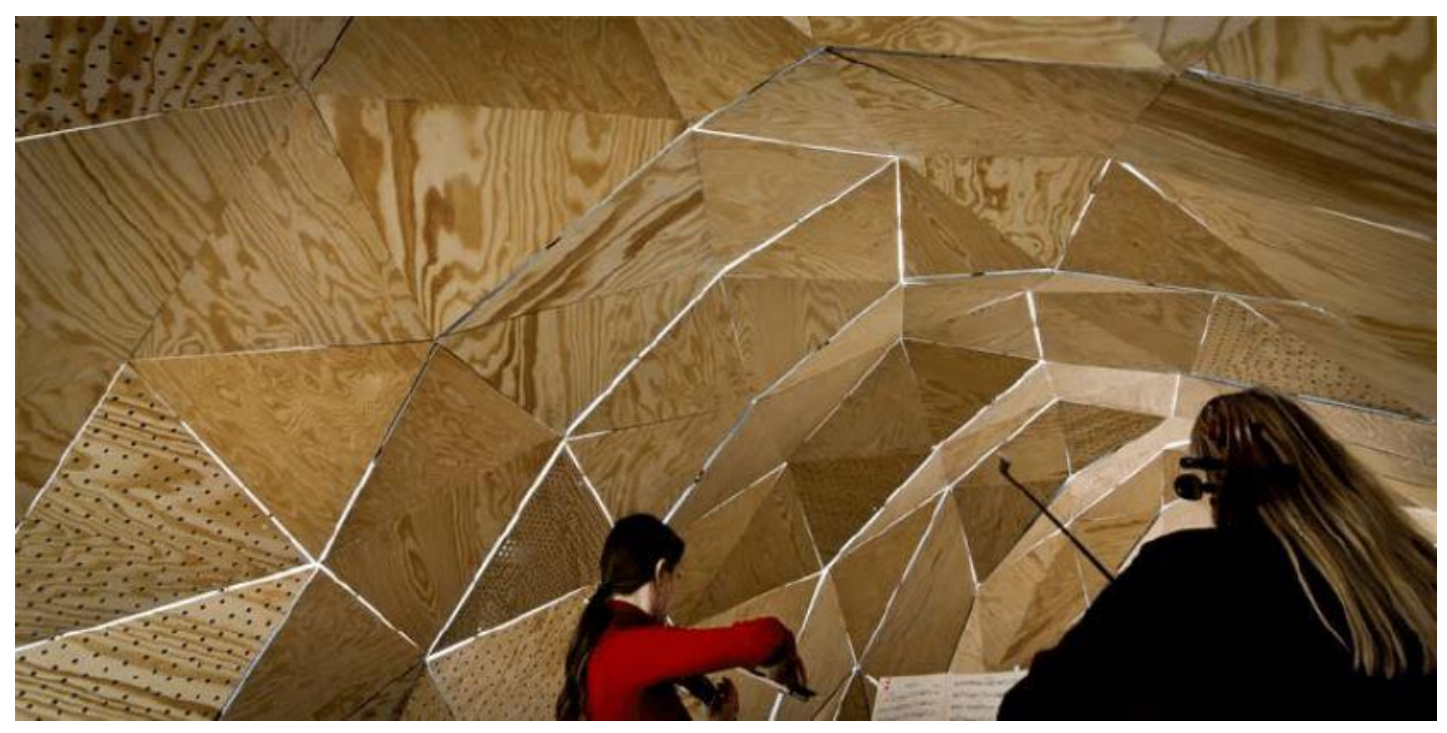

Figura 22: Interior do pavilhão que teve sua acústica otimizada. Fonte: Foged; Pasold; Jensen (2014).

Pasternak e Kwieciński (2015) aplicam o plug-in na análise de insolação no entorno de edifícios altos. A pesquisa foi realizada no contexto de grupos de trabalho de alunos e apontou que um dos principais problemas no processo de projeto orientado ao desempenho a partir do Galapagos, foi a dificuldade de compreensão completa dos componentes do algoritmo genético. Desse modo, dificulta-se a definição adequada das relações entre os vários parâmetros e a construção de uma função de objetivo adequada. 
Suyoto et al. (2015) usou modelagem paramétrica, simulação e otimização com o Galapagos para resolver problemas durante todas as etapas do processo de projeto desde o programa, planejamento da implantação, estrutura e fachada de um projeto de edifício de uso misto. Os autores concluíram que se aprimorou a qualidade do projeto, pois basearam-se em análises científicas. $O$ processo de projeto orientado ao desempenho permitiu que os profissionais monitorassem as mudanças durante o processo, o que aumentou a compreensão e o conhecimento sobre o espaço de design.

Martino (2015) desenvolveu uma série de implementações e experimentos aplicando otimização. São desenvolvidos os casos de implantação de edifícios, definição volumétrica de modelo a partir de insolação, configuração de brises, exploração criativa para desenho de uma cobertura e definições volumétricas a partir de implantações. Os casos são apresentados em ordem progressiva de complexidade e o autor expressa como pôde utilizar a otimização através do Galapagos, explorando os seus potenciais e limites.

Em suas conclusões, o autor aponta que como o propósito dos experimentos foi de verificar a possibilidade de implementação dos algoritmos de otimização de maneira simplificada, mesmo diante de algumas limitações, os ganhos obtidos com o Galapagos contribuíram para o processo de projeto (MARTINO; 2015). 
Geração 1

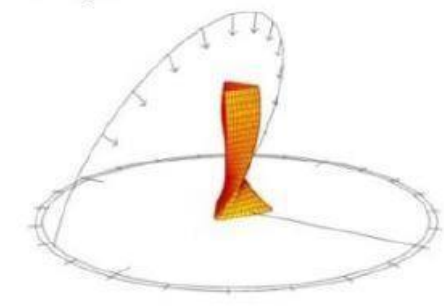

Geração 10

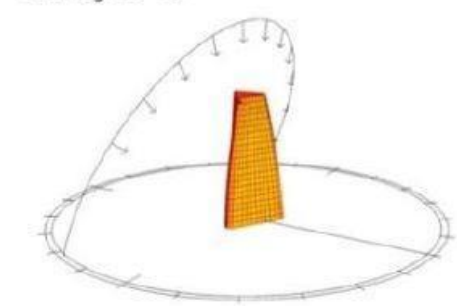

Geração 30

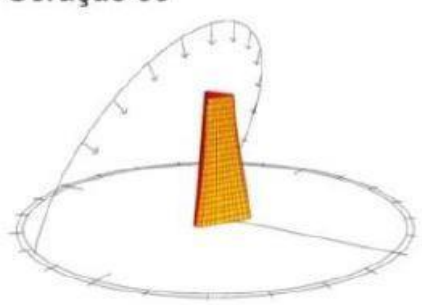

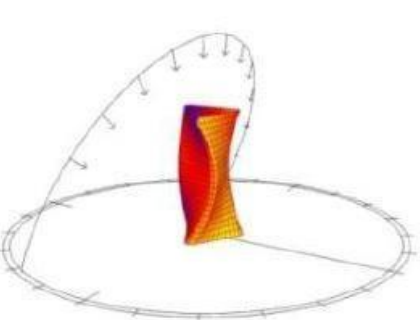

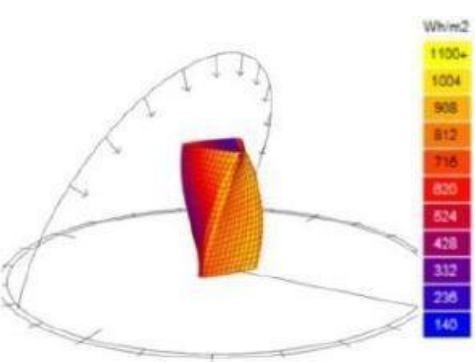

Geração 20
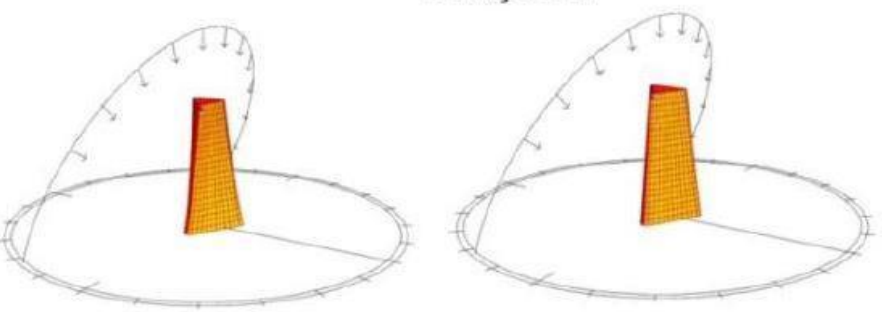

Geração 40

Geração 50
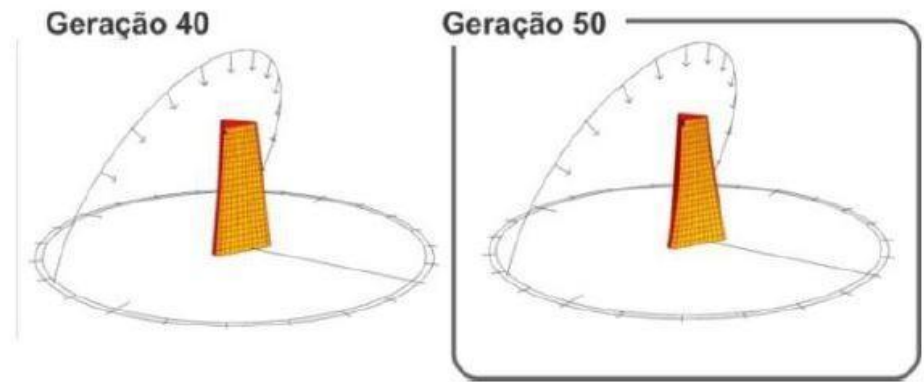

Figura 23: Comparação entre os melhores indivíduos a cada dez gerações de alternativas de projeto obtidas a partir da otimização da distribuição da insolação de forma homogênea sobre a volumetria do edifício. Fonte: Martino (2015).

Qingsong e Fukuda (2016) utilizaram simulação energética e o Galapagos para otimizar as aberturas de um edifício de escritórios com o objetivo de minimizar o consumo de energia, potencializando a iluminação natural. Os autores concluem que o emprego de simulação e otimização pode melhorar significativamente a qualidade do projeto e fornecer opções de estratégias para a solução de problemas em AEC.

Calixto (2016) realizou uma série de experimentos explorando o emprego de otimização com o Galapagos em problemas de layout em escalas e formas diversas. O pesquisador também aplicou o workshop Space Planning, pelo qual grupos de trabalho exploraram o processo de projeto orientado ao desempenho na resolução de um problema arquitetônico. A proposta do exercício foi a criação de um estudo de plano de massas para um complexo multifuncional. Pela proposta, o estudo criado por cada um 
dos grupos deveria considerar a legislação urbana do local e o programa de necessidades dado.

O objetivo principal do workshop era que os processos de projeto dos grupos aplicassem os algoritmos de space planning fornecidos e que fossem incrementados com outras estratégias de projeto otimizadas através do Galapagos (Calixto, 2016). O autor conclui que foi possível perceber que o método de Space Planning com a otimização tem um grande potencial a ser explorado pelos arquitetos e identificou a aceitação dos participantes aos processos explorados.

Anton e Tanase (2016) exploraram diversas formas arquitetônicas livres aplicando simulação e otimização com Galápagos. No processo de projeto foram otimizadas a redução da radiação solar ao mesmo tempo em que as formas projetavam a maior área de sombra. A pesquisa conclui que a combinação entre modelagem paramétrica, simulação e otimização abre novas oportunidades práticas na arquitetura, sendo que equipes interdisciplinares podem trabalhar juntas no desenvolvimento de projetos com desempenhos maiores. Os autores também afirmam que o processo de projeto orientado ao desempenho cria uma sinergia com a criatividade do arquiteto propiciando projetos mais informados, eficientes e significativos.

Sem dúvidas o método caixa-preta através do Galapagos teve grande adesão no design computacional em arquitetura e sua facilidade de implementação no processo de projeto é a principal razão para sua popularidade. Contudo, existem poucas reflexões a respeito da verificação da eficiência e adequações do método de otimização empregado no processo de projeto. O próprio Galapagos utiliza algoritmos evolutivos, o Algoritmo Genético e o Recozimento Simulado, porém possui o código fonte fechado e carece de material sistematizado sobre o funcionamento dos operadores dentro de seus métodos. A clareza sobre o método de otimização empregado pode ser importante na obtenção dos melhores resultados de projeto dentro do espaço de design, como apresenta o item a seguir. 


\subsection{CLAREZA SOBRE O MÉTODO DE OTIMIZAÇÃO}

Existe pouca reflexão na arquitetura sobre quais métodos são mais apropriados para a otimização do projeto arquitetônico (WORTMANN et al., 2015). Apesar das crescentes pesquisas e aplicações de processos de projeto orientado ao desempenho, poucos pesquisadores relatam em seus métodos as técnicas e conjuntos de procedimentos utilizados. Ao analisarem pesquisas que implementam algoritmos personalizados de otimização em arquitetura, Machairas, Tsangrassoulis e Axarli (2013) afirmam que grande parte das pesquisas não oferecem detalhes nem disponibilizam as implementações, impossibilitando conclusões seguras sobre as características dessas otimizações.

Essa condição dificulta as investigações e inovações no conjunto de procedimentos operados na otimização e inviabiliza a adaptação do método para problemas específicos. Além disso, dificulta a validação dos resultados obtidos no sentido da eficiência da otimização realizada, em comparação a outros métodos. Uma vez que não existe clareza ampla sobre - método aplicado, a otimização pode ser problemática, pois as especificidades de um método de otimização deveriam ser baseadas nas necessidades e na natureza de um problema específico (COENDERS; WAGEMANS 2005; KOZIEL; YANG 2011; MACHAIRAS et al., 2013; WORTMANN et al., 2015; WORTMANN; NANCINNI, 2016).

Isso quer dizer que, se não se pode verificar com precisão os métodos e técnicas empregadas no processo de otimização ao se utilizar um plug-in closed source, então, pode-se ter optado por uma estratégia de otimização que não é ideal para o problema em questão. O próprio modelo praticado nas publicações dos resultados das pesquisas de otimização em arquitetura muitas vezes é insuficiente. Em arquitetura, é comum que o algoritmo implementado no processo de projeto não seja compartilhado nos métodos de trabalhos publicados. Muitas vezes, nas publicações existem apenas 
imagens dos algoritmos dentro das telas de programação visual, com pouquíssima legibilidade.

Portanto, a clareza dos métodos de otimização aplicados no processo de projeto de arquitetura é importante para a obtenção de melhores resultados e a abertura de tais métodos para a área representa uma contribuição no estímulo à replicabilidade e aperfeiçoamento do processo de projeto orientado ao desempenho.

Para maior clareza dos métodos, contudo, é necessário a abertura de seus conjuntos de procedimentos e o esclarecimento sobre suas aplicações, potenciais e limites. Assim, o conteúdo que fundamenta os métodos de otimização abordados na presente pesquisa comparece no capítulo a seguir. 


\section{CAPÍTULO 2}

\section{MÉTODOS DE OTIMIZAÇÃO}

A presente pesquisa investiga os métodos de otimização e adota a ênfase nos algoritmos evolutivos. A razão da ênfase se deve ao fato, como demonstrado anteriormente, dos algoritmos evolutivos serem os mais aplicados no processo de projeto em arquitetura, porém normalmente são tratados como caixas-pretas. Portanto, o presente capítulo apresenta um olhar mais aproximado ao recorte da presente pesquisa, ou seja, apresenta uma série de conhecimentos fundamentais ao desenvolvimento prático dos métodos de otimização, enfatizando conceitos relacionados aos algoritmos evolutivos e, em especial, os chamados algoritmos genéticos.

Em linhas gerais, os problemas respondidos pela otimização são puramente a maximização ou a minimização de uma função objetivo com uma ou mais variáveis presentes em um determinado domínio (HOLTZ, 2005). Frequentemente existe um conjunto de restrições ou limitações nas variáveis que caracterizam as necessidades do projeto, e tais variáveis podem ter valores de igualdades ou desigualdades, sendo os projetos de valores desiguais os mais complexos (KIUSALAAS, 2005). Como exemplo, pode-se citar um projeto que tem como objetivo minimizar a quantidade de aço na armadura de reforço da laje mista, que ainda deve resistir a uma carga determinada. As variáveis são as áreas das seções das barras da armadura e suas respectivas posições considerando a carga do concreto e a dimensão do vão, ou seja, as restrições desta otimização são desiguais pois cada barra responderá a esforços de resistência às cargas que variam em diferentes pontos da laje, e provavelmente terão valores desiguais.

Ao lidar com um problema como esse, os recursos computacionais podem auxiliar com o poder de cálculo que possuem, dessa maneira é 
necessário a implementação de algum método de otimização através de algoritmos. Veremos o escopo teórico de alguns dos principais métodos aplicados na AEC a seguir.

\subsection{ALGORITMOS DETERMINÍSTICOS}

A grande maioria dos métodos clássicos de otimização são baseados em algoritmos determinísticos, que geram um encadeamento determinado de possíveis soluções. O encadeamento sempre vai ser o mesmo em diferentes execuções se não houver alterações nas variáveis de entrada, ou seja, o seu comportamento pode ser completamente previsto a partir do que começa a ser operado no seu estado inicial. Logo, algoritmos determinísticos apresentam a propriedade de retornar o mesmo estado final a partir de determinado estado inicial, ou no contexto de solução de problemas, a mesma solução final para o mesmo conjunto de dados de entrada de um problema.

Conforme mencionado anteriormente, problemas de otimização podem ser representados por uma função e suas restrições. Segundo Olivieri (2004) e Bastos (2004) apud Holtza (2005), de acordo com a função objetivo e restrições, é possível classificar os problemas de otimização em problemas de programação linear e problemas de programação não-linear.

A programação linear aborda problemas de otimização cuja função objetiva e restrições são lineares. Como exemplo, um lote que tem $\mathrm{Lm}^{2}$ que será ocupado com a construção de um edifício comercial ou um edifício residencial ou uma combinação dos dois edifícios. Existe, porém, um limite de orçamento para os materiais de acabamento em revestimento Re e pintura $P$. Também é sabido a média de uso de materiais de acabamento por unidade de área de edifício residencial $\left(R_{1}, P_{1}\right)$ e para edifício comercial $\left(R_{2}, P_{2}\right)$. Sejam $E_{1} \circ$ preço de venda $\left(\$ / \mathrm{m}^{2}\right)$ do edifício comercial e $E_{2} \circ$ preço de venda do edifício residencial. Se nomearmos a área construída dos edifícios comercial e residencial como $x_{1}$ e $x_{2}$ respectivamente, o número 
ideal em $\mathrm{m}^{2}$ de construção de edifício comercial versos edifício residencial poderá ser expresso como um problema de programação linear onde:

$$
\begin{array}{ll}
\operatorname{Max} E_{1} x_{1}+E_{2} x_{2} & \text { (Função objetivo: Maximização do lucro) } \\
x_{1}+x_{2} \leq L & \text { (Restrição: Limite da área total do lote) } \\
R_{1} x_{1}+R_{2} x_{2} \leq R & \text { (Restrição: Limite de recursos para reinvestimento) } \\
P x_{1}+R_{2} x_{2} \leq P & \text { (Restrição: Limite de recursos para pintura) } \\
x_{1} \geq 0 x_{2} \geq P & \text { (Restrição: Obra em um lote com área negativa) }
\end{array}
$$

Há métodos determinísticos para solucionar problemas de programação linear como o algoritmo Simplex, criado pelo matemático George Dantzig (HADLEY, 1982) e o método de e numeração Branch \& Bound (LAND; DOIG, 1960).

A programação não-linear se aplica quando algumas das restrições ou a função objetivo são não-lineares. Grande parte dos fenômenos físicos ou econômicos geralmente são melhor representados por modelos não-lineares. Alguns dos métodos não-lineares são os algoritmos de programação quadrática sequencial e lagrangeano aumentado (SCHUVERDT, 2006).

\subsection{ALGORITMOS NÃO DETERMÍSTICOS}

Algoritmos não determinístico se caracterizam por uma sequência de passo que não necessariamente leva à solução ótima. Destacamos três tipos de algoritmos não determinísticos: aproximativos, heurísticos e metaheurísticos.

Os algoritmos aproximativos não garantem encontrar a solução ótima para um problema de otimização, mas podem geralmente dar uma garantia a respeito do quão distantes estamos desta solução. Assim, tal algoritmo fornece um fator a de aproximação para determinado problema, se e somente se, encontra soluções para qualquer caso (instancia) daquele 
problema dentro de um fator a da solução ótima (WILLIAMSON; SHMOYS, $2011)$.

Algoritmos heurísticos e metaheurísticos não fornecem garantias de que possam encontrar a solução ótima como, por exemplo, um fator de aproximação para tal solução. Os algoritmos heurísticos em geral são elaborados para solucionar problemas específicos, ou seja, o algoritmo é elaborado baseado em características do problema, visando otimizar a busca por soluções de boa qualidade. Os algoritmos metaheurísticos são abordagens de propósito geral, podendo ser aplicados a uma gama maior de problemas sem a necessidade de mudanças relevantes em seus passos principais. O aspecto mais geral dos algoritmos metaheurísticos permitem inclusive que eles possam incorporar ou gerenciar procedimentos heurísticos (BLUM; ROLI, 2003).

$\mathrm{Na}$ classe de algoritmos metaheurísticos, temos os algoritmos de otimização estocásticos. Tais algoritmos empregam uma busca aleatória pelo espaço de soluções do problema (HOOS; STUTZLE, 2004). Os algoritmos evolutivos são um tipo de algoritmo de otimização estocástico, baseado na geração aleatória de uma população de soluções durante o processo de exploração do espaço de soluções (ONWUBOLU; BABU, 2013). Os algoritmos evolutivos serão abordados nas próximas seções.

\subsection{COMPUTAÇÃO EVOLUTIVA}

A Computação Evolutiva, ou Computação Evolucionária, é uma das áreas da Inteligência Artificial, que compõem uma classe de métodos de otimização inspirados em princípios presentes nos mecanismos evolutivos da natureza (JONG, 2006).

No ano de 1953, Barricelli publicou o primeiro trabalho em computação evolutiva, a pesquisa foi realizada quando Baricelli trabalhava no projeto de John Von Neumann no Institute for Advanced Study em 
Princeton, que tinha por finalidade a realização de um computador de circuitos de alta velocidade (JONG, 2006).

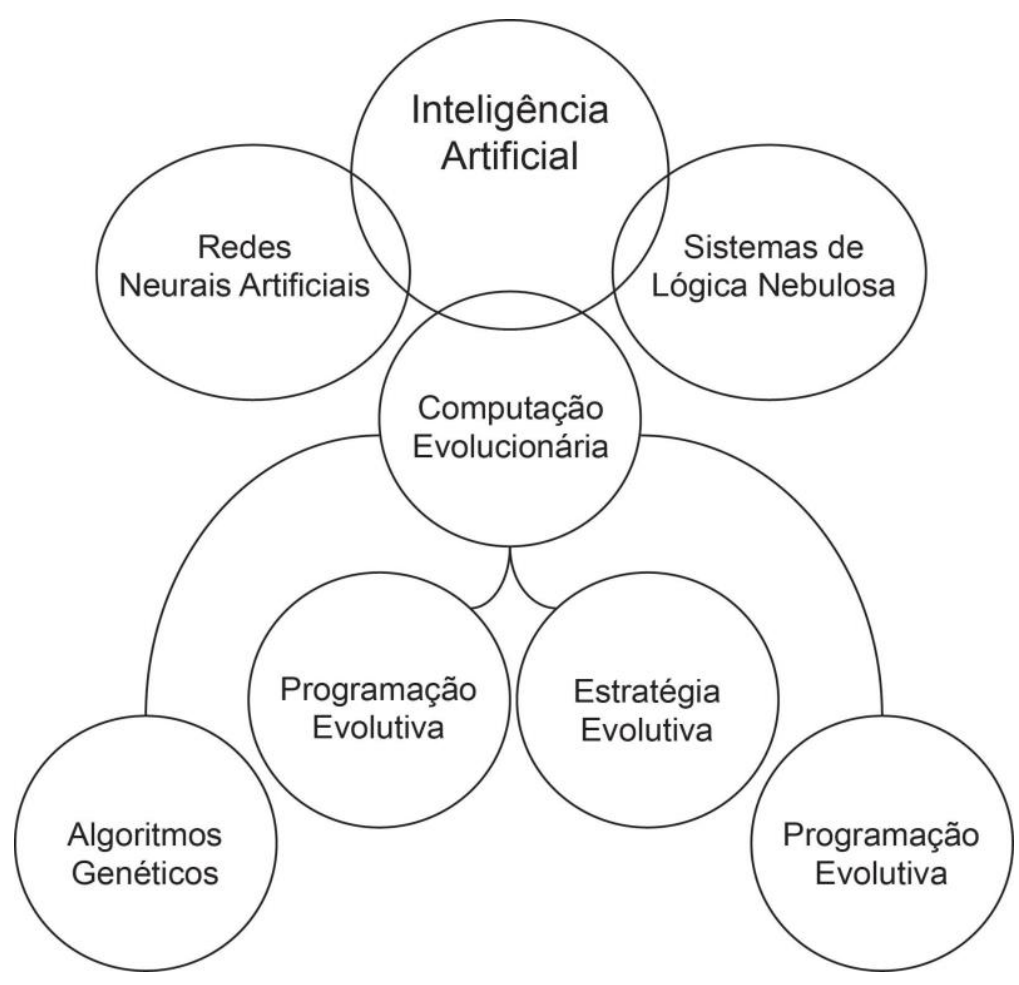

Figura 24: Subdivisões descendentes da Inteligência Artificial. Adaptado de OLIVIERI (2004).

A partir da década de 1960, as pesquisas realizadas por Holland, Rechenberg, Shwefel e Foger foram essenciais no desenvolvimento e aquecimento do interesse por AEs (HOLTZA, 2005; JONG, 2006). Assim, com o aumento de pesquisas o campo se ramificou e consolidou estudos de métodos relacionados. Deles derivaram três abordagens de Algoritmos Evolutivos (AEs) de forma independente: Estratégia Evolutiva (EE); Programação Evolutiva (PE); Algoritmos Genéticos (AG) (JONG, 2006).

\subsection{ALGORITMOS EVOLUTIVOS}

Os AEs são meta-heurísticas, ou seja, métodos heurísticos aplicados na otimização de problemas genéricos que têm como base a população e operações como a mutação, recombinação, seleção natural e sobrevivência de indivíduos adaptados, mecanismos inspirados no processo de evolução natural (JONG, 2006). 
A adaptação do processo de evolução natural para métodos de buscas computacionais, visando solucionar problemas de otimização é sistemática e eficiente, e tem como vantagem, comparada a outros métodos, permitir a modelagem do problema a partir de uma descrição simples de uma potencial solução. Essa característica os torna facilmente adaptáveis para a diversidade de problemas complexos (GABRIEL, 2010).

As abordagens de AEs, partem de princípios similares (EIBEN; SMITH, 2003 apud GABRIEL; DELBEM 2008): a partir de uma população de indivíduos é desencadeado um processo de seleção natural através de pressões do ambiente. Portanto, um processo de seleção que privilegia as melhores soluções para os problemas encontrados, forçando um incremento na adaptação das soluções. Diante de uma função a ser otimizada, é gerado um conjunto de soluções iniciais aleatoriamente, respeitando os elementos que pertencem ao domínio da função. Para medir as características das soluções candidatas, é aplicada a função objetivo também chamada de fitness.

Em seguida, uma nova população (filhos ou descendentes) é criada através de operadores de recombinação aplicados nas melhores soluções selecionadas anteriormente (país) com base no desempenho do fitness, parte do processo conhecida como crossover. Operadores de mutação também podem aplicar modificações em alguns indivíduos com a finalidade de gerar características emergentes.

$\mathrm{Na}$ etapa seguinte, os novos indivíduos da população, que são candidatos a permanecer na população, competem com os indivíduos da geração anterior com base em seus desempenhos do fitness. Os melhores indivíduos da nova geração e da anterior são selecionados para compor a próxima população. Esse processo é repetido até que determinado indivíduo apresente uma solução que seja adequada ao objetivo da otimização, ou até que determinado critério de parada seja satisfeito. 


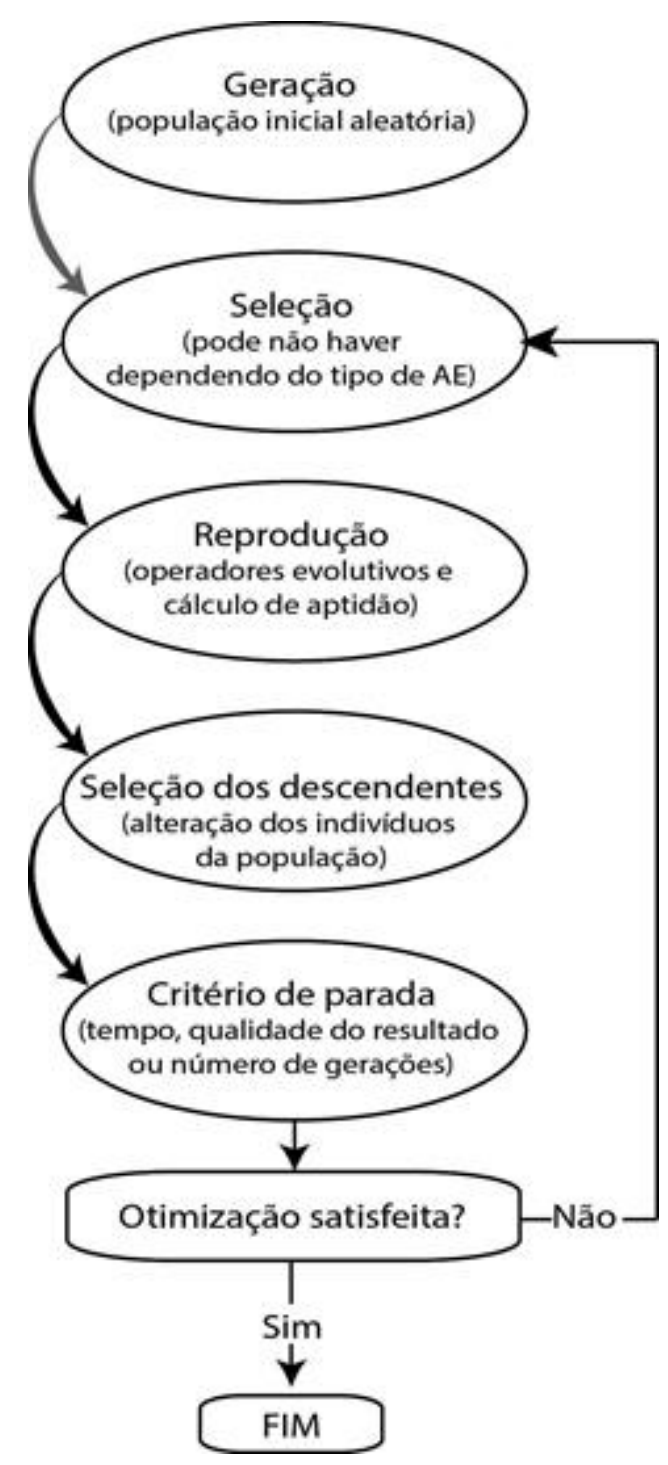

Figura 25: Fluxograma de Algoritmo Evolutivo Clássico. Adaptado de Gabriel (2010).

Os fundamentos das partes e operações envolvidas em cada uma das etapas dos AEs serão descritos a seguir.

\subsection{SISTEMAS EVOLUTIVOS}

Os termos utilizados no processo de otimização com AEs tornam ainda mais evidente a relação das técnicas evolutivas com conceitos originados em campos da biologia, especialmente em ideias evolucionista e da genética (GABRIEL; DELBEM, 2008).

Um sistema evolutivo pode ser visto como um processo que parte de uma condição inicial, segue uma trajetória ao longo do tempo dentro de um 
espaço de estado evolutivo (EIBEN; SMITH, 2003). Nesse contexto, os principais componentes dos sistemas evolutivos são (JONG, 2006):

População de indivíduos: A concorrência por recursos ocorre em uma ou mais populações de indivíduos.

Aptidão: Sobreviver e se reproduzir é produto da capacidade do indivíduo.

Mudanças dinâmicas: $\bigcirc$ nascimento e a morte dos indivíduos refletem a noção do dinamismo das mudanças nas populações.

Variabilidade e hereditariedade: Os descendentes possuem grande parte da característica de seus pais, embora sejam distintos na sua totalidade.

Tais componentes foram inspirados na Teoria Sintética da Evolução, o neodarwinismo, que fundamenta duas conclusões principais. A primeira conclusão afirma que os fenômenos evolutivos estão fundamentados nos mecanismos genéticos, a segunda afirma que a evolução é esclarecida por fatores evolutivos, através do processo de seleção natural derivado da mutação e recombinação genética (RIDLEY, 1996 apud GABRIEL 2010).

Dominar esses fundamentos com a finalidade de desenvolver otimizações, baseadas em AEs, para serem aplicadas em projetos na arquitetura, engenharia e construção requer a compreensão conceitual dos fatores evolutivos. Para o neodarwinismo os principais fatores evolutivos são a mutação, a recombinação genética e a seleção natural, descritos resumidamente a seguir.

\subsection{FATORES EVOLUTIVOS}

Os fatores evolutivos responsáveis por causar variações genéticas na população em AEs são:

Mutação: processo que confere alterações na estrutura do gene ocasionando variabilidade. Gene, por sua vez, é o segmento de DNA que 
possui as informações codificadas que orientam certas características ou processo próprio da célula ou que ela executa (AMABIS e MARTHO, 1985). Essas alterações na estrutura do gene ocorrem na sequência de bases do DNA. A ocorrência de mutação pode ocasionar alterações que podem favorecer ou não o organismo (AMABIS e MARTHO, 1985). No contexto dos AEs, a mutação representa a chance de trazer variabilidade para o conjunto soluções do problema de otimização que estão em processo de evolução (EIBEN; SMITH, 2003).

Recombinação: Operadores de crossover vem de uma analogia biológica à recombinação gênica no processo de meiose, quando ocorre a divisão celular seguida pelo cruzamento que leva a troca de genes. No caso dos AEs, a recombinação permite a troca de informações entre partes de duas soluções visando a geração de novas soluções. Sem essa possibilidade de recombinação o processo evolutivo seria lento (GABRIEL; DELBEM, 2008).

Seleção Natural: os indivíduos que herdaram a combinação gênica mais adaptada para as pressões do seu meio natural são os com maior aptidão a passarem pela seleção natural (GABRIEL; DELBEM, 2008).

\subsection{TERMINOLOGIA FUNDAMENTAL EM AE}

Uma terminologia básica e seu contexto nos AEs serão apresentados. A terminologia será apresentada a partir da adaptação e complementação de Sait e Youssef (1999) apud Gabriel e Delbem (2008):

\section{Cromossomos Genes e Alelos}

Cromossomo é a estrutura de codificação da construção dos organismos. O número de cromossomos é diferente entre as espécies e diferentes associações formam organismos distintos (AMABIS; MARTHO, 1985). O genótipo é o conjunto completo de cromossomos de um ser vivo, e o fenótipo são as características geradas com base no genótipo.

A codificação dos cromossomos acontece em um conjunto de símbolos conhecidos como genes. Valores distintos de um gene é conhecido 
como alelos, e a posição do gene no contexto de um cromossomo é conhecido por lócus (COELLO et al., 2002).

A fase inicial da elaboração de um AE é a representação ou codificação dos indivíduos como soluções candidatas para o problema de otimização. Essa fase é fundamental para o desempenho do $A E$, onde o tipo de codificação adotada define o espaço dos genótipos do AE. Essa codificação será mapeada no espaço dos fenótipos, que representa o resultado da decodificação dos indivíduos como soluções para o problema de otimização.

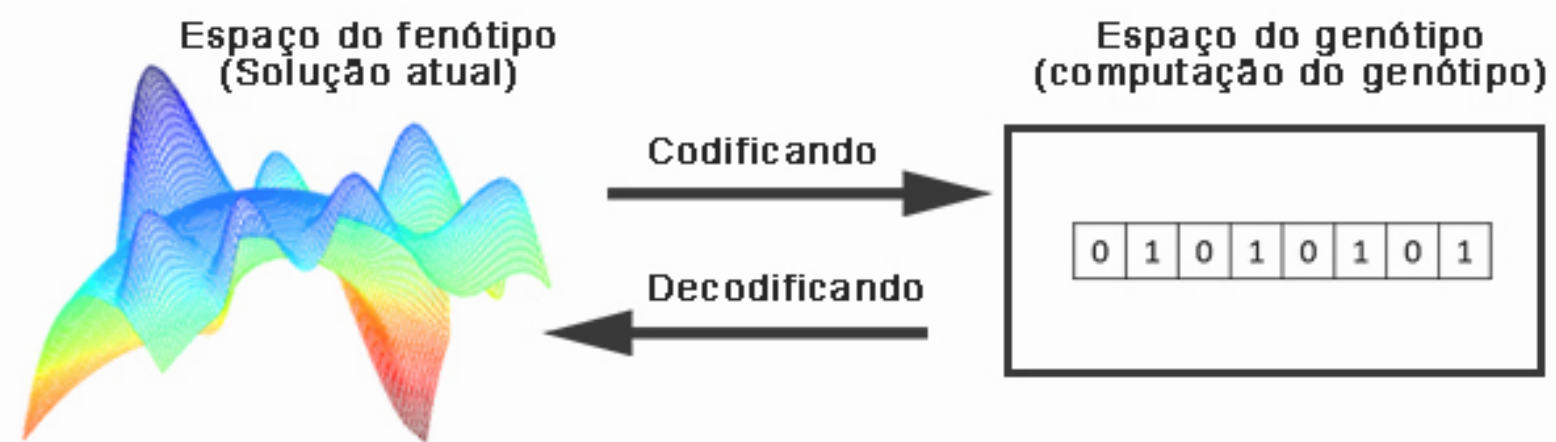

Figura 26: Exemplo do processo de codificação e decodificação. Fonte: Autor.

A codificação conhecida por binária é o modelo mais simples, onde o genótipo é uma composição variável de zero (0) e um (1), respeitando o tamanho definido para a composição e o mapeamento do genótipo e fenótipo. Porém, em diversas aplicações em problemas complexos, a representação binária pode ser ineficiente na precisão das possíveis soluções, e demonstrar baixo poder de expressão (DEB, 2001). No entanto, os AEs são capazes de operar simultaneamente variáveis reais, lógicas e inteiras na busca de soluções, então como alternativa na solução de problemas de imprecisão é possível empregar a representação em ponto flutuante ou representação real (GABRIEL; DELBEM, 2008). 


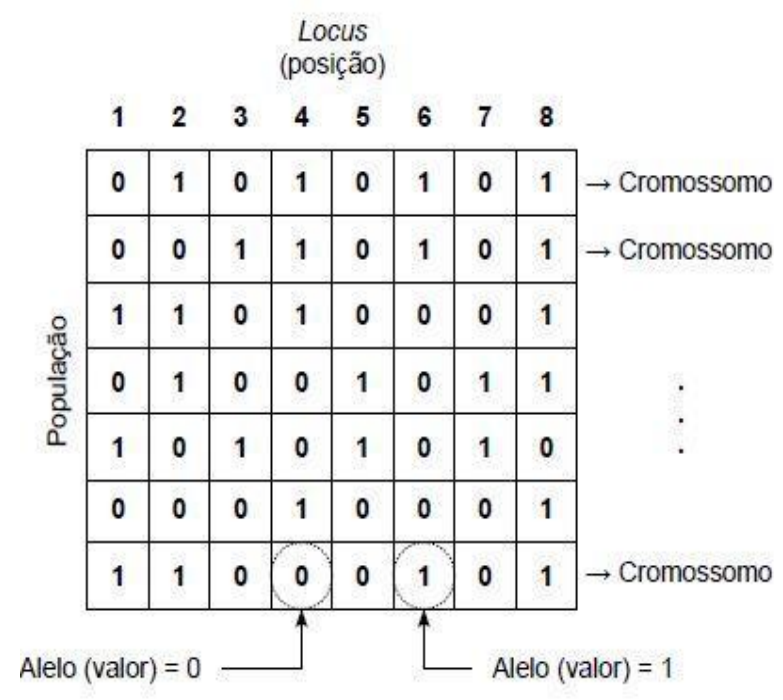

(a) Cromossomos com oito genes e alelos binários.

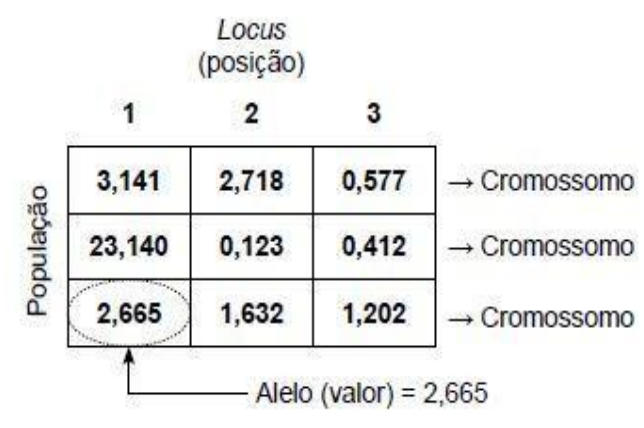

(b) Cromossomo com três genes e alelos correspondendo a valores reais.

Figura 27: Exemplo das partes do Algoritmo Evolutivo com suas terminologias. Fonte: Gabriel e Delbem (2010).

Os termos indivíduos ou cromossomos são frequentemente utilizados para se referir a representação de uma solução do problema de otimização no espaço dos genótipos.

\section{Fitness}

É um número que representa a medida de adequação da solução, ou seja, representa o desempenho de um indivíduo.

\section{Pais, Operadores de Reprodução e Descendentes}

Com o objetivo de gerar novas soluções, ou descendentes, os AEs operam sobre um ou mais cromossomos.

\section{Geração e Seleção}

A geração é uma iteração do AE, na qual os indivíduos da população atual são selecionados, recombinados e modificados por mutação, gerando descendentes (GABRIEL; 2010). Devido a criação de novos descendentes, o tamanho da população cresce, então a estratégia de seleção para próxima geração é responsável por controlar esse tamanho. 
A partir desses fatores evolutivos, cada tipo de AE pode realizar sua própria estratégia de evolução conforme será descrito sucintamente na seção seguinte.

\subsection{ALGORITMOS CANÔNICOS}

Diferentes estratégias de evolução serão ilustradas a partir dos algoritmos chamados canônicos apresentados a seguir.

\subsubsection{PROGRAMAÇÃO EVOLUTIVA}

Lawrence Fogel (1962) desenvolveu a programação evolutiva (PE) (Evolutionary Programming) em suas pesquisas realizadas na University of California, em Los Angeles, com a finalidade de empregar os conceitos da evolução no desenvolvimento de Inteligência Artificial. A partir dessas pesquisas, Fogel obteve sucesso na evolução de indivíduos em uma máquina de estados finitos. Desde então, a programação evolutiva passou a ser aplicada a uma série de problemas diferentes da proposta inicial e continua relevante para aplicações atuais (BENTLEY, 1999; JONG, 2006; GABRIEL, 2010).

Na PE, cada um dos indivíduos de uma população é representado a partir de uma máquina de estado finito. Trata-se de uma máquina abstrata que converte uma sequência de dados de entrada em uma sequência de dados de saída, portanto é responsável por processar uma sequência de símbolos (HOLTZ, 2005).

Os indivíduos são avaliados a partir da comparação do seu desempenho e o resultado desejado registrado na máquina. A avaliação de aptidão dos indivíduos compara a semelhança dos dois desempenhos através de uma função de recompensa (payoff) (BENTLEY, 1999). Um processo de reprodução assexuada é realizado na $P E$, onde os operadores de mutação são responsáveis por criarem todos os descendentes a partir da população de indivíduos atuais (GABRIEL, 2013). 
A seleção dos indivíduos mais aptos da população mantém nesta população apenas os indivíduos de melhores fitness, sendo que para isso realiza uma comparação entre o fitness dos pais e dos descendentes. A manutenção total dos melhores indivíduos na população é conhecida por elitismo total, que não é a estratégia mais utilizada pois tem chance de diminuir consideravelmente a diversidade. A diversidade é importante para que a otimização não se prenda em ótimos locais (MORALES; GARCÍA, 2001; MORALES, 2004; JONG, 2006).

Sendo assim, o emprego mais comum do elitismo garante uma taxa menor da sobrevivência dos melhores indivíduos que o tamanho total da população.

Ocorreram evoluções da PE desde sua criação, entre elas a introdução do conceito de auto adaptação é uma das mais significativas, pois foi fundamental na divisão do método em três tipos: PE padrão, meta-PE e Rmeta-PE (BENTLEY, 1999).

Na PE não existe nenhum nível de auto adaptação, diferente da metaPE que engloba a mudança de valores de variação dos indivíduos da população, e da Rmeta-PE que engloba a variação e parâmetros de covariação de forma interdependente nos indivíduos da população, através do processo de mutação, potencializando a precisão da adaptação (BENTLEY, 1999). Portanto, a PE destaca a utilização da mutação e não incorpora a recombinação.

\subsubsection{ESTRATÉGIA EVOLUTIVA}

Rechenberg e Schwefel (1965), a partir de pesquisas realizadas na Technische Universität em Berlin, demonstraram um algoritmo baseado em processos evolutivos capaz de resolver problemas complexos de otimização de funções de números reais, chamado Estratégias Evolutivas (Evolution Strategies) (EE) (JONG, 2006). A versão inicial do EE partiu do algoritmo (1+1) 
EE OU two membered ES e tratava de problemas de otimização em mecânica (FOGEL, 2006 apud GABRIEL; DELBEM, 2008).

A lógica de concorrência pela sobrevivência proposta nesse algoritmo é direta entre pai e filho, onde um único pai cria um descendente gerado randomicamente através de mutação dos parâmetros do pai. Dessa maneira, os cromossomos são compostos por duas listas de valores (arrays), uma das listas é composta pelos cromossomos e a outra lista é composta pelo desvio padrão desses valores, que representam a média dos valores absolutos dos valores obtidos no desvio da função (GABRIEL; DELBEM, 2008).

Após a avaliação do pai e do descendente, caso o pai apresente a melhor aptidão, o descendente é descartado e o pai é encaminhado novamente a operação de mutação para gerar um novo descendente; caso contrário, o pai é descartado e o descendente assume seu lugar na população de indivíduos (BENTLEY, 1999).

O processo de mutação é realizado em cada vetor e em cada elemento do cromossomo de forma independente, respeitando o operador que é feito através de probabilidade Gaussiana, conhecida também como distribuição normal, onde o desvio padrão corresponde ao valor presente no gene do pai e a média é zero (GABRIEL; DELBEM, 2008).

No entanto, a EE original utiliza elitismo total, sendo também suscetível a estagnação em um ótimo local e convergência lenta. Por isso, na década de 1980, foram elaborados outros modelos de EEs (BENTLEY, 1999; JONG, 2006).

Dois modelos comuns de EEs, são $\circ(\mu, \lambda)-E E$, que é definido por: $\lambda$ que representa os indivíduos atuais e $\mu$ que equivale a população gerada pela interação, assim $(\mu, \lambda)-E E$ seleciona apenas os melhores $\mu$ indivíduos da solução filho, enquanto o segundo modelo que é o $(\mu+\lambda)-E E$ seleciona os melhores $\mu$ indivíduos entre as soluções filho e as soluções pai ( $\lambda$ ) (BENTLEY, 1999; GABRIEL; DELBEM, 2008). 


\subsubsection{ALGORITMO GENÉTICO}

O algoritmo genético (Genetic Algorithm) (AG) foi proposto por John Henry Holland, decorrente de suas pesquisas realizadas na Universidade de Michigan nos anos de 1960. As pesquisas compreendiam que os processos evolutivos deveriam ter a capacidade de incluir mudanças e incertezas presentes nos ambientes. Holland, então, concentrou sua pesquisa em um algoritmo capaz de criar um sistema capaz de se auto adaptar ao longo do seu tempo de execução, através de uma função de feedback (JONG, 2006). A evolução natural é compreendida como um processo simples, porém poderoso e de muita robustez, que está relacionado à capacidade do AG, na maior parte dos casos, produzir soluções de qualidades adequadas aos problemas de otimização (GOLDBERG, 1989).

Após a seleção dos indivíduos, geralmente baseada no valor do seu fitness, a criação dos descendentes é realizada no AG pelo operador de recombinação, que combina os genes dos pais para gerar novos descendentes. O operador de recombinação é a principal característica dos AGs em relação aos demais AEs (JONG, 2006).

Sendo assim, a aplicação dos operadores de seleção, recombinação e mutação equilibra dois objetivos, a exploração do espaço de busca e o aproveitamento das melhores soluções, portanto o processo de busca é multidimensional já que preserva as soluções candidatas e a troca de informação entre as soluções exploradas (GABRIEL; DELBEM, 2010). O balanceamento entre as etapas de seleção, recombinação e mutação são muito importantes para o bom desempenho do AG (MITCHELL, 1998). 


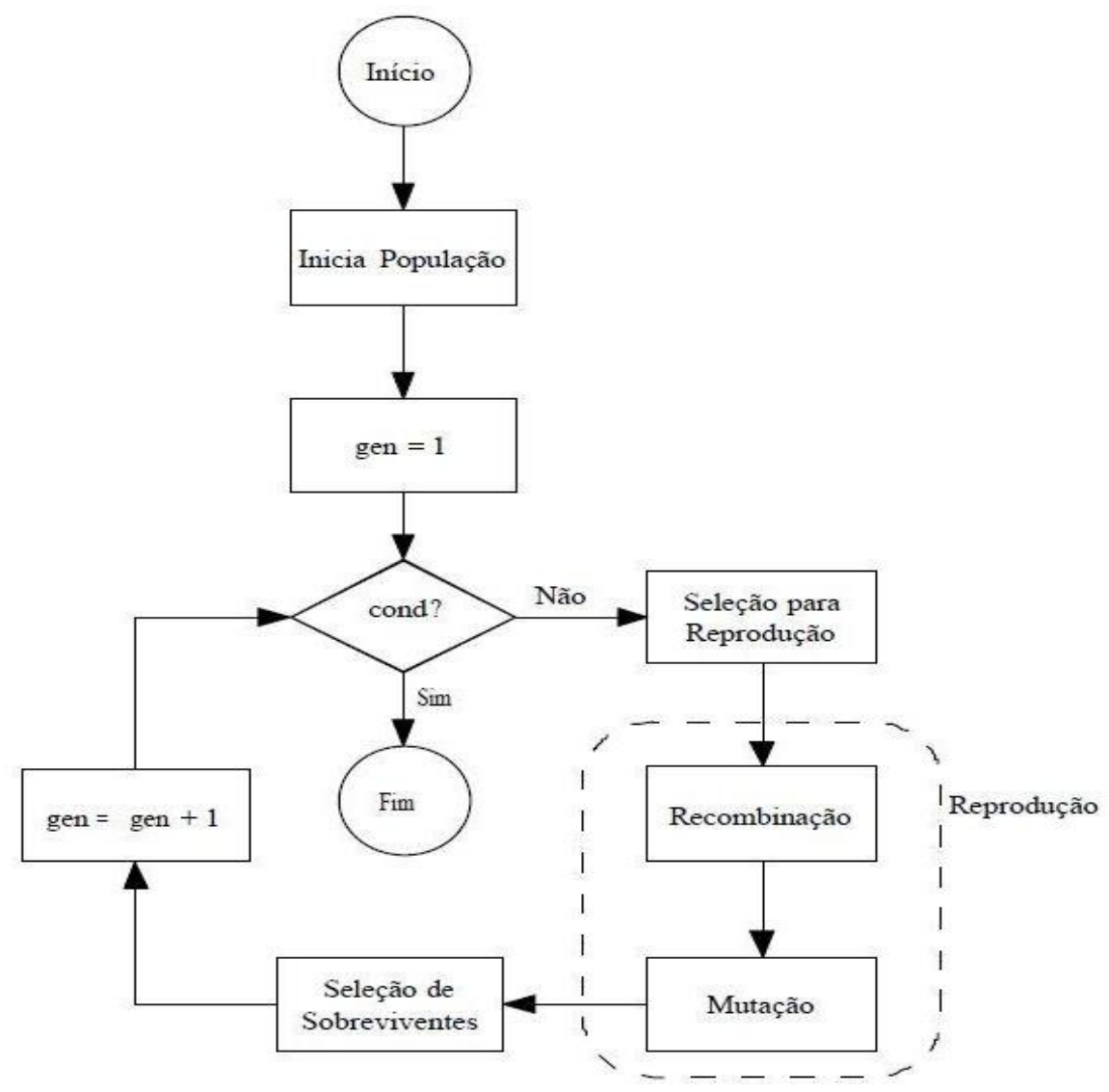

Figura 28: Fluxograma do algoritmo genético. Fonte: Tamakoshi (2016).

As etapas dos principais métodos de seleção, recombinação e mutação indicados na literatura comparecem nas subseções a seguir.

\subsubsection{CRITÉRIOS DE SELEÇÃO PARA AES}

O método de seleção indica quais indivíduos produzirão descendentes, e essa avaliação é feita com base nos valores de aptidão dos indivíduos a partir da função objetivo. Portanto, o desempenho do AE pode ser alterado a partir do método de seleção adotado, apresentando resultados melhores ou piores de otimização. Os principais métodos de seleção indicados pela literatura são descritos a seguir.

\subsubsection{ROLETA}

Utilizado no AG canônico, o método de seleção por roleta é aplicado para selecionar uma quantidade de indivíduos dentro de uma população. 
Aplica-se usualmente a Roleta como critérios de seleção para reprodução, onde os indivíduos selecionados serão utilizados como geradores de descendentes.

Na roleta a probabilidade da escolha de determinado indivíduo é diretamente proporcional ao seu fitness, pois dentro da roleta os indivíduos com maiores valores de aptidão têm maiores chances de serem indicados para a reprodução. Isso acontece porque os indivíduos são relacionados a taxas de porcentagem que totalizam a distribuição dentro da roleta. Portanto, indivíduos mais aptos recebem taxas maiores dentro da roleta que os menos aptos, assim cada indivíduo é representado por uma fatia da roleta, proporcional ao seu fitness (MITCHELL, 1998).

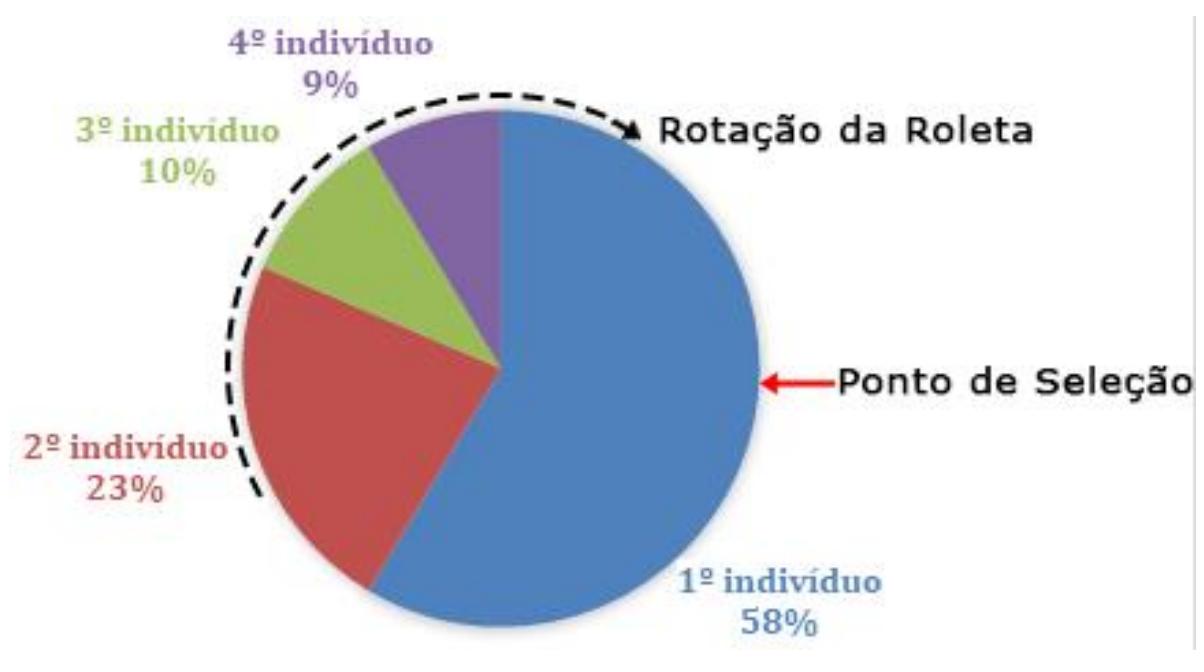

Figura 29: Sistema de seleção por roleta. Fonte: Autor.

Dessa maneira, os cromossomos recebem um pedaço proporcional a sua avaliação de aptidão, a roleta é lançada virtualmente fazendo a combinação dos pais e conferindo o fator randômico a seleção. No entanto, esse método pode requerer maior tempo de processamento por realizar duas passagens por todos os indivíduos da população e apresentar convergência prematura estagnado em um ótimo local. (POzO et al., 2005). 


\subsubsection{TORNEIO}

O método de seleção por torneio não depende de uma análise global da aptidão de todos os indivíduos da população e não considera nenhum ranque (rank) da aptidão do indivíduo. O torneio utiliza em seu método o fitness dos indivíduos somente para verificar qual indivíduo é melhor, entre os aleatoriamente selecionados (MITCHELL, 1998). A seleção por torneio não demanda conhecimento global da população, pois depende apenas de uma relação de ordenação capaz de ranquear quaisquer $k$ indivíduos. Inicialmente, seleciona-se $k$ indivíduos aleatoriamente, com ou sem substituição de indivíduos repetidos. Em seguida, o melhor destes $k$ indivíduos é selecionado ao se comparar seus valores de fitness. Logo, a seleção por torneio considera valores relativos ou invés de valores absolutos de fitness. Nesse caso, a probabilidade de um indivíduo ser selecionado como resultado de um torneio depende de fatores como o tamanho $k$ do torneio. Valores maiores de k aumentam a pressão de seleção. Assim, há chance de o melhor indivíduo não ser selecionado.

\subsubsection{ELITISMO}

A seleção por método de elitismo tem como objetivo conservar os melhores indivíduos de uma população para a próxima geração. O método foi proposto por Jong em 1975 (MITCHELL,1998), baseado nas possíveis perdas dos melhores indivíduos da população após a reprodução de uma nova população.

O uso do elitismo deve ser ponderado pois existe a possibilidade de convergência prematura da população, no entanto, de forma geral, seu uso melhora significativamente $\mathrm{O}$ desempenho do algoritmo genético em otimização (MITCHELL, 1998). 


\subsubsection{RANQUE}

A seleção por ranque foi proposta por Barker (1995) com objetivo de evitar a convergência prematura dos algoritmos genéticos. O ranque utiliza as posições dos indivíduos ordenados de acordo com seus valores de fitness para designar a probabilidade de seleção através do uso de mapeamentos não-lineares e lineares (GABRIEL; DELBEM, 2008).

O ranque opera atribuindo um valor de posição aos indivíduos da população, pontuando os mesmos de 1 a $N$, a partir dos indivíduos com os piores fitness até aqueles com melhores fitness. Na sequência, como demonstra Mitchell (1998), é atribuído um valor esperado para os indivíduos com valores min e max representando os limites definidos pelo desenvolvedor do algoritmo. O aumento no valor do parâmetro min diminui a pressão seletiva e sua diminuição aumenta a pressão seletiva. No parâmetro max o aumento do valor desencadeia o aumento da pressão seletiva, e a sua redução o contrário, sendo assim, o valor do ranque relacionado ao indivíduo $i$ é representado por $\operatorname{rank}(i)$ em $N$, onde o valor esperado ExpVal de cada indivíduo $i$ em um tempo $t$, é expresso por:

$$
\operatorname{ExpVal}(i, t)=\min +(\max -\min ) \frac{\operatorname{rank}(i, t)-1}{N-1}
$$

Desacelerar a pressão seletiva pode significar que o GA, em alguns casos, será mais lento em encontrar os valores dos indivíduos, porém em muitos casos, o aumento da preservação seletiva leva a uma pesquisa de maior sucesso pelo espaço dos genótipos (MITCHELL, 1998).

\subsubsection{OPERADORES GENÉTICOS}

Os operadores genéticos são responsáveis pela mutação e recombinação (crossover) que definem a composição dos descendentes de uma população. 


\subsubsection{MUTAÇÃO}

O operador de mutação tem por objetivo alterar um ou mais genes do cromossomo aleatoriamente. A mutação é aplicada nos descendentes dos indivíduos de uma população (MITCHELL, 1998). Seu uso típico tem como característica a atribuição de pequenos valores na taxa probabilística de sua aplicação, chamada taxa de mutação, uma vez que a mutação também é capaz de atribuir características que pioram o desempenho dos descendentes em relação aos pais (GABRIEL; DELBEM, 2008). O objetivo da mutação, no entanto, é que em alguns casos, através de alterações pequenas e aleatórias nos genes dos descendentes, este recurso permita que o AG busque por soluções em espaços ainda não explorados.

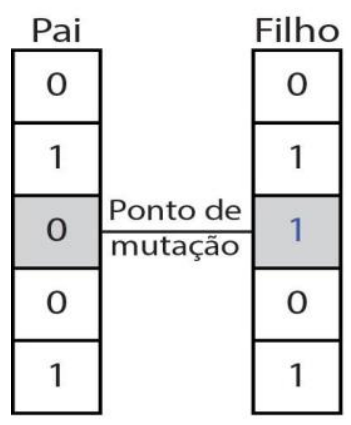

Figura 30: Representação do operador de mutação. Fonte: Tamakoshi (2016).

O operador padrão de mutação, em codificação binária, troca um ou mais genes escolhidos aleatoriamente, se o alelo do gene selecionado é 0 , será alterado para 1 (GOLDBERG, 1989 apud GABRIEL; 2010).

\subsubsection{RECOMBINAÇÃO}

A recombinação é responsável pela troca de material genético através da combinação de alelos. O resultado desse processo é a geração de novos indivíduos distintos, onde cada indivíduo descendente possui características dos cromossomos dos pais (MITCHELL, 1998). O propósito desse operador é gerar indivíduos que combinem as melhores características 
dos pais. Existem distintos métodos de recombinação descritos na literatura, alguns entre os comuns serão apresentados a seguir.

\subsubsection{RECOMBINAÇÃO DE UM PONTO}

Na recombinação de um ponto é definido um ponto aleatório entre dois genes do cromossomo, dividindo o mesmo em duas partes. O ponto definido é conhecido por ponto de troca ou de corte. O ponto de corte representa o ponto de recombinação genética que cambiará a troca entre as partes dos cromossomos pais (MITCHELL, 1998).

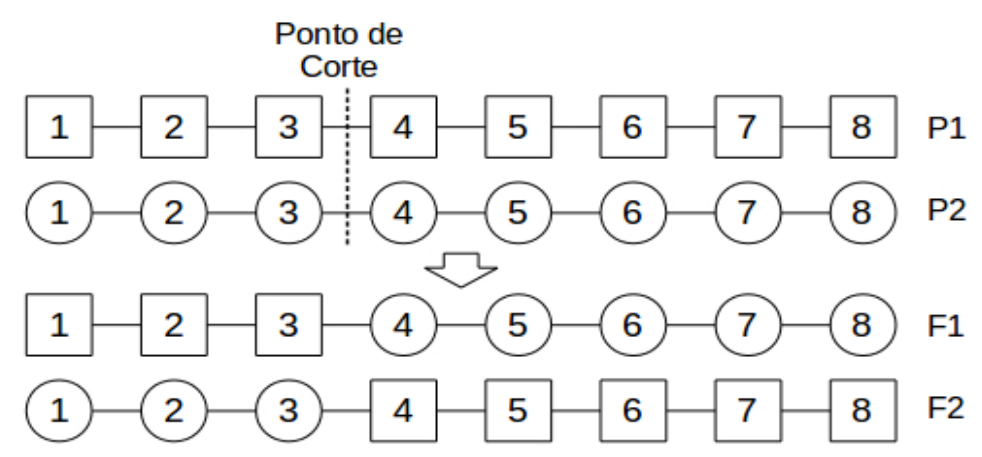

Figura 31: Recombinação de um ponto. Fonte: Tamakoshi (2016).

Dessa maneira, a condição de combinação entre dois pais, pail e pai2 resulta na descendência de dois indivíduos, filhol e filho2. O primeiro segmento do cromossomo do filhol, que corresponde ao início do cromossomo até o ponto de corte, é herdada do pail; o segundo segmento do cromossomo, após o ponto de corte, é herdada do pai2. O filho2 corresponde à inversão da ordem dos segmentos, o primeiro segmento do cromossomo é herdado do pai2, e o segundo segmento do pail.

\subsubsection{RECOMBINAÇÃO DE N-PONTOS}

A recombinação por n-pontos difere da recombinação por um ponto na definição de mais de um ponto de troca. Os n-pontos de troca são distribuídos de forma aleatória dividindo os cromossomos em diferentes 
seções utilizadas na recombinação genética dos pais e geração dos descendentes (MITCHELL, 1998).

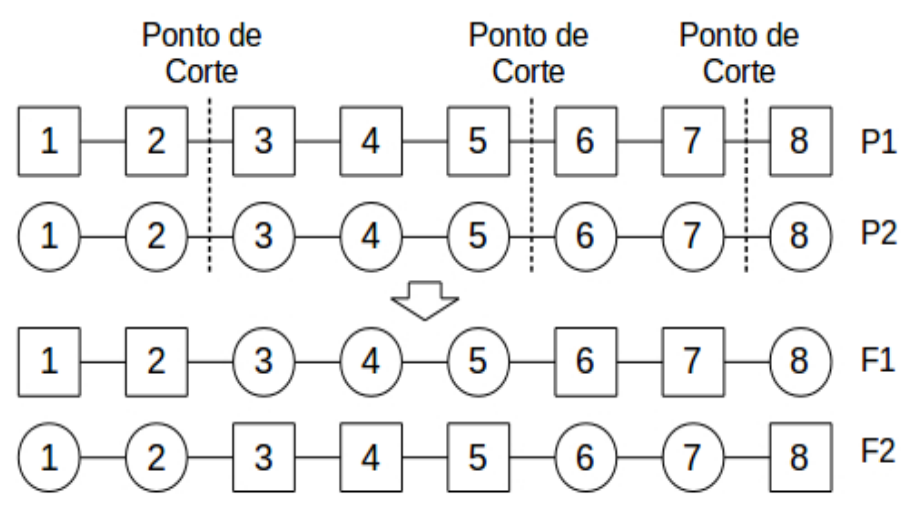

Figura 32: Recombinação de n-ponto. Fonte: Tamakoshi (2016).

\subsubsection{RECOMBINAÇÃO UNIFORME}

Diferente da recombinação de um ponto e de n-pontos, na recombinação uniforme, em vez de segmentos de genes, é avaliado cada gene individualmente. Dessa maneira essa recombinação é capaz de combinar características de diferentes posições nos cromossomos (GABRIEL, 2010).

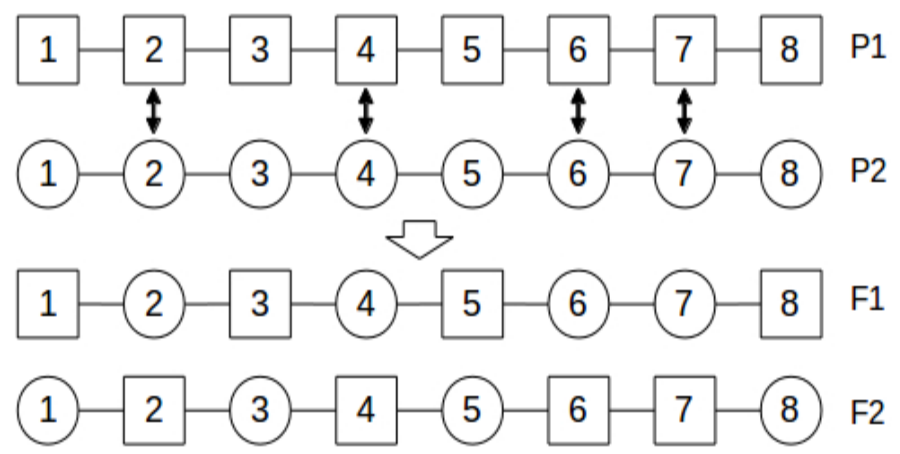

Figura 33: Recombinação uniforme. Fonte: Tamakoshi (2016).

O funcionamento comum da recombinação uniforme é gerar um valor aleatório com distribuição uniforme em $[0,1]$. Se esse valor for maior que 0.5, o gene herdado pelo filho vem do pail; caso contrário, virá do pai 2. 
Os três operadores de recombinação apresentados são originários da codificação binária, porém podem ser aplicados a outras formas de codificação da solução do problema de otimização. Além disso, não há nenhum operador de recombinação que apresente um desempenho geral superior aos demais, variando de acordo com o problema da otimização (JONG, 2006).

\subsubsection{RECOMBINAÇÃO BLEND CROSSOVER}

A recombinação blend crossover (BLX-a), ou recombinação da mistura, foi desenvolvida por Eshelman e Schaffer (1993) a partir de um estudo desenvolvido por Goldberg (1991). O Blend Crossover trata os indivíduos como pontos e gera descendentes entre um pai e o outro, dessa maneira os descendentes são construídos também como pontos obtidos na reta estabelecida entre os dois pais, que possuem a mesma probabilidade de intervalo. Assim, para dois pais, pail e pa2 assumindo que pail $\leq$ pai2, o BLX-a seleciona aleatoriamente um número real entre 0 e 1. A localização da recombinação gerada pelo BLX-a depende da diferença entre as soluções dos pais, portanto se a diferença entre os pais for pequena, a diferença entre os filhos também será, contudo, se a diversidade da população for grande é esperada uma grande diversidade na população seguinte (GABRIEL; DELBEM, 2010). A recombinação é aplicada através de ponto flutuante.

\subsubsection{CONSIDERAÇÕES SOBRE O AG}

Entre as meta-heurísticas, ou seja, heurísticas para resolver de forma genérica problemas de otimização, o AG é o mais comum em aplicações de problemas de arquitetura. Contudo, embora existam generalizações afirmando que algoritmos evolutivos, e especialmente o AG, são robustos em explorar o espaço de design para uma ampla gama de construção de problemas de otimização (ATTIA, et al., 2013), há também apontamentos 
sobre a eficiência de algoritmos que dependem menos da aleatoriedade e mais de fundamentos matemáticos, pois encontram soluções com menor número de simulações (HOLMSTRÖM, 2008; RIOS, 2009; COSTA; et al., 2014).

O que se pode afirmar é que nenhum método de otimização tem o melhor desempenho em todos os problemas possíveis. Assim, é relevante apontar que o AG é um processo heurístico, portanto, pode não necessariamente gerar soluções ótimas. Contudo, a vasta documentação do conjunto de procedimentos do $A G$, assim como a quantidade de exemplos práticos em arquitetura aplicando esse método em seu processo de projeto, como demonstrado no Capítulo 1, motivaram o enfoque da presente pesquisa. Assim, a partir do conjunto de procedimentos apresentados no presente capítulo, foram desenvolvidos experimentos no sentido de contribuir com a complementação sobre entendimento dos potenciais e limites do emprego de otimização através de $A G$ no processo de projeto de arquitetura. Os experimentos desenvolvidos comparecem no capítulo a seguir. 


\section{CAPÍTULO 3}

\section{EXPERIMENTOS}

O presente capítulo representa a conexão entre o conhecimento teórico e prático envolvido no presente trabalho. Nele serão explorados não só a aplicabilidade da otimização de projeto orientado ao desempenho em arquitetura, através de problemas pertinentes ao campo, mas também os conjuntos de procedimentos e ferramentas envolvidos nos processos de projeto. A realização e descrição dos experimentos colaboram com a abertura dos métodos de otimização e de suas aplicabilidades no processo de projeto de arquitetura. Ao longo do capítulo serão apresentados detalhadamente o fazer empregado em cada verificação executada na realização de dois experimentos. O primeiro experimento se trata da otimização de um projeto conectado ao seu processo de fabricação digital e o segundo da otimização da eficiência energética de um edifício. Ambos os casos comparecem a seguir.

\subsection{CONTEXTO DO EXPERIMENTO A}

O presente experimento foi exposto no artigo "Architectural Optimization and Open Source Development: Nesting and Genetic Algorithms" (LANDIM; DIGIANDOMENICO; AMARO; TOLEDO, 2017) publicado no congresso ACADIA 2017: Disciplines \& Disruption, realizado no Massachusetts Institute of Technology em Cambridge.

O contexto de desenvolvimento do presente experimento parte da reflexão sobre a manufatura auxiliada por computador (CAM) como elemento do processo de projeto que tem se tornado intrínseco ao design 
computacional. A manufatura auxiliada por computador fornece acesso a um sistema de produção capaz de atender necessidades do projeto e da fabricação em escala regional ou individualizada (SASS, 2010). A fabricação de modelos físicos através de um processo automatizado é um recurso que auxilia a qualidade do produto independente de sua escala.

Segundo Chen e Sass (2016), muitos processos de produção passaram por transformações de uma abordagem manual ou semiautomática para uma abordagem inteiramente digital, sendo o corte de material a área mais afetada. Um dos tipos de corte mais utilizados é em superfícies bidimensionais, por exemplo, cortes a laser, plasma, jato de água e fresagem através de máquinas CNC. Esse tipo de corte consiste em orientar as seções que devem ser cortadas sobre a superfície do material utilizado na fabricação.

O processo de posicionamento das peças de corte em chapas planas (tais como chapas de madeira, chapas metálicas, entre outros materiais), a fim de minimizar a quantidade de sucata (restos de placas) produzidas após o corte, feito por máquinas de fabricação digital no sistema CAD/CAM, é conhecido como nesting.

No entanto, dependendo do projeto, a distribuição das seções de corte na área de placa do material pode tornar o nesting uma tarefa complexa, como demonstram Chen e Sass (2016), ao apresentarem três tipos de nesting que variam entre posicionar as peças para economizar o máximo de material e posicioná-las em relação à sua ordenação, facilitando a montagem em casos de projetos grandes que possuem um número elevado de partes cortadas.

Atualmente existem programas proprietários e pagos disponíveis para a área de manufatura e arquitetura como Rhinocam (MecSoft Corporation) e Trunest (Autodesk), que posicionam as partes que serão cortadas dentro da área da chapa. Porém, estes programas necessitam que as peças sejam geradas em ambiente CAD, selecionadas manualmente e configuradas 
dentro do programa de nesting. Logo, a cada conjunto de peças que deve ser cortado, utiliza-se um modelo de desenvolvimento estático. Neste caso, se forem necessárias mudanças no projeto, o posicionamento das peças nas placas de corte é perdido e todo o processo precisa ser refeito. Essa abordagem inviabiliza um processo generativo ou de rápida adaptação como o oferecido pelo sistema de modelagem paramétrica.

Existem plug-ins de nesting para o fluxo de trabalho paramétrico como Rhinonest (TDM Solutions) para Grasshopper, opção proprietária e paga, e Generation (Antonio Turiello), um plug-in closed source gratuito. Ambos fazem $O$ nesting de maneira generativa, permitindo atualizar $O$ posicionamento das peças na chapa assim que o projeto sofre mudanças. Porém, Generation apenas funciona com closed curves únicas, ou seja, não é possível obter o nesting com sucesso caso a geometria possua um furo ou outro recorte dentro de seus limites externos, sendo este a maioria dos casos em geometrias mais complexas.

Diante desse panorama, o experimento encaminhado apresenta 0 desenvolvimento de um plug-in para o Grasshopper em código aberto que realiza duas contribuições. A primeira o próprio AG desenvolvido para 0 problema e a segunda, o algoritmo de nesting. Ambos podem ser acessados para avaliação, aperfeiçoamento e adaptação em outros problemas arquitetônicos. O plug-in proposto foi testado em um experimento que verificou, além da própria viabilidade do desenvolvimento do plug-in open source a partir dos métodos de otimização estudados nesta pesquisa, a eficiência do método aplicado em solucionar o problema arquitetônico escolhido.

O experimento foi desenvolvido em parceria com os pesquisadores Gabriele do Rosário Landim (IAU-USP), que trabalhou comigo na concepção, desenvolvimento e implementação do experimento abordado, Jean Amaro (ICMC-USP), que trabalhou na implementação dos códigos e desenvolvimento do algoritmo proposto. O trabalho foi orientado pelo professor Dr. Cláudio Toledo (ICMC-USP). 


\subsection{METODOLOGIA}

O presente experimento foi realizado com base na metodologia Design Science (SIMON, 1996), dada sua natureza pragmática e interdisciplinar, envolvendo conhecimentos da arquitetura e da ciência da computação. Assim, cada uma das partes do experimento, incluindo materiais e métodos, comparecem a seguir.

\subsection{PROBLEMA ARQUITETÔNICO}

Foi selecionado como estudo de caso o projeto Wren, que explora a tecnologia estrutural do sistema construtivo Wikihouse, projeto open source desenvolvido no Reino Unido (PARVIN, 2013). O projeto foi originalmente desenvolvido pela Architecture 00 e todos os seus desenvolvedores podem ser consultados na página de compartilhamento do código Wren do GitHub. Na mesma página do Github constam informações sobre o projeto, fabricação e montagem, assim como o compartilhamento do código, escrito em programação visual através do plug-in Grasshopper para Rhinoceros.

Wikihouse é conhecido por ser um sistema construtivo para habitações simples em madeira. O sistema construtivo funciona com pórticos estruturais travados com seções transversais, os quais formam um chassi que permite acoplar (montar) outros componentes da construção como chapas de fechamento interno e externo, janelas e portas. Todo o sistema é travado com cunhas e parafusos. Todas as peças que compõem a habitação são feitas em chapas de madeira e foram projetadas para serem cortadas em uma fresadora CNC. 


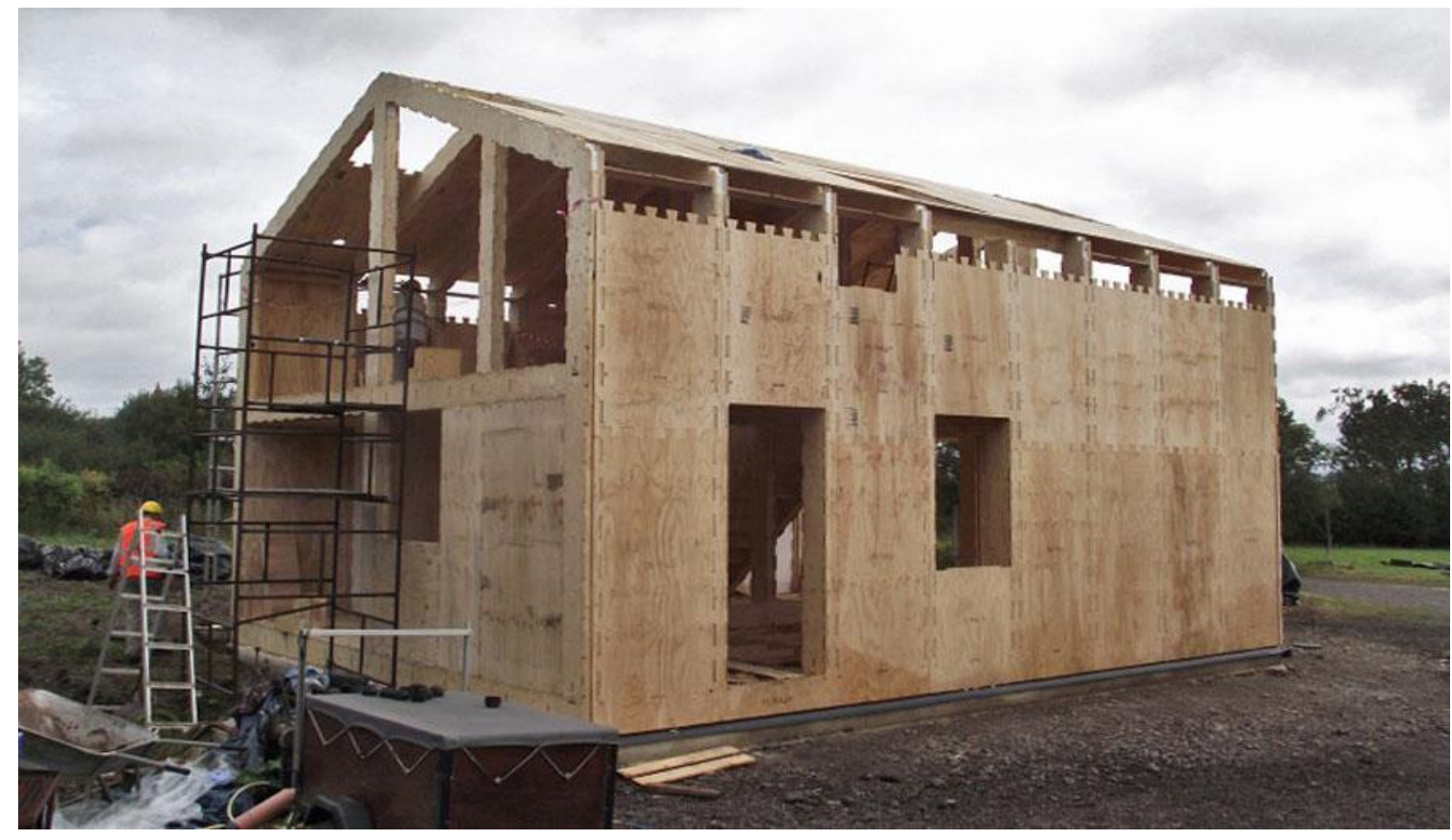

Figura 34: Construção de casa sistema Wikihouse. Fonte: Urbannext (2017).

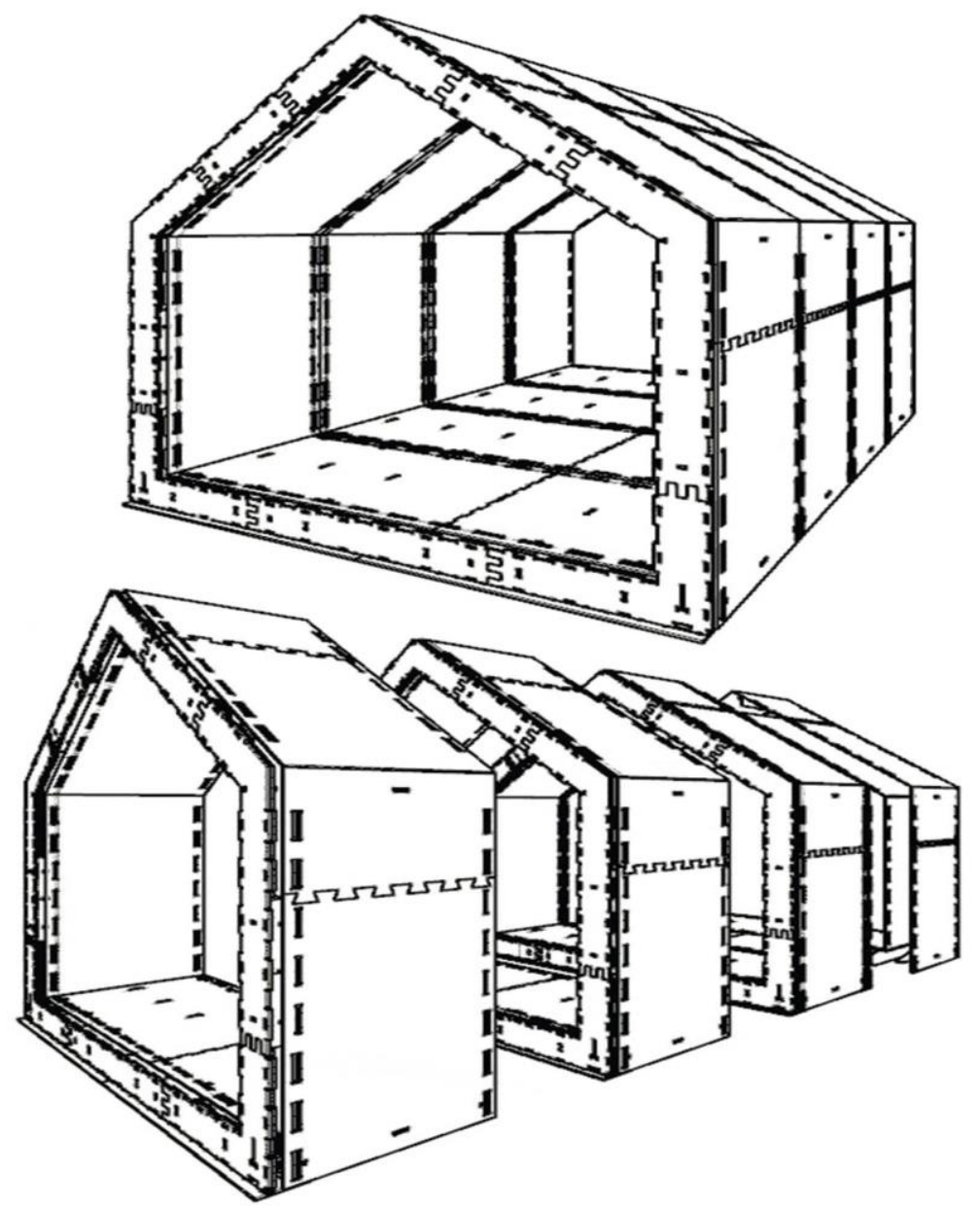

Figura 35: llustração de sistema construtivo Wikihouse. Fonte: Autores. 
O projeto foi escolhido por permitir ao experimento o desenvolvimento de um plug-in open source voltado a um problema de projeto real com nível de complexidade ideal para o primeiro experimento da pesquisa. Além disso, o projeto escolhido é apropriado à aplicação de nesting para fabricação digital, por se tratar de um sistema construtivo projetado unicamente para ser cortado em placas de madeira. O projeto Wren também incentiva o desenvolvimento de projetos de código aberto, semelhante a proposta do presente experimento, que visa partir de um projeto que já funciona, copiar, adaptar e compartilhar (re-share).

A pesquisa propõe um plug-in open source e gratuito, que implementa um algoritmo de nesting otimizado a partir de um algoritmo genético, capaz de alocar as geometrias das peças nas placas de corte, considerando, num momento inicial, a forma da habitação, e a minimização da quantidade de placas de madeira utilizada. A figura abaixo ilustra o nesting a ser obtido pelo plug-in proposto, no qual a geometria de peças com recortes ou furos são consideradas.

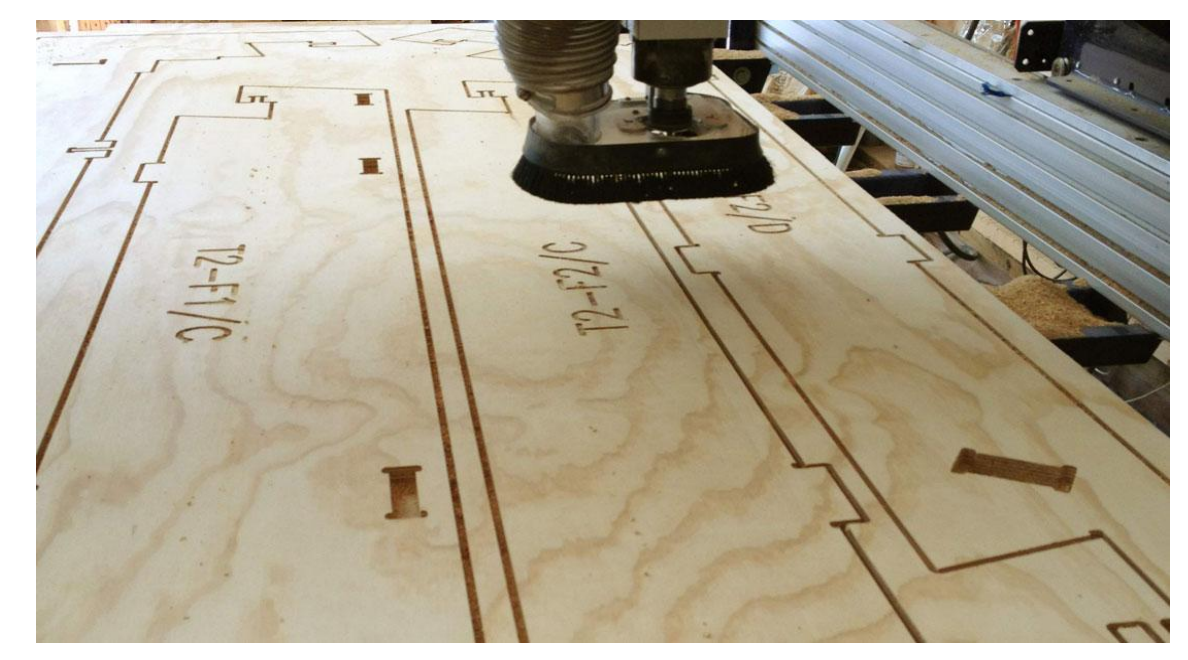

Figura 36: Peças do modelo Wikihouse dispostas na chapa e cortas por fresadora CNC. Fonte: Urbannext (2017). 


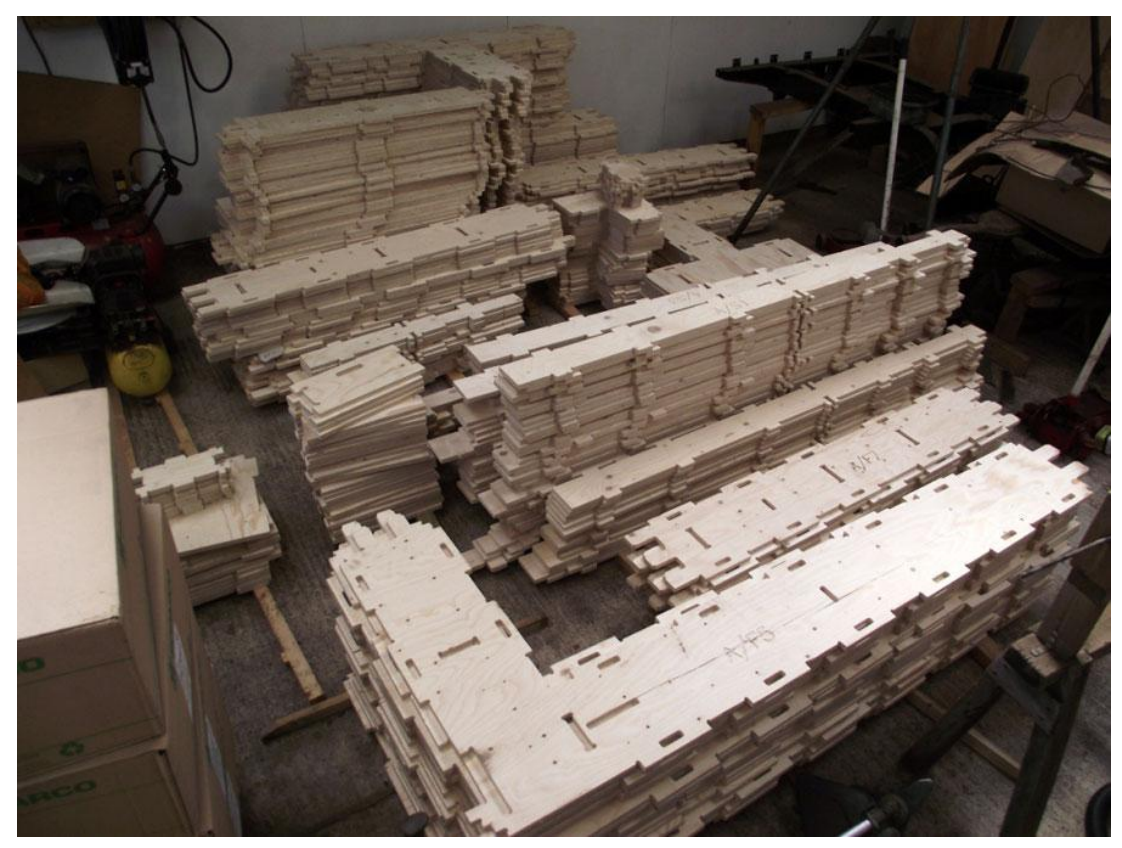

Figura 37: Exemplo de peças a serem distribuídas em chapa para corte. Fonte: Urbannext (2017).

\subsection{PROJETO DE PLATAFORMA E FERRAMENTAS}

O fluxo das operações parte do modelo paramétrico do código Wren desenvolvido no Grasshopper. As variáveis utilizadas são quatro: o domínio máximo e mínimo da dimensão em milímetros das alturas das paredes direita e esquerda, altura do telhado e posição no eixo $x$ da cumeeira, que configuram o perfil externo e interno da habitação.

Foi identificado que algumas geometrias geradas são inválidas, por apresentarem erros geométricos na construção. Diante desse problema, o código Wren foi adaptado pelos pesquisadores, incluindo uma avaliação da geometria, que verifica se os polígonos de entrada são válidos ou não. Se forem, a representação da solução codificada no AG (indivíduo) é considerada e computada pelo AG; caso contrário, é descartado sendo atribuídos novos valores para as variáveis que geram a forma. Sendo o método construtivo Wikihouse uma replicação de módulos, o código adaptado para o experimento se concentrou em testar a evolução formal e planificação das peças para fabricação de apenas um módulo. 
O plug-in desenvolvido se conecta ao código no Grasshopper, acessando as variáveis que controlam a forma geométrica do projeto contidas em numbers sliders, como ilustrado na figura abaixo.

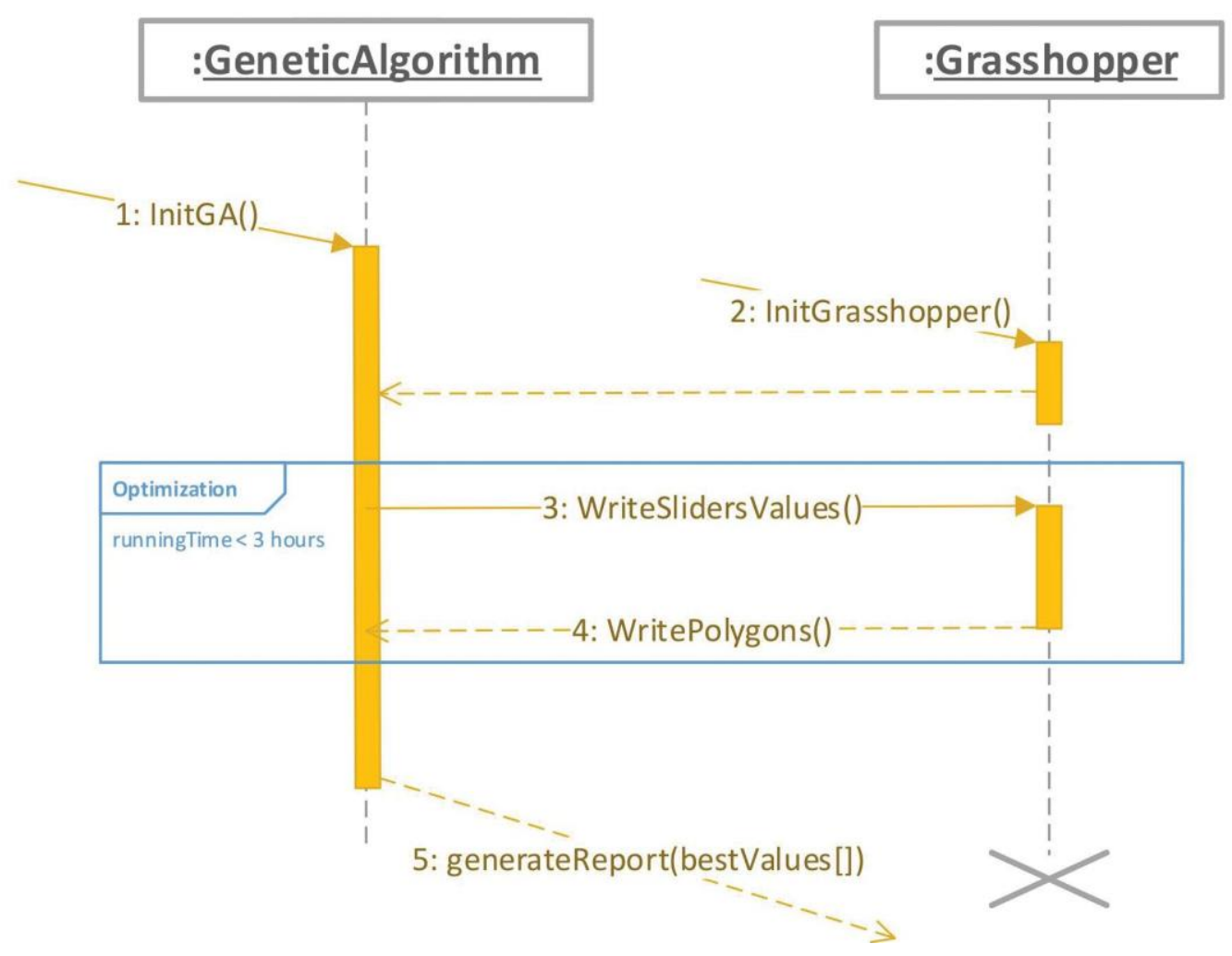

Figura 38: Estrutura da ferramenta computacional proposta. Fonte: Autores.

O plug-in foi desenvolvido em C\#, uma das linguagens de programação aceitas pelo Grasshopper para o desenvolvimento de aplicações. O plug-in se comunica com a aplicação externa proposta neste experimento. Essa aplicação externa foi desenvolvida em C++ e a comunicação entre plug-in em C\# e aplicação externa em C++ ocorre através da troca de informações por arquivo. A aplicação externa avalia os polígonos gerados no Grasshopper, verifica a relação entre as peças e as perfurações de encaixe, aplica o algoritmo de nesting, estabelece um valor de fitness para $o$ indivíduo e atribui novos valores aos numbers sliders que controlam a forma geométrica do projeto. 
A motivação para a escolha da linguagem de programação C++ para esta parte da implementação se dá pela eficiência na execução, considerando que o Benchmarking de linguagens de programação indica que, entre as linguagens orientada a objeto, $\mathrm{C}++$ é a que possui maior desempenho (FULGHAM et al., 2009).

O tipo de modelagem paramétrica suportada pelo Grasshopper é a modelagem de fluxos de dados (JANSEN e STOUFF, 2015), isso significa que a operação de recursão não é aceita nativamente. Para superar essa restrição, o plug-in proposto implementa uma estratégia para tornar o processo iterativo, sendo assim os sliders são atualizados ao fim de cada execução, ocasionando modificações no modelo da habitação. 


\subsection{ALGORITMO GENÉTICO PROPOSTO}

O fluxo de execução do AG proposto está representado na figura a seguir:

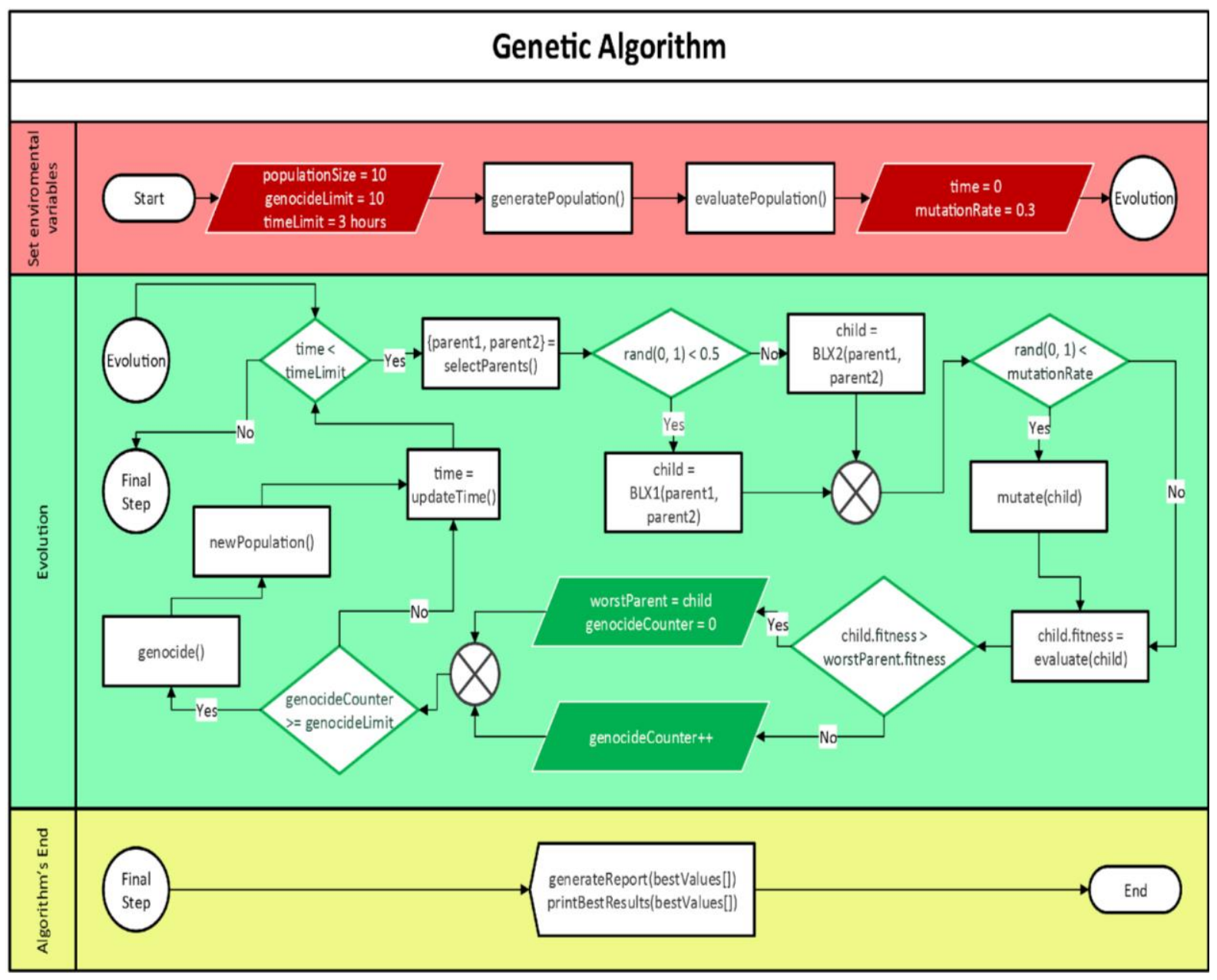

Figura 39: Fluxograma do funcionamento do AG proposto. Fonte: Autores.

O método gera uma população de soluções chamadas de indivíduos a partir dos parâmetros de entrada fornecidos. As soluções são codificadas como vetores $n$ dimensionais $v=(v 1, v 2, \ldots, v i, \ldots, v n)$, onde cada entrada $v_{i} \in$ [min, max]. Os parâmetros min e max representam o intervalo de variação das dimensões em milímetros que compõem a forma das peças. Assim, cada vetor $v$ representa um indivíduo no $A G$ e a população inicial de indivíduos é gerada assumindo uma distribuição uniforme na determinação das entradas $v_{i}$.

A avaliação dos indivíduos utiliza uma função fitness que mensura a soma entre a área total de cada chapa (2750 mm x $1830 \mathrm{~mm}$ ) utilizada e a 
área ocupada da última placa. Logo, o objetivo é encontrar indivíduos $v$ com valor de fitness que minimize o número de chapas utilizadas.

O processo evolutivo em um AG consiste na aplicação de operadores de seleção para reprodução, crossover, mutação e seleção para sobrevivência como descritos no Capítulo 2. O processo evolutivo ocorre até que um critério de parada seja atendido. No AG proposto, o critério de parada utilizado foi um tempo limite de execução.

Durante o tempo de execução, o torneio é utilizado como estratégia de seleção para reprodução (EIBEN, 2003), onde $p$ indivíduos são aleatoriamente escolhidos a partir de uma população composta por $M$ indivíduos com $p \leq M$. O indivíduo com melhor valor de fitness entre os $p$ selecionados é escolhido para reprodução. Assim, a etapa de seleção para reprodução retorna os pais, representados por parent 1 e parent 2, através da seleção por torneio.

Durante a etapa de reprodução, uma recombinação das informações codificadas em dois indivíduos $v 1$ e $v 2$ (parentl e parent2 na figura do fluxograma do funcionamento do AG proposto) gera uma nova solução $v$ (child). O operador blend alpha crossover $(B L X-\alpha)$ foi aplicado, onde duas versões foram implementadas como se segue:

$$
\begin{gathered}
B L X-\alpha 1: v_{i}=\alpha v_{i}^{1}+(1-\alpha) v_{i}^{2} \text { onde } \alpha \in[0,1] \\
B L X-\alpha 2: v_{i}=\alpha_{1} v_{i}^{1}+(1-\alpha) v_{i}^{2} \text { onde } \alpha_{i} \in[0,1]
\end{gathered}
$$

No crossover $B L X-\alpha 1$, o parâmetro a, aleatoriamente selecionado no intervalo [0,1], é o mesmo aplicado a todas as entradas das soluções $v^{1}$ e $v^{2}$ durante o processo de recombinação. No $B L X-\alpha 2$, um valor $\alpha i$ diferente pode ser aplicado na recombinação que gera cada entrada $v_{i}$.

Durante a fase de mutação, alterações em cada entrada vi podem ocorrer, caso a taxa de mutação $\lambda$ seja satisfeita. Isso significa que, para cada entrada $v_{i}$ da nova solução, um número aleatório $\beta \in[0,1]$ é gerado e, se $\beta<\lambda$, um novo valor $v_{i} \in[\min , \max ]$ é definido. Uma vez criada a nova solução a partir do crossover e mutação, o algoritmo de nesting é aplicado 
utilizando $v$ como entrada e um valor de fitness é atribuído (evaluate (child) na Figura 25).

Se a nova solução $v$ apresentar valor de fitness melhor que $v^{1}$ ou $v^{2}$, ela assume o lugar daquele com pior valor de fitness. Se nenhuma nova solução $v$ for melhor que uma das soluções selecionadas $v^{1}$ e $v^{2}$ por dez gerações consecutivas, toda a população é reiniciada com exceção do melhor indivíduo que permanece na próxima geração.

\subsection{ALGORITMO DE NESTING}

O algoritmo de nesting implementa a distribuição das peças nas placas que deverão ser cortadas através da heurística de seleção de itens DJD e de um algoritmo de grid (BURKE et al., 2007; CAMACHO et al., 2013).

O plug-in recebe todos os vértices das peças que deverão ser posicionadas na placa, reconstrói o polígono de acordo com a lista recebida, calcula a área de cada polígono e posiciona os maiores na menor dimensão possível no eixo x. Além disso, o nesting executa três rotações de $90^{\circ}$ para cada peça, restringindo o seu espelhamento. As operações são repetidas até que todos os polígonos tenham sido posicionados nas áreas disponíveis nas placas.

Caso o indivíduo gerado pelo AG resulte em peças que não possam ser posicionadas na placa, esse indivíduo será descartado no processo evolutivo recebendo um valor de fitness penalizado.

Observou-se também que polígonos com valores corretos eram gerados com erro pelo algoritmo dentro do Grasshopper. Por exemplo, criando peças em que vértices dos polígonos se cruzam. Assim, o plug-in proposto foi adaptado para contornar tal situação de erro, descartando a solução gerada com problema no Grasshopper. O mais relevante nesta situação foi a capacidade do plug-in de lidar com problemas de um código fechado, evitando que o mesmo simplesmente travasse ou abortasse a execução. 


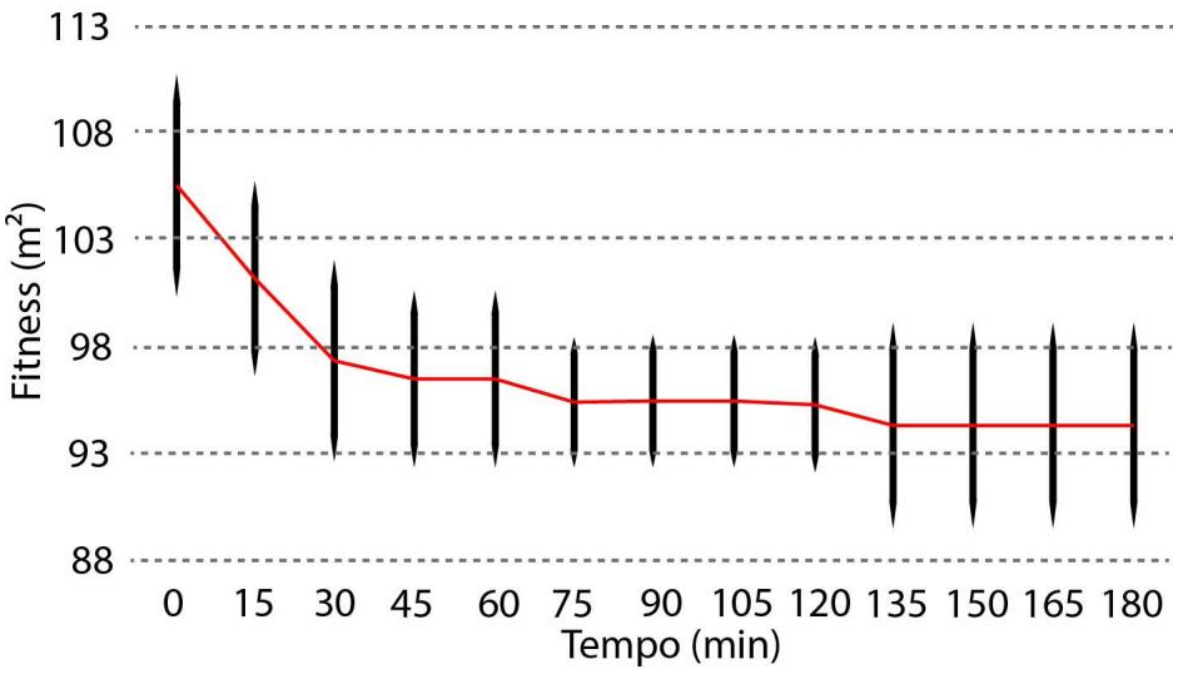

Figura 40: Média e desvio dos valores das melhores soluções ao longo do tempo. Fonte: Autores.
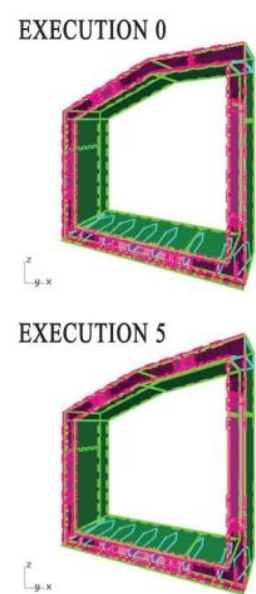

EXECUTION 0

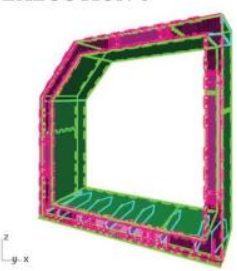

EXECUTION 5

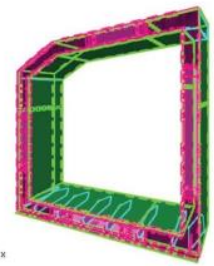

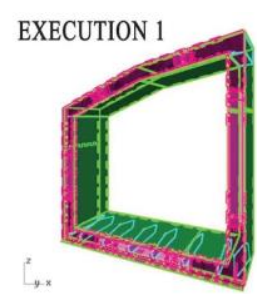

EXECUTION 6

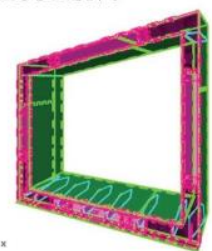

EXECUTION 1

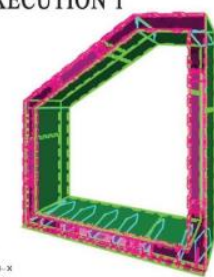

EXECUTION 6

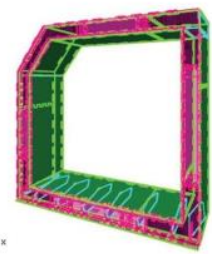

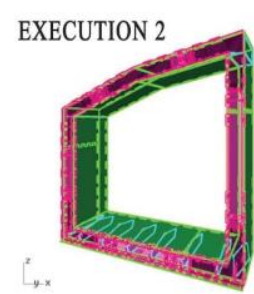

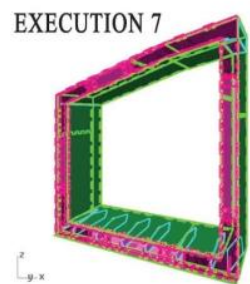

EXECUTION 2

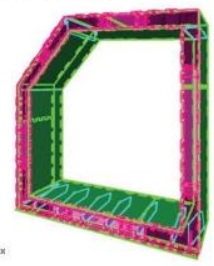

EXECUTION 7

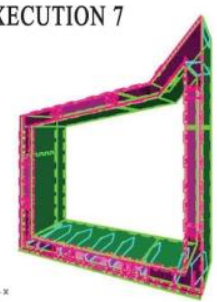

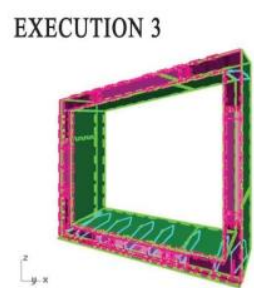

EXECUTION 8

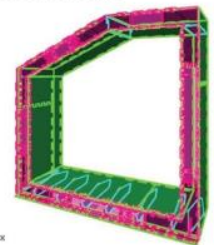

EXECUTION 3

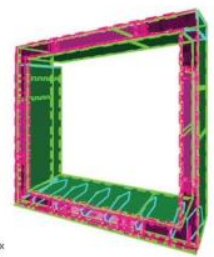

EXECUTION 8

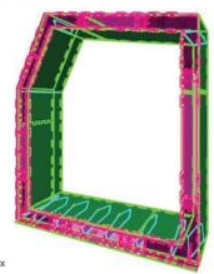

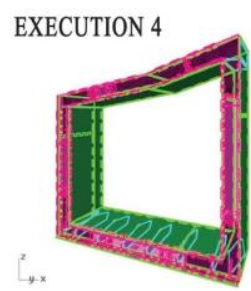

EXECUTION 9

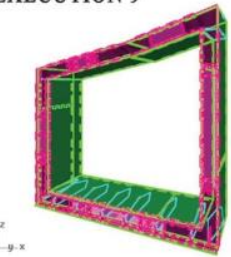

EXECUTION 4

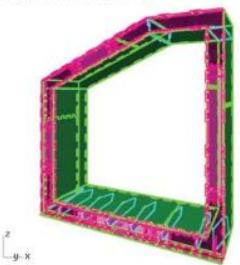

EXECUTION 9

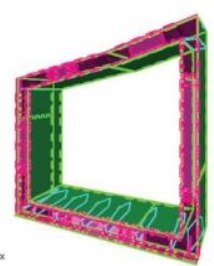

Figura 41: Melhores resultados obtidos em cada execução. Fonte: Autores. 
A média do valor da melhor solução encontrada, ao final das 10 execuções realizadas foi de $94.19925 \mathrm{~m}^{2}$ de área de placa utilizada, com desvio padrão de $4.744687 \mathrm{~m}^{2}$. O valor baixo do desvio padrão indica a tendência de que o valor de fitness convirja para a média apresentada, garantindo a estabilidade do resultado final encontrado em diferentes execuções do algoritmo. A tabela abaixo resume o valor médio do fitness e os desvios no decorrer do tempo.

Valores do fitness médio e desvio padrão

\begin{tabular}{|c|c|c|}
\hline \multicolumn{3}{|c|}{ AG } \\
\hline $\begin{array}{c}\text { Tempo em } \\
\text { Min. }\end{array}$ & Média de 10 execuções & Desvio Padrão \\
\hline 0 & 105,436479 & 5,324471231 \\
\hline 60 & 96,3115275 & 4,202867933 \\
\hline 120 & 95,20575 & 3,182832464 \\
\hline 180 & 94,19925 & 4,74468650 \\
\hline
\end{tabular}

Fonte: Autores.

O nesting aplicou o método heurístico DJD e posicionamento de grid, apresentando resultados coerentes no que diz respeito à distribuição das peças ao longo das placas, além de conservar a relação entre as peças e suas perfurações. A figura a seguir ilustra esses aspectos, sendo que as linhas vermelhas representam as placas, as pretas as peças cortadas e as azuis são as respectivas perfurações das peças. 


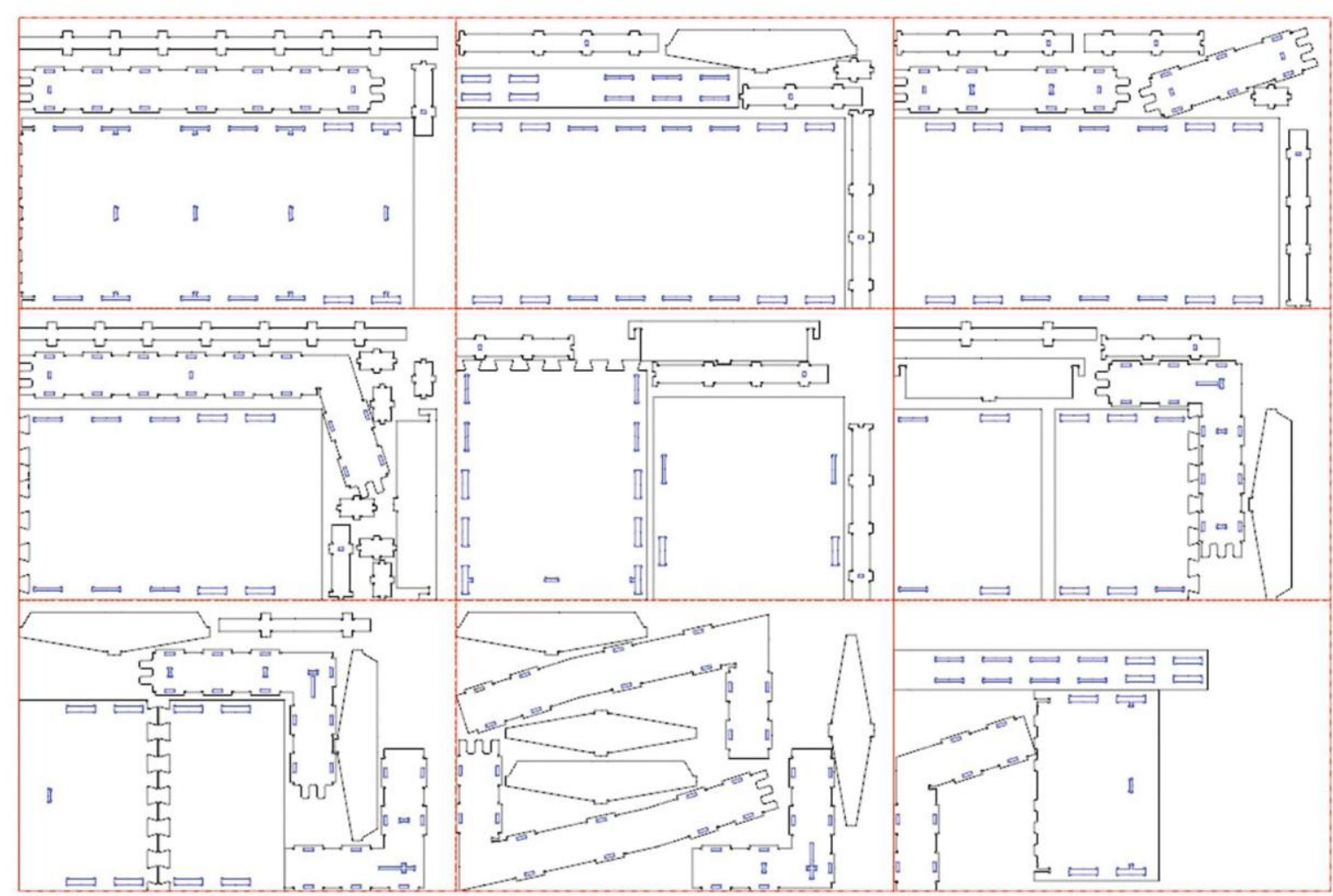

Figura 42:Resultado das peças planificadas como nesting. Fonte: Autores.

Além disso, por se tratar de um algoritmo de posicionamento em grid, as peças estão dispostas na placa com o desempenho esperado. Tal desempenho supera as expectativas para o processo de nesting atualmente disponível em implementações gratuitas em plataformas de modelagem paramétrica. Todo o conjunto de operações desenvolvidas pelo plug-in permaneceram abertas para verificação ao longo do experimento, assim podem ser acessadas para adaptações e aperfeiçoamentos.

\subsection{DISCUSSÃO E CONCLUSÕES DO EXPERIMENTO}

O resultado da otimização retornou muitas opções com o mesmo valor de fitness entre os melhores resultados de todas as execuções, ou seja, com a menor área de chapa utilizada. No entanto, apesar dos resultados apresentarem o valor de fitness igual ou aproximado, os resultados formais apresentaram variação considerável. Isso reforça a relevância da aplicação do uso de AGs em relação a outros métodos de otimização determinísticos 
que resultam em apenas uma solução retornada. No processo de projeto em arquitetura, a otimização que pode resultar em um conjunto de soluções diversificada e com desempenho satisfatório pode amparar amplamente o arquiteto nas decisões de projeto.

Embora seja uma característica conhecida do projeto do design computacional, a capacidade de gerar e avaliar diversas soluções de projeto em um tempo relativamente curto, contribui para o fato de métodos de otimização com algoritmos evolutivos serem cada vez mais utilizados no processo de projeto de arquitetura por sua eficiência e diversidade de soluções do problema.

A implementação do algoritmo de nesting atrelada à otimização também é uma contribuição importante ao processo de projeto em arquitetura. Até onde a pesquisa investigou, não foram encontradas implementações open source e gratuitas para nesting capazes de lidar com peças que possuem perfurações e que possam ser utilizadas no ambiente de modelagem paramétrica Grasshopper. Além disso, é comum em projetos que necessitam usar a planificação de peças e fabricação digital, para verificar durante a fase de concepção, o custo ou quantidade de materiais que poderão ser utilizados, e o nesting possibilita esta quantificação.

Dentro desse panorama, o experimento contribui para a afirmação de que a otimização do projeto arquitetônico pode avançar se os esforços de pesquisa se concentrarem também em métodos e procedimentos de código aberto para verificação, reprodução e melhora dos algoritmos. Isso significa que, à medida que o problema arquitetônico é desenvolvido e resultados são obtidos parcialmente durante a fase de otimização, pode ser útil alterar alguns dos procedimentos dos métodos adotados. No caso de um otimizador que utilize AG, por exemplo, torna-se possivel alterar parâmetros relacionados à função de fitness, tamanho da população e operadores de crossover e mutação, entre outros. 
Nesse sentido, o presente experimento identificou possíveis aprofundamentos para pesquisas futuras. A implementação de função multiobjetivo no AG permitirá que os arquitetos possam balancear mais de um valor do projeto a ser otimizado. O plug-in também receberá uma interface mais amigável na sua fase de acabamento. A implementação de outro método de posicionamento de polígonos no algoritmo de nesting também será realizada, apontando para a possível implementação do método No Fit Polygon (BURKE et al., 2007).

Os recursos computacionais demonstrados neste experimento são capazes de promover e ampliar as revisões no processo de projeto em arquitetura. Na mesma medida, a crescente complexidade do projeto arquitetônico solicita que o arquiteto relacione o saber de sua área com o domínio de recursos computacionais que possuem métodos e conjuntos de procedimentos próprios. De forma geral, a contribuição se estende da produção do plug-in aberto, que implementa o AG e o algoritmo de nesting, além da discussão que propicia sobre a relevância da abertura e clareza dos métodos empregados nos processos de otimização aplicados a problemas arquitetônicos.

Contudo, dada a pequena escala de complexidade do caso arquitetônico explorado no experimento, para confirmações a respeito da escalabilidade e adaptabilidade do plug-in a outro problema de arquitetura, cujo espaço de design seja maior e sua varredura mais sofisticada, foi modelado e realizado o experimento descrito a seguir.

\subsection{CONTEXTO DO EXPERIMENTO B}

Como demonstrado na revisão bibliográfica e no experimento anterior realizados na presente pesquisa, a aplicação de otimização no processo de projeto orientado ao desempenho requer conhecimentos de disciplinas diversas para a formulação do método de otimização responsável pelas buscas dentro do espaço de design. $O$ processo de projeto ganha 
complexidade com a intenção de fornecer respostas eficientes às crescentes solicitações na AEC, dentre as quais, a maximização da eficiência energética do projeto.

Os sistemas de classificação de sustentabilidade, desenvolvidos em todo o mundo nas últimas décadas, alavancaram pesquisas de otimização em AEC por envolverem requisitos de projeto sofisticados, onde muitas vezes é necessário balancear fatores concorrentes como, por exemplo, a maximização do uso da luz natural e a minimização do calor por radiação solar. Diante desse panorama, muitas vezes a varredura do espaço de design, sem a aplicação de um método de otimização, torna-se complexo e custoso para as equipes de projeto. Considerando este contexto, o presente experimento apresenta o desenvolvimento de um plug-in para o Grasshopper em código aberto que propõe realizar duas contribuições.

A primeira contribuição é a implementação do método de otimização por AG como recurso de buscas dentro de um grande espaço de design, operando junto com simuladores de eficiência energética, procurando verificar alguns dos potenciais e limites da implementação do design computacional, simulação e otimização que compõem o processo de projeto orientado ao desempenho.

A segunda contribuição é a abertura dos métodos de otimização implementados no presente experimento. Assim, é realizado um experimento comparativo detalhado entre os dois métodos de otimização implementados no mesmo estudo de caso, abrindo a possibilidade de os métodos investigados serem verificados e adaptados a outros problemas arquitetônicos, esclarecendo e estimulando a aplicação de otimização de projeto em arquitetura.

O experimento foi desenvolvido em parceria com os pesquisadores Gabriele do Rosário Landim (IAU-USP), que trabalhou comigo na concepção, desenvolvimento e implementação do experimento abordado, Jean Amaro (ICMC-USP), que trabalhou na implementação dos códigos e 
desenvolvimento do algoritmo proposto. O trabalho foi orientado pelos professores Dr. David Sperling (IAU-USP) e Dr. Cláudio Toledo (ICMC-USP). Também parte do experimento foi realizado sob supervisão do professor Prof. Dr. António Leitão (INESC-ID/ IST, Universidade de Lisboa).

\subsection{METODOLOGIA}

Em certa medida $\bigcirc$ presente experimento representa um desdobramento do método e conjunto de procedimentos explorados no experimento anterior, tendo sido igualmente realizado com base na metodologia Design Science (SIMON, 1996), dada sua natureza pragmática e interdisciplinar, envolvendo conhecimentos da arquitetura e da ciência da computação.

\subsection{PROBLEMA ARQUITETÔNICO}

O problema corresponde ao estudo de caso o projeto Vancouver Academic Building, do escritório de arquitetura Perkins+Will da cidade de Atlanta, Geórgia, nos Estados Unidos. Através de métodos do design computacional, o projeto de arquitetura é otimizado para balancear objetivos conflitantes e atender pré-requisitos de certificações internacionais de sustentabilidade. São eles, a carga de resfriamento e aquecimento Standard da International Passive House Association (IPHA) e a maximização do uso da luz natural disponível definido pelo Leadership in Energy and Environmental Design (LEED). Portanto, a otimização do projeto se concentra na fachada do edifício compondo a distribuição de painéis pré-moldados, aletas, brises e a definição dos valores de ganho de calor aceitáveis para o vidro e para as paredes opacas. 


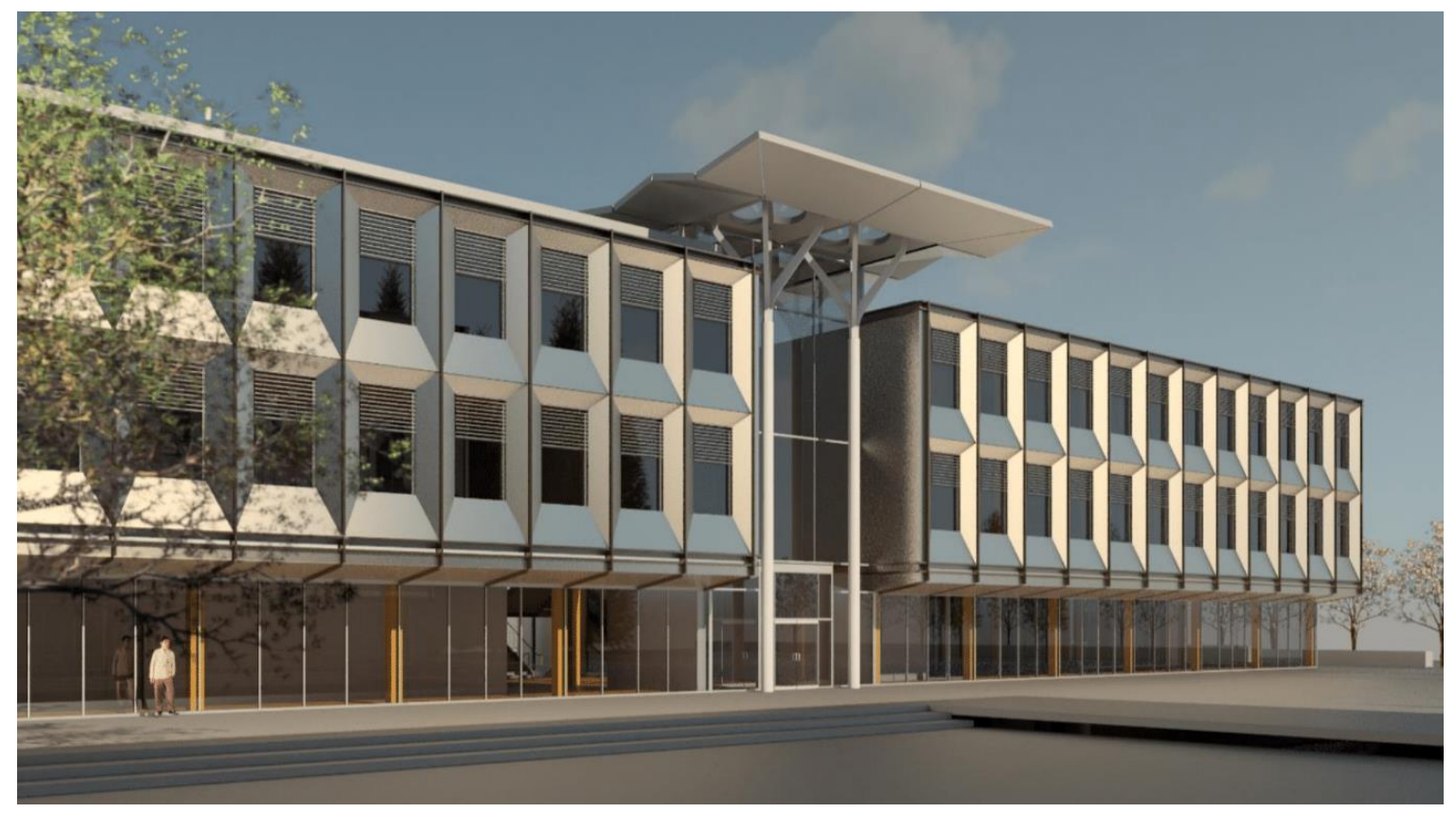

Figura 43: Vancouver Academic Building. Fonte: Perkins+Will (2017)

A equipe envolvida no experimento teve a autorização do escritório Perkins+Will para a utilização do projeto, que concedeu acesso a parte dos dados do processo de projeto. A autorização foi concedida pelos arquitetos pesquisadores John Haymaker, diretor de pesquisa da Perkins+Will San Francisco, professor na Georgia University of Technology, Estados Unidos e Marcelo Bernal, diretor de pesquisa da Perkins+Will Atlanta e professor na Universidad Técnica Federico Santa María, Chile, que demonstraram interesse nos resultados da presente proposta de pesquisa. Tais dados englobam o fluxo de trabalho do processo, informações sobre os critérios de decisão do projeto, métricas de desempenho e os métodos de otimização.

O projeto Vancouver Academic Building foi selecionado como estudo de caso por integrar concepção, simulação e otimização de desempenho em arquitetura, assim, possui características processuais que colaboram com as investigações da presente pesquisa.

O processo de projeto aplicado no estudo de caso se baseia na abordagem Design Space Construction (DSC), que propõe permitir que as equipes de projeto de AEC apliquem tecnologias computacionais para construir e explorar o espaço de design (HAYMAKER et al. 2018). 
O DSC está relacionado à reflexão sobre o processo de projeto computacional guiado pela formulação do problema, definição dos objetivos e preferências, que expressam as prioridades que o projeto deve contemplar. A partir de tais prioridades são geradas as alternativas, e analisado o desempenho de cada uma delas. Dessa maneira, o estudo de caso segue o quadro conceitual de implementação proposto por Haymaker et al. (2018), descrito a seguir.

\section{Modelo Paramétrico}

A implementação do estudo parte do modelo paramétrico, compartilhado no material disponibilizado pelo escritório de arquitetura Perkins+Will no workshop "Design Space Construction: Defining, optimizing, and communicating performance-based building design spaces", realizado no congresso Association for Computer-Aided Design in Architecture ACADIA 2017.

Dentre o material disponibilizado, os itens fundamentais são, um arquivo Rhinoceros (.3dm) e uma arquivo Grasshopper (.gh), que geram o modelo paramétrico do projeto. $O$ arquivo Rhinoceros contém a representação computacional volumétrica do projeto do estudo de caso. Os dados do projeto estão reunidos em cinco conjunto de layers, que reúnem o volume dos elementos das lajes, áreas ocupadas, volumes internos, fachadas estáticas e curvas da silhueta do volume. 


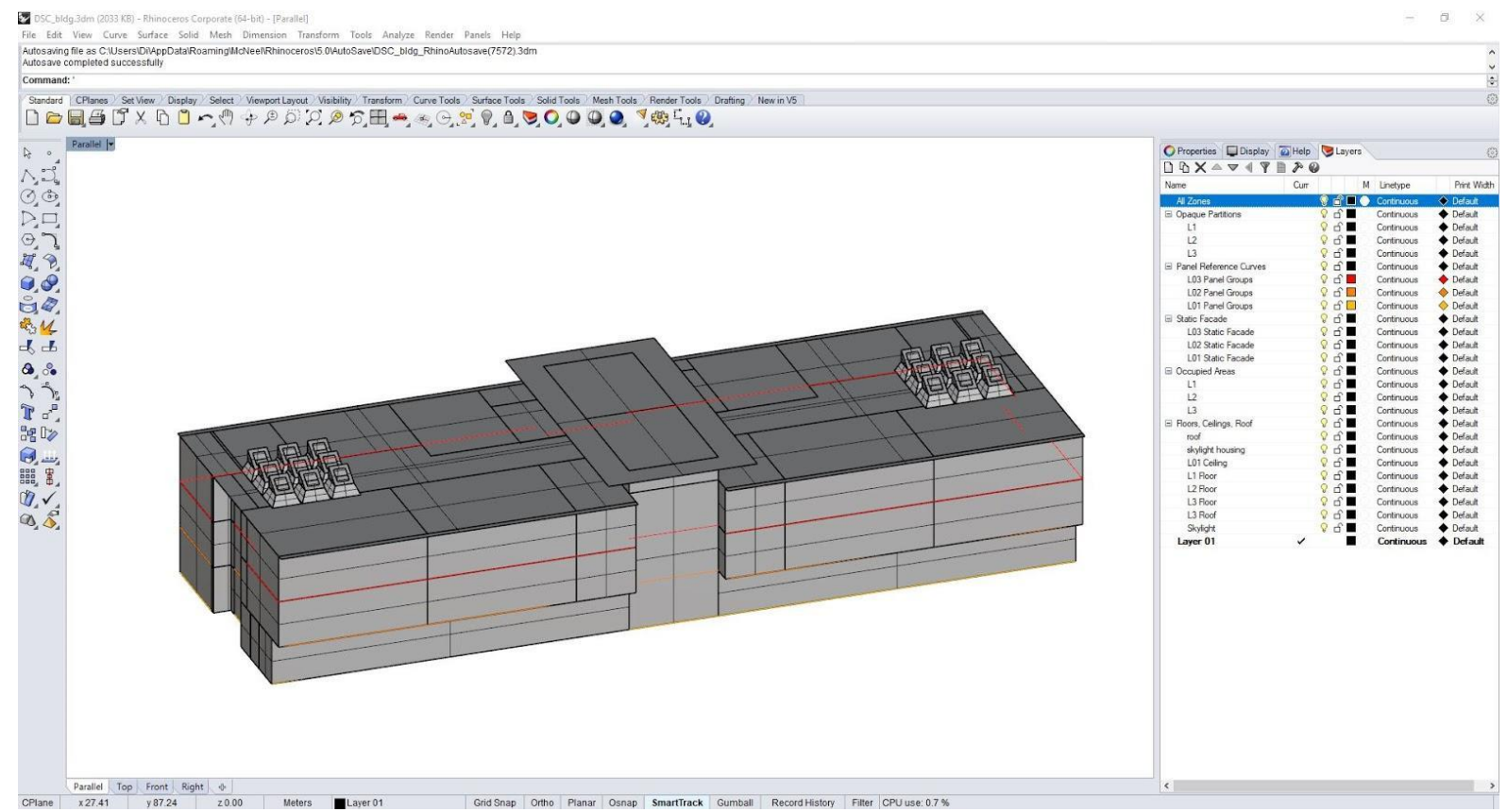

Figura 44: Modelo base no Rhinoceros para a criação do modelo paramétrico no Grasshopper. Fonte: Autores.

Os dados contidos nos layers que representam a geometria volumétrica do projeto estão relacionados ao algoritmo do arquivo Grasshopper. Contudo, para a utilização do algoritmo do Grasshopper do estudo de caso, é necessária a instalação de plug-ins e programas específicos que atuam em fases distintas do fluxo do projeto. A descrição e função de tais plug-ins comparece a seguir.

\section{Interface de comunicação}

Ladybug e Honeybee, iniciados por Mostapha Sadeghipour Roudsari, são plug-ins de código aberto para Grasshopper. Integram dinamicamente - Grasshopper com conjuntos de dados ambientais validados e motores de simulação com a finalidade de explorar e avaliar o desempenho ambiental. Portanto, são responsáveis por inserir no modelo paramétrico os dados obtidos através dos mecanismos de simulação.

Dessa maneira, o Ladybug torna possível a importação de arquivos padrão do WeatherPlus Weather (.EPW) para o Grasshopper e o Dynamo. Também é capaz de fornecer uma variedade de gráficos climáticos interativos 2D e 3D. Assim, o Ladybug apoia a avaliação das opções de 
projeto por meio de estudos de radiação solar, análises de visão, modelagem de horas do sol e outras funções. Por estar integrado a ferramentas de programação visual, é capaz de produzir feedback instantâneo em modificações do projeto.

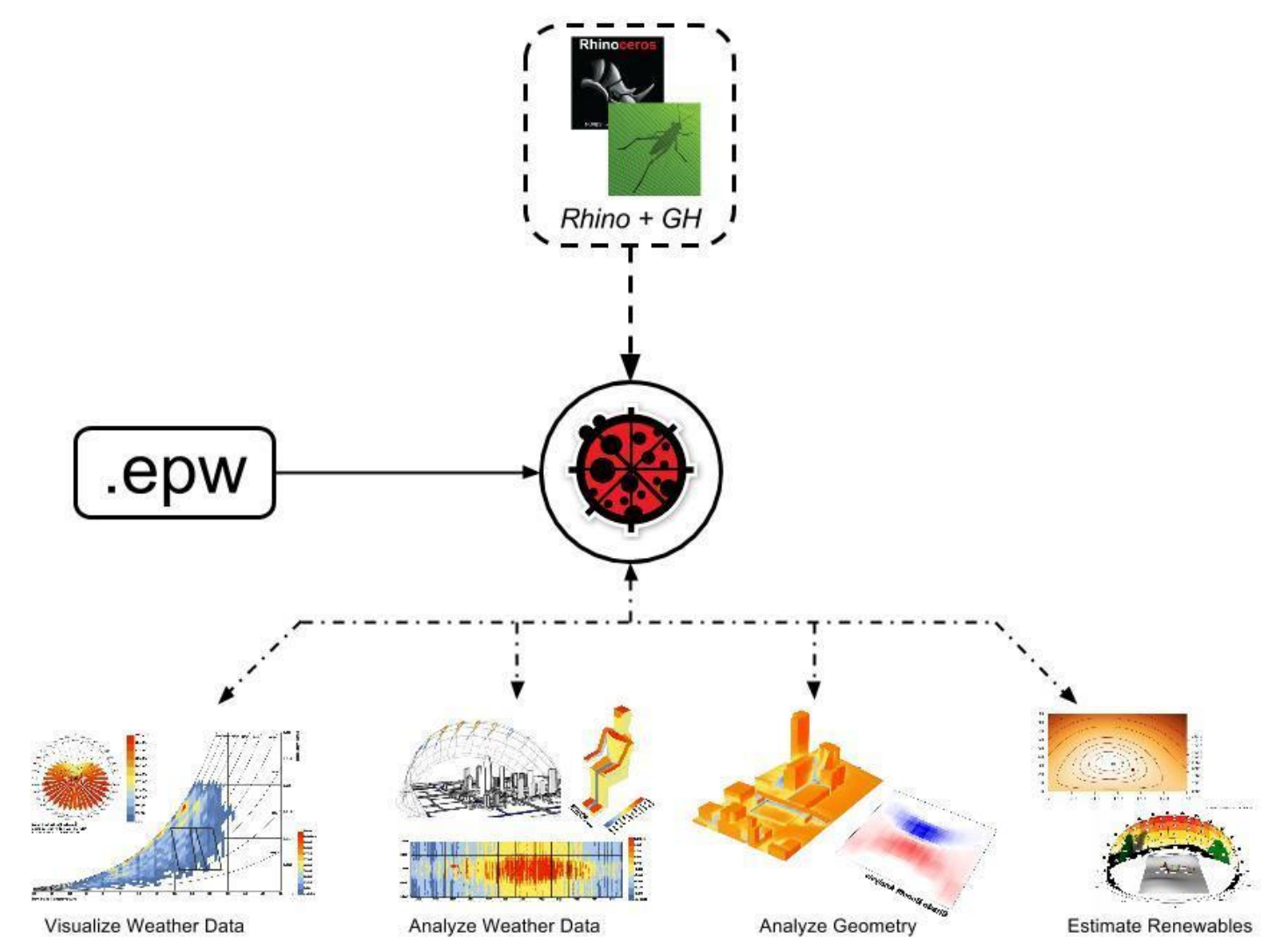

Figura 45: Diagrama de interação e potências do Ladybug. Fonte: Ladybug Tools (2018).

O Honeybee permite a realização de análises termodinâmicas e de iluminação através da integração com simuladores consolidados. Assim é capaz de criar, executar e visualizar análises da luz do dia utilizando o Radiance, modelos de energia do EnergyPlus e Openstudio, e fluxo de calor através do Berkeley Lab Therm e o Window. O Honeybee liga esses mecanismos de simulação à interface do Dynamo e Revitplug-ins, além do Rhinoceros e Grasshopper, utilizados no presente experimento. 


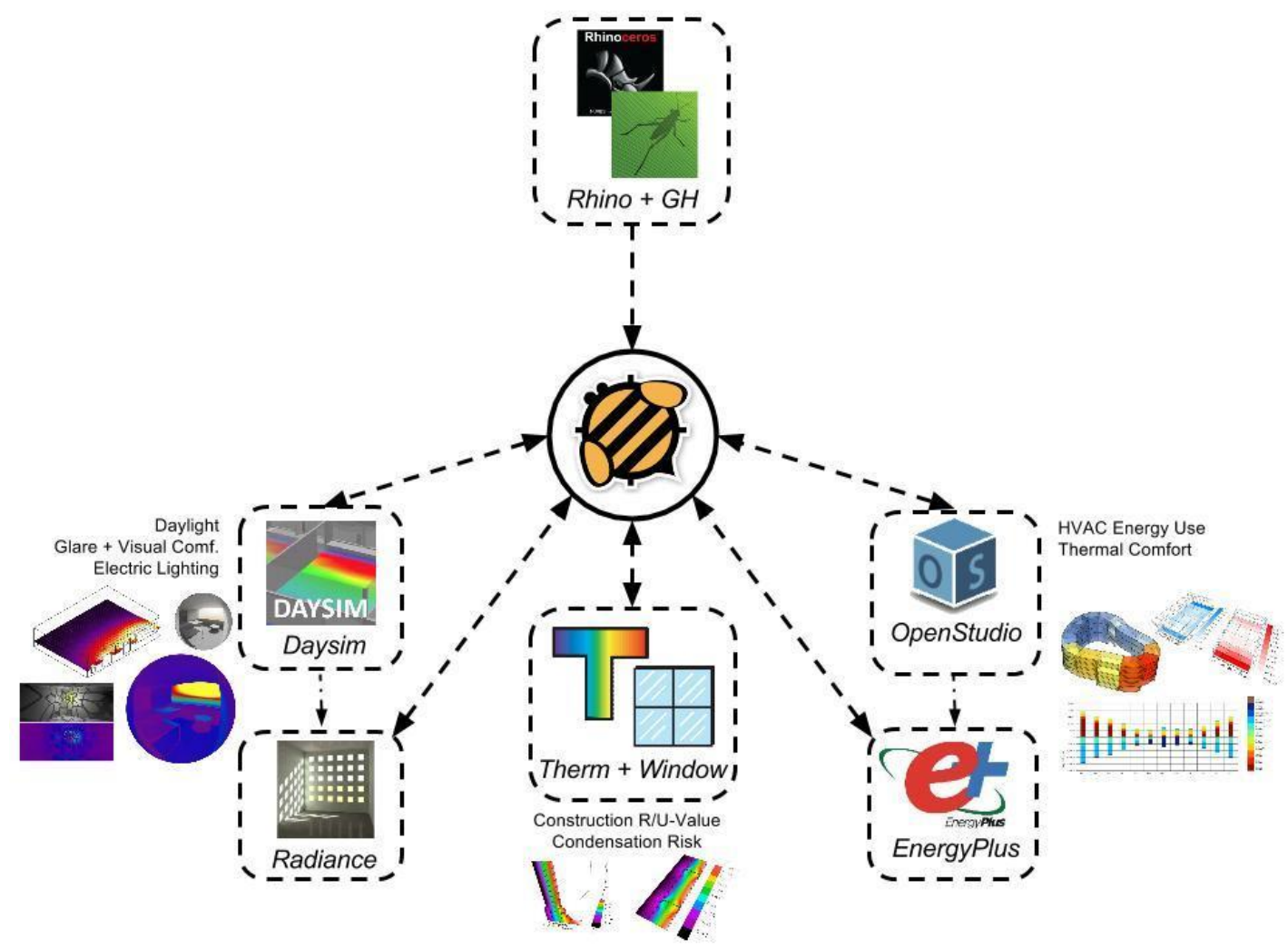

Figura 46: Diagrama de interação e potências do Honeybee. Fonte: Ladybug Tools (2018).

Entre os simuladores integrados pelo Ladybug e Honeybee, os utilizados no presente experimento comparecem a seguir.

\section{Análises}

EnergyPlus é um programa de simulação de energia capaz de avaliar consumo energético para aquecimento e resfriamento, ventilação, iluminação e cargas. Além disso, o programa é capaz de incorporar durante a simulação questões como cálculo de horas específicas, sendo que as etapas de tempo podem ser pré-definidas para análise de zonas térmicas do ambiente. O Energyplus é gratuito e de código aberto, financiado e desenvolvido pelo Building Technologies Office (BTO) do United States Department of Energy (DOE).

Open Studio reúne um conjunto de programas que suportam a modelagem de energia do edifício através do EnergyPlus e Radiance acrescendo a interface gráfica de visualização no seu funcionamento, que também pode ser inicializado por entradas em linguagens textuais, como 
C++, Ruby e C\#, é gratuito e de código aberto, também financiado e desenvolvido pelo Building Technologies Office (BTO) do United States Department of Energy (DOE).

Radiance, reúne um conjunto de programas de análise e visualização focado na iluminação, utilizado por profissionais da construção e pesquisadores para simulação de luminosidade e qualidade visual. Os cálculos realizados pelo programa incluem índices de brilho, luminância e cor, ou seja, radiância espectral e irradiância. Randiance foi desenvolvido por Greg Ward no Building Technologies Program na Environmental Energy Technologies Division do Lawrence Berkeley National Laboratory em Berkeley.

DAYSIM, é um programa de análise capaz de modelar a iluminação natural dentro de um período específico, medindo a quantidade de luz no interior e entorno dos edifícios operando baseado no Radiance. O desenvolvimento do programa foi coordenado por Christoph Reinhart e as implementações foram realizadas no Fraunhofer Institute for Solar Energy Systems (ISE), Harvard University, Massachusetts Institute of Technology (MIT) e no National Research Council (NRC) do Canada.

\section{Otimizador}

A otimização da busca no campo do espaço de design do projeto é realizada através do JMP, um programa de análise estatística e exame de dados com gráficos interativos, desenvolvido pela SAS Institute Inc.

\section{Visualização de dados}

T_Toolbolx, iniciado pelo estúdio Thornton Tomasetti e atualmente desenvolvido pelo CORE Studio, é um plug-in de Grasshopper que possui uma gama de ferramentas complementares. Entre elas, um escritor de Excel capaz de criar arquivos e um ouvinte de Excel, capaz de verificar atualizações em uma planilha automaticamente. Outra ferramenta disponível no plug-in e utilizada no processo estudado é o Colibri, capaz de transformar as definições no Grasshopper em conjuntos de dados compatíveis com o Design Explorer. 
Microsoft Excel, o aplicativo de criação de planilhas eletrônicas desenvolvido pela Microsoft e amplamente conhecido.

Design Explorer é uma ferramenta desenvolvida pelo CORE Studio, de código aberto para a exploração do espaço de busca. Funciona através de interface que permite visualizar e filtrar grupos de interações do conjunto de soluções dentro do espaço de busca. Os dados resultantes de métodos paramétricos de varredura são convertidos e lidos no formato data.csv. A partir do arquivo data.csv a ferramenta gera a visualização 2D do espaço de busca do projeto através da plotagem do Gráfico de Coordenadas Paralelas (Parallel Coordinates Plot).

\section{[?DesignExplorer Geroata}

1. Reset Selection Exclude Selection Zoom to Selection Save Selection to File My Static Link Tutorial Services Info $C$
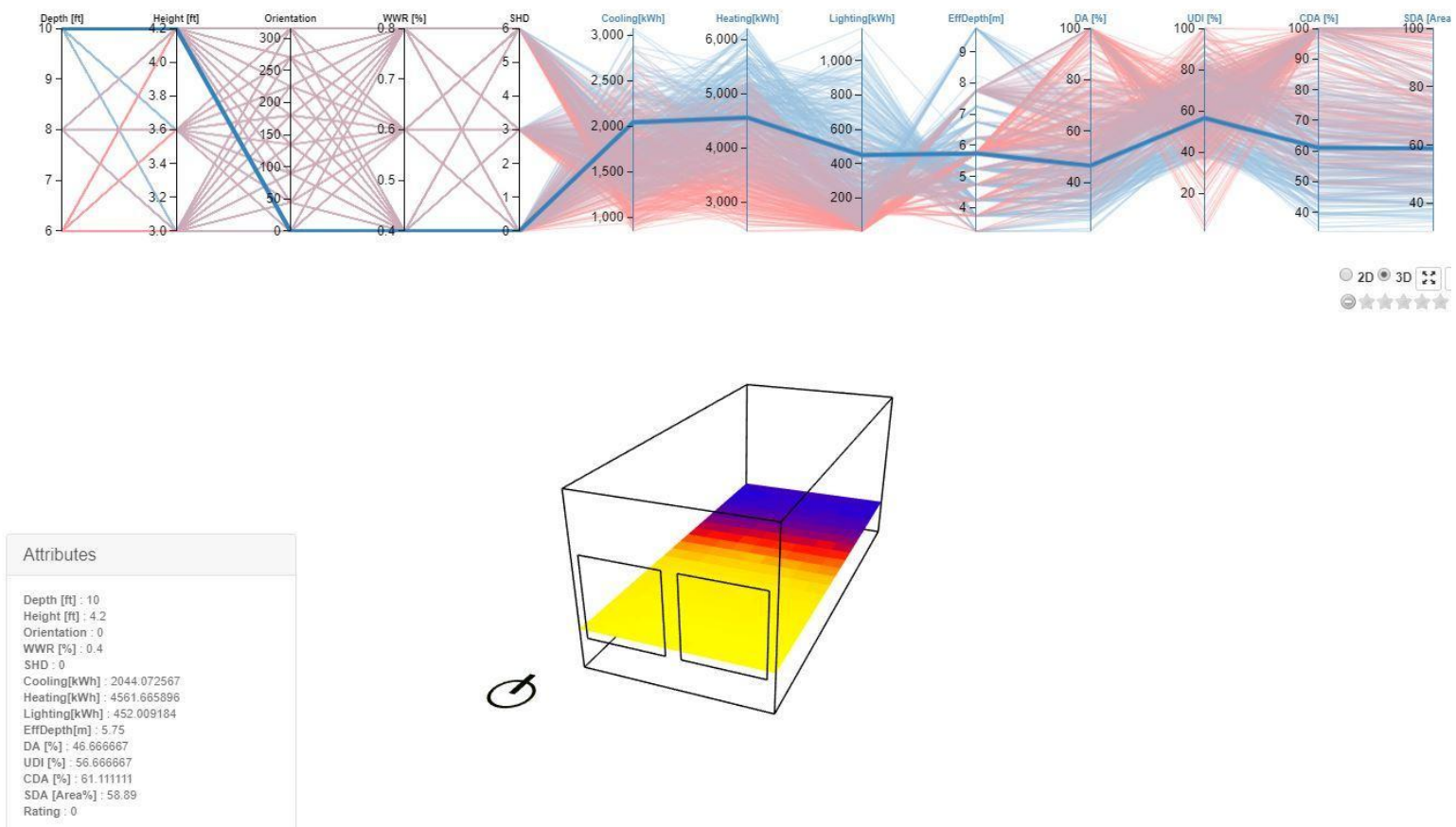

Figura 47. Interface do Design Explorer na plotagem dos resultados. Fonte: Design Explore (2018).

O gráfico representa a correlação entre as colunas de alternativas de projeto, os objetivos propostos e os índices de desempenho de cada alternativa de projeto, balizadas pela função objetivo da otimização. 
A partir dos recursos apresentados, o fluxo da implementação do DSC pode ser conceitualmente descrito em cinco etapas:

Ełapa 1. Início do fluxo da implementação, onde são definidos os objetivos e parâmetros de entradas de projeto, atrelados a geometria volumétrica do arquivo Rhinoceros $(.3 \mathrm{dm})$ e a modelagem algorítmica no Grasshopper. Nessa etapa, também são estabelecidas as zonas e os intervalos da análise energética.

Ełapa 2. O projeto computacional gera as alternativas de projeto através de modelos analíticos tridimensionais incluindo os painéis paramétricos que serão alocados na fachada do edifício. Os modelos analíticos são encaminhados para a etapa posterior.

Etapa 3. O espaço de design contendo as alternativas é construído através de um método randômico ou por uma análise de sensibilidade, realizada pelo programa JMP, nos parâmetros. Essa análise reduz os parâmetros do projeto, e consequentemente o espaço de design.

Ełapa 4. São realizadas as simulações para análises e validações das alternativas de projeto.

Etapa 5. Os resultados de desempenho das análises são computados na função objetivo que classifica as melhores alternativas de projeto.

\section{Implementação do estudo de caso}

A partir desse conjunto de programas, é composto o fluxo de trabalho do estudo de caso. No entanto, mesmo com todos os programas instalados e verificados, o código cedido pelo escritório, desenvolvido no Grasshopper, apresentou erros de operação. Na fase de implementação foram superados erros intermitentes do código que operava em algumas máquinas e não em outras. O motivo não foi declarado nas mensagens de erro do Grasshopper e o próprio programa não possui suporte a nenhum método automatizado de revisão e testes de códigos. Portanto, foi necessário recriar e avaliar o código por inteiro. Os erros encontrados possuem fontes diversas, entre eles um arquivo solicitado pelos plug-ins Ladybug e Honeybee ao programa 
EnergyPlus que não era encontrado. O código fonte dos plug-ins desenvolvido em Python foram atualizados manualmente para buscar outra versão do arquivo dentro da biblioteca do programa EnergyPlus, sanando esse problema.

Além disso, o código original do escritório correspondia à simulação e otimização apenas de um pavimento do edifício. Isso significa que no código cedido não era considerada a interferência da arquitetura de um pavimento no outro. Desse modo, o desempenho do edifício não poderia ser simulado e otimizado como um todo.

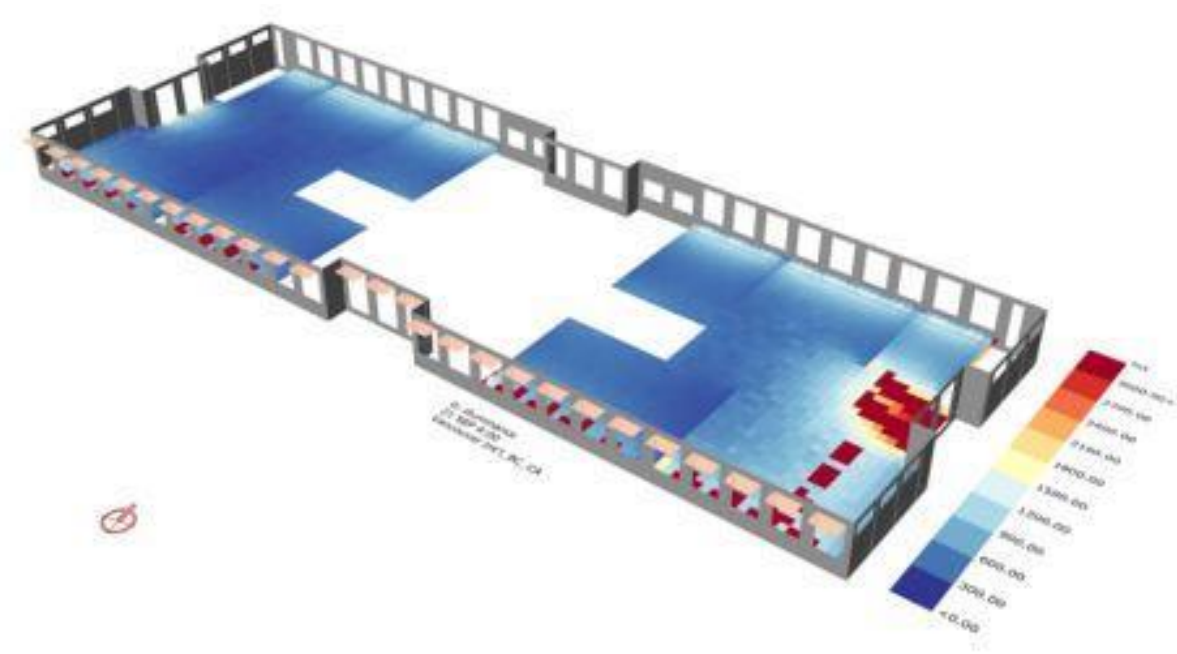

Figura 48: Processo DSC na avaliação de uma parte de um pavimento do edifício. Fonte: (HAYMAKER et al. 2018).

Para executar o estudo de caso do edifício integralmente, entendeuse ser necessário que o código fosse capaz de realizar as simulações de eficiência energética em aquecimento, resfriamento, ventilação e iluminação de todos os pavimentos simultaneamente. 


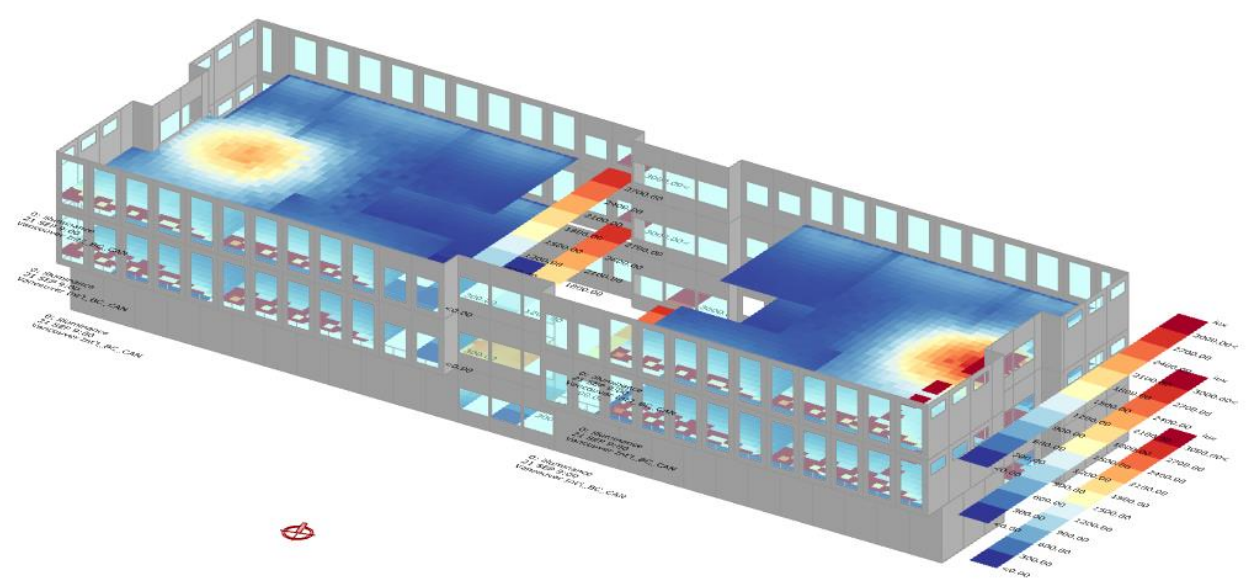

Figura 49: Processo DSC adaptado para realizar a avaliação de todos os pavimentos do edifício. Fonte: Autores.

Assim, foi realizada a reestruturação do código que passou por diversas alterações para que a complexidade da simulação e otimização de todos os pavimentos do edifício fosse abarcada, sem custos computacionais desnecessários por limitações da linguagem de programação visual Grasshopper.

\section{Parâmetros do processo de projeto}

A seguir serão descritos os parâmetros utilizados no código DSC do escritório Perkins+Will.

Painéis paramétricos, variação de 8 tipos de painéis que são distribuídos em 15 grupos de áreas da fachada do edifício chamada de PG ${ }^{21}$. A equipe do escritório Perkins+Will delimitou qual PG poderia receber algum dos 8 tipos de painéis, por exemplo, alguns dos grupos podem receber apenas 2 tipos de painéis disponíveis, e há partes da fachada que não recebem nenhum tipo de painel paramétrico, por se tratar de alguma outra especificação da decisão projetual.

21 "PG" abreviação do termo em inglês "Panel Group". 


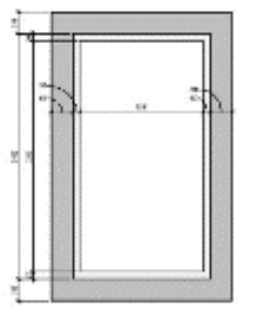

B GLAZED PANEL

Amea Opaque: $3.54 \mathrm{~m}^{2}$

Ares frame: $1.02 \mathrm{mz}$

Anes Glemet $5.44 \mathrm{~m} 2$

TH Glszing $9.8 \mathrm{~m}$

TR Install: $10.6 \mathrm{~m}$

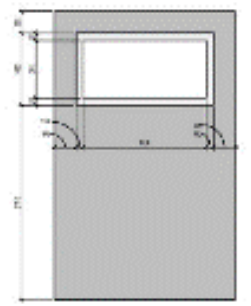

F CLERESTOREY

Ares Opaquen: $8.1 \mathrm{~m} 2$

Ara Frane: 0.54n2

Ares Gisend: $1.36 \mathrm{~m} 2$

TR Guzing $5.0 \mathrm{~m}$

TB installi $5.8 \mathrm{~m}$

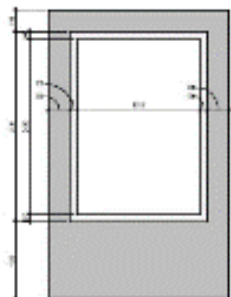

C BENCH

Area Opaques $5.003 \mathrm{~m} 2$

Ares Frame: $0.868 \mathrm{m2}$

Ansa Glems: $4.131 \mathrm{ma}$

TB Glaing $8.260 \mathrm{~m}$

TR Irstell: $9.06 \mathrm{~m}$

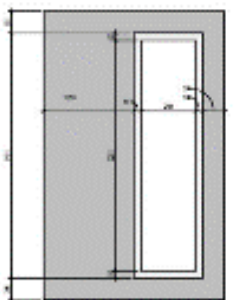

G HALF VERTICAL

Âres 0psque $6.77 \mathrm{~m} 2$

Area Frame: $0.83 \mathrm{~m} 2$

Ares Gisont $2.40 \mathrm{~m} 2$

TB Glaving: $7.9 \mathrm{~m}$

Th Iratsili $8.7 \mathrm{~m}$

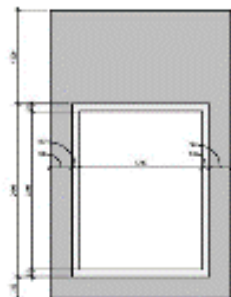

D CROPPED CELING

Area $C_{p} 2 q u=5.44 \mathrm{~m} 2$

Ares Frame: $0.82 \mathrm{~m} 2$

Anes Glemet: $3.74 \mathrm{~m} 2$

TB Glxoing $7.8 \mathrm{~m}$

TB Inatall: $8.6 \mathrm{~m}$

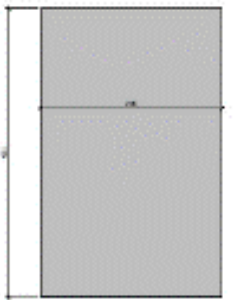

H FULLY SOLID

Àres Opsques $10 \mathrm{~m} 2$

Area Frame: -172

Àmen Glooxd: - -m2

TB Glaxing: - m

TB Instally -m

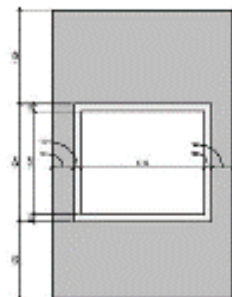

E BENCH -

OROPPED CEILING

Anes Opreque $6.903 \mathrm{~m} 2$

Area Frams: $0.566 \mathrm{~m} 2$

Ares Glaxpedi 2,131m?

TB Glasng: $6.250 \mathrm{~m}$

TB instal: $7.06 \mathrm{~m}$

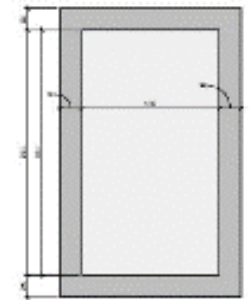

I SERVICENEECHANICA

Aven Opraque: 3.54m?

Aves 'Frand' = $6.46 \mathrm{m2}$

TB Instal: $10.6 \mathrm{~m}$

Figura 50: Tipos de painéis disponíveis a serem alocados nos grupos da fachada. Fonte: Perkins+Will. 

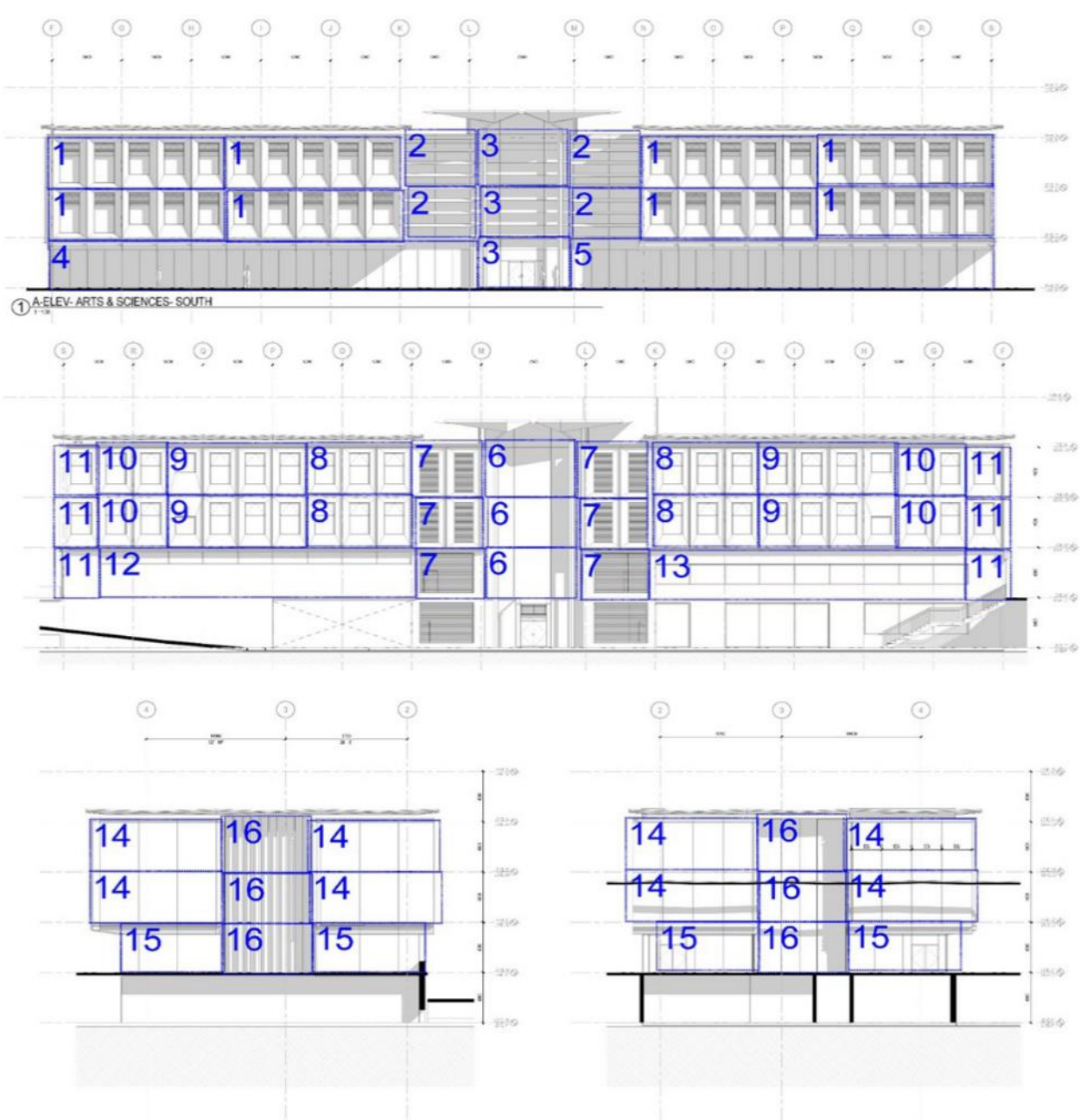

Figura 46: Grupos da fachada do edifício Vancouver Academic Building, os números são um exemplo da alocação dos diferentes tipos de painéis. Fonte: Perkins+Will. 


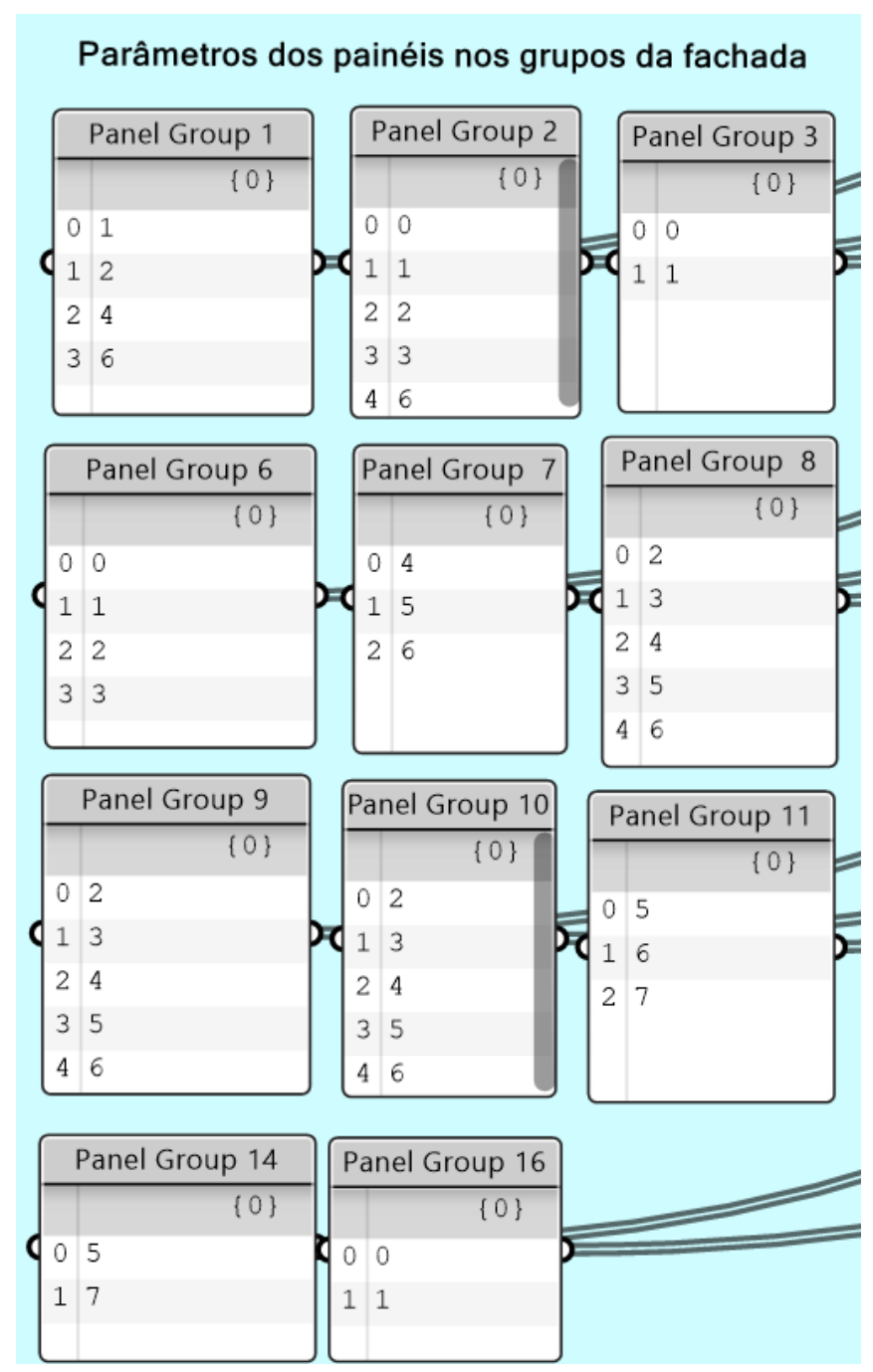

Figura 47: Parte do código no Grasshopper que declara os parâmetros dos tipos de painéis permitidos em cada grupo de fachada, definido pela equipe do escritório Perkins+Will. Fonte: Autores.

Além dos tipos de painéis nos grupos das fachadas, outros parâmetros aplicados no processo de projeto DSC, e diretamente relacionados à eficiência energética são:

$\boldsymbol{R}$-Value, representa a resistência térmica de um material isolante, ou seja, sua habilidade de condução da energia térmica. Assim, quanto maior o valor $R$, maior a eficácia do material isolante, que varia de acordo com a sua espessura e densidade do material, e em alguns casos depende também da sua temperatura, envelhecimento e acúmulo de umidade.

A equipe do escritório Perkins+Will definiu a representação dos parâmetros de $R$-Value permitidos para o projeto com os números 5,6 , e 7 , 
que correspondem a uma representação simplificada da tolerância da resistência térmica do material medida em watts por metro quadrado kelvin.

U-Value, representa a transferência térmica de um material isolante, ou seja, sua habilidade de transferência de calor. Assim, quanto menor o valor de $U$, maior a eficácia do material isolante, que varia de acordo com a sua capacidade de transferir energia térmica da massa quente para uma massa mais fria, configurando a troca de energia calórica entre dois sistemas de temperatura.

A equipe do escritório Perkins+Will definiu a representação dos parâmetros de U-Value permitidos o projeto com os números $0.65,0.7,0.8$, que correspondem a uma representação simplificada da tolerância da resistência térmica do material medida em watts por metro quadrado por kelvin.

SHGC, representa a fração de radiação solar incidente transmitida, absorvida e liberada para dentro o ambiente através de uma janela. Assim, quanto menor for o coeficiente SHGC menor será o calor solar transmitido.

A equipe do escritório Perkins+Will definiu os parâmetros permitidos no projeto com os números 0.3, 0.4, 0.5, que correspondem à tolerância de SHGC expressa entre o domínio de 0 e 1.

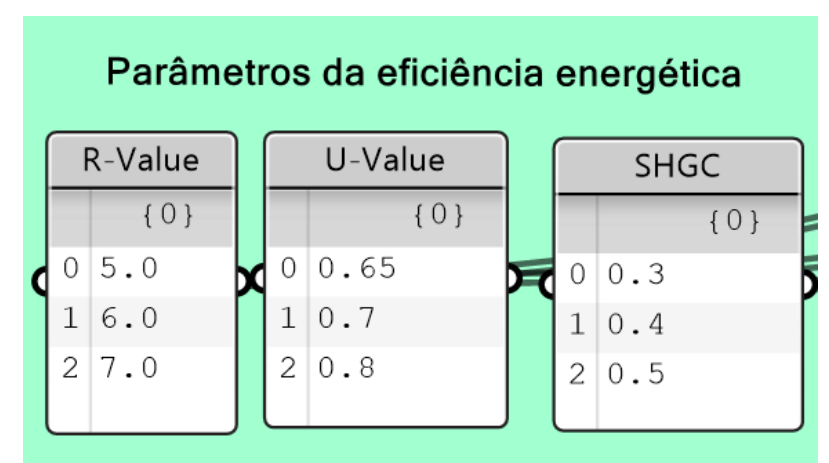

Figura 48: Parte do código no Grasshopper que declara os parâmetros de eficiência energética permitidos pela equipe do escritório Perkins+Will. Fonte: Autores.

Shading, elemento de brise que serve como anteparo para a incidência da luz solar, posicionados na verga superior dos painéis da fachada do projeto. A equipe do escritório Perkins+Will definiu os parâmetros 
de largura em metros permitidas nos brises do projeto com os números $0,0.5$, 1 para fachada sul, 0.05, 0.5, para fachada norte e $0,0.5,1$ para as fachadas leste e oeste.

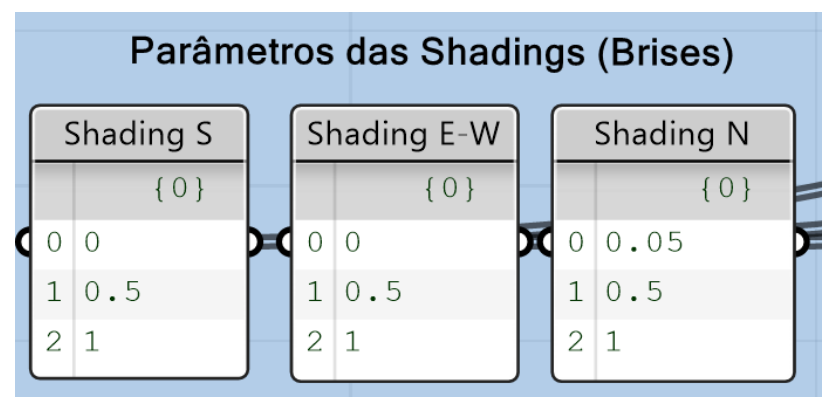

Figura 49: Parte do código no Grasshopper que declara os parâmetros das shadigns (brises) definidos pela equipe do escritório Perkins+Will. Fonte: Autores.

Os parâmetros são introduzidos em uma parte do código que gera uma tabela de input formato Excel (.xlsx). A tabela de inputs tem seus dados lidos e estruturados com o Colibri após chamada no Grasshopper.

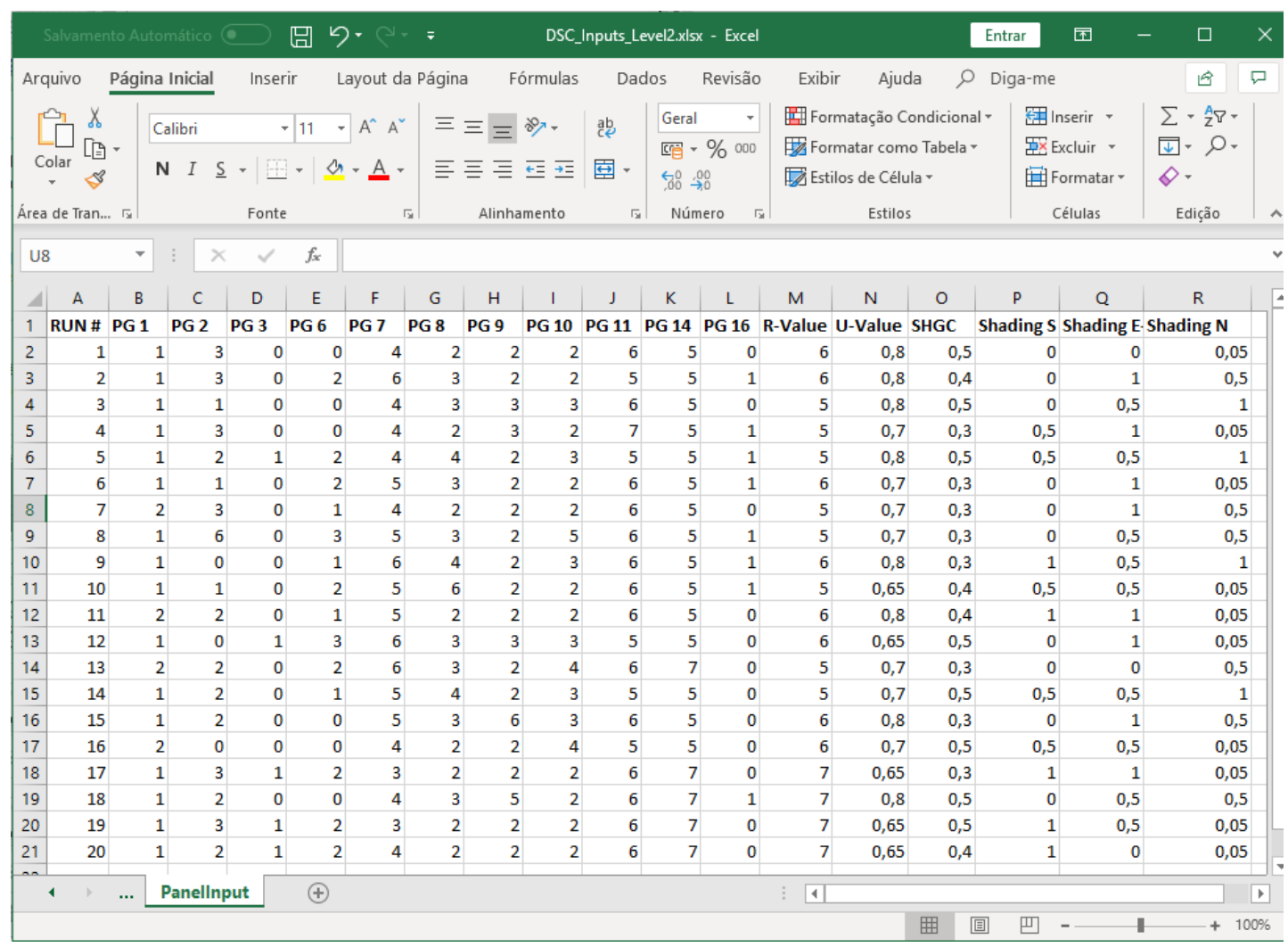

Figura 50: Imagem da tabela de Input dos parâmetros de projeto. Cada linha representa os parâmetros de uma alternativa de projeto, ou seja, de um indivíduo no espaço de design explorado no processo de projeto. Fonte: Autores.

Assim, a partir dos parâmetros estabelecidos são geradas as possíveis soluções, ou alternativas de projeto, que irão compor a tabela de input. 
Para compor a tabela de input, são aplicados dois métodos, o primeiro é um método randômico, definido no código do Grasshopper, que randomicamente adota algum dos valores dentro dos parâmetros estabelecidos. O segundo, é realizado a partir de uma análise de sensibilidade, realizada pelo programa JMP, um programa proprietário de código fechado. O escritório não descreve em nenhum artigo ou material disponibilizado como essa análise é realizada. Teoricamente a análise de sensibilidade é empregada com a finalidade de determinar o efeito de uma variação de determinado item no seu valor total, assim é um recurso para determinar a importância de uma variável sobre o resultado final de uma avaliação. Assim, a partir do JMP o escritório reduz o espaço de design do projeto, diminuindo os parâmetros disponíveis no projeto, retirando os que seriam menos relevantes ao desempenho do projeto. Hipoteticamente essa é a parte da otimização do espaço de busca realizada pelo escritório. 


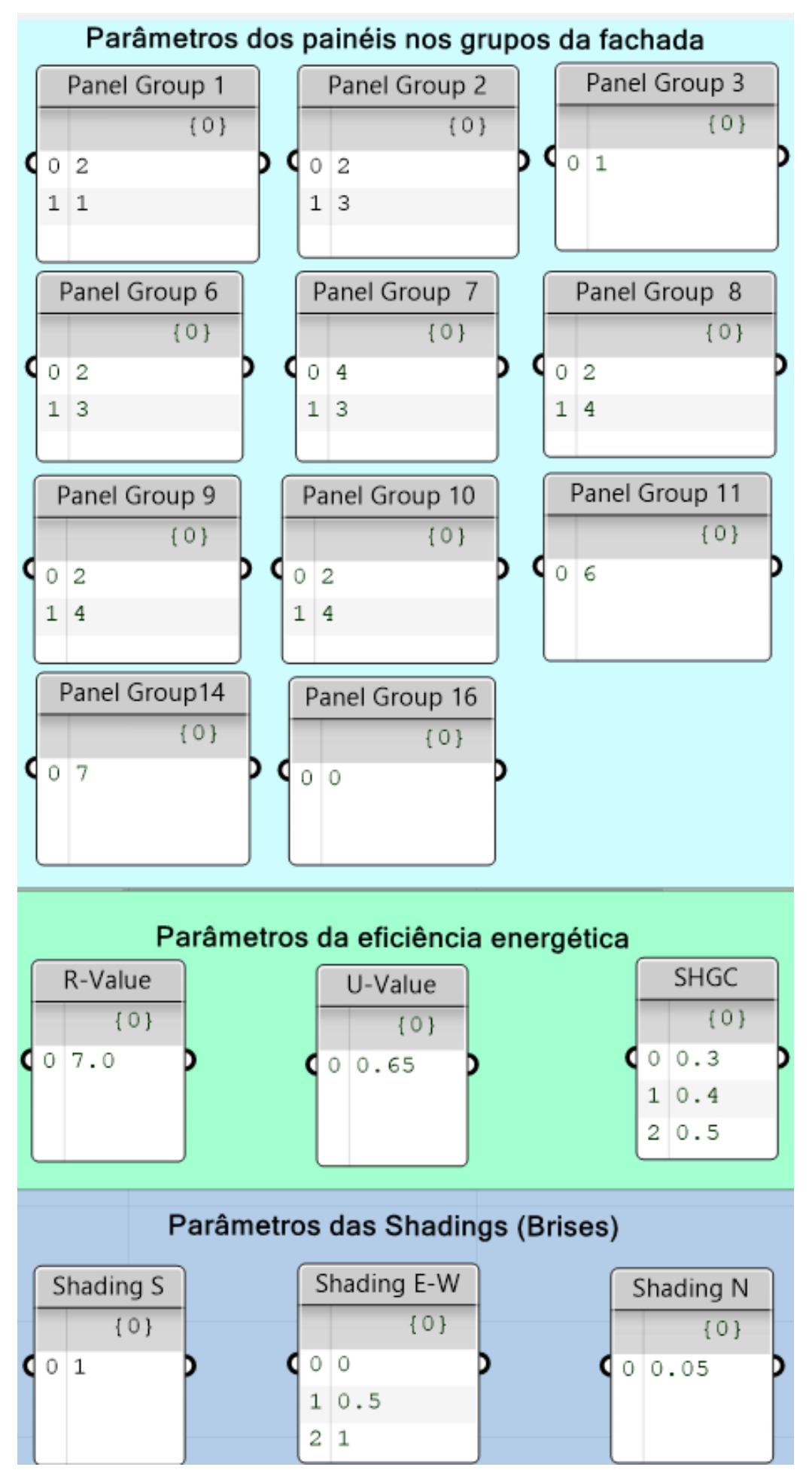

Figura 51: Parte do código no Grasshopper que declara os parâmetros dos tipos de painéis, eficiência energética e shadings (brises) permitidos em cada grupo de fachada, definido pela equipe do escritório Perkins+Will após a análise realizada com o programa JMP e redução do espaço de design. Fonte: Autores.

Após a modelagem das possíveis soluções, ou alternativas de projeto, a partir dos parâmetros estabelecidos, são realizadas as análises de desempenho através dos simuladores de eficiência energética, que se 
comunicam com o código do Grasshopper através de chamadas nos plugins Ladybug e Honneybee.

Os resultados das simulações são escritos em uma tabela de output no formato .CSV, e três dos resultados são fundamentais na continuidade do fluxo do processo DSC. Nos arquivos cedidos pelo escritório, não havia função de fitness implementada no fluxo do processo. Contudo, havia um material de apresentação que descrevia a função de fitness empregada, assim, ela foi implementada na tabela de Excel, que após todas as operações descritas avalia o desempenho de cada indivíduo gerado pelo método do escritório. A função de fitness será detalhadamente descrita na seção "Algoritmo Genético Proposto".

\subsection{PROJETO DE PLATAFORMA E FERRAMENTAS}

Parte do trabalho produzido nessa fase e na seguinte foi realizada durante estágio de pesquisa no Exterior (BEPE-FAPESP) em um período de quatro meses, sob a supervisão do Professor Dr. António Leitão, do Instituto Superior Técnico da Universidade de Lisboa, Portugal (IST-LISBOA) e coordenador do grupo ADA (Algorithmic Design for Architecture).

O plug-in chamado de ArchOptimum, representa uma continuação do plug-in desenvolvido no experimento anterior da presente pesquisa (LANDIM et al., 2017). O ArchOptimum foi desenvolvido em C\# e se comunica com a aplicação externa desenvolvida em $\mathrm{C}^{++}$através da troca de informações via arquivo, que avalia os valores obtidos nas simulações de eficiência energética e atribui um valor de desempenho para cada solução de projeto analisada. Assim, o fluxo de trabalho tem início através de adaptações no algoritmo da Perkins+Will implementado no Grasshopper, que gera o modelo do projeto com os parâmetros e restrições descritas nos painéis de input do ArchOptimum, responsável pela otimização do projeto.

Nessa etapa foram testadas adaptações para a implementação do protótipo, análises que avaliaram a estabilidade da comunicação do plug-in 
com o Grasshopper e o desempenho da otimização proposta, que após os testes e ajustes necessários definiu o método empregado no ArchOptimum.

\subsection{ALGORITMO GENÉTICO PROPOSTO}

O desenvolvimento do ArchOptimum, representa o aperfeiçoamento de sua fase de protótipo para de artefato. O ArchOptimum emprega um algoritmo genético (AG), no processo de otimização das alternativas de projeto.

AG gera uma população de indivíduos a partir dos parâmetros de entrada fornecidos, os mesmos estabelecidos pelo escritório Perkins+Will. As soluções são codificadas como vetores $n$ dimensionais $v=$ $(v 1, v 2, \ldots, v i, \ldots, v n)$, onde cada entrada corresponde a $v_{i} \in[\min , \max ]$. Os parâmetros min e max representam o intervalo de variação ponderada do resultado obtidos nas simulações. Assim, cada vetor $v$ representa um indivíduo no AG e a população inicial de indivíduos é gerada assumindo uma distribuição uniforme na determinação das entradas $v_{i}$.

A avaliação dos indivíduos utiliza a mesma função fitness proposta pelo escritório, para efeito de comparação do desempenho dos dois métodos. Assim, a função fitness mensura três resultados de desempenho, são eles:

III Within, resultado das simulações das distribuições anuais de iluminação diurna dentro dos ambientes do projeto.

Cooling, resultado das simulações de resfriamento dos ambientes do projeto.

Heating, resultado das simulações de esfriamento dos ambientes do projeto.

Apesar das simulações gerarem muitos outros resultados de eficiência energética, esses são os três valores que compõem a função objetivo definida pelo escritório Perkins+Will no seu processo de otimização. 
Contudo, os três resultados de desempenho dos indivíduos são normalizados, pois são valores de natureza e grandeza distintas, assim, a normalização e função fitness aplicada foi:

$x=$ resultado atual.

$n=$ resultado normalizado de 0 a 1 , em que 0 é o menor e 1 o mais alto.

$i=$ invertido (O baixo consumo de energia é o alvo, buscando evitar números altos).

$\min =$ resultado mínimo dentro da amostra.

max $=$ resultado máximo dentro da amostra

$w=$ fator de ponderação de acordo com as preferências da equipe de projeto (onde $w 1=30, w 2=50, w 3=20$ )

$v=$ valor

$n=(x-\min ) \quad /(\max -\min )$

$i=1-n$

$v=w 1 * n i$ Cooling $+w 2 * n i$ Heating $+w 3 * n$ Ill Within

Durante a etapa de reprodução, uma recombinação das informações codificadas em dois indivíduos $v 1$ e $v 2$ (parent1 e parent2, que equivalem aos pais) gera uma nova solução $v$ (child). O operador blend alpha crossover $(B L X-\alpha)$ foi aplicado, onde duas versões foram implementadas como se segue:

$B L X-\alpha 1: v_{i}=\alpha v_{i}^{1}+(1-\alpha) v_{i}^{2}$ onde $\alpha \in[0,1]$

$B L X-\alpha 2: v_{i}=\alpha_{1} v_{i}^{1}+(1-\alpha) v_{i}^{2}$ onde $\alpha_{i} \in[0,1]$

No crossover $B L X-\alpha 1$, o parâmetro a, aleatoriamente selecionado no intervalo $[0,1]$, é o mesmo aplicado a todas as entradas das soluções $v^{1}$ e $v^{2}$ 
durante $\circ$ processo de recombinação. No $B L X-\alpha 2$, um valor $\alpha i$ diferente pode ser aplicado na recombinação que gera cada entrada $v_{i}$.

Durante a fase de mutação, alterações em cada entrada vi podem ocorrer, caso a taxa de mutação $\lambda$ seja satisfeita. Isso significa que, para cada entrada $v_{i}$ da nova solução, um número aleatório $\beta \in[0,1]$ é gerado e, se $\beta<\lambda$, um novo valor $v_{i} \in[\min , \max ]$ é definido. Uma vez criada a nova solução a partir do crossover e mutação, um valor de fitness é atribuído, esse valor é atualizado a cada verificação de $v_{i} \in[\min , \max ]$ nos valores de III Within, Cooling e Heating.

Se a nova solução $v$ apresentar valor de fitness melhor que $v^{1}$ ou $v^{2}$, ela assume o lugar daquele com pior valor de fitness.

Após os testes realizados na fase anterior do experimento, foi implementado um gatilho de genocídio, pelo qual um número é determinado pelo usuário e representa o limite da quantidade de gerações sem melhora no valor do fitness. Caso esse limite seja atingido, o melhor indivíduo é preservado, todo o restante da população é eliminado e uma nova população é iniciada. Isso evita que a população fique estagnada em um mínimo local por várias gerações. Nos parâmetros do ArchOptimum também foi implementado um contador para o limite de tempo da execução dado em segundos e um indicador do tamanho da população inicial. 


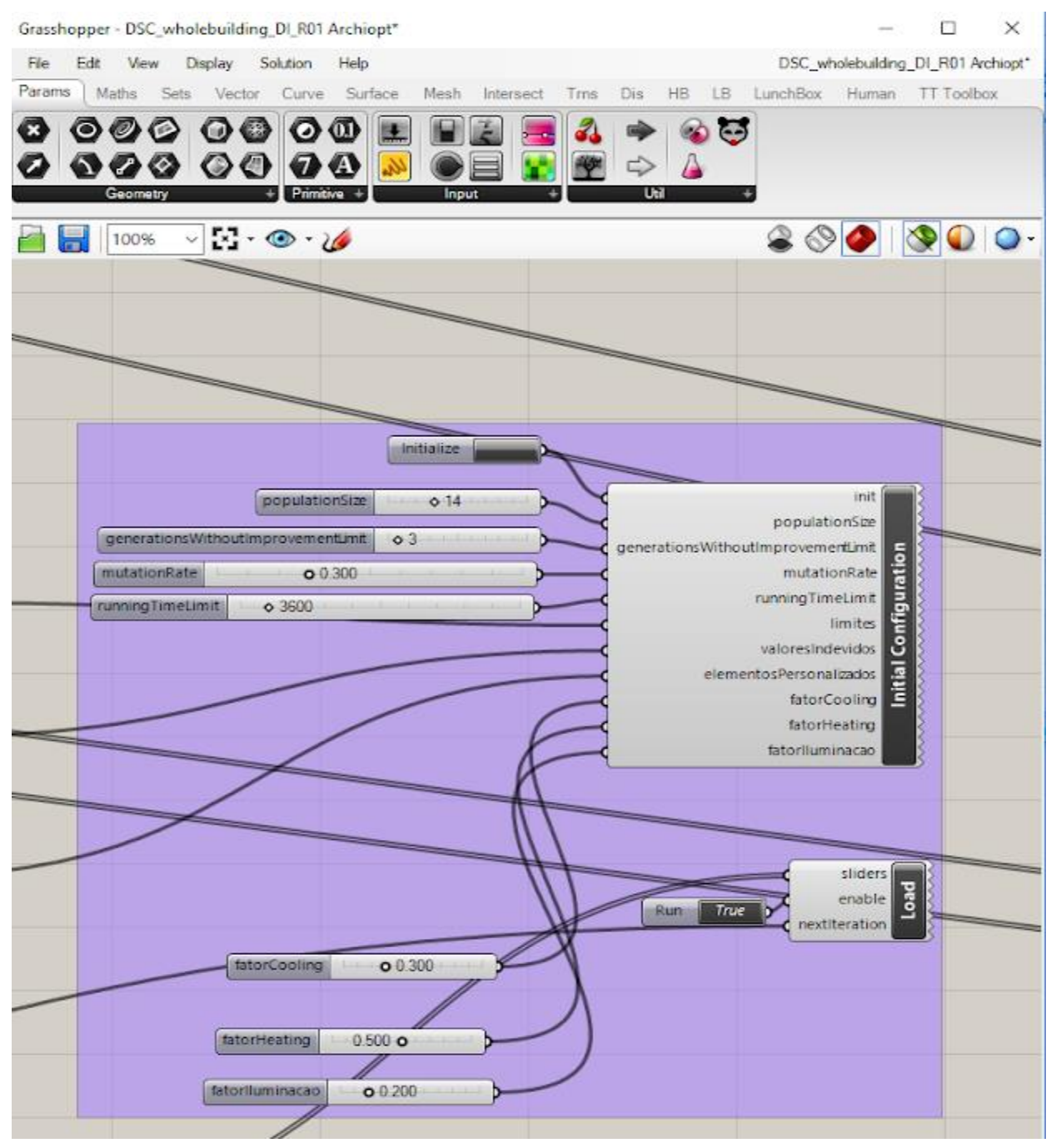

Figura 52: Imagem do ArchOptimum com seus parâmetros de funcionamento. Fonte: Autores.

Também foram implementados os controladores para taxa de mutação, tamanho da população inicial e a ponderação de III Within, Cooling e Heating, assim os parâmetros podem ser ajustados pelo usuário na interface do plug-in.

\subsection{COMPARAÇÃO ENTRE OS MÉTODOS}

Os dois métodos descritos compuseram o experimento comparativo entre o método de otimização originalmente implementado pelo escritório de arquitetura Perkins+Will e o do artefato "ArchOptimum." Foi verificado qual dos dois métodos apresenta o melhor resultado de função fitness. Não foram considerados índices qualitativos ou quantitativos de certificações de 
eficiência energética na comparação dos resultados, apenas a comparação direta do desempenho entre os métodos experimentados.

O AG proposto foi executado 8 vezes em um computador com processador i7-7700HQ, 2.8GHz, 4 núcleos físicos e 8 núcleos lógicos, 16GB de RAM, com sistema operacional Windows 10 de 64 bits, versão do kernel 10.0.14393. Os programas Rhinoceros 6 Version 6 (6.1.18023.13161, 01/23/2018) e Grasshopper versão 1.0 também foram utilizados. O código C++ foi desenvolvido no Visual Studio 2015 Enterprise, atualização 3, compilador Visual $\mathrm{C}++14.0,64$ bits.

Os parâmetros definidos para as execuções do ArchOptimum, nos respectivos campos, foram:

populationSize, tamanho da população inicial, definida em 6 indivíduos.

generationsWithoutlmprovementLimit, gatilho do genocídio da população em caso de estagnação, definido em 3 gerações.

mutationRate, taxa de mutação empregada, definida em 0,3.

runningTimeLimit, limite do tempo máximo de cada execução, definida em 3 horas de execução.

O espaço de design explorado pelo método é composto por todos os parâmetros estabelecidos nos painéis paramétricos, R-Valve, U-Value, SHGC, shading, sem a redução dos parâmetros executada pelo escritório com o programa JMP. Os valores ponderados dos componentes do cálculo da função de fitness preservaram a especificação do estudo de caso:

fatorCooling, definido em 0,3.

fatorHeating, definido em 0,5.

fatorllluminacao, definido em 0,2.

O método do Perkins+Will foi executado 2 vezes, com as mesmas 64 alternativas já determinadas após a redução do espaço de design. Foi utilizada a mesma configuração de software e hardware. O tempo médio 
para cada simulação analisada foi de 7 minutos, e o tempo médio de execução de todas 64 avaliações totalizou 7 h50 minutos.

Assim, o método do escritório Perkins+Will teve duas vantagens a seu favor, o espaço de busca já reduzido por sua estratégia de otimização e mais que o dobro de tempo para sua execução.

Durante a execução do experimento foi identificado um ruído nos resultados das análises produzidas pelos simuladores que poderia interferir nos resultados. Foram realizados diversos testes e pesquisas em fóruns e manuais dos desenvolvedores dos simuladores utilizados, todos os programas envolvidos no processo foram reinstalados e executados em diferentes computadores. O erro se tratava de uma intermitência nos simuladores que não poderia ser facilmente identificado. Em algumas simulações, o mesmo modelo apresentava valores diferentes nos resultados, alterando o valor de fitness do indivíduo avaliado. Contudo, a alteração só acontecia quando o programa de simulação era acionado novamente no terminal do Grasshopper, após todas as execuções predefinidas já terem sido executadas, ou seja, os simuladores apresentavam estabilidade de funcionamento a cada execução.

Além disso, os valores dos fitness não poderiam ser comparados entre execuções diferentes uma vez que na função de fitness estabelecida pelo escritório os valores máximos e mínimos aplicados na normalização dos resultados eram atualizados pelos valores obtidos em cada uma das execuções.

Assim, para contornar tal situação e validar os valores de desempenho dos métodos, foi modelada a estratégia na qual o ArchOptimum foi rodado inicialmente 8 vezes, e em cada execução foi gerada e avaliada uma média de 25 indivíduos. Os indivíduos foram salvos, e os 3 melhores indivíduos de cada uma das 7 primeiras execuções e 4 indivíduos da última execução foram agrupados, totalizando um grupo com os 25 melhores indivíduos de todas as execuções do ArchOptimum. Esse grupo foi inserido na tabela que 
já continha todos os indivíduos gerados pelo método da Perkins+Will. Em sequência, todos os indivíduos foram avaliados numa mesma execução dos simuladores, contornando a variação de valores do ruído ao reiniciar a execução da simulação. Os valores máximos e mínimos utilizados no cálculo de fitness considerou os valores de todos os indivíduos da tabela.

Assim, o resultado obtido no experimento de comparação entre os métodos demonstrou que entre as 30 melhores soluções de projeto, as 21 melhores foram produzidas através do método do ArchOptimum. O resultado confirmou o desempenho favorável do plug-in ArchOptimum em comparação ao método desenvolvido pelo escritório: 


\begin{tabular}{|c|c|c|c|}
\hline Indiv & Fitness & \multirow{2}{*}{\multicolumn{2}{|c|}{ Maior fitness ArchOptimum: $\quad 0,71042393$}} \\
\hline 1 & 0,71042393 & & \\
\hline 2 & 0,687830655 & \multirow[t]{4}{*}{ Maior fitness Perkins+Will: } & \multirow[t]{4}{*}{0,463817006} \\
\hline 3 & 0,635317417 & & \\
\hline 4 & 0,63194942 & & \\
\hline 5 & 0,617228123 & & \\
\hline 6 & 0,616548542 & \multirow[t]{2}{*}{ Os valores máximos e mínimos } & no cálculo do fitness foram: \\
\hline 7 & 0,614352944 & & \\
\hline 8 & 0,613735921 & \multirow[t]{4}{*}{ max cooling:16,092628 } & \multirow[t]{2}{*}{ min cooling: 12,291498} \\
\hline 9 & 0,603772484 & & \\
\hline 10 & 0,602215447 & & min heatina: 15.429598 \\
\hline 11 & 0,590470948 & & \\
\hline 12 & 0,588957856 & \multirow[t]{19}{*}{ max ILL:37,432328 } & \multirow[t]{19}{*}{$\min$ ILL: 26,074467} \\
\hline 13 & 0,573913386 & & \\
\hline 14 & 0,551725748 & & \\
\hline 15 & 0,542376698 & & \\
\hline 16 & 0,52897754 & & \\
\hline 17 & 0,528325989 & & \\
\hline 18 & 0,513514592 & & \\
\hline 19 & 0,492946232 & & \\
\hline 20 & 0,48449132 & & \\
\hline 21 & 0,477783033 & & \\
\hline 22 & 0,463817006 & & \\
\hline 23 & 0,460735865 & & \\
\hline 24 & 0,451107423 & & \\
\hline 25 & 0,438774803 & & \\
\hline 26 & 0,423307369 & & \\
\hline 27 & 0,422712283 & & \\
\hline 28 & 0,413764587 & & \\
\hline 29 & 0,412177513 & & \\
\hline 30 & 0,407466289 & & \\
\hline
\end{tabular}

Figura 53: Ranque dos 30 melhores indivíduos, com grifo em azul os indivíduos gerados com o ArchOptimum. Fonte: Autores. 


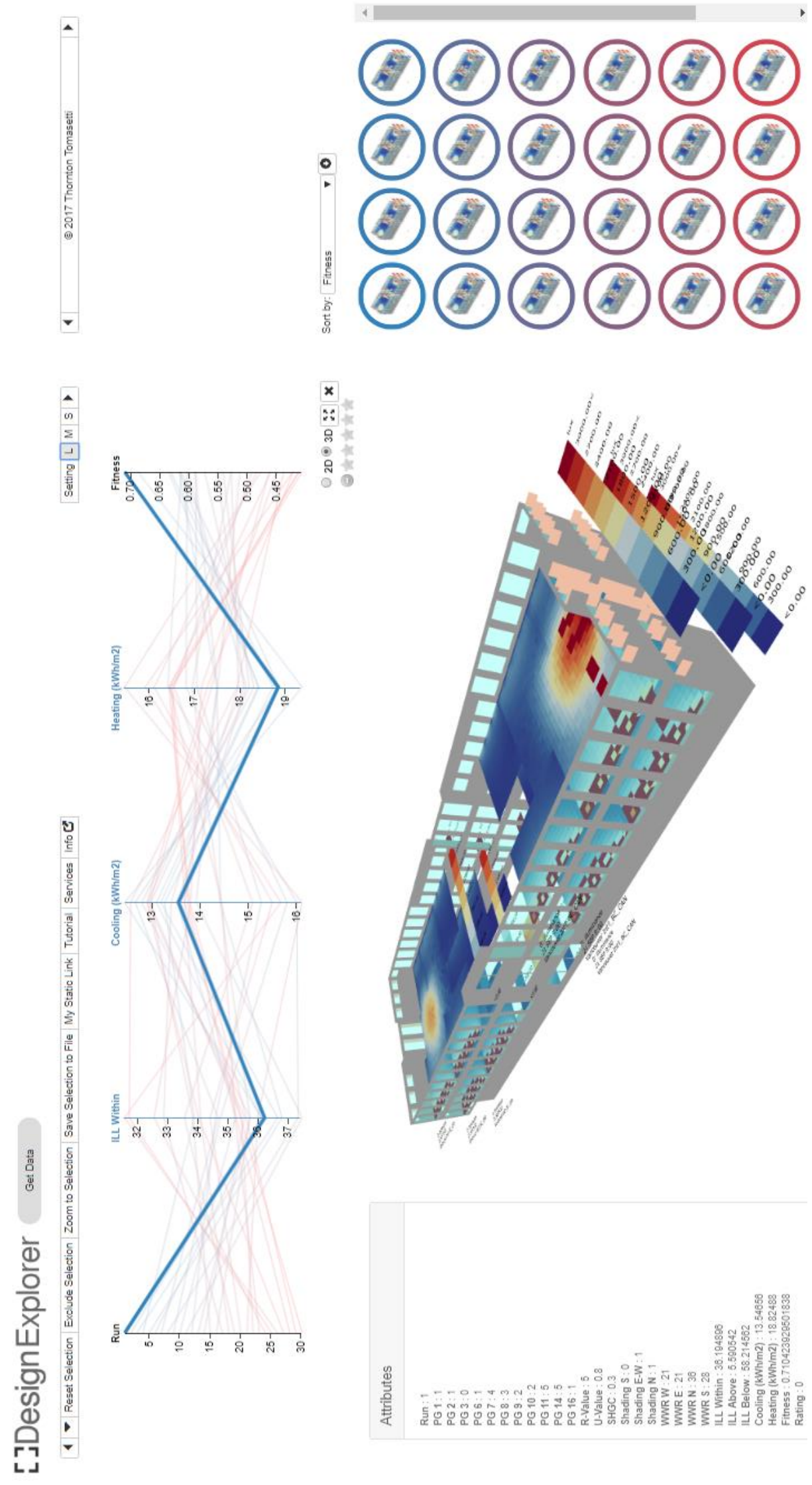

Figura 51: Melhor indivíduo obtido através do ArchOptimum. Fachada Sul. Fonte: Autores. 


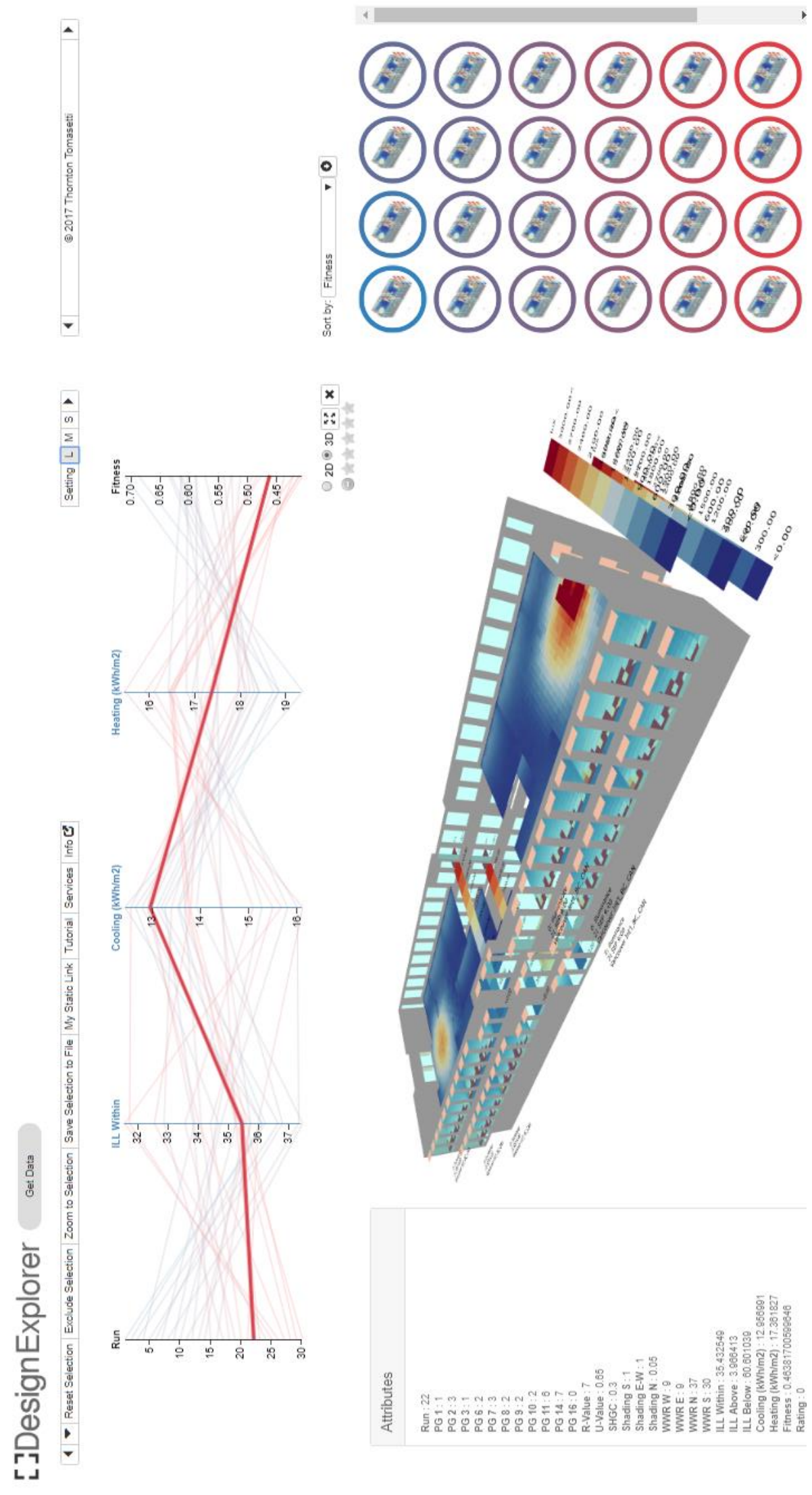

Figura 52: Melhor indivíduo obtida através do método do escritório Perkins+Will. Fachada Sul. Fonte: Autores. 


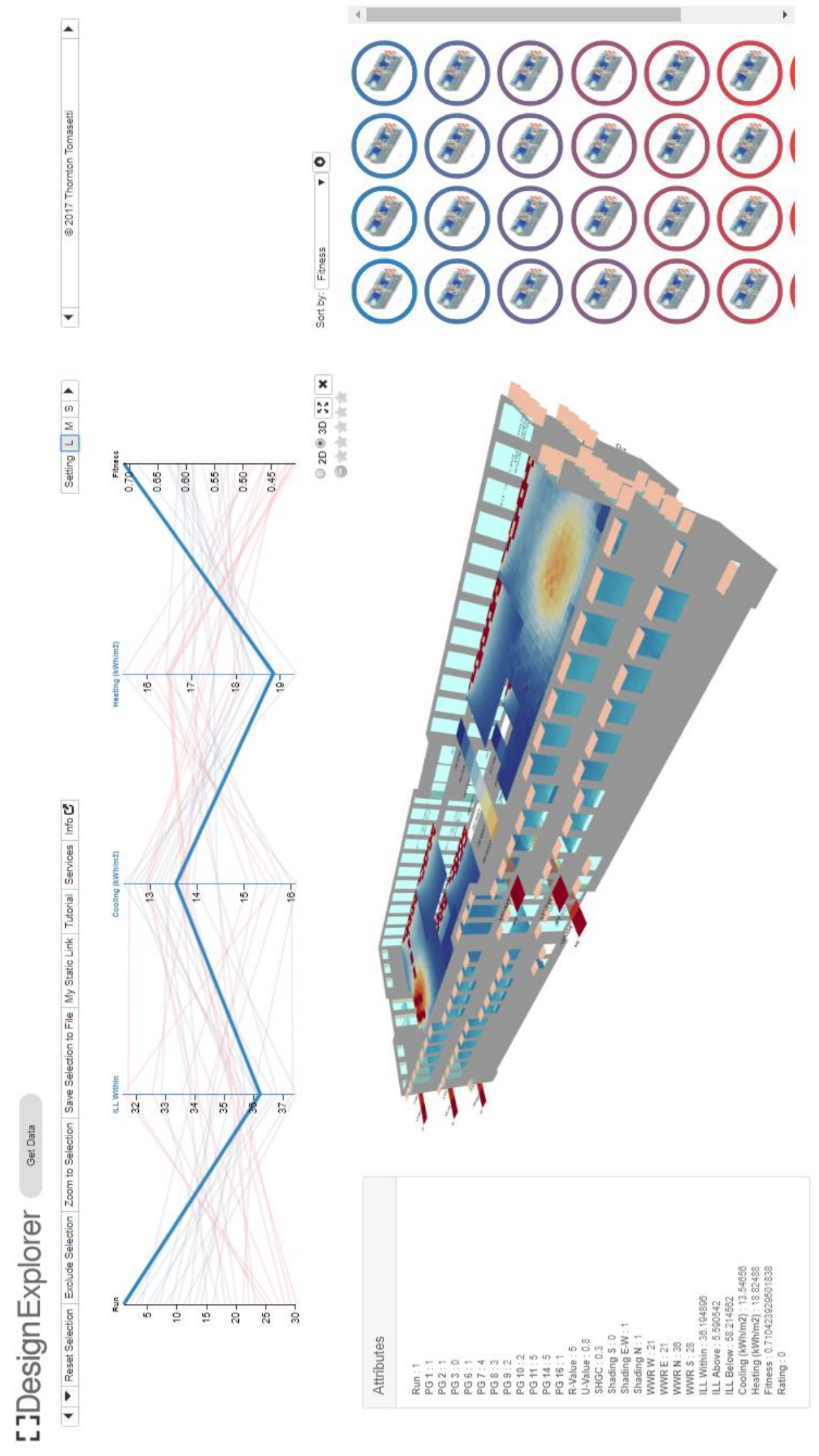

Figura 53: Melhor indivíduo obtido através do ArchOptimum. Fachada Norte. Fonte: Autores. 


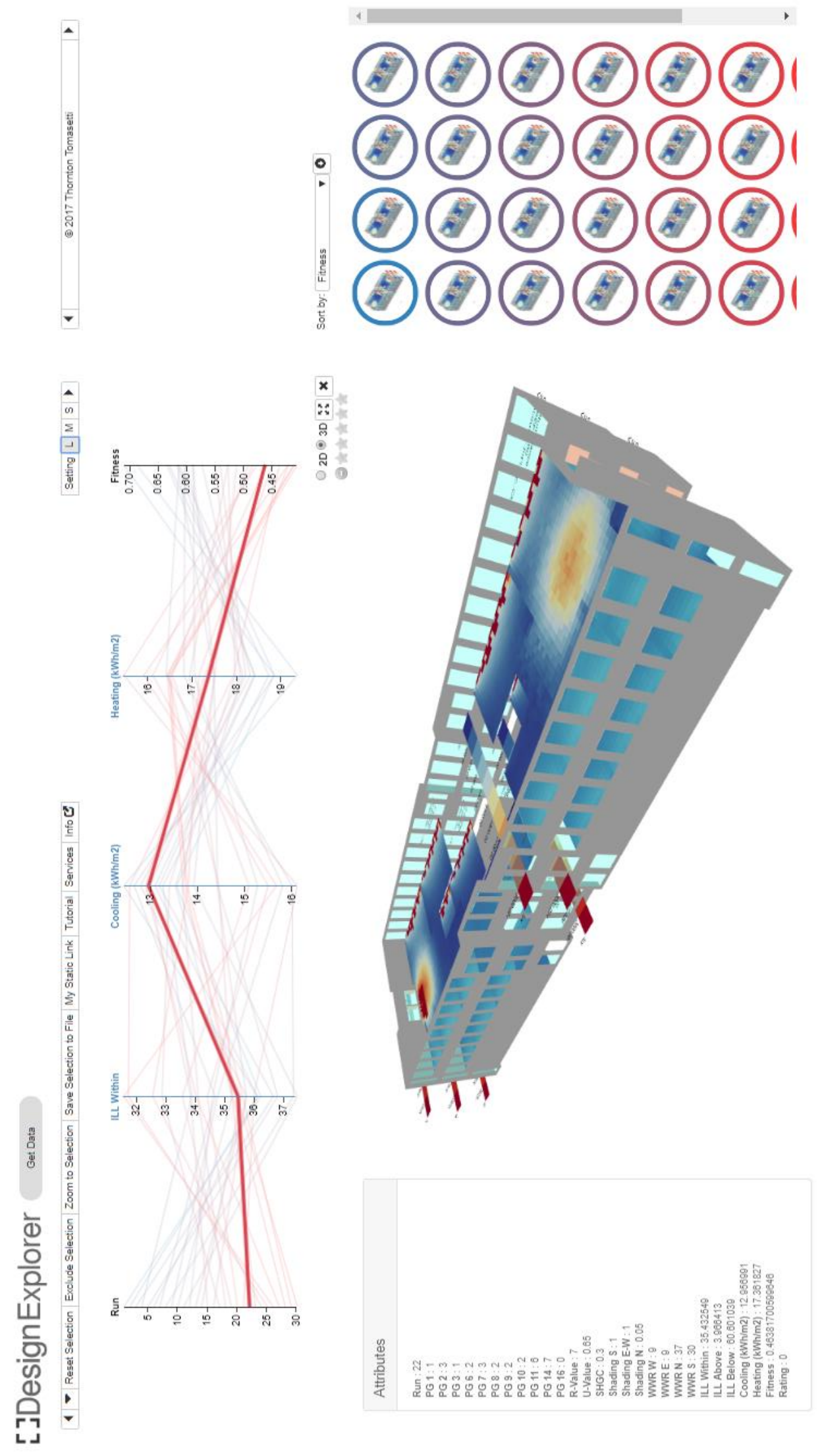

Figura 54: Melhor indivíduo obtida através do método do escritório Perkins+Will. Fachada Norte. Fonte: Autores. 


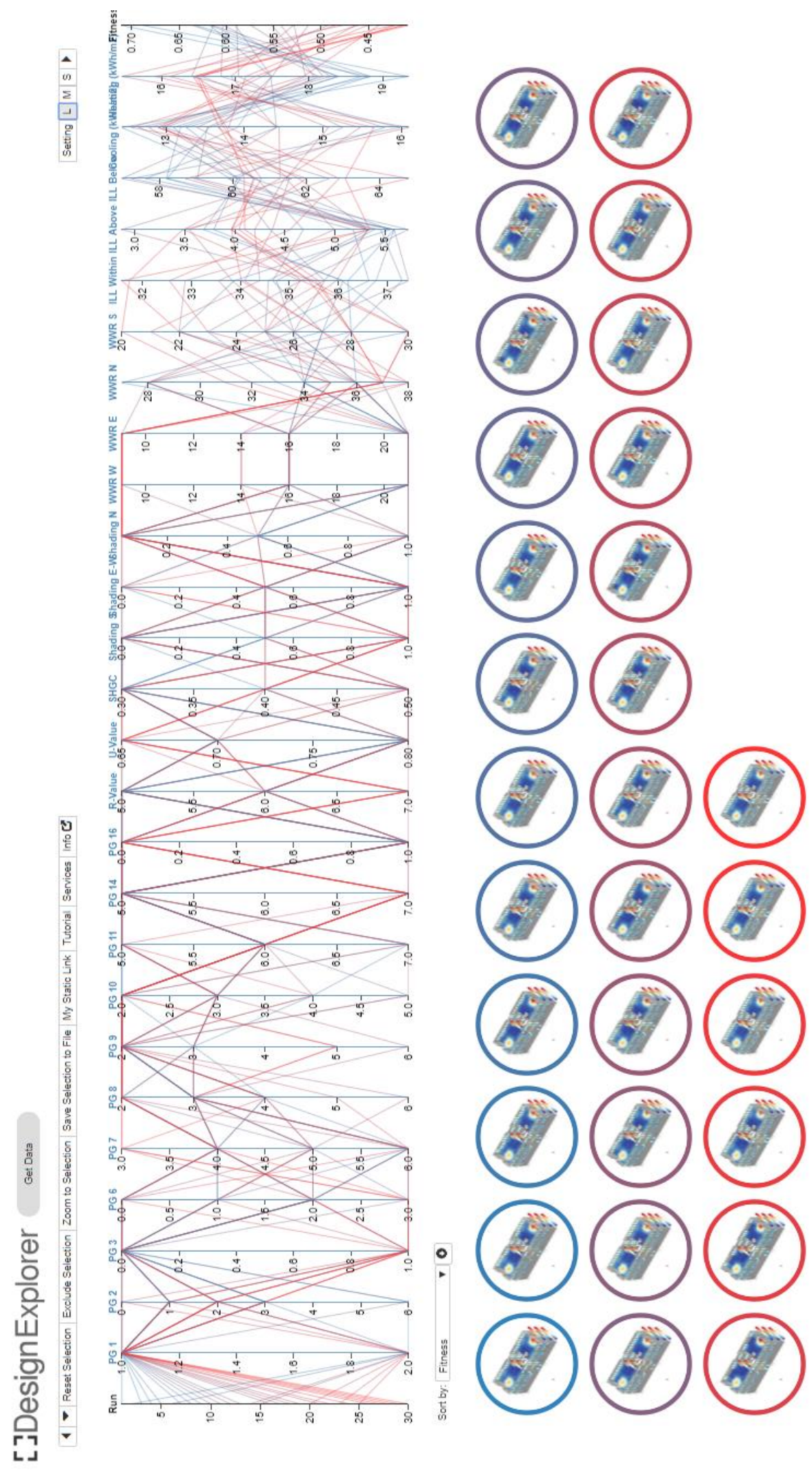

Figura 55: Gráfico de Coordenadas Paralelas de todos os parâmetros de todos indivíduos. A cor azul representa os melhores resultados, a vermelha os piores resultados. Fonte: Autores. 


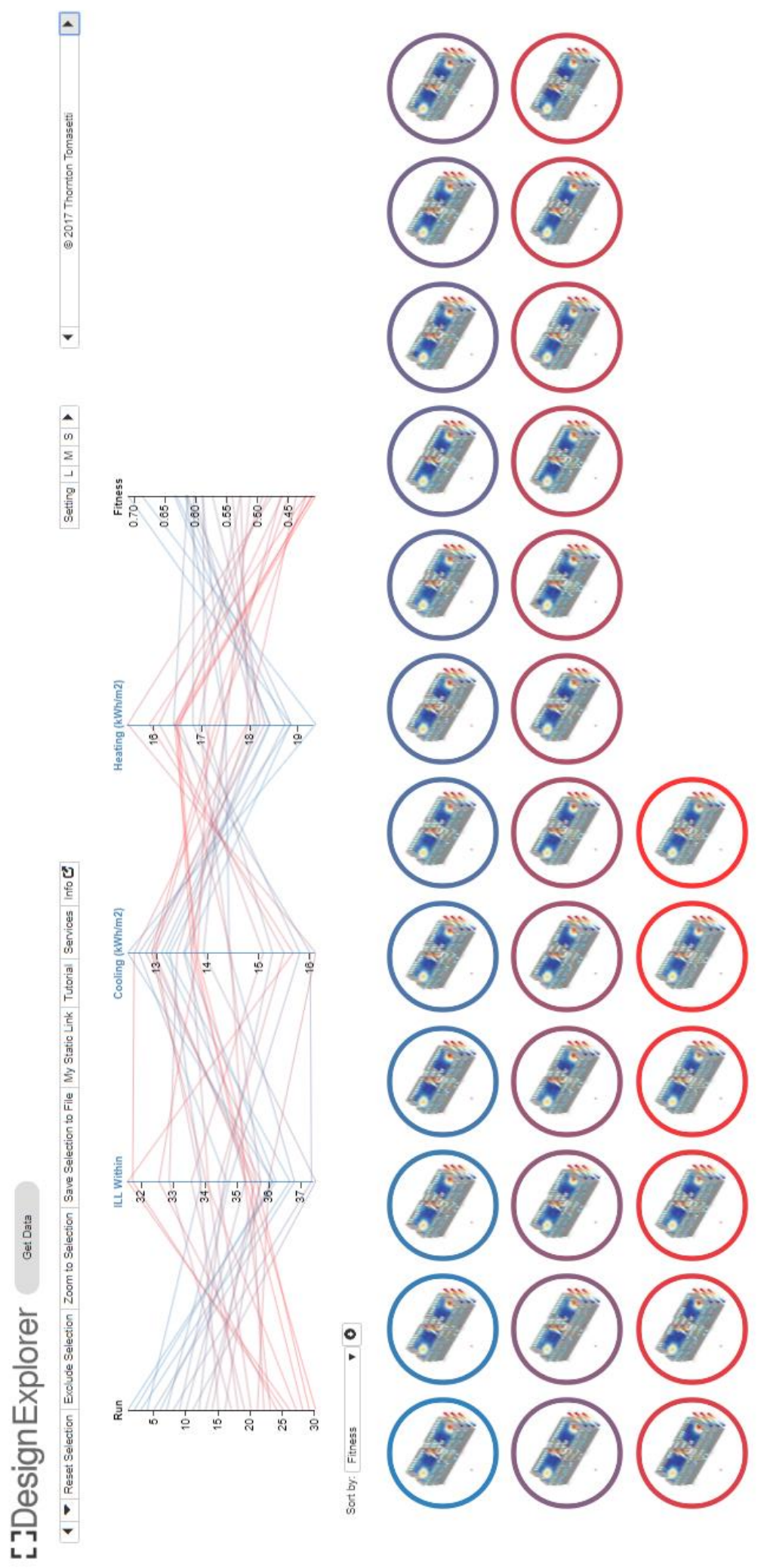

Figura 56: Gráfico de Coordenadas Paralelas dos parâmetros utilizados no cálculo do fitness e o respectivo resultado de todos indivíduos. A cor azul representa os melhores resultados, a vermelha os piores resultados. Fonte: Autores. 


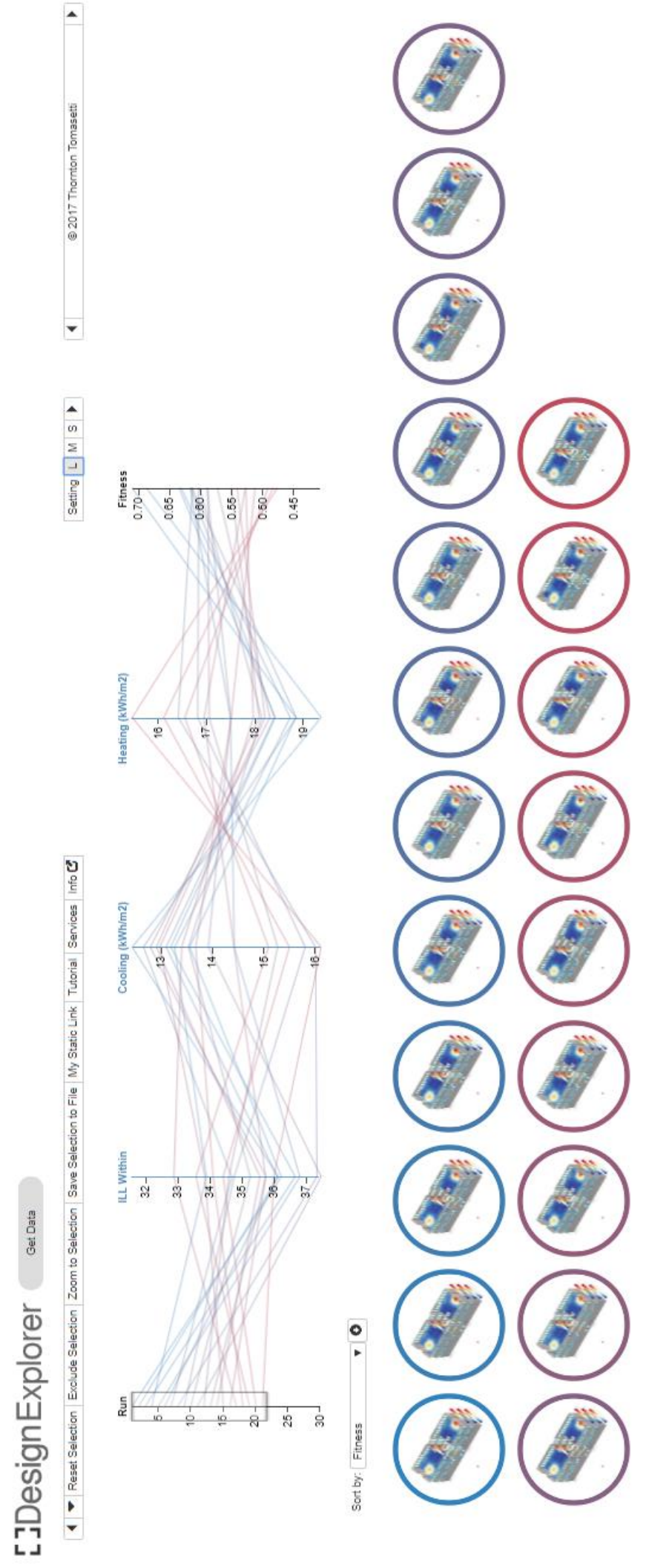

Figura 57: Gráfico de Coordenadas Paralelas dos parâmetros utilizados no cálculo do fitness e o respectivo resultado dos indivíduos gerados através do ArchOptimum. A cor azul representa os melhores resultados, a vermelha os piores resultados. Fonte: Autores. 


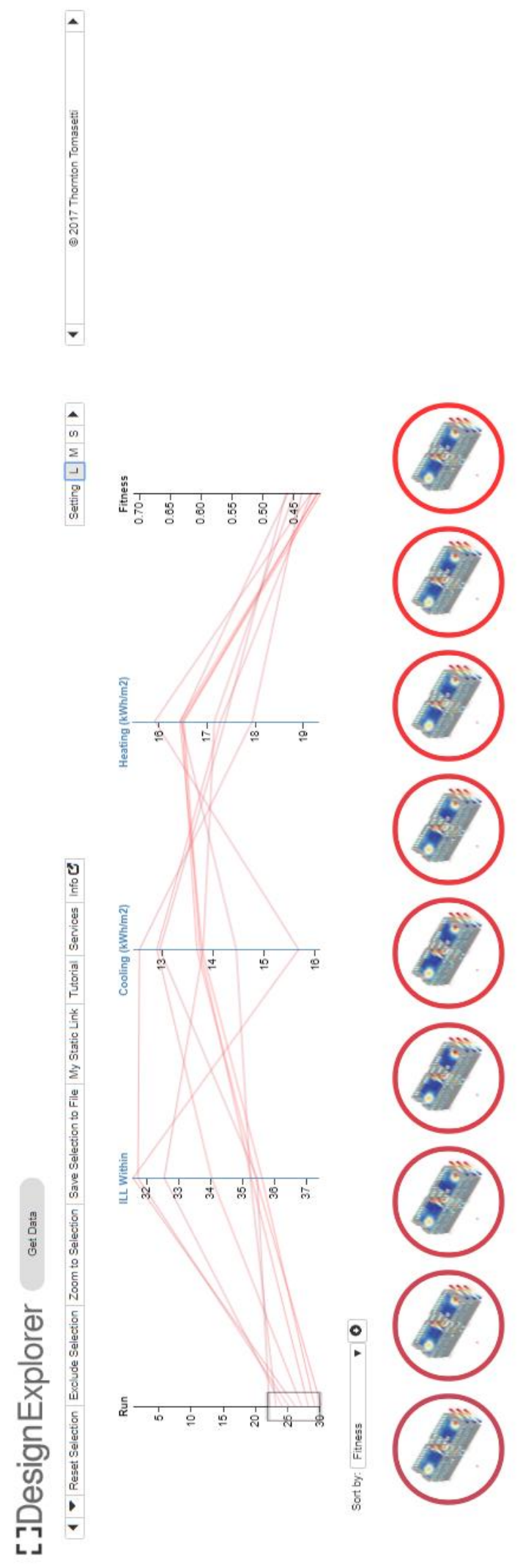

Figura 58: Gráfico de Coordenadas Paralelas dos parâmetros utilizados no cálculo do fitness e o respectivo resultado dos indivíduos gerados através do método do escritório Perkins+Will. A cor azul representa os melhores resultados, a vermelha os piores resultados. Fonte: Autores. 


\subsection{DISCUSSÃO E CONCLUSÕES DO EXPERIMENTO}

A abertura e comparação dos dois métodos explorados durante o experimento demonstraram que o resultado obtido pelo ArchOptimum, superou consideravelmente o desempenho do método do escritório Perkins+Will. O desenvolvimento do plug-in em código aberto, cujo método de otimização pode ser verificado e adaptado, contribui com a discussão sobre a relevância do próprio método no processo de projeto. Assim, todas operações desenvolvidas pelo plug-in permaneceram abertas para intervenções ao longo do experimento, possibilitando adaptações e aperfeiçoamentos. Também foi demonstrada a capacidade de adaptabilidade do plug-in ao se encaixar no processo de projeto DSC desenvolvido pelo escritório. O experimento também evidenciou a complexidade técnica de se trabalhar com simuladores de eficiência energética, dado o tempo das execuções que é longo e a quantidade de variáveis técnicas a serem ajustadas, exigindo conhecimentos específicos da área. Além disso, o Grasshopper, responsável por realizar a comunicação entre os simuladores, otimizador e o próprio modelo paramétrico, não possui suporte robusto na revisão interativa do código, o que dificulta a identificação de fontes de erros e falhas no código.

Superadas tais questões técnicas, o experimento demonstrou a capacidade do plug-in ArchOptimum de desempenhar a otimização mesmo com uma população inicial pequena, visto que o contrário acarretaria um grande período de execução dos simuladores. O tempo de execução do AG dentro do processo de projeto se tornou irrelevante no tempo total de cada avaliação de indivíduo, pois era executado em poucos segundos, enquanto a simulação ocupava em média 7 minutos.

O ArchOptimum poderá receber como implementações e melhorias futuras a opção para que o usuário possa alternar entre opções de método de otimização, sendo o método já implementado uma das opções. Também poderá receber a plotagem em gráfico dos resultados obtidos na otimização e uma interface mais amigável. Em pesquisas futuras o plug-in 
poderá ser aplicado em benchmarking com outros plug-ins de otimização disponíveis, entre eles o Galápagos e o Octopus, dos quais se destaca por ser desenvolvido em código aberto.

Os recursos computacionais explorados no presente experimento são capazes de promover e ampliar as revisões no processo de projeto em arquitetura. De forma geral, a contribuição do experimento se estende a produção do plug-in, que adaptada e implementa o AG, a própria abertura e clareza dos métodos empregados nos processos de otimização aplicados ao problema arquitetônico do estudo de caso desenvolvido. 


\section{CONSIDERAÇÕES FINAIS}

\section{CONCLUSÃO}

O processo de projeto orientado ao desempenho em arquitetura é fruto da evolução de diversas áreas de pesquisa, portanto, uma composição interdisciplinar. Assim, a aplicação de métodos de otimização na busca do balanceamento ideal de parâmetros presentes desde a concepção até a fabricação do projeto requer conhecimentos específicos, que muitas vezes, não são comuns à formação do arquiteto. Contudo, recursos do design computacional estão apoiando os profissionais a inserir a otimização em seus processos através de modelos paramétricos produzidos a partir de recursos da programação visual.

Os modelos paramétricos são analisados por simuladores, que são também fundamentais ao processo de projeto orientado ao desempenho, pois os dados que produzem informam as decisões de otimização dentro do espaço de design averiguado. A busca dentro do espaço de design pode ser dirigida à exploração da criatividade e da eficiência, ou apenas uma dessas. Porém, a construção do próprio espaço de busca é uma competência da modelagem do processo de projeto. Ou seja, o arquiteto é responsável pela construção do espaço de design que será analisado e para isso precisa entender com clareza não só as exigências do programa do projeto, mas também os potenciais e limites das ferramentas que irão apoiar sua busca.

Nesse contexto, é muito comum na arquitetura o emprego de programas, tanto de simulação quanto de otimização, que operam métodos através de caixas-pretas, geralmente em forma de programas closed source. Essa condição, por um lado, facilita a popularização do processo, mas por outro, enviesa algumas questões, como a validação dos 
resultados obtidos ou a clareza sobre os limites da eficiência dos métodos empregados no processo de projeto.

Contudo, pode-se afirmar que o processo de projeto orientado ao desempenho representa uma grande alternativa ao processo de projeto de arquitetura convencional, em que, neste último, o modelo é gerado, simulado, avaliado e então aprovado ou rejeitado. A introdução da otimização, representa a inserção de recursividade entre a geração e a avaliação do modelo na exploração do espaço de design por melhores alternativas de projeto. Ademais, para a geração de alternativas a partir do modelo inicial ser eficiente é necessário o emprego de métodos específicos de otimização.

O conteúdo da investigação de métodos de otimização também é interdisciplinar e relaciona conhecimentos de campos como da arquitetura, computação, matemática e procedimentos inspirados na biologia. Para estimular a discussão e difusão dos métodos de otimização no processo de arquitetura, envolvendo conhecimentos de áreas distintas, é necessário que as pesquisas reportem não apenas os resultados obtidos, mas também o conjunto de procedimentos aplicados e os códigos desenvolvidos, relatando com clareza suas limitações e potenciais.

Todo o conteúdo produzido na presente pesquisa, incluindo o código fonte do plug-in desenvolvido, está disponibilizado juntamente com o volume desta dissertação22, desejando servir de ponto de partida ou apoio para pesquisas correlatas ao tema. Os estudos realizados evidenciaram que os métodos de otimização por algoritmos evolutivos representam os métodos de otimização aplicados ao design computacional de arquitetura mais populares. Os métodos desenvolvidos nos experimentos, algoritmos genéticos, atuaram com eficiência no processo de projeto de arquitetura, assim pode-se afirmar que a otimização de projeto orientado ao 
desempenho possui grande potencial em pesquisas futuras ou em aplicações comerciais.

O plug-in ArchOptimum é resultado da metodologia Design Science adotada na pesquisa, dada sua natureza pragmática e interdisciplinar. Um dos principais desdobramentos futuros possíveis da presente pesquisa é a melhoria do plug-in, com atualizações na sua interface, visualização dos resultados e implementação de outros métodos de otimização. Outro desdobramento futuro da presente pesquisa é a comparação do plug-in desenvolvido com outros disponíveis e populares em otimização de projeto orientado ao desempenho em arquitetura.

Por fim, pode-se afirmar que com 0 apoio da metodologia empregada na presente pesquisa, desde a revisão bibliográfica aos experimentos realizados, obteve-se resultados que colaboram com a compreensão e abertura dos potenciais da associação entre a arquitetura e a ciência da computação através do design computacional. 


\section{REFERÊNCIAS BIBLIOGRÁFICAS}

AISH, R. First Build Your Tools. In: PETER B.; PETER T. Inside Smartgeometry. Expanding the Architectural Possibilities of Computational Design. West Sussex: John Wiley \& Sons Ltd. 2013. p. 36-49.

AMABIS, J. M.; MARTHO, G. R. Curso básico de biologia: seres vivos. São Paulo: Moderna, 1985, p. 14-16.

ANTON, I.; TĀNASE, D. Informed geometries. Parametric modelling and energy analysis in early stages of design. Energy Procedia, v.85, p. 9-16, 2016.

ASL, R. M.; STOUPINE, A.; ZARRINMEHR, S.; YAN, W.; Optimo: A BIM-based MultiObjective Optimization Tool Utilizing Visual Programming for High Performance Building Design. 33rd Education and research in Computer Aided Architectural Design in Europe, eCAADe. Vienna, 2015 p. 1-11.

ATTIA, S.; HAMDY, M.; O'BRIEN, W.; CARLUCCI, S. Assessing gaps and needs for integrating building performance optimization tools in net zero energy buildings design. Energy and Buildings, ed. 60, pp 110-124, 2013.

BACK, T.; HAMMEL, U.; SCHWEFEL, H.P. Evolutionary computation: Comments on the history and current state. IEEE transactions on Evolutionary Computation, v. 1, n. 1, p. 3-17, 1997.

BASTOS, E. A. Otimização de Seções Retangulares de Concreto Armado Submetidas à Flexo-Compressao Oblíqua Utilizando Algoritmos Genéticos. Dissertação de Mestrado - Universidade Federal do Rio de Janeiro, Rio de Janeiro, 2004.

BAYAZIT, N. Investigating Design: a review of forty years of design research. Design Issues, v. 20, n. 1, p. 16-29, 2004.

BENJAMIN, D. Beyond efficiency. In: SCOTT, M. (Ed.). Digital Workflows in Architecture: Design - Assembly - Industry. Birkhäuser, p. 14-25, 2012.

BENTLEY, P. Evolutionary design by Computers. Morgan Kaufmann, 1999.

BERTALANFFY, L. V. Teoria geral dos sistemas. Petrópolis: Vozes/INL, 1975.

BESSERUD, K. Engaging with Complexity: Computational Algorithms in Architecture and Urban Design. In: ANDIA, A.; SPIEGELHALTER, T. Postparametric automation in design and construction. 1. ed. London: ARTECH House London, 2014. p. 39-45.

BESSERUD, K.; COTTON, J. Architectural Genomics, Silicon + Skin: Biological Processes and Computation. 28th Association for Computer Aided Design in Architecture, ACADIA. Minneapolis, 2008, p. 238-245. 
BEYER, H.; SCHWEFEL, H. P.; WEGENER, I. How to analyse evolutionary algorithms. Theoretical Computer Science, v. 287, n. 1, p. 101-130, 2002.

BIJL, A.; SHAWCROSS, G. Housing site layout system. Computer Aided Design, n.7, p. 2-10, 1975.

BLUM, C.; ROLI, A. Metaheuristics in combinatorial optimization: Overview and conceptual comparison. ACM Computing Surveys. v. 35, ed. 3. 2003. P. 268-308.

BRADNER, E.; IORIO, F.; DAVIS, M. Parameters tell the design story: Ideation and abstraction in design optimization. Simulation Series, v. 46, n. 7, p. 172197, $2014 . \quad$ Disponível em: <http://www.scopus.com/inward/record.url?eid=2-s2.0-

$84901821610 \&$ partnerlD=tZOtx3yl>. Acessado em janeiro de 2018.

BROUGHTON, T.; TAN, A.; COATES, P. S. The use of genetic programming in exploring 3d design worlds. In: CAAD futures, Istanbul, Turkey: Springer Netherlands, 1997. p. 885-915.

BURKE, E. K.; KENDALL H. G.; WHITWELL, G. Complete and robust no-fit polygon generation for the irregular stock cutting problem. European Journal of Operational Research, v. 179, n. 1, p. 27-49, 2007.

CALDAS, L. Generation of energy-efficient architecture solutions applying GENE_ARCH: An evolution-based generative design system. Advanced Engineering Informatics, v. 22, n. 1, p. 59-70, 2008.

CALIXTO, V. Geração automatizada de layouts com uso de algoritmos evolutivos: Aplicações em Arquitetura e Urbanismo. Dissertação de Mestrado - Programa de Pós-graduação em Faculdade de Engenharia Civil, Arquitetura e Urbanismo da Unicamp, Campinas, 2016.

CAMACHO, L.; OCHOA, E. G.; MARÍN; H. T.; BURKE, E. An Effective Heuristic for the Two-Dimensional Irregular Bin Packing Problem. Annals of Operations Research 206. New York, p. 241-264, 2013.

CAMPOREALE, P. Genetic Algorithms Applied to Urban Growth Optimization: Solar Envelope and Solar Fan. 31 st Conference on eCAADe. Delft, The Netherlands, 2013. p. 227-236.

CANDANCE, S.; WOOD, A. Sustainable Rating Systems Around the World; Council on Tall Buildings and Urban Habitat. CTBUH Research Paper. Chicago, Vol. 2, p. 18-29, 2008.

CHASZAR, A.; SAVOV, A.; LIEBSCH, P.; BOHNENBERGER, S. Responsive Design: Towards an Ecology of Objects and People. Inside Smartgeometry: Expanding the Architectural Possibilities of Computational Design, $v$. 9781118522, p. 92-101, 2013. 
CHEN, L.; SASS, L. Generative computer-aided design: multi-modality largescale direct physical production. Computer-Aided Design and Application v. 14, n. 1, p. 83-94, 2016.

CICHOCKA, J. Architectural Design Optimization (ADO) opens new horizons in practice. Archimag. v. 1. 20-23, 2018.

CICHOCKA，J.; MIGALSKA， A.; BROWNE，W.; RODRIGUEZ， E. SILVEREYE-The Implementation of Particle Swarm Optimization Algorithm in a Design Optimization Tool. 16th Computer-Aided Architectural Design Futures Foundation, CAADFutures. Istanbul, 2017. p.151-169.

CICHOCKA, J.; MUSIKHINA, E. A. Methods of Optimization in Architecture. Research Journal of International Studies. N. 1 (20) Part 3, p. 109-111, 2014.

CLARKE, J. A.; HENSEN J. L. M. Integrated Building Performance Simulation: Progress, Prospects and Requirements. Building and Environment, p.1-13. doi:10.1016/j.buildenv.2015.04.002, 2015.

CLAUSSNITZER, S.; KATZ, N.; SHAXTED, M.; PARK, S. K.; YORI, R. Workshop high throughput computing (HTC) for parametric exploration by SOM. 14th Association for Computer Aided Design in Architecture, ACADIA, LOS Angeles, 2014. p.112-121.

COENDERS, J.; WAGEMANS, L. Structural Design Tools: The next step in modelling for structural design. IABSE Symposium Report. 2006. Budapest, International Association for Bridge and Structural Engineering, 2006. p. 5764.

COENDERS, J.; WAGEMANS, L. The next step in modelling for structural design: Structural Design Tools. International symposium on shell and spatial structures; theory, technique, valuation, maintenance, Dalas, 2006, p. 8592.

COSTA, A.; SCHROEPFER, T.; NANNICINI, G.; WORTMANN, T. Black-Box Optimization of Lighting Simulation in Architectural Design. Complex Systems Design \& Management Asia, Springer, Cham, v.1, p. 27-39, 2014.

DAVIS, D. Modelled on software engineering: Flexible parametric models in the practice of architecture. Ph. D. Thesis. School of Architecture and Design, College of Design and Social context, RMIT University. Melbourne, 2013.

DEB K. Multi-Objective Optimization Using Evolutionary Algorithms. John Wiley \& Sons, Inc., New York, 2001.

DELANDA, M. Deleuze and the Use of the Genetic Algorithm in Architecture. Architectural Design, v. 71, n. 7, p. 9-12, 2002. 
DÍAZ, H. et al. Multidisciplinary design optimization through process integration in the AEC industry: Strategies and challenges. Automation in Construction, v. 73, p. 102-119, 2017.

DIAZ, H.; ALARCON, L. F.; MOURGUES, C.; GARCIA, S. Multidisciplinary design optimization through process integration in the AEC industry: Strategies and challenges. Automation in Construction, v. 73, p. 102-119, 2017.

EIBEN, A. E.; SMITH, J. E. Introduction to evolutionary computing. Natural Computing Series. Berlin: Springer, 2003, p.18-26.

EIBEN, E.; SMITH, J. E. Introduction to Evolutionary Computing. Springer Verlag, 2003.

ESHELMAN, L. J.; SCHAFFER, J. D. Real-Coded Genetic Algorithms and IntervalSchemata. Foundations of Genetic Algorithms 2, p. 187-202, 1993.

EVINS, R. A Review of Computational Optimization Methods Applied to Sustainable Building Design. Renewable and Sustainable Energy Reviews, v. 22 p. 230-45. doi:10.1016/j.rser.2013.02.004, 2013.

FERREIRA, B.; LEITÃO, A. Design Generativo Para Building Information Modeling. $1^{\circ}$ Congresso Português de Building Information Modelling. Guimarães, 2016, p. 251-261.

FLÖRY, S.; SCHMIEDHOFER, H.; REIS, M. Goat. Rechenraum, Vienna, 2012, p. 32-40.

FOGED, I. W.; PASOLD, A.; JANSEN, M. B. Evolution of an Instrumental Architecture. 32th Education and research in Computer Aided Architectural Design in Europe, eCAADe. Newcastle, 2014. p.365-372.

FOGEL, L. Autonomus automata. Industrial Research, v. 4, n. 1, p. 14-19, 1962.

FRAZER, J. An evolutionary architecture. London: Architectural Association, 1975.

FULGHAM, B.; GOUY, I. The computer language benchmarks game. Disponível em <https://benchmarksgameteam.pages.debian.net/benchmarksgame/>. Acessado em 10 de janeiro de 2018.

GABRIEL P. H. R. Algoritmos evolutivos e modelos simplificados de proteínas para predição de estruturas terciárias. Dissertação de Mestrado Programa de Pós-Graduação do Instituto de Ciências Matemática e de Computação - Universidade de São Paulo, São Carlos. 2010.

GABRIEL, P. H. R.; DELBEM A. C. B. Fundamentos de algoritmos evolutivos. São Carlos: ICMC-USP, 2008. 
GARBER, R. BIM Design: Realising the Creative Potential of Building Information Modelling. New Jersey. Wiley, 2014.

GERHARDT, T. E.; SILVEIRA, D. T. Métodos de pesquisa. Plageder, 2009.

GERO, J. Design Optimization. ACADEMIC PRESS, INC. Harcourt Brace Jovanovi, v. 1, 1985.

GOLDBERG, D. E. Genetic algorithms in search, optimization, and machine learning. New York, Addison-Wesley, 1989. p. 412-437.

GOLDBERG, D. E. Real coded gentic algorithms, virtual alphabets, and blocking. Complex Systems, v. 5, n. 2, p. 139-168, 1991.

Gregson, S. Nelder-Mead Optimization. Eckersley O'Callaghan, London, v. 2, n. 2, p. 63-71, 2017.

HADLEY, G. Programação linear. Rio de Janeiro: Ed. Guanabara Dois, 1982.

HARDING, J. Meta-Parametric Design: Developing a Computational Approach for Early Stage Collaborative Practice. Press University of Bath. Bath, p. 1-25, 2014.

HAYMAKER, J. et al. Design Space Construction: A Framework to Support Collaborative, Parametric Decision Making. Journal of Information Technology in Construction. v. 23, p 157-178, 2018.

HEMSATH, T.L. Conceptual energy modeling for architecture, planning and design: Impact of using building performance simulation in early design stages. 13th Conference of IBPSA, Chambery, France, p. 2013. 376-384.

HENSEL, M.; MENGES, A.; WEINSTOCK, M. Emergent technologies and design: towards a biological paradigm for architecture. Routledge, 2013.

HIEN, W. N.; POH, L. K.; FERIADI, H. The use of performance-based simulation tools for building design and evaluation - A Singapore perspective. Environ. v. 35, p. 709-736, 2000.

HOLMSTRÖM, K. An adaptive radial basis algorithm (ARBF) for expensive black-box global optimization. Journal of Global Optimization n.41 v.3, p. 447-464, 2008

HOLTZ G. C. C. Traçado automático de envoltórias de esforços em estruturas planas utilizando um algoritmo evolucionário. Dissertação de - Programa de Pós-graduação em Engenharia Civil, Pontifícia Universidade Católica do Rio de Janeiro, Rio de Janeiro. 2005.

HOOS, H. H.; STÜTZLE, T. Stochastic Local Search: Foundations and Applications. Morgan Kaufmann, Elsevier, 2004. 
HOSKINS, E. Computer aids in system building. Computer-Aided Design, New York: North Holland Press, p. 127-140, 1973.

ILAL, M. E. The Quest for Integrated Design System: A Brief Survey Of Past And Current Efforts. METU JFA, n.24, v.2 149-158, 2007.

JABI, W. Parametric spatial models for energy analysis in the early design stages. In: Symposium on Simulation for Architecture \& Urban Design. Society for Computer Simulation International. Tampla, 2014. p. 16-34.

JANSSEN, P. D. A scalable and extensible platform for experimenting with population-based design exploration algorithms. Artificial Intelligence for Engineering Design, Analysis and Manufacturing, v. 29, n. 04, p. 443-455, 2015.

JANSSEN, P.; STOUFFS, R. U. D. I. Types of parametric modelling. In: 20th Int. Conf. Computer-Aided Architectural Design Research in Asia, CAADRIA. Shanghai, 2015. p. 157-166.

JARRYER, A. M. Algoritmos Evolutivos Como Método Para Desenvolvimento De Projetos De Arquitetura. Tese de Doutorado - Programa de Pósgraduação em Faculdade de Engenharia Civil, Arquitetura e Urbanismo da Unicamp, Campinas, 2015.

JIN, J. T.; JEONG, J. W. Optimization of a free-form building shape to minimize external thermal load using genetic algorithm. Energy Build, n. 85, 473482, 2014.

JONES, J. C. Conference on design methods. 1976. Disponível em: <www.softopia.demom.co.uk/2.2/dmconference1962.htmls. Acessado em março de 2017.

JONES, J. C. Discovering that there were other people in this invisible subject. $1963 . \quad$ Disponivel em: $<w w w . s o f t o p i a . d e m o m . c o . u k / 2.2 /$ early_days 1.2.html>. Acesso em março de 2017.

JONES, J. C. Opus one, number two. Design Studies, vol. 1, n 6, p. 375-389, 1980.

JONG, D. K. A. Evolutionary computation: a unified approach. MIT press, 2006.

JUNGHANS, L. Optimization Algorithms for Building Energy Demand Optimization: Concept 2226, Austria. In: ANDIA, A.; SPIEGELHALTER, T. Postparametric automation in design and construction. London: ARTECH House London, 2014. p. 119-116. 
KEELING, M. (2015). Exploring the Design Space. Disponível em: <http://www.neverletdown.net/2010/09/exploring-de- sign-space.html>. Acessado em: 12 de agosto de 2018.

KEOUGH, I; BENJAMIN, D. Multi-objective optimization in architectural design. In: Proceedings of the $\mathbf{2 0 1 0}$ Spring Simulation Multiconference. Society for Computer Simulation International. Orlando, 2010. p. 191-202.

KIUSALAAS, J. Numerical Methods in Engineering whit MATLAB. Cambridge, 2005.

KOLAREVIC, B. Architecture in digital age: design and manufacturing. Taylor \& Francis, 2004.

KOTNIK, Toni. Digital architectural design as exploration of computable functions. International journal of architectural computing, v. 8, n. 1, p. 116, 2010.

KOZIEL, S; YANG, X. S. Computational optimization, methods and algorithms. Springer, 2011.

LAND, A. H.; DOING, A. G. An automatic method of solving discrete programming problems. Econometrica. v.28 ed.3. 1960. pp. 497-520.

LANDIM, G.; DIGIANDOMENICO, D.; AMARO J.; TOLEDO, C. Architectural Optimization and Open Source Development: Nesting and Genetic Algorithms. 17th Association for Computer Aided Design in Architecture, ACADIA. Cambridge, 2017, p. 340-349.

LAWSON, B. How designers think: the design process demystified. Routledge, 2006.

LIN, S.H. E.; GERBER, D. J. Designing-in performance: A framework for evolutionary energy performance feedback in early stage design. Automation in Construction, v. 38, p. 59-73, 2014.

LÓPEZ, C. et al. An effective heuristic for the two-dimensional irregular bin packing problem. Annals of Operations Research, v. 206, n. 1, p. 241-264, 2013.

LUEBKEMAN, C.; SHEA, K. CDO: Computational design+ optimization in building practice. The Arup Journal, v. 3, p. 17-21, 2005.

MACHAIRAS, V. TSANGRASSOULIS, A.; AXARLI, K. Algorithms for optimization of building design: A review. Renewable and Sustainable Energy Reviews, $v$. 31, p. 101-112, 2014. 
MALARD, M. L.; RHODES, P.; ROBERTS, S. E. O Processo de projeto e o computador: realidades que interagem virtualmente. Graf \& Tec UFSC. Florianópolis, v. 1, n.1, p. 25-37, 1997.

MEAGER M. The application of computer aids to hospital building. ComputerAided Design, New York, p. 424-453, 1973.

MENGES, A.; AHLQUIST, S. Computational Design Thinking: Computation Design Thinking. John Wiley \& Sons, 2011.

MITCHELL, M. An introduction to genetic algorithms. MIT press, 1998.

MITCHELL, W. J. Computer-aided architectural design. MIT press, 1977.

MITCHELL, W. J. The reconfigured eye: Visual truth in the post-photographic era. Mit Press, 1994.

MORALES, K. A. F. Pattern recognition via vasconcelos genetic algorithm. Progress in Pattern Recognition, Image Analysis and Applications, Berlin, V. 3287, p. 328-335, 2004.

MORALES, K. A. F.; GUTIÉRREZ G. J. Penalty functions methods for constrained optimization with genetic algorithms: A statistical analysis. In: COELLO, C. A.; ALBORNOZ, A.; SUCAR, L. E.; BATTISTUTTI, O. C. 2nd Mexican International Conference on Artificial Intelligence (MICAI 2002), Germany, 2001, p. 108-117.

MUELLER, C.; OCHSENDORF, J. Combining structural performance and designer preferences in evolutionary design space exploration. Automation in Construction. doi 52. 10.1016/j.autcon.2015.02.011, pl-24, 2015.

NAGY, D. The design space. Disponivel em: <https://medium.com/generative-design/step-1-generate-6bf73fb3a004>. Acessado em 03 de março de 2017.

NEGROPONTE, N. The Architecture Machine. Cambridge, MIT Press, 1970.

OLIVEIRA, J. C. C. B.; PINTO, G. A. O movimento dos métodos de projeto. Arquitextos, São Paulo, Vitruvius, ano 09, n. 105.06, 2009.

OLIVIERI, B. P. Otimização do projeto de pontes protendidas pré-moldadas pelo método dos algoritmos genéticos. Tese de Doutorado - Programa do Pós-Graduação de Engenharia. Universidade Federal do Rio de Janeiro, Rio de Janeiro, 2004.

OLIVIERI, B. P. Otimização do Projeto de Pontes Protendidas Pré-moldadas pelo método dos Algoritmos Genéticos. Dissertação de Mestrado Universidade Federal do Rio de Janeiro, Rio de Janeiro, 2004. 
ONWUBOLU, G. C.; BABU, B. V. New optimization techniques in engineering. Springer, 2013.

OXMAN, R. Theory and design in the first digital age. Design studies, Elsevier, $v$. 27, n. 3, p. 229-265, 2006.

OXMAN, R.; HAMMER, R.; ARI, S. B. Performative design in architecture. 25th Education and research in Computer Aided Architectural Design in Europe, eCAADe. Frankfurt, 2007, p. 227-234.

PARVIN, A. Architecture (and the Other 99\%): Open-Source Architecture and Design Commons. Architectural Design n. 83 p. 90-95, 2013.

PASK, G. Foreword. In: FRAZER, John. An evolutionary architecture. London: John Frazer and the Architectural Association, 1995. p. 6-9

PASTERNAK, A.; KWIECIŃSKI, K. High-Rise Building Optimization - A Design Studio Curriculum. 33rd Education and research in Computer Aided Architectural Design in Europe, eCAADe. Vienna, 2015. p. 305-314

PAUL E. B. Algoritmo probabilístico, em Dictionary of Algorithms and Data Structures Disponível em: <https://www.nist.gov/dads/HTML/probablAlgo.html>. Acessado em 20 de agosto de 2017.

QINGSONG, M.; FUKUDA, H. Parametric office building for daylight and energy analysis in the early design stages. Procedia Social and Behavioral Sciences. n. 215, p. 818-828, 2016.

REAS, C. C. M.; BARENDSE, J. Form+Code in Design, Art, and Architecture. Princeton Architectural Press, 2010.

RECHENBERG, I. Cybernetc solution path of an experimental problem. Royal Aircraft Establishment, Franborough, 1965.

Referências Bibliográficas

RIDLEY, M. Evolution. Cambridge. Blackwell Science, Inc. 2 ed. 1996.

RIOS L.M.; Algorithms for derivative-free optimization. Ph.D. Thesis - University of Illinois at Urbana-Champaign, Illinois, 2009.

ROEL C.G.M. et al. Current status, requirements and opportunities for building performance simulation of adaptive facades. In: FAVOINO, F. Building Performance Simulation and Characterisation of Adaptive Facades Adaptive Facade Network. Ed. 1. TU Delft Open for the COST Action 1403 adaptive facade network. p. 21-47, 2018. 
RUTTEN, D. Galapagos On the Logic and Limitations of Generic Solvers. In: PETERS, B.; KESTELIER, X. Computation Work: The building of Algorithmic Thought. Architectural Design - AD. p. 132-135, 2013.

SAIT, S. M.; YOUSSEF, H. Iterative computer algorithms with applications in engineering: solving combinatorial optimization problems. IEEE Computer Society Press, 1999.

SASS, L. The Next Revolution: Digital Buildings Kits, p. 545-553, 2010.

SCHEURER, F.; PETERS, B.; PETERS, T. Encoding Design. Inside Smartgeometry: Expanding the Architectural Possibilities of Computational Design, 2013. p. 186-195.

SCHUVERDT, M. L. Métodos de Lagrangiano Aumentado com Convergência Utilizando a Condição de Dependência Linear Positiva Constante. Tese de Doutorado, Universidade Estadual de Campinas, 2006.

SCHWEFEL, H.P. Evolutionsstrategie und numerishe optimierung. Ph.D. Thesis Technical University of Berlin, Berlin, 1975.

$\mathrm{SHI}, \mathrm{X}$. et al. A review on building energy efficient design optimization rom the perspective of architects. Renewable and Sustainable Energy Reviews, v. 65, p. 872-884, 2016.

$\mathrm{SHI}, \mathrm{X}$. Performance-based and performance-driven architectural design and optimization. Frontiers of Architecture and Civil Engineering in China, v. 4, n. 4, p. 512-518, 2010.

SHI, X.; YANG, W. Performance-driven architectural design and optimization technique from a perspective of architects. Automation in Construction, $v$. 32 , p. 125-135, 2013.

SIMON, H. A. The Sciences of the Artificial. 3rd ed. Cambridge: MIT Press, 1996.

SPAETH, A. B.; MENGES, A. Performative design for spatial acoustics: concept for an evolutionary design algorithm based on acoustics as design driver. 29rd Education and research in Computer Aided Architectural Design in Europe, eCAADe. Slovenia, 2011, p.461-468.

SU, Z.; YAN, W. A fast genetic algorithm for solving architectural design optimization problems. Artificial Intelligence for Engineering Design. Analysis and Manufacturing, v. 29, n. 04, p. 457-469, 2015.

SUTHERLAND, I. E. Sketchpad a man-machine graphical communication system. Transactions of the Society for Computer Simulation, v. 2, n. 5, p. 320, 1964. 
SUYOTO, W.; INDRAPRASTHA, A.; PURBO, H. W. Parametric approach as a tool for decision-making in planning and design process. Case study: Office tower in Kebayoran Lama. Social and Behavioral Sciences, n. 184, p.328337, 2015.

TAKEDA, H.; VEERKAMP, P.; TOMIYAMA, T.; YOSHIKAWAM, H. Modeling Design Processes. Al Magazine, n1, p 37-48, 1990.

TOULOUPAKI, E.; THEODOSIOU, T. Performance Simulation Integrated in Parametric 3D Modeling as a Method for Early Stage Design Optimization - A Review. Energies, v. 10, n. 5, p. 637-648, 2017.

TRCKA, M.; HENSEN J. L. M.; WETTER M. Co-Simulation of Innovative Integrated HVAC Systems in Buildings. Journal of Building Performance Simulation. doi:10.1080/19401490903051959. 2009, n. 2 p.209-230, 2009.

VAISHNAVI, $V_{. ;}$KUECHLER, W. Design Research in Information Systems. Association for Information Systems. Disponível em: <desrist.org/designresearch-in-information-systems>. Acessado em: 14 de janeiro de 2018.

VANNINI, V.; BUENO, E.; TURKIENICZ, B. "Otimização Geométrica de Superfícies de Fachada Para Uso Fotovoltaico." 16th Iberoamerican Congress of Digital Graphics, SIGRADI. Fortaleza, 2012. p. 201-212.

VIERLINGER, R. Octopus. Bollinger+Grohmann Engineers. Al Magazine, p.1, Vienna, 2012.

VON B. P. Techniques for More Productive Genetic Design: Exploration with GAs using non-destructive dynamic populations. Adaptive Architecture, $\mathrm{p}$. 234-242, 2013.

WEBER J. E. Matemática para economia e administração. Harbra, Rio de Janeiro, 1976.

WEINSTOCK, M. Emergence and the Forms of Cities. Architectural Design - AD v.80, n.3, p.42-67, 2010.

WELLE, B.; HAYMAKER, J.; ROGERS, Z. ThermalOpt: A methodology for automated BIM-based multidisciplinary thermal simulation for use in optimization environments. In: Building Simulation. Tsinghua University Press co-published with Springer-Verlag GmbH. p. 293-313. 2011.

WESTERLUND, B. Design space conceptual tool-grasping the design process. Proceedings of the Nordic Design, p.22-41, 2005.

WILLIAMSON, D.; SHMOYS, D. The design of approximation algorithms. Cambridge University Press. ISBN 9780521 195270. 2011.

WOODBURY, R. Elements of parametric design. New York: Routledge, 2010. 
WORTMANN, T. Efficient, Visual, and Interactive Architectural Design Optimization with Model-based Methods. Ph D. Thesis - Singapore University of Technology and Design in fulfillment of the requirement. Singapura, 2018.

WORTMANN, T. et al. Advantages of surrogate models for architectural design optimization. AI EDAM, v. 29, n. 4, p. 471-481, 2015.

WORTMANN, T.; NANNICINI, G. Black-box optimization for architectural design: an overview and quantitative comparison of metaheuristic, direct search, and model-based optimization methods. 21th Association for ComputerAided Architectural Design Research in Asia, CAADRIA. Hong Kong, 2016, p. 177-186.

WORTMANN, T.; ZUARDIN, A.; DEMIN. D.; WAIBEL, C. FrOG. Disponível em: <https://github.com/Tomalwo/FrOG>. Acessado em: 12 de janeiro de 2018.

$\mathrm{XIA}, \mathrm{C} ; \mathrm{ZHU}, \mathrm{Y}$.; LIN, B. Building simulation as assistance in the conceptual design. In: Building simulation. Tsinghua University Press, co-published with Springer-Verlag GmbH, p. 46-52, 2008.

ZÖRNIG, P. Introdução à programação não linear. Brasília: UNB, 2011. 


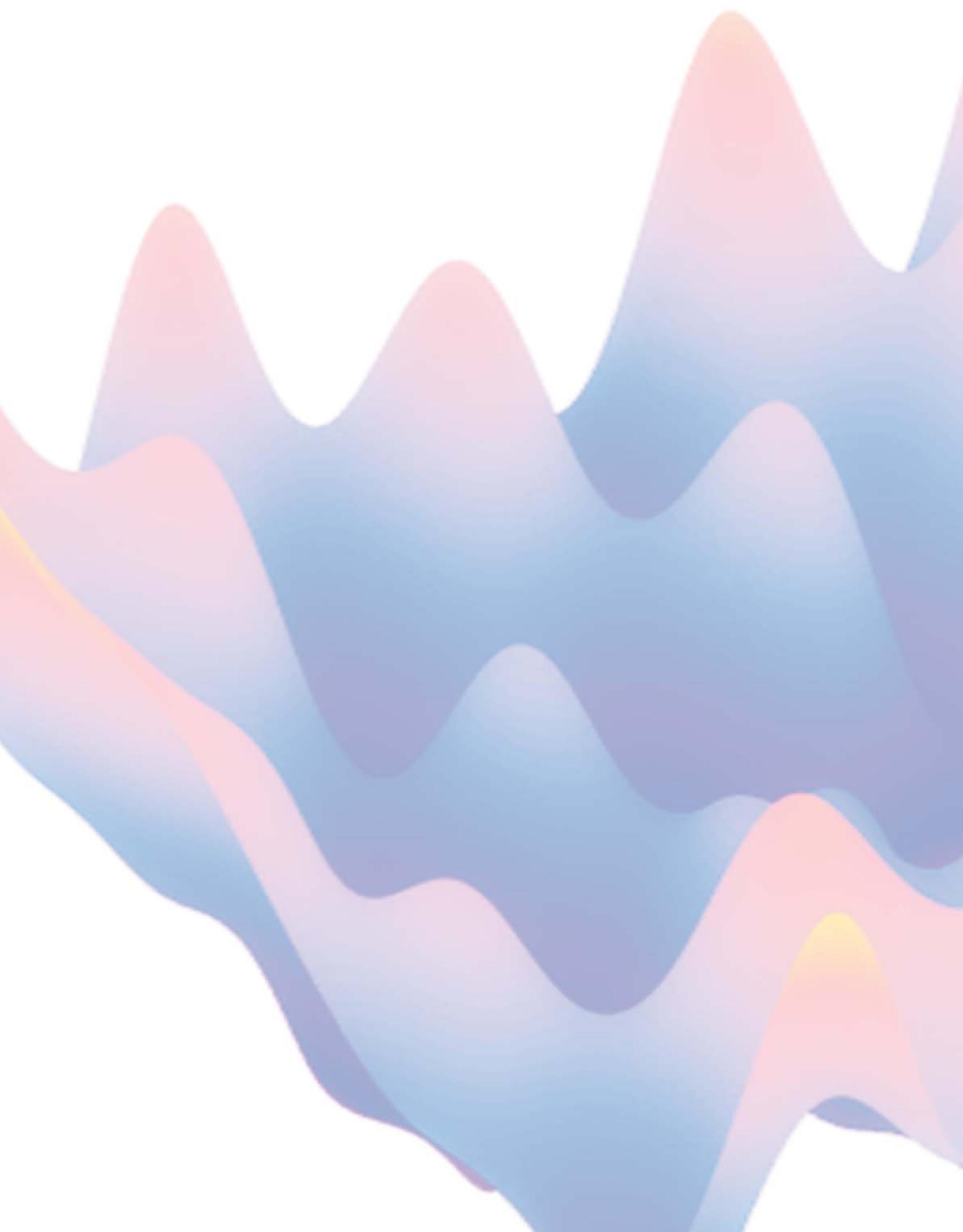

